\title{
ANÁLISE NUMÉRICA, VIA M.E.F, DO COMPORTAMENTO DE LIGAÇÕES PARAFUSADAS VIGA-COLUNA COM CHAPA DE TOPO
}

\section{YURI IVAN MAGGI}

Dissertação apresentada à Escola de Engenharia de São Carlos, da Universidade de São Paulo, como parte dos requisitos para obtenção do título de Mestre em Engenharia de Estruturas.

ORIENTADOR: Prof. Dr. Roberto Martins Gonçalves

São Carlos

2000 
Aos meus pais, Carlos e Hilda, e aos meus irmãos Gustavo e Cibelle, verdadeiramente uma família. 


\section{AGRADECIMENTOS}

Ao professor Dr. Roberto Martins Gonçalves pelo total incentivo e excelente orientação, apontando caminhos e estimulando sempre o espírito crítico tão importante para o desenvolvimento deste trabalho.

À CAPES, pela bolsa de estudos.

A Luiz Fernando Loureiro Ribeiro, que por meio de sua tese de Doutorado contribuiu imensamente para as análises e comparações realizadas neste trabalho, e pela presteza com que esclareceu eventuais pormenores de seus ensaios experimentais.

A Nadir e Eliana, bibliotecárias do Departamento de Engenharia de Estruturas, pela importante colaboração na pesquisa da bibliografia e pela revisão paciente das referências bibliográficas deste trabalho.

Aos professores e amigos Roberto Dalledone e Sérgio Scheer, pela iniciação à pesquisa e pelos ensinamentos, dentro e fora da sala de aula, durante a época da graduação na Universidade Federal do Paraná.

A minha grande amiga Patrícia Lizi, pelo companherismo afinco e por dividir comigo muitas opiniões, ansiedades, alegrias, tudo enfim, durante todo o Mestrado. 
Aos amigos George, Rodrigo, Marcelo, Joel, Patricia Garcia, Palmira, Ana Cláudia, Valentim, Rejane, Roberto, Gerson, Alio, Edna, Eduardo e agregados, pela turma que formamos e pelo convívio sempre especial.

Aos demais professores e funcionários do Departamento de Engenharia de Estruturas, pela presteza nos momentos de necessidade, em especial a Rosi e Toninho.

A todos aqueles que, embora não citados nominalmente, contribuíram direta ou indiretamente para a execução deste trabalho.

E finalmente, mas não menos importante, um agradecimento especial a meus pais, Carlos e Hilda, que me incentivaram a prosseguir os estudos com todo o apoio necessário, e a meus irmãos Gustavo e Cibelle, por serem tão especiais. 


\section{SUMÁRIO}

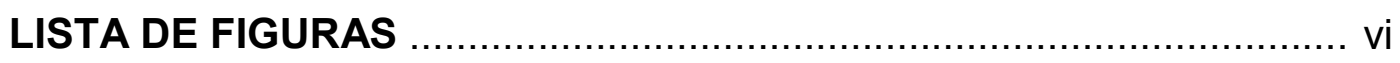

LISTA DE TABELAS ..............................................................

LISTA DE SÍMBOLOS ............................................................ xii

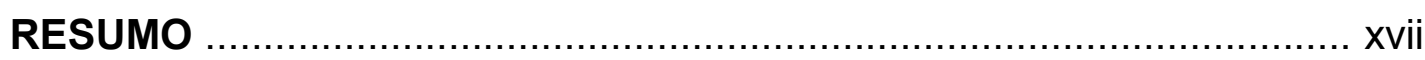

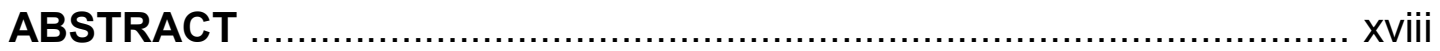

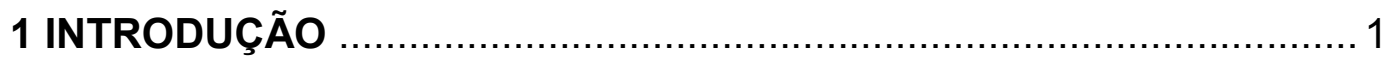

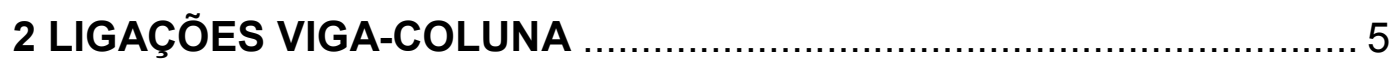

2.1 CONSIDERAÇÕES INICIAIS ............................................. 5

2.2 HISTÓRICO E EVOLUÇÃO DAS PESQUISAS .......................... 6

2.3 LIGAÇÕES VIGA-COLUNA COM CHAPA DE TOPO ................ 18

2.3.1 Procedimento proposto por KRISHNAMURTHY (1978) .... 19

2.3.2 Procedimento proposto pelo EUROCODE (1993) ............ 32

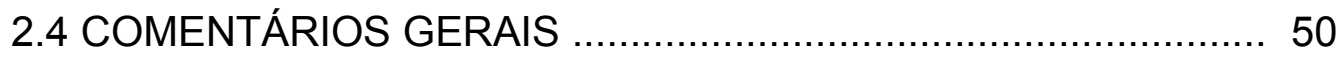

3 CLASSIFICAÇÃO DAS LIGAÇÕES .......................................... 51

3.1 COMPORTAMENTO MOMENTO-ROTAÇÃO ........................ 52

3.2 A RESPOSTA DAS LIGAÇÕES ......................................... 54

3.3 ORGANIZAÇÃO DOS SISTEMAS DE CLASSIFICAÇÃO ............ 54

3.4 PROPOSTAS DE CLASSIFICAÇÃO PARA AS LIGAÇÕES ........ 56

3.4.1 Classificação do AISC (1978) e AISC/LFRD (1986) .......... 56

3.4.2 Classificação de STARK \& BIJLAARD (1988) .................. 58

3.4.3 Classificação do EUROCODE-3 (1992) .......................... 61 
3.4.3.1 Parâmetros utilizados

3.4.3.2 Observações sobre a proposta do EUROCODE-3 (1992) ….................................. 64

3.4.4 Classificação de BJORHOVDE et al. (1990) ...................... 65

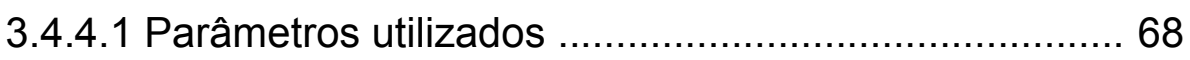

3.4.4.2 Capacidade rotacional da ligação ............................. 71

3.4.4.3 Observações - proposta

de BJORHOVDE et al. (1990) ................................. 72

3.4.5 Classificação de NETHERCOT et al. (1998) ..................... 74

3.4.5.1 Ligações totalmente conectadas ............................. 76

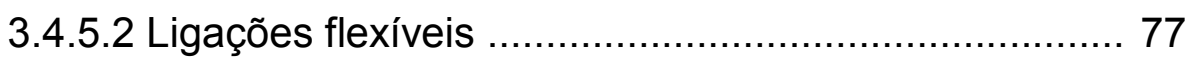

3.4.5.3 Ligações parcialmente conectadas ........................... 79

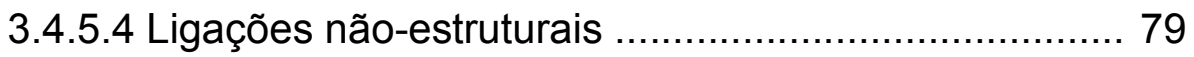

3.4.5.5 Resumo da classificação …………………….......... 80

3.4.5.6 Observações - proposta de NETHERCOT et al. (1998) ................................... 80

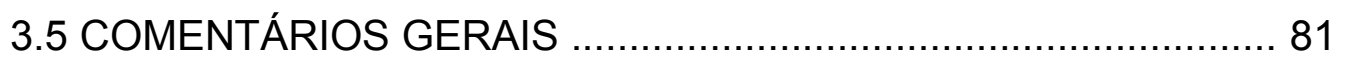

4 MODELOS NUMÉRICOS …........................................................... 83

4.1 CRITÉRIOS GERAIS UTILIZADOS NA ANÁLISE NUMÉRICA .... 84

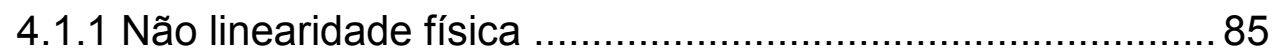

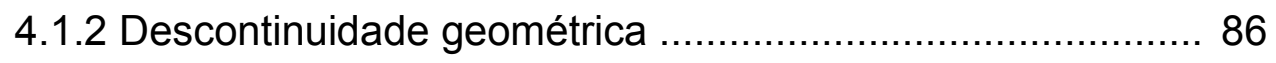

4.2 RESULTADOS EXPERIMENTAIS ESCOLHIDOS ..................... 87

4.3 PREPARAÇÃO DOS MODELOS NUMÉRICOS ……................. 90

4.3.1 Consideração gerais sobre o modelo ................................. 91

4.3.2 Características geométricas dos modelos numéricos ......... 92

4.3.3 Elementos finitos utilizados .............................................. 95

4.3.3.1 Elemento volumétrico ............................................. 96

4.3.3.2 Elemento de contato ............................................. 97

4.3.4 Características dos materiais ............................................ 99

4.3.5 Definição da malha de elementos finitos ............................ 101

4.3.5.1 Viga e chapa de topo ............................................ 101 


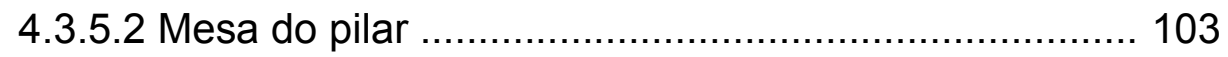

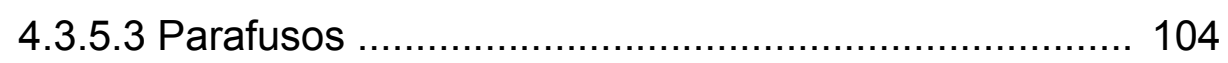

4.3.5.4 Elementos de contato ............................................... 104

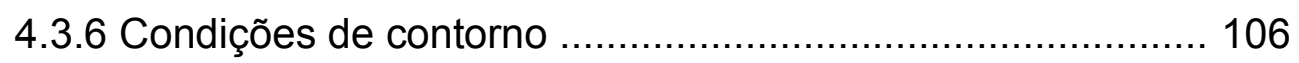

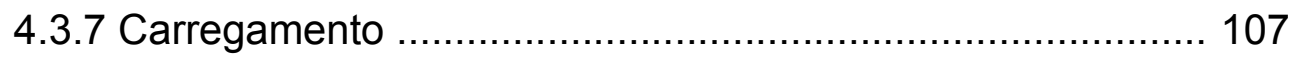

4.4 MODELOS PRELIMINARES - APOIO RÍGIDO ........................ 110

4.4.1 Geometria e malha de elementos finitos ............................ 111

4.4.2 Condições de contorno ..................................................... 112

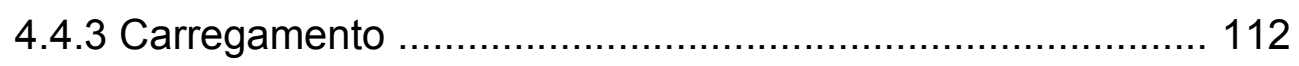

4.5 PROCESSAMENTO DOS MODELOS NUMÉRICOS .................. 113

5 RESULTADOS DA ANÁLISE NUMÉRICA …..................................... 115

5.1 DISTRIBUIÇÃO DE TENSÕES NA VIGA ……........................... 116

5.1.1 Distribuição de tensões longitudinais ................................ 116

5.1.2 Distribuição de tensões transversais de cisalhamento ........ 124

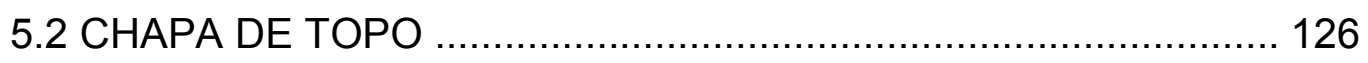

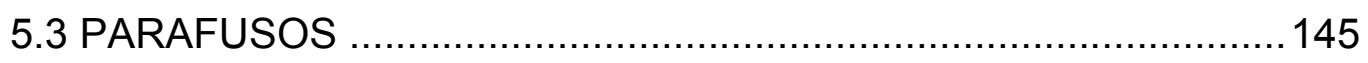

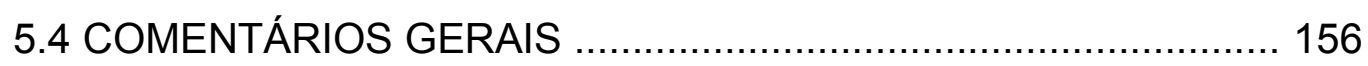

6 COMPARAÇÃO DOS RESULTADOS

NUMÉRICOS E EXPERIMENTAIS ................................................ 158

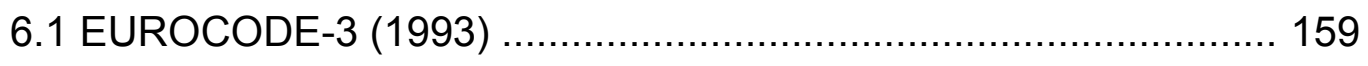

6.2 AFASTAMENTO CHAPA DE TOPO/MESA DO PILAR ................ 170

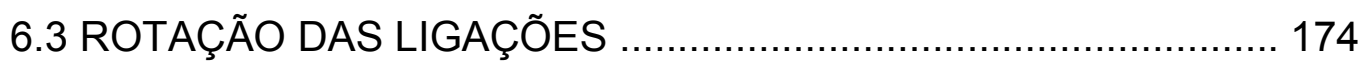

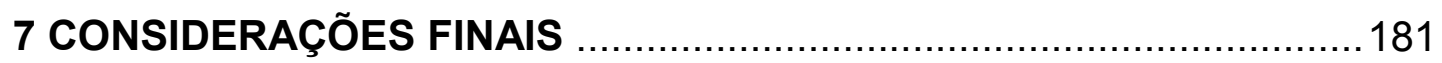

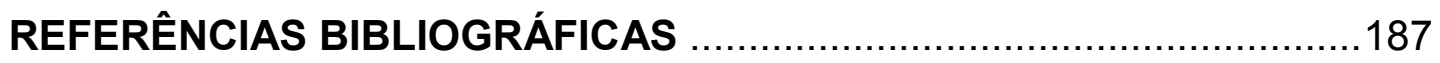

ANEXO I - CÁLCULO DA CAPACIDADE RESISTENTE

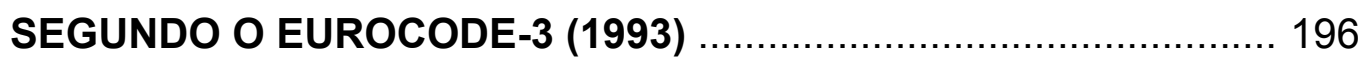

ANEXO II - RESULTADOS COMPLEMENTARES …............................ 221 


\section{LISTA DE FIGURAS}

Figura 2.1 - Ligação viga-coluna com chapa de topo …………….... 8

Figura 2.2 - Ligação completamente soldada ................................. 11

Figura 2.3 - Ligações ensaiadas por CHEN \& LUI (1988a) ............... 12

Figura 2.4 - Ligação viga-coluna com chapa de topo ....................... 13

Figura 2.5 - Ligação viga-coluna com perfil "T" .............................. 14

Figura 2.6 - Modelo analítico proposto por KRISHNAMURTHY (1978b) ..................................... 21

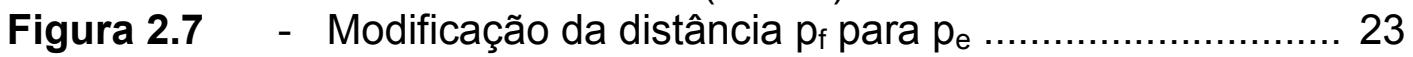

Figura 2.8 - Geometria e malha da análise numérica de

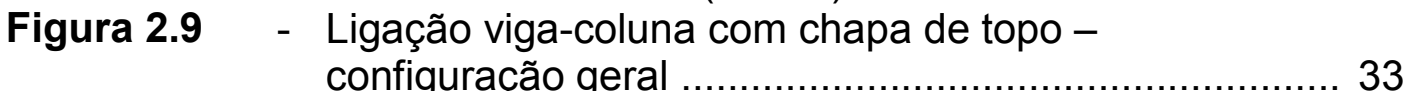

Figura 2.10 - Regiões para verificação da resistência Ligação viga-coluna com chapa de topo ....................... 35

Figura 2.11 - Braço de alavanca do binário tração/compressão ........ 35

Figura 2.12 - Distribuição plástica das forças nas linhas de parafusos ............................................... 36

Figura 2.13 - Etapas da verificação da capacidade resistente nas linhas de parafusos .............................................. 37

Figura 2.14 - Perfis "T" equivalentes .............................................. 39

Figura 2.15 - Modos de falha - Flexão da mesa do pilar ou da chapa de topo e resistência dos parafusos .............................. 40

Figura 2.16 - Variáveis geométricas da formulação ........................... 42

Figura 2.17 - Verificações típicas para tração na alma ....................... 43

Figura 2.18 - Limite da distribuição triangular para as forças

Figura 3.1 - Ligação rígida teórica e semi-rigidez …………................... 53

Figura 3.2 - Regiões representativas da resposta não linear ............ 56

Figura 3.3 - Simplificação da curva momento x rotação ..................... 56

Figura 3.4 - Comportamento da ligação para viga com

Figura 3.5 - Tipos de ligação na análise plástica …………………... 59

Figura 3.6 - Ligações tipicamente flexíveis ..................................... 60

Figura 3.7 - Ligações tipicamente rígidas ........................................ 60

Figura 3.8 - Ligações semi-rígidas .............................................. 60

Figura 3.9 - Classificação do EUROCODE-3 (1992) ......................... 63 
Figura 3.10 - Curvas momento-rotação para diferentes

Figura 3.11 - Resistência máxima a níveis associados de ductilidade ........................................................ 67

Figura 3.12 - Classificação adimensional - regiões segundo o comprimento de referência 69

Figura 3.13 - Classificação adimensional para rigidez e resistência máxima das ligações

Figura 3.14 - Diagrama com a consideração da capacidade rotacional ................................................ 72

Figura 3.15 - Ligações com diferentes classificações .......................... 74

Figura 3.16 - Relação entre a rigidez necessária da ligação e a rigidez relativa entre os elementos conectados ....... 77

Figura 3.17 - Sistema de classificação unificado

Figura 4.1 - Representação do diagrama bilinear .................................... 85

Figura 4.2 - Representação esquemática dos protótipos de ensaio. Protótipo cruciforme ..................................... 89

Figura 4.3 - Pórtico de reação. RIBEIRO (1998) ............................... 89

Figura 4.4 - Detalhe dos apoios. RIBEIRO (1998) .......................... 89

Figura 4.5 - Visão geral do protótipo. RIBEIRO (1998) ..................... 90

Figura 4.6 - Dimensões da seção transversal da viga.

Figura 4.7 - Geometria esquemática das chapa de topo ................... 93

Figura 4.8 - Gabaritos das chapas de topo ..................................... 93

Figura 4.9 - Dimensões do pilar (mm) ........................................... 94

Figura 4.10 - Dimensões padronizadas dos parafusos

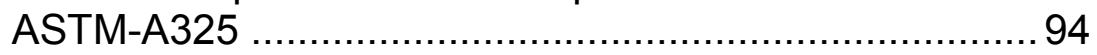

Figura 4.11 - Esquema da simulação do parafuso ............................... 95

Figura 4.12 - Elemento volumétrico SOLID45. ANSYS Help System ................................................... 96

Figura 4.13 - Elemento de contato CONTAC49.

Figura 4.14 - Visualização das rigidezes do contato ............................ 99

Figura 4.15 - Malha de elementos finitos para a viga e chapa de topo. Modelo CT1A-1 ........................................... 102

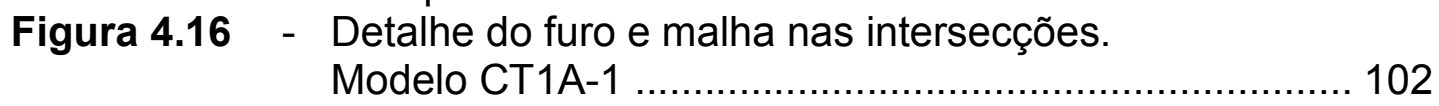

Figura 4.17 - Malha da mesa do pilar. Modelo CT1A-1 …................. 103

Figura 4.18 - Malha do conjunto parafuso/porca. Modelo CT1A-1 ......104

Figura 4.19 - Posicionamento dos elementos de contato. Modelo CT1A-1 ............................................................. 105

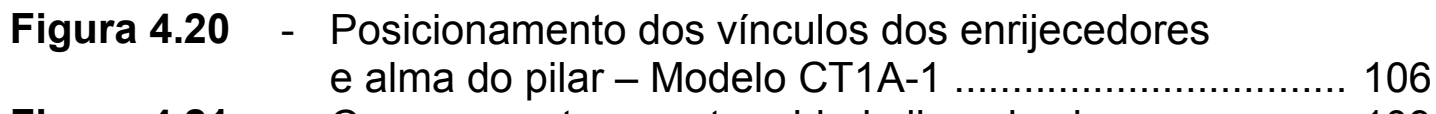

Figura 4.21 - Carregamento na extremidade livre da viga ................... 109

Figura 4.22 - Acoplamento dos nós da extremidade livre da viga .......109

Figura 4.23 - Visão geral do modelo numérico CT1A-1 ...................... 110 
Figura 4.2

Figura 4.25

Figura 4.26

Figura 4.27

Figura 5.1

Figura 5.2

Figura 5.3

Figura 5.4

- Parafuso do modelo CT1A-1R

- Detalhe da geometria dos parafusos no modelo CT1A-1R

Mesa do pilar como apoio totalmente rígido.

Detalhe dos vínculos

- Direção dos deslocamentos prescritos para a protensão dos parafusos

- Posição das seções transversais na viga

- Distribuição de tensões longitudinais. Seção de intersecção viga/chapa de topo - modelo CT1A-1

- Distribuição de tensões longitudinais. Seção H/2 modelo CT1A-1

- Tensões longitudinais médias na mesa superior.

Seção H/2 - modelo CT1A-1

Figura 5.5 - Tensões longitudinais médias na seção H/2.

Variação da espessura da chapa de topo

Figura 5.6 - Tensões longitudinais médias na seção H/2. Variação do diâmetro dos parafusos

Figura 5.7 - Distribuição de tensões longitudinais na alma da viga.

Seção de intersecção viga/chapa de topo modelo CT1A-1

Figura 5.8 - Distribuição de tensões longitudinais na alma da viga.

Seção H/2 - modelo CT1A-1

Figura 5.9 - Tensões longitudinais na alma da viga $-\mathrm{M}=11700 \mathrm{kNcm}$. Variação da espessura da chapa de topo e diâmetro dos parafusos. Seção H/2

Figura 5.10 - Tensões longitudinais nas mesas e alma da viga do modelo CT1A-1

Figura 5.11 - Distribuição de tensões transversais na alma da viga Modelo CT1A-1

Figura 5.12

- Seções na chapa de topo

Figura 5.13 - Deslocamento relativo chapa/pilar.

Seção AA' - modelo CT1A-1

Figura 5.14 - Deslocamento relativo chapa/pilar.

Seção BB' - modelo CT1A-1

Figura 5.15 - Deslocamento relativo chapa/pilar.

Seção CC' - modelo CT1A-1

Figura 5.16 - Deslocamento relativo chapa/pilar.

Seção DD' - modelo CT1A-1

Figura 5.17 - Deslocamento relativo chapa/pilar.

Seção EE' - modelo CT1A-1

Figura 5.18 - Deslocamento relativo chapa/pilar.

Seção FF' - modelo CT1A-1

Figura 5.19 - Deslocamento relativo chapa/pilar.

Seção GG' - modelo CT1A-1

Figura 5.20 - Deslocamento relativo chapa/pilar - seção AA'

Variação da espessura da chapa de topo 


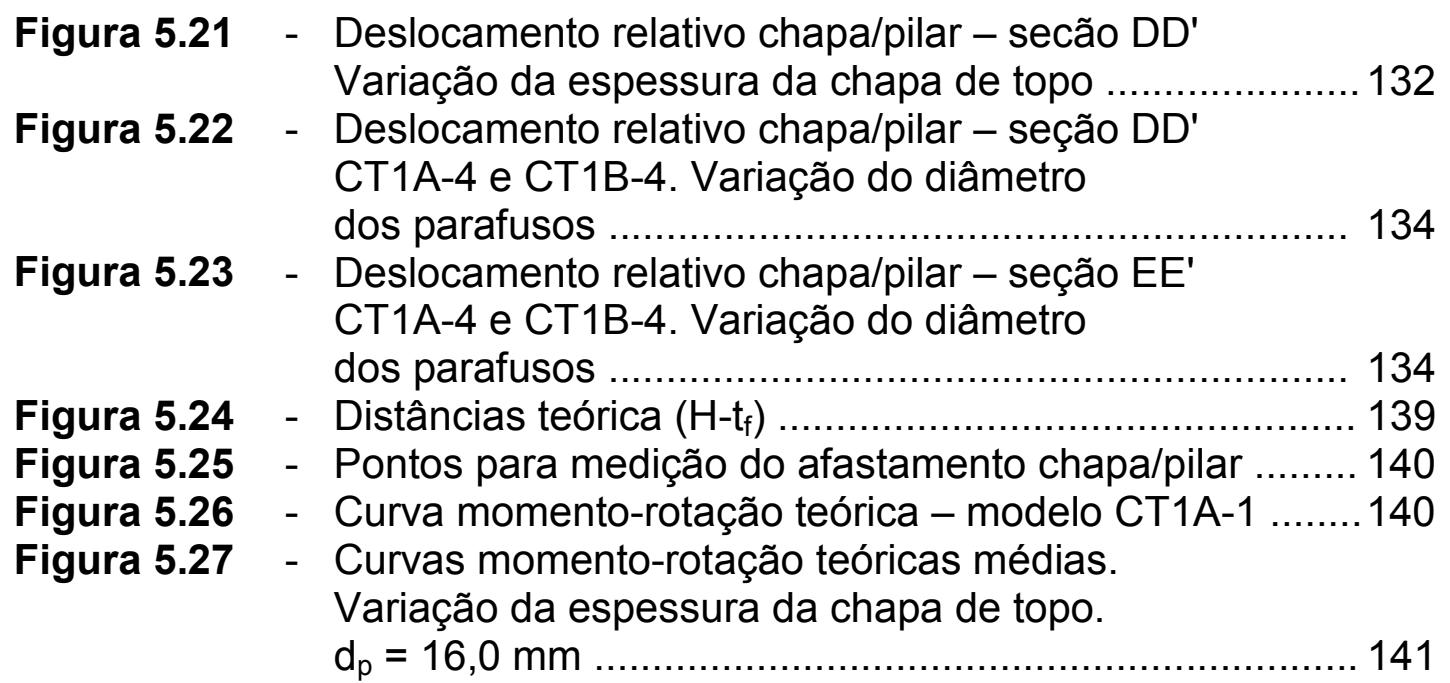

Figura 5.28 - Curvas momento-rotação teóricas médias. Variação da espessura da chapa de topo . $\mathrm{d}_{\mathrm{p}}=19,0 \mathrm{~mm}$ 142

Figura 5.29 - Deformadas da chapa de topo .................................... 143

Figura 5.30 - Curvas momento-rotação teóricas médias. Variação do diâmetro dos parafusos ........................... 144

Figura 5.31 - Deformada típica dos parafusos .................................. 146

Figura 5.32 - Forças de tração nos parafusos - modelo CT1A-1. $\mathrm{F}=85 \mathrm{kN} \rightarrow$ força de protensão ............................ 150

Figura 5.33 - Forças de tração nos parafusos - modelo CT1A-4 ........151

Figura 5.34 - Configuração das forças no modelo CT1A-4 ................ 151

Figura 5.35 - Forças de tração nos parafusos - modelo CT1B-4

Figura 5.36 - Forças de tração nos parafusos - modelo CT1B-6 ..........153

Figura 5.37 - $\begin{aligned} & \text { Forças de tração nos parafusos. } \\ & \text { Variação do diâmetro dos parafusos } \ldots \ldots \ldots \ldots \ldots \ldots \ldots \ldots \ldots \ldots \ldots \ldots \ldots \ldots \ldots \ldots\end{aligned}$

Figura 5.38 - Deformações devido à protensão $-d_{p}=16,0 \mathrm{~mm}$.......... 155

Figura 5.39 - Deformações devido à protensão $-d_{p}=19,0 \mathrm{~mm}$......... 155

Figura 6.1 - Modos de falha para a flexão da mesa do pilar ou da chapa de topo - anexo J do EUROCODE-3 (1993) .......160

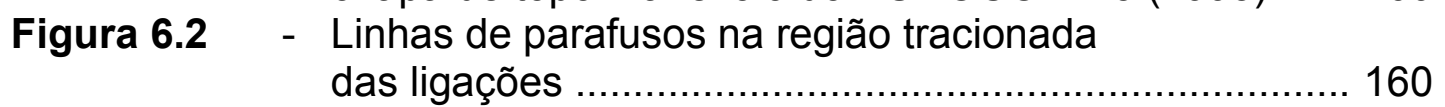

Figura 6.3 - Seções na chapa de topo ........................................... 161

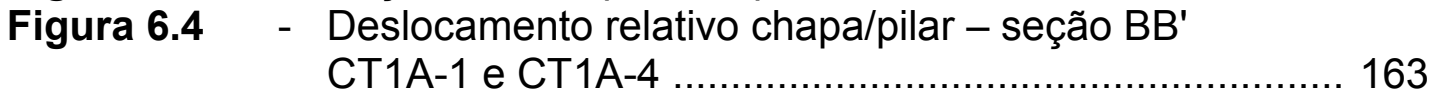

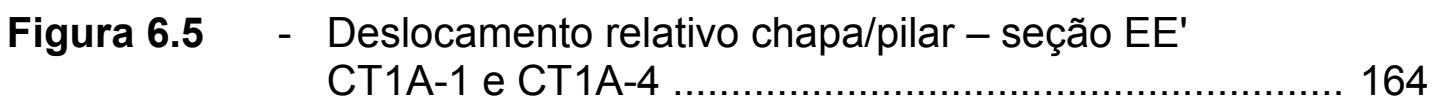

Figura 6.6 - Deslocamento relativo chapa/pilar - seção GG'

Figura 6.7 - Deslocamento relativo chapa/pilar - seção EE'

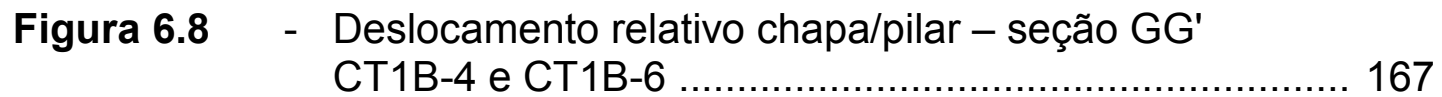


Figura 6.9 - Deformada final do protótipo CT1B-6. Detalhe da ruptura dos parafusos da linha interna

Figura 6.10 - Ponto de medição dos afastamentos chapa/pilar ...........170

Figura 6.11 - Afastamento chapa/pilar. CT1A-1 …........................... 171

Figura 6.12 - Afastamento chapa/pilar. CT1A-4 ………………....... 171

Figura 6.13 - Afastamento chapa/pilar. CT1B-4 ............................... 172

Figura 6.14 - Curvas momento-rotação da ligação.

Figura 6.15 - Curvas momento-rotação da ligação.

Figura 6.16 - Centro de rotação da chapa de topo ............................. 175

Figura 6.17 - Curvas momento-rotação da ligação.

Figura 6.18 - Curvas momento-rotação da ligação. Modelo CT1B-6 .................................................... 177

Figura 6.19 - Curva momento-rotação modificada. Modelo CT1A-1 ……....................................... 179

Figura 6.20 - Curva momento-rotação modificada.

Figura 6.21 - Curva momento-rotação modificada.

Figura 7.1 - Curvas momento-rotação -modelo CT1A-1 ................... 183 


\section{LISTA DE TABELAS}

Tabela II.I - Evolução geral das pesquisas sobre ligações viga-coluna. Ênfase na avaliação da rigidez e parâmetros de dimensionamento 9

Tabela II.II - Verificações de resistência nos elemento da ligação .....34

Tabela III.I - Comprimentos de referência para as ligações. Resultado da análise de 55 experimentos .................... 68

Tabela IV.I - Protótipos das ligações com chapa de topo .................. 88

Tabela IV.II - Espessuras das chapa de topo ................................... 93

Tabela IV.III - Dimensões dos parafusos e porcas (mm) .....................94

Tabela IV.IV - Características dos materiais ........................................ 100

Tabela IV.V - Variação de temperatura e força de protensão ............... 108

Tabela IV.VI - Fases do carregamento e incrementos de carga ............114

Tabela V.I - Deformada da chapa de topo para os modelos numéricos ................................................. 126

Tabela V.II - Tensões $\sigma_{x}$ na chapa de topo. Modelo CT1A-1 ............. 136

Tabela V.III - Tensões $\sigma_{x}$ na chapa de topo. Modelo CT1A-4 ............. 136

Tabela V.IV - Tensões $\sigma_{y}$ na chapa de topo. Modelo CT1A-1 ............. 138

Tabela V.V - Tensões longitudinais e deformadas dos parafusos ...... 147

Tabela VI.I - Capacidade resistente para a flexão da chapa de topo Segundo o EUROCODE-3 (1993). Modelo CT1A-1 e CT1A-4

Tabela VI.II - Capacidade resistente para a flexão da chapa de topo Modelo CT1B-4 e CT1B-6 .......................................... 166

Tabela VI.III - Capacidade resistente para a flexão da chapa de topo Modelo CT1A-4 e CT1B-4

Tabela VII.I - Modos de falha - EUROCODE-3 (1993) vs Protótipos ..184 


\section{LISTA DE SÍMBOLOS}

$\mathbf{a}_{\mathbf{t}} \quad$ - área mínima necessária, teoricamente, por linha de parafusos KRISHNAMURTHY (1978b)

A $_{\mathrm{fv}} \quad$ - área da seção transversal da mesa da viga

A $\quad$ - área da seção transversal da alma da viga

B - largura da mesa do pilar

$\mathbf{b}_{\mathrm{ch}} \quad$ - largura da chapa de topo

bef $_{\text {ef }} \quad$ - largura mínima da chapa de topo - KRISHNAMURTHY (1978b)

$b_{\mathrm{fv}} \quad$ - largura da mesa da viga

C $\quad$ - parâmetro de correção da força de tração transmitida pela mesa da viga, obtido por KRISHNAMURTHY (1978b) via método dos elementos finitos

$\mathbf{C}_{2}$ - parâmetro de correção da distância efetiva $\mathbf{p}_{\mathbf{e}}$ entre a face da mesa da viga e a linha de centro dos parafusos, obtido por KRISHNAMURTHY (1978b), via método dos elementos finitos

C C $_{3}$ - parâmetro de correção do momento fletor crítico na chapa de topo, obtido por KRISHNAMURTHY (1978b), via método dos elementos finitos

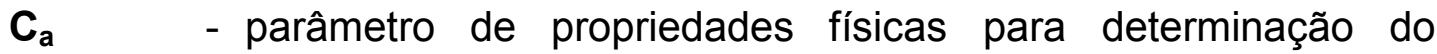
momento crítico na chapa de topo - KRISHNAMURTHY (1978b)

C $\quad$ - parâmetro de relação entre as larguras da mesa da viga e da chapa de topo - KRISHNAMURTHY (1978b)

$\mathbf{d}_{\mathbf{p}} \quad$ - diâmetro nominal do parafuso

E - módulo de elasticidade longitudinal (Young) 

ex - distância do centro do parafuso à extremidade da chapa de topo
F 1 - força de tração corrigida, transmitida pela mesa da viga - KRISHNAMURTHY (1978b)
$\mathbf{F}_{\mathbf{t}} \quad$ - força de tração transmitida pela mesa da viga
$\mathbf{f}_{\mathrm{ch}} \quad$ - tensão admissível à flexão na chapa de topo
$\mathbf{f}_{\mathrm{ct}} \quad$ - tensão admissível à flexão na chapa de topo
$\mathbf{f}_{\mathrm{pt}} \quad-$ tensão admissível à tração nos parafusos
$\mathbf{f}_{\mathrm{pu}} \quad$ - tensão última de tração nos parafusos
fup - resistência última à tração do parafuso
$\mathbf{f}_{\mathrm{v}, \mathrm{ch}}$ - máxima tensão de cisalhamento na chapa de topo - KRISHNAMURTHY (1978b)
fy $\quad$ - tensão limite nominal de escoamento do aço
$\mathbf{f}_{\mathrm{y}, \mathrm{ch}} \quad$ - limite de escoamento do aço da chapa de topo
$\mathbf{f}_{\mathbf{y}, \mathrm{fp}} \quad$ - limite de escoamento do aço da mesa do pilar

g - distância horizontal entre 0 centro dos parafusos EUROCODE-3 (1993)

H $\quad$ - altura total da viga

I - inércia da viga à flexão

L $\quad$ - vão da viga

L $L_{\text {ef }} \quad$ - comprimento efetivo da linha de escoamento no perfil "T" equivalente, calculado de acordo com a posição das linhas ou grupos de linhas de parafusos e da presença ou não de enrijecedores - EUROCODE-3 (1993)

Lt - comprimento efetivo da alma (da viga ou do pilar) à tração, admitindo-se um espraiamento máximo de $60^{\circ}$ dos parafusos em relação ao plano médio da alma - EUROCODE-3 (1993)

M $\quad$ - momento fletor na junção da chapa de topo com a mesa KRISHNAMURTHY (1978b) 


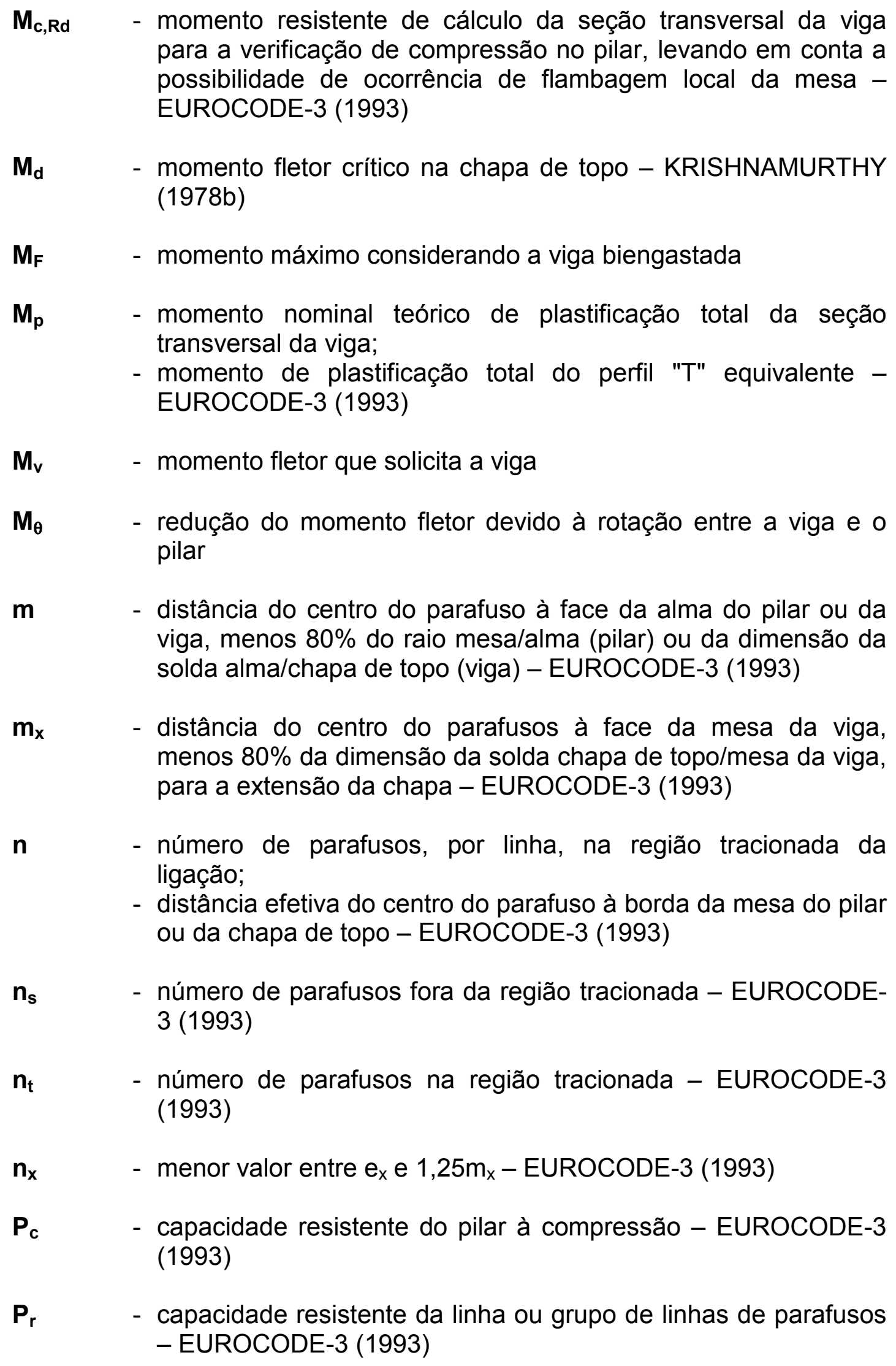




\begin{tabular}{|c|c|}
\hline $\mathbf{P}_{\mathrm{ss}}$ & $\begin{array}{l}\text { - capacidade resistente ao cisalhamento, de um parafuso, } \\
\text { tomando-se o menor dos valores calculados para cisalhamento } \\
\text { puro no parafuso e para pressão de contato na chapa de topo e } \\
\text { na mesa do pilar - EUROCODE-3 (1993) }\end{array}$ \\
\hline $\mathbf{P}_{\mathrm{t}}^{\prime}$ & $\begin{array}{l}\text { - limite superior de resistência do parafuso quando o efeito } \\
\text { alavanca é considerado - EUROCODE-3 (1993) }\end{array}$ \\
\hline $\mathbf{P}_{\mathrm{ts}}$ & $\begin{array}{l}\text { - capacidade resistente ao cisalhamento, de um parafuso - } \\
\text { EUROCODE-3 (1993) }\end{array}$ \\
\hline $\mathbf{p}_{\mathrm{e}}$ & $\begin{array}{l}\text { - distância efetiva entre a face da mesa e a linha de centro dos } \\
\text { parafusos - KRISHNAMURTHY (1978b) }\end{array}$ \\
\hline $\mathbf{p}_{\mathrm{f}}$ & $\begin{array}{l}\text { - distância da face da mesa da viga à linha de centro dos } \\
\text { parafusos }\end{array}$ \\
\hline q & - carregamento uniformemente distribuído na viga \\
\hline$S_{j}$ & - rigidez rotacional secante da ligação \\
\hline $\mathbf{s}$ & $\begin{array}{l}\text { - distância da face da mesa da viga ao ponto de momento fletor } \\
\text { nulo - KRISHNAMURTHY (1978b) }\end{array}$ \\
\hline $\mathbf{s}_{\mathrm{wf}}$ & - altura da solda de filete entre chapa e mesa da viga \\
\hline $\mathbf{s}_{\mathrm{ww}}$ & - altura da solda de filete entre chapa e alma da viga \\
\hline $\mathbf{t}$ & $\begin{array}{l}\text { - espessura da mesa do pilar ou da chapa de topo - } \\
\text { EUROCODE-3 (1993) }\end{array}$ \\
\hline $\mathbf{t}_{\mathrm{ch}}$ & - espessura da chapa de topo \\
\hline$t_{f p}$ & - espessura da mesa do pilar \\
\hline$t_{f v}$ & - espessura da mesa da viga \\
\hline $\mathbf{t}_{\mathrm{w}}$ & - espessura da alma da viga ( $\left.t_{w v}\right)$ ou do pilar ( $\left.t_{w p}\right)$ \\
\hline$t_{w p}$ & - espessura da alma do pilar \\
\hline$t_{w v}$ & - espessura da alma da viga \\
\hline $\mathbf{v}$ & - força cortante na ligação - EUROCODE-3 (1993) \\
\hline $\mathbf{W}_{\text {ef }}$ & $\begin{array}{l}\text { - módulo resistente elástico efetivo da seção da viga - } \\
\text { EUROCODE-3 (1993) }\end{array}$ \\
\hline
\end{tabular}


$\mathbf{w}_{\mathbf{t}} \quad$ - garganta efetiva da solda de filete entre a mesa da viga e a chapa de topo - KRISHNAMURTHY (1978b)

$\mathbf{Z}_{\mathrm{x}} \quad$ - módulo resistente plástico da seção da viga - EUROCODE-3 (1993)

$\alpha_{m} \quad$ - fator de correção do momento fletor $\mathbf{M}_{1}$ na junção da chapa de topo com a mesa da viga - KRISHNAMURTHY (1978b)

$\gamma_{\mathrm{M} 0, \mathrm{M} 1}-$ coeficiente de segurança com valor 1,1 - EUROCODE-3 (1993)

$\phi \quad$ - coeficiente de segurança

$\theta \quad$ - rotação relativa entre viga e pilar 


\section{RESUMO}

MAGGI, Y. I. (2000). Análise numérica, via M.E.F., do comportamento de ligações parafusadas viga-coluna com chapa de topo. São Carlos. Dissertação (Mestrado). 195p. Escola de Engenharia de São Carlos, Universidade de São Paulo.

Este trabalho apresenta uma análise numérica sobre 0 comportamento estrutural das ligações parafusadas viga-coluna com chapa de topo. São estudados dois métodos tradicionais de dimensionamento e são apresentados cinco sistemas de classificação propostos para as ligações. Modelos numéricos das ligações estudadas são preparados com a utilização de elementos finitos e os resultados numéricos são comparados com resultados experimentais conhecidos. São abordados aspectos relativos às propostas de dimensionamento, em comparação com os resultados numéricos e experimentais. Em particular, é discutida a rigidez das ligações, verificando-se a influência da variação da espessura da chapa de topo e diâmetro dos parafusos. Com a comparação entre resultados numéricos e experimentais, é analisada a representatividade dos modelos numéricos com relação ao comportamento das ligações estudadas. Finalmente, são apresentadas as conclusões e recomendações para futuras pesquisas.

Palavras-chave: Estruturas, aço, ligações, semi-rígidas, viga 


\begin{abstract}
MAGGI, Y. I. (2000). Numerical analysis, by F.E.M, of bolted beam-to-column end plate connection behavior. São Carlos. Dissertação (Mestrado). 195p. Escola de Engenharia de São Carlos, Universidade de São Paulo.

This work presents a numerical analysis on the structural behavior of bolted beam-to-column end plate connection. Two traditional design methods are studied and five proposed classification systems for connections are presented. Numerical models representing the studied connections are prepared using finite elements and numerical results are compared with existing experimental results. The design proposals are compared with numerical and experimental results. In particular, the connection rigidity is discussed by verifying the influence of variations in end plate thickness and bolt diameter. Comparing numerical and experimental results the reliability of F.E.M models is appraised. Finally, conclusions are presented with some suggestions for future researches.
\end{abstract}

Keywords: Structures, steel, connections, semi-rigid, beam 


\section{Capítulo}

\section{INTRODUÇÃO}

As estruturas metálicas, em geral, possibilitam uma grande diversidade de configurações e dispositivos para as ligações das peças que as compõem. Esses dispositivos, por introduzirem efeitos locais e imperfeições, são origem de descontinuidades geométricas e mecânicas que devem ser observadas de modo cuidadoso e preciso, uma vez que podem induzir a um comportamento global não linear da estrutura.

Considerando a análise estrutural convencional, pressupõe-se a estrutura como sendo um conjunto de barras unidimensionais e interligadas, sendo a prática considerar as ligações entre os elementos como pontos nodais. Desta maneira, idealiza-se o comportamento dos nós, classificandoos como rígidos ou rotulados, no que diz respeito às rotações relativas entre os elementos e à transmissão do momento fletor entre as barras.

Neste procedimento, os nós que mantêm a continuidade rotacional, não modificando o ângulo relativo entre os elementos após a atuação do carregamento na estrutura, são classificados como rígidos, ocorrendo, neste caso, a transmissão total do momento fletor.

Em contrapartida, os nós onde se deseja nenhuma transmissão de momento fletor, são classificados como rotulados, não havendo continuidade rotacional entre os elementos.

Considerando a grande variedade de ligações e os efeitos locais que as mesmas podem introduzir nas estruturas, é intuitivo observar que torna-se precária a classificação do comportamento das ligações como 
rígidas (nós rígidos) ou flexíveis (nós rotulados), sendo necessária a inserção de um tipo intermediário: as ligações semi-rígidas ${ }^{1}$.

Desta maneira pode-se definir as ligações semi-rígidas como sendo aquelas com comportamento intermediário ao das ligações idealizadas como rígidas ou flexíveis, quanto à continuidade rotacional e à transmissão de momentos fletores.

Devido à crescente necessidade de incorporar o estudo das ligações semi-rígidas às etapas de análise e dimensionamento das estruturas, diversas pesquisas têm sido desenvolvidas de modo a melhor representar a contribuição dessas ligações para o comportamento global e local das estruturas, bem como na determinação efetiva de seus estados limites últimos.

Dentre os trabalhos desenvolvidos houve desde a preocupação quanto à procura de classificações mais consistentes no que diz respeito ao comportamento estrutural das ligações até a análises teóricas mais refinadas. Neste último caso, o avanço das pesquisas foi motivado, também, pelo grande desenvolvimento tecnológico, principalmente na área da computação, o que possibilitou o uso de equipamentos e técnicas mais avançadas para análise de modelos matemáticos, os quais procuraram, por sua vez, melhor representar os fenômenos físicos que ocorrem nestas ligações.

Dentro deste contexto, o presente trabalho tem como objetivo o estudo do comportamento das ligações parafusadas viga-coluna com chapa de topo, nas estruturas metálicas, visando a análise de modelos teóricos que possam, com maior rigor numérico, estabelecer relações condizentes com resultados experimentais, no que diz respeito aos aspectos de rigidez e dos estados limites últimos.

Devido à grande quantidade de parâmetros que envolvem as ligações, a análise numérica é justificada à medida que evita extrapolações de resultados para situações que não puderam ser comprovadas experimentalmente. Pesquisas experimentais podem tornar-se caras em

\footnotetext{
1 "semi-rígidas" é uma denominação corrente utilizada na área de estruturas metálicas
} 
demasia dependendo dos fatores a serem analisados e alguns dados muitas vezes não podem ser coletados por inacessibilidade da instrumentação, ou por impossibilidade de monitoramento. Pode-se citar, neste caso, a aquisição de dados relativos às forças de alavanca e o acompanhamento da plastificação dos elementos.

Procura-se então, através da modelagem por elementos finitos, a obtenção de modelos teóricos onde se possa, satisfatoriamente, analisar os efeitos do comportamento estrutural do tipo de ligação proposta neste trabalho. A partir dos resultados obtidos numericamente é possível analisar o desempenho dos elementos conectados, incorporando parâmetros relativos à rigidez das ligações, bem como analisar a influência da variação de alguns parâmetros, como espessura da chapa de topo, diâmetro dos parafusos, posicionamento dos parafusos na chapa de topo, entre outros.

As simulações numéricas foram realizadas através do software ANSYS, programa comercial amplamente conhecido e utilizado para análise com elementos finitos.

Os capítulos que compõem este trabalho estão disposto de maneira a esclarecer aspectos relativos ao comportamento das ligações, fornecer um panorama sobre as classificações existentes de ligações vigacoluna, bem como apresentar a metodologia utilizada para a preparação dos modelos teóricos e a análise e comparações pertinentes dos resultados obtidos pela análise teórica com resultados experimentais conhecidos.

Apresenta-se também um histórico do desenvolvimento das pesquisas relativas às ligações viga-coluna, juntamente com uma visão geral dos modelos de dimensionamento existentes. Além disso, são apresentadas, em anexo, análises que permitiram a verificação da confiabilidade dos resultados em estágios anteriores à confecção dos modelos finais, validando a utilização dos modelos com elementos finitos e do software escolhido.

Pretende-se, desta maneira, contribuir para que sejam possíveis conclusões mais realistas em torno do comportamento estrutural das ligações viga-coluna com chapa de topo por meio das comparações dos resultados obtidos numericamente com outros experimentais e permitir 
assim que se criem subsídios para análises mais investigatórias e econômicas - quando comparadas às análises experimentais - uma vez comprovada a confiabilidade dos resultados obtidos por meio da análise numérica. 


\section{Capítulo}

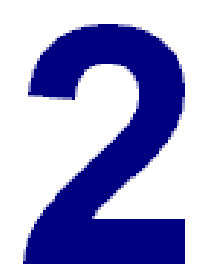

\section{LIGAÇÕES VIGA-COLUNA}

\subsection{CONSIDERAÇÕES INICIAIS}

Este capítulo é dedicado à apresentação das ligações viga-coluna, de uma forma geral, tendo por objetivo um levantamento sucinto envolvendo a evolução das pesquisas relativas a este tipo de ligação. Procura-se, também, apresentar e discutir as propostas de dimensionamento específicas para as ligações viga-coluna com chapa de topo, com as devidas considerações.

Alguns aspectos, preliminarmente, devem ser ressaltados para que se entenda a importância de um estudo profundo das ligações estruturais na concepção, projeto e construção de estruturas metálicas.

Um aspecto diz respeito a uma característica própria deste tipo de estrutura, a qual, se observada cuidadosamente, traduz-se na influência do desempenho das ligações entre vigas e colunas no comportamento global da estrutura. Sob um ponto de visto mais apurado, as ligações necessitam ser observadas e tratadas com cuidado, uma vez que são origem de descontinuidades geométricas e mecânicas. Torna-se necessária, então, uma análise de seu comportamento, tão precisa quanto possível.

Um outro aspecto a ser considerado refere-se à fabricação e montagem das estruturas metálicas, lembrando, neste caso, a importância da mão-de-obra e do custo das ligações.

McGUIRE (1988), citado por RIBEIRO (1998), estima que uma parcela entre 30 a $40 \%$ do custo total de um edifício metálico de múltiplos andares seja devido ao sistema estrutural, de cujo custo, a fabricação e 
montagem respondem, em conjunto, por aproximadamente 75\%. Mesmo em casos em que a mão-de-obra pode ser mais barata, deve-se levar em consideração a necessidade de qualificação do trabalhador, fase que pode se estender por anos.

Entre outros fatores, ainda há as simplificações adotadas, na prática, para a viabilização da análise estrutural, visto que é difícil avaliar o quanto uma ligação é rígida ou flexível. Embora se reconheça a existência desse comportamento intermediário, o engenheiro estrutural quase nunca dispõe, como lembrou RIBEIRO (1998), da possibilidade de obter dados sobre as ligações que pretende adotar em uma determinada estrutura, principalmente dados experimentais.

Visto isso, pela expressão "ligação viga-coluna", entende-se a ligação entre elementos metálicos nas quais a viga é conectada à mesa do pilar por meio de sua alma e/ou de suas mesas, utilizando-se a palavra "pilar" para a designação do elemento estrutural isolado. RIBEIRO (1998) coloca que a expressão "ligação viga-coluna" não é a mais adequada em termos de linguagem técnica, mas pode ser utilizada por tratar-se de expressão já consagrada na literatura especializada, a qual é tradução literal da expressão beam-to-column connection.

\subsection{HISTÓRICO E EVOLUÇÃO DAS PESQUISAS}

Em sua tese de doutorado, RIBEIRO (1998) faz uma extensa revisão da literatura existente, coletando informações de diversos trabalhos cujos resultados permitiram novas considerações e recomendações quanto ao comportamento estrutural das ligações, principalmente no que diz respeito às especificações de projeto.

O mesmo autor relata que o primeiro trabalho desenvolvido para avaliar a rigidez de uma ligação foi realizado na Universidade de Illinois, por WILSON \& MOORE (1917), havendo um crescente interesse no estudo e no uso de ligações semi-rígidas nas estruturas metálicas, impulsionados 
também com a popularização do uso da solda e dos parafusos de alta resistência.

RIBEIRO (1998) também cita alguns trabalhos que mereceram destaque no exterior, dentre os quais se incluem a pesquisa de JONES et al. (1980 e 1983), que coletou 323 testes obtidos em 29 diferentes trabalhos; as análises realizadas por NETHERCOT (1985), cujo trabalho reuniu mais de 800 ensaios relatados em diversos artigos; o banco de dados criado por GOVERDHAM (1984), reunindo 230 curvas momento-rotação obtidas experimentalmente; a contribuição dada por KISHI \& CHEN (1986) ao trabalho de GOVERDHAM (1984), totalizando 303 testes gerenciados por um sistema computadorizado para tratamento dos resultados experimentais; e trabalhos experimentais mais recentes, desenvolvidos por DAVISON et al. (1987a e 1987b).

No Brasil, a pesquisa realizada recentemente por RIBEIRO (1998) no Departamento de Estruturas da Escola de Engenharia de São Carlos (EESC-USP), à qual este trabalho dá continuidade, reúne um conjunto de 28 testes experimentais com ligações viga-coluna. $O$ autor também cita os trabalhos desenvolvidos por PRELORENTZOU (1991), RODRIGUES (1991) e QUEIROZ (1992 e 1995).

Os trabalhos acima citados preocuparam-se em estudar 0 comportamento estrutural das ligações em estruturas metálicas. Via de regra, consistem de uma ou mais das seguintes abordagens:

i. estabelecimento de modelos teóricos para posterior comparação com resultados experimentais;

ii. formulações empíricas com base em resultados experimentais;

iii. formulações empíricas, via modelos matemáticos e computacionais, com ou sem posterior aferição de resultados obtidos em ensaios de laboratório;

iv. análise dos efeitos do comportamento estrutural das ligações sobre o desempenho dos elementos conectados e/ou sua influência na resposta global da estrutura; 
v. incorporação de parâmetros relativos à rigidez das ligações na análise estrutural.

A tabela II.I apresenta a evolução das pesquisas sobre ligações viga-coluna, numa tentativa de melhor organizar as pesquisas que contribuíram para o desenvolvimento de estudos sobre esse tipo de ligação nas estruturas metálicas.

Seguindo o escopo deste capítulo, serão citados os trabalhos referentes ao estudo das ligações viga-coluna, com uma abordagem geral sobre o assunto.

Especificamente às ligações viga-coluna com chapa de topo, esquematizada na figura 2.1, reservou-se um item adicional, no qual pretende-se detalhar aspectos relativos ao dimensionamento, incluindo os modelos utilizados e sua análise.

A maioria das referências foi organizada em ordem cronológica, exceto para casos que reunam diversos trabalhos e autores em torno de um mesmo assunto ou fato específico. Estes casos serão devidamente comentados.

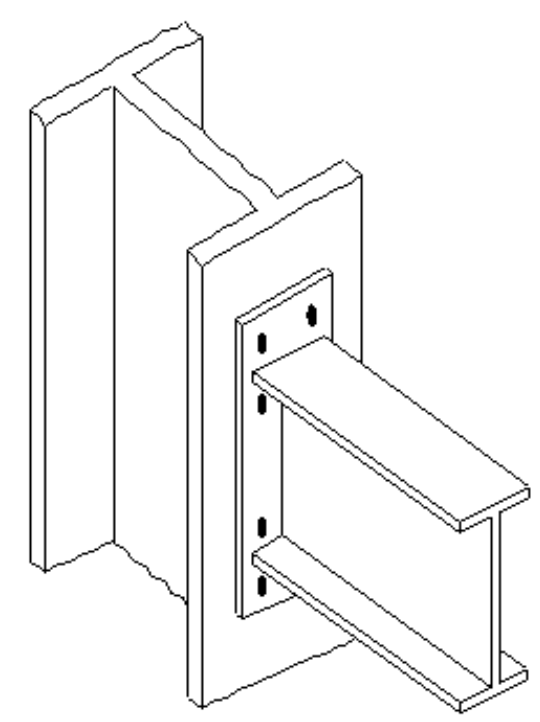

Figura 2.1 - Ligação viga-coluna com chapa de topo 
Tabela II.I - Evolução geral das pesquisas sobre ligações viga-coluna

Ênfase na avaliação da rigidez e parâmetros de dimensionamento

\begin{tabular}{|c|c|}
\hline Pesquisador(es) ou ano & Observações sobre os trabalhos realizados \\
\hline $\begin{array}{l}\text { WILSON \& MOORE (1917) } \\
\text { Illinois, Estados Unidos }\end{array}$ & $\begin{array}{l}\text { Desenvolvimento do primeiro estudo com o objetivo de avaliar a rigidez de uma ligação e } \\
\text { sua influência no comportamento da estrutura. O trabalho foi realizado utilizando-se } \\
\text { ensaios de vários tipos de ligações rebitadas, na Universidade de Illinois, Estados Unidos. }\end{array}$ \\
\hline 1929 & $\begin{array}{l}\text { Criação de um programa teórico-experimental pelo Steel Structures Research Committee } \\
\text { of Great Britain, envolvendo vários aspectos do comportamento das estruturas metálicas. } \\
\text { Este comitê interrompeu suas atividades com o início da Segunda Guerra Mundial. }\end{array}$ \\
\hline BATHO \& BATHEMAN (1934) & Sugeriram a substituição, nas ligações, dos rebites por parafusos de alta resistência. \\
\hline WILSON \& THOMAS (1938) & $\begin{array}{l}\text { Realizaram estudos sobre fadiga em ligações rebitadas, também constatando a } \\
\text { possibilidade de utilização de parafusos de alta resistência. }\end{array}$ \\
\hline 1947 & $\begin{array}{l}\text { Com a criação do Research Council on Riveted and Bolted Structural Joints (RCRBSJ), } \\
\text { atualmente denominado de Research Council on Structural Connections (RCSC), iniciou- } \\
\text { se, com mais ênfase, as pesquisas nesta área, nos Estados Unidos. O RCRBSJ reunia } \\
\text { órgãos governamentais, universidades, institutos de pesquisa e o setor industrial, tendo por } \\
\text { finalidade apoiar e financiar estudos sobre o comportamento estrutural de ligações } \\
\text { rebitadas e parafusadas. }\end{array}$ \\
\hline
\end{tabular}




\begin{tabular}{|c|c|}
\hline Pesquisador(es) ou ano & Observações sobre os trabalhos realizados \\
\hline RCRBSJ (1949) & $\begin{array}{l}\text { Com base em várias pesquisas, o RCRBSJ publica a primeira especificação para ligações } \\
\text { utilizando parafusos de alta resistência, na qual permitia-se a substituição de rebites por } \\
\text { parafusos, na proporção de um para um. }\end{array}$ \\
\hline RUBLE (1959) & $\begin{array}{l}\text { Relacionou e organizou em sua pesquisa uma grande quantidade de trabalhos } \\
\text { desenvolvidos na década de } 50 \text {, resultado da iniciativa da RCRBSJ. Dentre esses } \\
\text { trabalhos destacam-se as pesquisas realizadas por MUNSE et al. (1959a e 1959b) e } \\
\text { VASARHELY (1959). }\end{array}$ \\
\hline BALL \& HIGGINS (1959) & $\begin{array}{l}\text { Neste trabalho é feita uma discussão sobre os procedimentos de instalação e aperto dos } \\
\text { parafusos de alta resistência para a obtenção da protensão mínima especificada pelas } \\
\text { normas. }\end{array}$ \\
\hline Década de 60 & $\begin{array}{l}\text { Inicia-se, a partir dos anos sessenta, tanto nos Estados Unidos quanto na Europa, uma } \\
\text { ênfase quase que total para os estudos de ligações que utilizavam soldas e/ou parafusos } \\
\text { de alta resistência como meio de ligação. Neste período, começam a ser desenvolvidos } \\
\text { estudos sobre o comportamento de tipos específicos de ligações, como as completamente } \\
\text { soldadas. }\end{array}$ \\
\hline RCRBSJ (1962) & $\begin{array}{l}\text { É publicada, pela RCRBSJ, uma revisão da especificação para ligações estruturais } \\
\text { utilizando parafusos ASTM-A325. }\end{array}$ \\
\hline
\end{tabular}




\section{Observações sobre os trabalhos realizados}

As ligações completamente soldadas, como um tipo específico de ligação viga-coluna, começou a ser estudada a partir da publicação de JOHNSON (1959), pioneiro na realização de estudos experimentais sobre o comportamento estrutural deste tipo de ligação.

Considerada rígida ideal, as ligações completamente soldadas passaram a ser utilizadas como parâmetro de controle para a avaliação do desempenho de ligações, também consideradas rígidas, com outras configurações. Apresentada esquematicamente na figura 2.2, para as ligações completamente soldadas admitia-se a transmissão do momento fletor por meio de um binário atuando nas mesas, sendo a força cortante transmitido pela alma da viga.

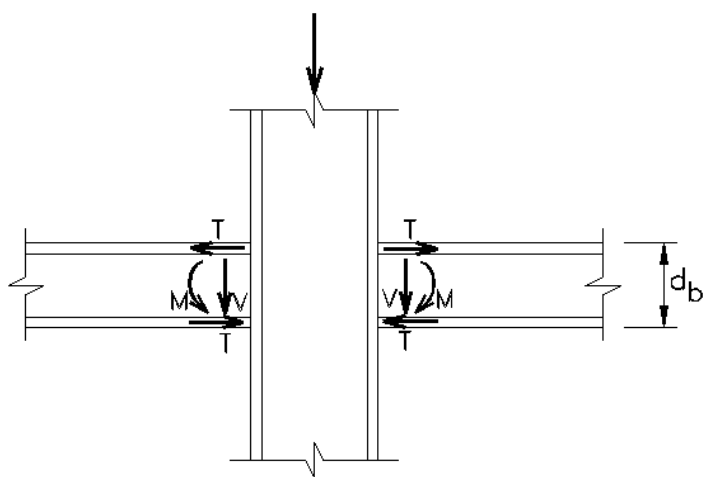

Figura 2.2 - Ligação completamento soldada

Outros estudos importantes sobre o comportamento deste tipo de ligação foram realizados por BEEDLE \& CHRISTOPHER (1964), HUANG et al. (1973), REGEC et al. (1973), PARFITT Jr. \& CHEN (1976), CHEN \& PATEL (1981), WITTEVEEN et al. (1982) e CHEN \& LUI (1988a). 
PARFITT \& CHEN (1976), CHEN \& PATEL (1981) e CHEN \& LUI (1988b), desenvolveram algumas pesquisas experimentais envolvendo outros meios de ligação, tanto das mesas quanto da alma, entre vigas e pilares. Os protótipos, ensaiados na Lehigh University, Estados Unidos, foram confeccionados mantendo-se a solda nas mesas, sendo a união da alma da viga à mesa do pilar feita pela utilização de chapas parafusadas. Os protótipos ensaiados incluíam ligações apenas soldadas, com e sem dispositivos para absorção das forças cortantes, como ilustrado nas figuras 2.3a e 2.3b, respectivamente, e três outros tipos de ligação que diferiam entre si apenas pela presença ou não de enrijecedores na alma do pilar e pela utilização de furos padrão ou alongados.

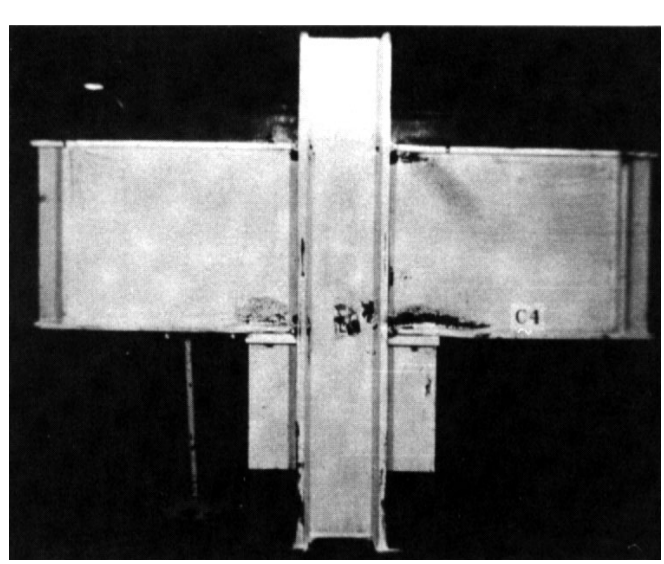

(a)

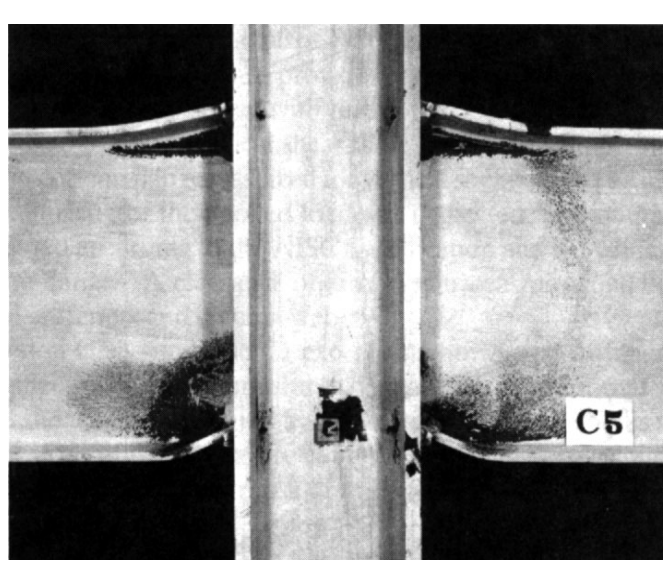

(b)

Figura 2.3 - Ligações ensaiadas por CHEN \& LUI (1988a) 


\begin{tabular}{|c|c|}
\hline Pesquisador(es) ou ano & Observações sobre os trabalhos realizados \\
\hline \multirow{3}{*}{ SHERBOURNE, 1961} & $\begin{array}{l}\text { Considerado como um dos pioneiros no estudo das ligações viga-coluna com chapa de } \\
\text { topo, estudou ligações nas quais a transmissão dos esforços da viga para o pilar se davam } \\
\text { por meio de uma chapa soldada à extremidade da viga e parafusada à mesa do pilar, como } \\
\text { esquematizado na figura } 2.4 \text {. } \\
\text { Suas pesquisas foram patrocinadas pela British Welding Research Association (BWRA), na } \\
\text { Universidade de Cambridge, Inglaterra. }\end{array}$ \\
\hline & \\
\hline & Figura 2.4 - Ligação viga-coluna com chapa de topo \\
\hline
\end{tabular}




\begin{tabular}{|c|c|}
\hline Pesquisador(es) ou ano & Observações sobre os trabalhos realizados \\
\hline$x^{2}$ & $\begin{array}{l}\text { Realizaram um importante estudo sobre ligações nas quais a ligação entre viga e pilar era } \\
\text { feita com perfis "T", conectados às mesas da viga e do pilar, como esquematizado na } \\
\text { figura } 2.5 \text {. } \\
\text { Analisaram tanto o comportamento local quanto global das ligações, dando maior ênfase } \\
\text { aos casos de solicitação de tração, em razão da possibilidade de aparecimento de forças } \\
\text { de alavanca (prying action). A partir dessas observações estabeleceram um modelo } \\
\text { analítico para relacionar as forças de tração aplicadas ao perfil " } \mathrm{T} \text { " com as forças de } \\
\text { alavanca. }\end{array}$ \\
\hline
\end{tabular}




\begin{tabular}{|c|c|}
\hline Pesquisador(es) ou ano & Observações sobre os trabalhos realizados \\
\hline NAIR et al. (1974) & $\begin{array}{l}\text { Realizaram um estudo analítico-experimental sobre o fenômeno das forças de alavanca, } \\
\text { englobando solicitações estáticas e cíclicas e determinaram a influência do efeito alavanca } \\
\text { por meio da comparação com o comportamento de ligações com perfis "T" com mesas de } \\
\text { grande espessura. Estabeleceram assim, a eficiência dos parafusos e a relação, sob } \\
\text { condições de solicitação última, entre a força de alavanca e a força de tração aplicado à } \\
\text { alma do perfil "T". No mesmo trabalho, realizaram um estudo paramétrico dessas ligações } \\
\text { utilizando análise numérica com elementos finitos. Desta maneira, analisaram a influência } \\
\text { de alguns parâmetros, como tipo de parafuso utilizado e espessura da mesa do perfil "T". }\end{array}$ \\
\hline $\begin{array}{l}\text { KRISHNAMURTHY } \\
(1978 \text { e 1979) }\end{array}$ & $\begin{array}{l}\text { Realizou diversos trabalhos com base em estudos desenvolvidos nas universidades de } \\
\text { Auburn, Vanderbilt e Birmingham, os quais consistiram, basicamente, da análise de } \\
\text { ligações via elementos finitos e da comparação dos resultados obtidos com a análise } \\
\text { numérica com outros obtidos em ensaios de laboratório. Examinando a questão das } \\
\text { ligações com chapa de topo, estudou a concentração de esforços nas ligações e os } \\
\text { problemas do efeito alavanca, sendo seu trabalho base da Norma Americana, AISC (1980). }\end{array}$ \\
\hline CHEN \& LUI (1988a) & $\begin{array}{l}\text { Observando os resultados de ensaios realizados com ligações parafusadas, os autores } \\
\text { estabeleceram uma série de conclusões e recomendações de projeto e cálculo, } \\
\text { constatando que a resistência ao momento fletor dessas ligações poderiam ter um } \\
\text { acréscimo de } 30 \% \text { ou mais, quando comparadas às ligações soldadas similares. Isso se dá } \\
\text { devido ao aumento da capacidade resistente da seção transversal da viga, proporcionado } \\
\text { pela presença das chapas soldadas à mesa do pilar e parafusadas às mesas da viga. }\end{array}$ \\
\hline
\end{tabular}




\begin{tabular}{|c|c|}
\hline Pesquisador(es) ou ano & Observações sobre os trabalhos realizados \\
\hline PRELOURENTZOU (1991) & $\begin{array}{l}\text { Pioneiro no estudo experimental de ligações no Brasil, analisou o comportamento de } \\
\text { ligações com chapa de topo e de ligações com cantoneira de alma, discutindo a sua } \\
\text { classificação quanto à rigidez. }\end{array}$ \\
\hline QUEIROZ (1992) & $\begin{array}{l}\text { Pesquisador brasileiro, analisou os estados limites aplicáveis às ligações completamente } \\
\text { soldadas e às ligações com chapa de topo, determinando as resistências últimas } \\
\text { considerando a presença ou não de enrijecedores no pilar. Propôs também um modelo de } \\
\text { dimensionamento segundo o qual são consideradas molas equivalentes ao efeito da } \\
\text { ligação - adaptação do modelo proposto por HUMER \& TSCHEMMERNEGG (1988). }\end{array}$ \\
\hline KISHI (1994) & $\begin{array}{l}\text { Analisou diversos métodos de previsão do comportamento momento rotação das ligações, } \\
\text { organizando um programa computacional chamado Steel Connection Data Bank (SCDB), } \\
\text { um banco de dados que incorpora uma grande quantidade de resultados experimentais } \\
\text { disponíveis na literatura especializada, e três diferentes equações de previsão do } \\
\text { comportamento momento-rotação para diversos tipos de ligação. }\end{array}$ \\
\hline QUEIROZ (1995) & $\begin{array}{l}\text { Analisou as informações disponíveis na bibliografia sobre resistência, rigidez e capacidade } \\
\text { de deformação das ligações completamente soldadas utilizando perfis soldados com } \\
\text { dimensões da seção transversal diferentes das usuais para perfis laminados. Com } \\
\text { resultados de ensaios, realizados no laboratório do Instituto para Construção em Aço e } \\
\text { Madeira, da Universidade de Innsbruck, Áustria, efetuou comparações com outros } \\
\text { resultados obtidos por análise elasto-plástica utilizando o método dos elementos finitos, } \\
\text { apresentando um modelo teórico para a análise de estruturas formadas por barras. }\end{array}$ \\
\hline
\end{tabular}




\section{Observações sobre os trabalhos realizados}

A modelagem numérica do comportamento das ligações viga-coluna confirma-se como uma das vertentes para o estudo da rigidez das ligações em estruturas metálicas. Com a análise numérica, busca-se o estabelecimento de métodos que levem em conta a flexibilidade das ligações, principalmente por meio das relações momento-rotação, para a análise e dimensionamento de estruturas metálicas.

Alguns trabalhos utilizaram modelos lineares - o que apresentava desvantagens por não representar o comportamento da ligação em toda a faixa da possível variação das rotações - como os trabalhos citados por KISHI (1994), desenvolvidos por RATHBUN (1936), MONFORTON \& WU (1963) e LIGHTFOOT \& LeMESSURIER (1974).

Outros, numa tentativa de corrigir as desvantagens dos modelos lineares, propuseram trabalhos com modelos bilineares, nos quais reconhecia-se a redução da rigidez da ligação acima de determinados níveis da rotação relativa entre os elementos conectados. RIBEIRO (1998) cita os trabalhos de LIONBERGER \& WEAVER (1969), ROMSTAD \& SUBRAMANIAN (1970), TARPY \& CARDINAL (1981) e LUI \& CHEN (1986).

Utilizando a modelagem numérica com o uso de elementos finitos, pode-se também citar o trabalho de BAHAARI \& SHERBOURNE (1994 e 1996), no qual apresentam uma simulação da ligação, introduzindo conceitos de contato entre as chapas e desenvolvendo uma metodologia para o estudo das relações momento-rotação utilizando modelos numéricos. Os modelos propostos pelos autores não consideraram, na análise, a deformação dos parafusos, introduzindo-os como elementos ligados à chapa de topo apenas para efeito da protensão. A espessura da chapa de topo e pilar foram desconsideradas uma vez que o modelo possuía elementos de casca, considerando-se espessura constante.

\begin{tabular}{|c|l}
\hline Pesquisador(es) ou ano & \multicolumn{1}{c}{ Observações sobre os trabalhos realizados } \\
\hline RIBEIRO (1998) & $\begin{array}{l}\text { Realizou um trabalho teórico-experimental onde ensaio 28 protótipos, sendo 24 utilizando } \\
\text { ligações viga-coluna com chapa de topo. Analisou alguns parâmetros de influência no } \\
\text { comportamento momento-rotação da ligação, como espessura da chapa de topo e } \\
\text { diâmetro dos parafusos, utilizando também simulações numéricas para comparação dos } \\
\text { resultados. Sua análise, que já levou em consideração os parafusos, mantém o apoio } \\
\text { rígido, não considerando a flexibilidade da mesa do pilar. }\end{array}$
\end{tabular}


O desenvolvimento dos trabalhos citados anteriormente permitiu, ao longo do tempo, o aprimoramento do estudo das ligações viga-coluna, possibilitando uma adequação paulatina dos métodos utilizados para o dimensionamento e análise das ligações em estruturas metálicas.

Algumas recomendações técnicas absorveram as propostas e resultados de muitos desses trabalhos. Pode-se citar, neste caso, o MANUAL brasileiro para cálculo de estruturas metálicas (1988), que baseou sua formulação segundo modelos propostos por DOUTY \& McGUIRE (1965), e os trabalhos desenvolvidos por KRISHNAMURTHY (1978) que serviram de base para a normalização americana segundo o American Institute of Steel Construction, o AISC.

Também atualizado, o EUROCODE-3 (1993) estabelece, em seu Anexo $\mathrm{J}$, os métodos de dimensionamento para ligações viga-coluna, entre as quais se incluem as ligações com chapa de topo.

A tabela II.I, como já dito anteriormente, tem o objetivo de apresentar, sucintamente, um histórico dos trabalhos desenvolvidos, bem como enfatizar a evolução dos estudos sobre as ligações viga-coluna, de acordo com os objetivos deste capítulo.

Uma abordagem mais detalhada sobre alguns trabalhos referidos na tabela II.I, incluindo os modelos adotados para dimensionamento das ligações viga-coluna com chapa de topo, será realizada a seguir para atender aos objetivos específicos do presente trabalho.

\subsection{LIGAÇÕES VIGA-COLUNA COM CHAPA DE TOPO}

Lembrando a importância de se conhecer o comportamento estrutural das ligações, torna-se necessário descrever os principais procedimentos para o seu dimensionamento.

Os modelos analíticos e procedimentos que deram origem aos métodos de dimensionamento atualmente conhecidos e utilizados por Normalizações e Manuais Técnicos, têm sua origem em trabalhos específicos, referidos anteriormente. Ao longo do tempo, receberam também 
contribuições de outros trabalhos, os quais sempre procuraram uma melhor representação das ligações para a análise estrutural.

Neste contexto, no que diz respeito às ligações viga-coluna com chapa de topo, serão apresentadas, a seguir, duas propostas de dimensionamento para as ligações supra-citadas, visando a análise e discussão dos modelos analíticos utilizados. A primeira foi originada do trabalho de KRISHNAMURTHY (1975 e 1978), cuja formulação é base da Norma Americana AISC (1980). A segunda é a proposta de dimensionamento do EUROCODE-3 (1993), com base em diversos estudos realizados na Europa.

Procura-se também, de forma sucinta, fornecer uma visualização da metodologia empregada para o dimensionamento, para cada proposta apresentada.

\subsubsection{Procedimento proposto por KRISHNAMURTHY (1978)}

Até a década de 70 , os estudos relacionados ao comportamento das ligações parafusadas viga-coluna contribuíram significativamente em alguns aspectos, principalmente na avaliação das variações das forças nos parafusos, que puderam ser medidas com boa aproximação nos testes efetuados por DOUTY \& McGUIRE (1965) e por AGERSKOV (1976), utilizando as ligações com perfis "T".

No entanto, a distribuição e magnitude das forças de alavanca fenômeno que ocorre devido às forças que tracionam os parafusos - eram conhecidas somente de forma qualitativa.

Muitos trabalhos, até aquela época, haviam sido desenvolvidos com a finalidade de introduzir modificações e ajustes nas fórmulas de cálculo do efeito alavanca, na tentativa de relacionar, com maior exatidão, os resultados obtidos analiticamente com os obtidos por meio de análises experimentais. Deve-se observar que as limitações dos métodos e modelos 
analíticos propostos se traduzem, por razões práticas, na inacessibilidade da instrumentação na região de interface entre a chapa de topo e a mesa do pilar.

KRISHNAMURTHY (1978a e 1978b), motivado pela necessidade de se quantificar o efeito alavanca e objetivando melhor analisar as ligações com chapa de topo, realizou estudos nas universidades de Auburn, Vanderbilt e Birmingham, os quais consistiram, basicamente, da análise de ligações viga-coluna com chapa de topo via elementos finitos com comparações dos resultados numéricos com outros obtidos em laboratório.

As primeiras constatações feitas por KRISHNAMURTHY (1978b) são que, para as ligações com chapa de topo, o problema do efeito alavanca envolve a consideração de forças concentradas na ligação e que o modelo até então utilizado pela Normalização Americana tinha base na extrapolação dos resultados observados para as ligações com perfis "T", os quais não eram condizentes com os resultados obtidos para ligações com chapa de topo.

A partir destas observações, KRISHNAMURTHY (1978b) sugere um modelo analítico, com base no equilíbrio de forças, para a representação das forças atuantes na região tracionada da ligação e, consequentemente, consideradas no dimensionamento da chapa de topo.

Para tal modelo, assume-se que o diagrama de momentos fletores a ser considerado para a chapa de topo deve apresentar uma variação não linear, como apresentado na figura 2.6, que esquematiza, de forma geral, o modelo analítico proposto por KRISHNAMURTHY (1978b), onde se tem:

(a) Geometria da região tracionada;

(b) Esforços e bulbo de pressão;

(c) Deformada da chapa de topo; e

(d) Diagrama de momentos fletores 


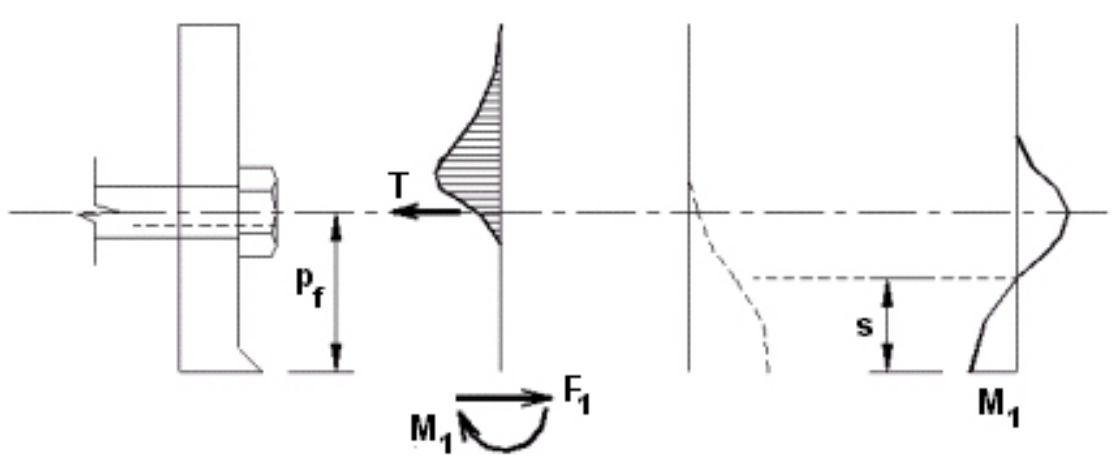

(a)

(b)

(c)

(d)

Figura 2.6 - Modelo analítico proposto por KRISHNAMURTHY (1978b)

Para o modelo proposto, KRISHNAMURTHY (1978b) enfatiza que o momento fletor nas proximidades da junção da mesa da viga com a chapa de topo é sempre maior que o momento fletor verificado na linha de parafusos e, portanto, será determinante no dimensionamento. Essa consideração é feita levando-se em conta que a seção transversal da chapa de topo é reduzida pelos furos, que a restrição ao deslocamento da chapa de topo se dá apenas em pontos isolados pela imposição dos parafusos e que a chapa está submetida a flexão em duas direções.

Considerando-se a região tracionada, observa-se que a chapa de topo deve ser dimensionada para uma força de cisalhamento $\mathbf{F}_{\mathbf{1}}$ e para um momento fletor $\mathbf{M}_{1}$, como indicado na figura 2.6.

De acordo com a mesma figura, e observando o diagrama de momentos fletores, vê-se que o braço de alavanca para a força $\mathbf{F}_{\mathbf{1}}$ é dado pela distância $\mathbf{s}$, sendo possível calcular o momento fletor $\mathbf{M}_{1}$, na figura $2.6 \mathrm{~d}$, pela seguinte expressão:

$$
\mathrm{M}_{1}=\mathrm{F}_{1} \mathrm{~S}
$$

Em contrapartida, a força de tração atuante na mesa da viga, convencionalmente, é calculada pela expressão: 


$$
F_{t}=\frac{M_{v}}{H-t_{f v}}
$$

onde: $\quad F_{\mathbf{t}}=$ força de tração transmitida à ligação pela mesa da viga;

$\mathbf{M}_{\mathbf{v}}$ = momento fletor que solicita a ligação;

$\mathbf{H}$ = altura total da viga;

$\mathbf{t}_{\mathrm{fv}}=$ espessura da mesa da viga;

A força $F_{t}$, na expressão 2.2 , é calculada considerando-se a transmissão do momento fletor somente pelas mesas da viga, como sendo um binário de forças.

A distância s é considerada como igual à metade da distância entre a linha de parafusos e a face da mesa da viga $\left(\mathbf{p}_{\mathbf{f}}\right)$, levando-se em conta que, por simetria, a projeção da chapa de topo é submetida à metade da força de tração transmitida pela mesa da viga, não havendo deslocamento na linha de parafusos. Assim, considera-se que a força $F_{1}$ seja igual à metade da força $\mathbf{F}_{\mathbf{t}}$.

Com relação à distância $\mathbf{p}_{\mathbf{f}}$, as correlações feitas por KRISHNAMURTHY (1978b) entre resultados de ensaios e análises por elementos finitos, juntamente com observações das pesquisas de NAIR et al. (1974) e FISHER et al. (1974), mostraram que a distância $\mathbf{p}_{\mathbf{f}}$ deve ser substituída pela distância $\mathbf{p}_{\mathbf{e}}$, menor que $\mathbf{p}_{\mathbf{f}}$, sendo adotado o valor obtido pela expressão

$$
p_{e}=p_{f}-0,25 d_{p}-w_{t}
$$

onde: $\quad \mathbf{d}_{\mathbf{p}}=$ diâmetro do parafuso;

$\mathbf{w}_{\mathbf{t}}$ = garganta efetiva da solda de filete entre viga e chapa de topo;

A figura 2.7 apresenta a modificação no modelo analítico pela inclusão da variável $\mathbf{p}_{\mathbf{e}}$. 


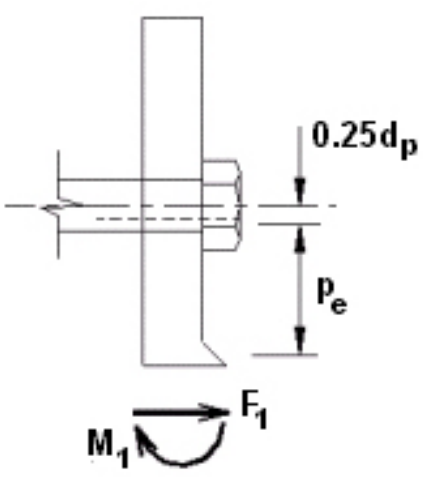

Figura 2.7 - Modificação da distância $p_{\mathrm{f}}$ para $p_{\mathrm{e}}$

Desta maneira, o momento fletor a ser considerado para o dimensionamento da chapa de topo é dado por

$$
M_{1}=\left(\frac{F_{t}}{2}\right)\left(\frac{p_{e}}{2}\right)
$$

A utilização da equação anterior, como ressaltou KRISHNAMURTHY (1978b), representa uma idealização bastante razoável, apesar de a distribuição da força de tração na chapa de topo não ser perfeitamente simétrica, devido à presença da alma da viga, e devido à simplificação para o valor do braço de alavanca s.

Em seus trabalhos, como já mencionado anteriormente, KRISHNAMURTHY (1975c) analisou modelos utilizando elementos finitos, para posterior comparação com resultados experimentais.

A sua análise considerou um estado plano de tensões, cuja geometria está apresentada na figura 2.8, juntamente com a idealização da malha de elementos finitos.

As considerações feitas por KRISHNAMURTHY (1975c), em compatibilidade com o modelo analítico proposto, não permitia nenhum deslocamento nas linhas dos parafusos. O apoio para a chapa de topo foi considerado totalmente rígido e o descolamento entre a chapa de topo e o apoio foi simulado por meio de um processo iterativo, no qual eram verificadas as reações nos vínculos do apoio. Sob outro ponto de vista, tal 
análise desconsiderou a flexibilidade do pilar e a contribuição dos parafusos nos deslocamentos da chapa de topo.

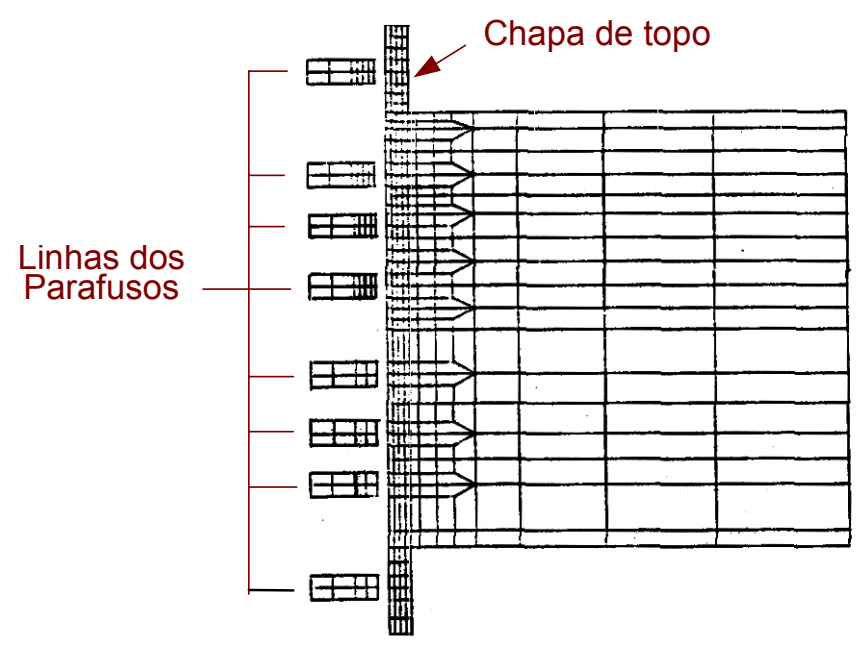

Figura 2.8 - Geometria e malha da análise numérica de KRISHNAMURTHY (1975c)

A análise por elementos finitos realizada por KRISHNAMURTHY (1975c) foi utilizada, juntamente com o modelo analítico proposto, com o objetivo de encontrar correlações condizentes quanto a alguns aspectos, principalmente para a determinação do momento solicitante na chapa de topo.

A primeira modificação é referente à transmissão da força de tração. Uma vez que a região interna às mesas da viga apresenta maior rigidez que a extensão da chapa de topo, devido à presença da alma, há uma assimetria na distribuição da força de tração com relação a mesa tracionada da viga. Com os resultados obtidos nos modelos numéricos, via elementos finitos, KRISHNAMURTHY (1975c) verifica uma variação de $\mathbf{0 , 3}$ a $\mathbf{0 , 5}$ na relação entre $\mathbf{F}_{\mathbf{1}}$ e $\mathbf{F}_{\mathbf{t}}$, escrevendo tal relação como:

$$
F_{1}=C_{1} F_{t} \quad \text { com } \quad 0,3 \leq C_{1} \leq 0,5
$$

Além disso, a redução de rigidez para a extensão da chapa de topo, juntamente com o alongamento e flexão observados nos parafusos - 0 
que deve permitir um aumento da rotação da chapa - podem provocar uma redução no valor do braço de alavanca s, modificado pela expressão

$$
\mathrm{s}=\mathrm{C}_{2} \mathrm{p}_{\mathrm{e}} \quad \text { com } \quad 0,5 \leq \mathrm{C}_{2} \leq 1,0
$$

segundo a qual a relação $s / p_{e}$ varia entre 0,5 e 1,0, confirmada pela análise numérica.

Da mesma maneira, considerando-se os efeitos decorrentes da dispersão das forças devido à altura da viga, juntamente com o aumento de rigidez dado pela alma, e a diminuição de rigidez nas linhas dos parafusos externos ao perfil da viga, o momento crítico $\mathbf{M}_{\mathbf{d}}$ na chapa é menor que $\mathbf{M}_{\mathbf{1}}$, estabelecendo-se que

$$
\mathrm{M}_{\mathrm{d}}=\mathrm{C}_{3} \mathrm{M}_{1} \quad \text { com } \quad \mathrm{C}_{3} \leq 1,0
$$

A combinação das equações 2.4, 2.5, 2.6 e 2.7 resulta numa expressão simplificada, dada por

$$
M_{d}=\alpha_{m} M_{1}
$$

onde $\alpha_{m}$ é considerado como um fator de correção do momento fletor $\mathbf{M}_{1}$ aplicado à chapa de topo para levar em consideração as hipóteses simplificadoras utilizadas no seu desenvolvimento, e é expresso por

$$
\alpha_{m}=4 C_{1} C_{2} C_{3}
$$

Posteriormente, utilizando um estudo paramétrico dos resultados obtidos por meio das simulações numéricas, com a aplicação de regressão matemática, KRISHNAMURTHY (1974c e 1975c) apresentou uma modificação ao fator $\alpha_{m}$, considerando não só as simplificações adotadas para o modelo analítico (coeficientes $\mathbf{C}_{1}, \mathbf{C}_{2}$ e $\mathbf{C}_{3}$ ), mas também aspectos 
relativos à geometria da ligação e as características dos materiais envolvidos.

De maneira geral, a nova formulação para o momento crítico $\mathbf{M}_{\mathbf{d}}$, na chapa de topo, apresenta-se na forma:

$$
M_{d}=1,29\left(\frac{f_{y}}{f_{p u}}\right)^{0,4}\left(\frac{f_{p t}}{f_{c h}}\right)^{0,5}\left(\frac{b_{f v}}{b_{c h}}\right)^{0,5}\left(\frac{A_{f v}}{A_{w v}}\right)^{0,32}\left(\frac{p_{e}}{d_{p}}\right)^{0,25} M_{1} \quad 2.10
$$

sendo o fator $\alpha_{m}$ expresso por

$$
\alpha_{m}=C_{a} C_{b}\left(\frac{A_{f v}}{A_{w v}}\right)^{0,32}\left(\frac{p_{e}}{d_{p}}\right)^{0,25}
$$

e os coeficientes $\mathbf{C}_{a}$ e $\mathbf{C}_{b}$ dados por

$$
\begin{aligned}
C_{a} & =1,29\left(\frac{f_{y}}{f_{p u}}\right)^{0,4}\left(\frac{f_{p t}}{f_{c h}}\right)^{0,5} \\
\text { e } \quad C_{b} & =\left(\frac{b_{f v}}{b_{c h}}\right)^{0,5}
\end{aligned}
$$

Os diversos parâmetros envolvidos nas equações 2.10 a 2.13, são:

$A_{\mathrm{fv}}$ - área da seção transversal da mesa tracionada da viga;

$\mathbf{A}_{w v}$ - área da seção transversal da alma da viga;

$\mathbf{b}_{\mathrm{fv}}$ - largura da mesa da viga;

$\mathbf{b}_{\text {ch }}$ - largura da chapa de topo;

$\mathbf{d}_{\mathrm{p}}$ - diâmetro do parafuso;

$\mathbf{f}_{\mathbf{y}}$ - limite de escoamento do aço da viga e chapa (média);

$\mathbf{f}_{\mathrm{pu}}$ - tensão última de tração nos parafusos;

$\mathbf{f}_{\mathrm{pt}}$ - tensão admissível de tração nos parafusos; 
$\mathbf{f}_{\mathrm{ch}}$ - tensão admissível de flexão na chapa de topo;

$\mathbf{p}_{\mathrm{e}}$ - distância efetiva entre parafuso e face da mesa da viga;

$\mathbf{d}_{\mathbf{p}}$ - diâmetro nominal do parafuso.

Devido à complexidade do estudo paramétrico realizado por KRISNHAMURTHY (1974c) - o qual envolveu 168 ligações com chapa de topo e 559 casos de carregamento - e das equações apresentadas acima, é importante uma interpretação física dos coeficientes $\mathbf{C}_{\mathbf{a}}$ e $\mathbf{C}_{\mathbf{b}}$, no sentido de evidenciar as variáveis envolvidas na determinação do fator $\alpha_{m}$.

O coeficiente $\mathbf{C}_{\mathbf{a}}$ é representante das características dos materiais envolvidos na ligação, levando em consideração a interação entre as capacidades resistentes dos materiais da viga, da chapa de topo e dos parafusos.

A análise paramétrica assumiu que os materiais da viga e da chapa são iguais para todas as ligações estudadas. No entanto, se os valores forem diferentes, KRISHNAMURTHY (1978b) observa que se pode utilizar a média dos valores do limite de escoamento $\left(\mathbf{f}_{\mathrm{y}}\right)$ como valor consistente ao método. A única restrição ao valor de $\mathbf{C}_{\mathbf{a}}$ é de que não seja menor que o valor utilizado para $\mathbf{f}_{\mathbf{y}}$.

O coeficiente $\mathbf{C}_{b}$, por sua vez, representa uma correção na geometria, relativa à largura da chapa de topo e à largura da mesa da viga. KRISHNAMURTHY (1978b) recomenda que a largura mínima da chapa de topo seja dada por

$$
b_{e f}=b_{f v}+2 \sqrt{2} w_{t}+t_{c h}
$$

onde: $\quad \mathbf{t}_{c h}=$ espessura da chapa de topo.

A relação $\left(\mathbf{A}_{\mathrm{fv}} / \mathbf{A}_{\mathrm{wv}}\right)$, entre as áreas da mesa e da alma da viga, tem a função de determinar a fração da força longitudinal aplicada que é transferida para a extensão da chapa de topo. 
Finalmente, a relação $\left(\mathbf{p}_{\mathrm{e}} / \mathbf{d}_{\mathbf{p}}\right)$ representa a influência do diâmetro do parafuso e das forças relacionadas ao seu comportamento, com relação à distância efetiva da linha de parafusos até a face da mesa tracionada. Esta última relação, segundo observado por KRISHNAMURTHY (1978b), tem grande dominância na variação dos valores de $\alpha_{m}$, representando um comportamento de grande complexidade.

Quanto à formulação apresentada acima, KRISHNAMURTHY (1979c) argumenta que os coeficientes $\mathbf{C}_{1}, \mathbf{C}_{2}$, e $\mathbf{C}_{3}$ foram, inicialmente, introduzidos por conveniência de conceituação do problema, sendo substituídos pelo fator $\alpha_{m}$ devido ao fato de se englobar grupos de parâmetros que são mais fisicamente significativos.

Como complemento ao processo de dimensionamento da ligação, o diâmetro do parafuso é obtido em função da área mínima necessária, teoricamente, por fila de parafusos, que pode ser expressa por

$$
a_{t}=0,5 \frac{F_{t}}{f_{p t}}
$$

onde: $\mathbf{a}_{\mathbf{t}}$ = área necessária por fila de parafusos;

$\mathbf{F}_{\mathbf{t}}=$ força total de tração transmitida pela viga;

$\mathbf{f}_{\mathrm{pt}}=$ tensão admissível de tração nos parafusos.

Note-se que a expressão 2.15 despreza o efeito alavanca e a distribuição desigual entre parafusos externos e internos.

Utilizando as equações apresentadas acima, KRISHNAMURTHY (1978b) estabeleceu um procedimento de cálculo, que consistia das seguintes etapas:

1) Calcular a força de tração $\boldsymbol{F}_{\mathbf{t}}$ na mesa da viga (expressão 2.2);

2) Calcular a área mínima necessária $a_{t}$ para uma fila de parafusos (expressão 2.15), determinando o diâmetro $\mathbf{d}_{\mathbf{p}}$;

3) Calcular a distância efetiva $\mathbf{p}_{\mathbf{e}}$ (expressão 2.3); 
4) Calcular o momento fletor $\mathbf{M}_{1}$ (expressão 2.4);

5) Calcular o fator de correção do momento fletor $\alpha_{m}$ para a chapa de topo (expressão 2.11);

6) Calcular o momento fletor $\mathbf{M}_{\mathbf{d}}$ (expressão 2.8);

7) Calcular a espessura da chapa de topo, utilizando-se a teoria de flexão, com a expressão

$$
t_{c h}=\sqrt{\frac{6 M_{d}}{b_{c h} f_{c h}}}
$$

8) Verificar a largura efetiva da chapa de topo (expressão 2.14). Se $b_{c h}<b_{\text {ef }}$ repetir as etapas 5 a 8 , utilizando $\mathbf{b}_{\text {ef }}$ em lugar de $\mathbf{b}_{c h}$;

9) Calcular a máxima tensão de cisalhamento na chapa de topo, dada por

$$
f_{v, c h}=\frac{F_{t}}{2 b_{c h} t_{c h}} \leq 0,4 f_{y}
$$

Se $f_{v, c h}>0,4 f_{y}$, deve-se aumentar $t_{c h}$ para que $f_{v, c h} \leq 0,4 f_{y}$.

KRISHNAMURTHY (1978b) ainda recomenda que a distância do centro do parafuso à borda da chapa de topo seja igual a 1,75 vezes o diâmetro.

Citado por RIBEIRO (1998), McGUIRE (1979) comenta a grande importância do método proposto por KRISHNAMURTHY (1978b), acrescentando que são merecedoras de toda a atenção as propostas que possam justificar a adoção de procedimentos mais liberais no dimensionamento de estruturas metálicas.

O método proposto por KRISHNAMURTHY (1978b) foi tomado como base da Norma Americana, sendo incorporado no AISC (1980), com algumas modificações, nas quais: 
i. adota para expoente da relação ( $\mathbf{A}_{\mathrm{fv}} / \mathbf{A}_{\mathbf{w v}}$ ), na expressão 2.11, o valor $1 / 3$

ii. recomenda, para a distância $p_{f}$, o valor $d_{p}+1 / 2 "$, justificando esse acréscimo pela necessidade de uma folga mínima para permitir o aperto do parafuso; e

iii. adota, para a máxima largura da chapa de topo, o valor $1,15 b_{f v}$, não fazendo menção à largura mínima, que obviamente, deve ser igual à largura da mesa da viga.

Posteriormente, o AISC (1986), no tópico relativo às ligações com chapa de topo, faz algumas modificações, sendo as mais relevantes no que diz respeito à determinação da área mínima por fila dos parafusos tracionados (expressão 2.14) e à determinação da espessura da chapa de topo (expressão 2.16).

A área mínima por fila de parafusos tracionados é, então, expressa por

$$
a_{t}=\frac{F_{t}}{2 n \phi f_{p t}}
$$

onde $\phi f_{p t}$ é a tensão limite de cálculo para a tração nos parafusos e $\mathbf{n}$ é o número de parafusos, por linha, na região tracionada da ligação.

Para o cálculo da espessura da chapa de topo deve-se utilizar

$$
t_{c h}=\sqrt{\frac{4 M_{d}}{b_{c h}(0,9) f_{y, c h}}}
$$

sendo $\mathbf{f}_{\mathrm{y}, \mathrm{ch}}$ o limite de escoamento da chapa de topo.

O AISC (1989), na sua nona edição, com base no método das tensões admissíveis, introduz as seguintes recomendações: 
i. que a largura da chapa de topo deve ser, aproximadamente, igual à largura da mesa da viga mais 1"; e

ii. que o valor recomendado no item (i) seja considerado como o máximo valor admissível para a largura efetiva a ser utilizada nos cálculos, eliminando a verificação do cisalhamento na chapa de topo.

Visto a incorporação do método de dimensionamento proposto por KRISHNAMURTHY (1978b) pelo AISC (1980), comprova-se a grande importância das pesquisas realizadas. Adicionalmente, algumas observações são pertinentes com relação ao desenvolvimento do método, principalmente quanto às ferramentas e simplificações utilizadas, e quanto à sua aplicabilidade.

Analisando, primeiramente, o tipo de formulação adotada para a correlação entre os modelos analítico e numérico, levanta-se um questionamento sobre a determinação dos parâmetros $\mathbf{C}_{1}, \mathbf{C}_{2}$ e $\mathbf{C}_{3}$, na representação da solicitação de flexão na chapa de topo.

O desenvolvimento do método reconhece o grau de aproximação atingido com os parâmetros $\mathbf{C}_{1}, \mathbf{C}_{2}$ e $\mathbf{C}_{3}$, obtidos por meio de análises numéricas utilizando o método dos elementos finitos. Apesar disso, não há indicações sobre o grau de sofisticação dos elementos finitos utilizados e a simulação numérica, visto os recursos e simulações praticadas atualmente, pode ser classificada como "rudimentar". Esse comentário tem validade devido à própria descrição, encontrada nos relatórios das pesquisas, da simulação do contato da chapa de topo com a mesa do pilar.

Outra questão a ser levantada, como lembrou RIBEIRO (1998), refere-se à não consideração da rigidez do pilar, ou seja, "o modelo é adequado apenas para os casos em que seja possível afirmar que o flange e a alma do pilar, por suas dimensões ou através de enrijecedores, não exerçam nenhuma influência sobre o comportamento do conjunto viga/chapa de topo/parafusos". 
Acrescenta-se, ainda, a observação de que não se considera o deslocamento da chapa de topo nas linhas de parafusos e ao fato de que o método proposto não faz nenhuma ressalva quanto à flexibilidade da ligação. Desta maneira, o dimensionamento é feito como se a ligação fosse idealmente rígida, resistindo ao momento fletor transmitido pela viga sem apresentar rotação, o que pode tornar o método, em determinadas situações, muito conservador quanto à espessura da chapa de topo.

Quanto à aplicabilidade do método desenvolvido por KRISHNAMURTHY (1978b), deve-se observar que seu desenvolvimento teve como base os perfis com padrão americano (série $W$ ), o que requer certo cuidado, visto à grande dependência dos parâmetros $\mathbf{C}_{\mathbf{a}}$ e $\mathbf{C}_{\mathbf{b}}$ com relação às propriedades geométricas da seção transversal das vigas.

Os trabalhos desenvolvidos por KRISHNAMURTHY (1973a-b, 1974a-c, 1975a-e, 1976, 1978c-e e 1979a-b), alguns citados anteriormente, contêm todos os detalhes referentes ao extenso projeto de pesquisa, desenvolvido nas já citadas universidades americanas.

\subsubsection{Procedimento proposto pelo EUROCODE (1993)}

O método de dimensionamento proposto pelo EUROCODE (1993) apresenta, em seu Anexo J, os procedimentos para dimensionamento de ligações viga-coluna resistentes ao momento fletor, com elementos constituídos por perfis laminados, ou soldados com dimensões similares, e solicitadas por carregamento predominantemente estático, incluindo-se as ligações viga-coluna com chapa de topo, denominadas "bolted connections with extended end-plates".

A proposta do EUROCODE-3 (1993), com base em diversos estudos realizados na Europa, traz diversas modificações no que diz respeito à consideração das ligações e seu dimensionamento. Como característica principal, neste caso, pode-se citar a maneira de tratar as ligações, que são divididas segundo seus componentes básicos. 
Dessa forma, apresenta-se, preliminarmente, uma série de definições para a caracterização da ligação, itemizadas a seguir, e que podem ser visualizadas na figura 2.9 .

i. componentes básicos de um nó $\rightarrow$ parte específica de um nó que desempenha contribuição relevante em uma ou mais das propriedades estruturais do nó;

ii. ligação (connection) $\rightarrow$ região da interligação de dois elementos estruturais;

iii. nó (joint) $\rightarrow$ conjunto dos componentes básicos que possibilitam a interligação dos elementos estruturais, permitindo a transmissão dos esforços internos - incorpora as características da ligação; e

iv. propriedades estruturais de um nó $\rightarrow$ resistência aos esforços internos, rigidez rotacional e capacidade de rotação do nó.

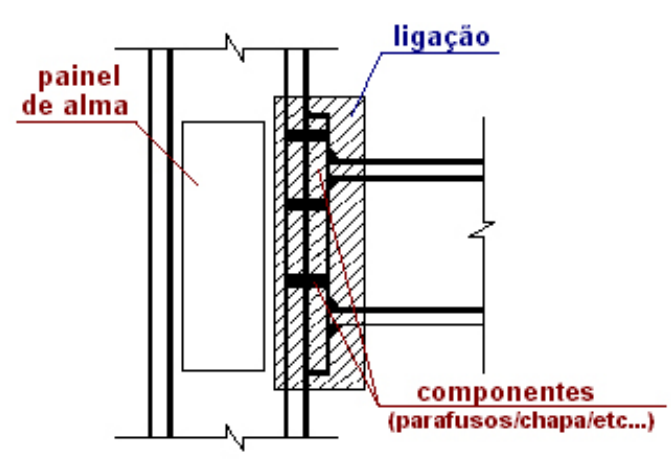

(a) pilar com uma ligação

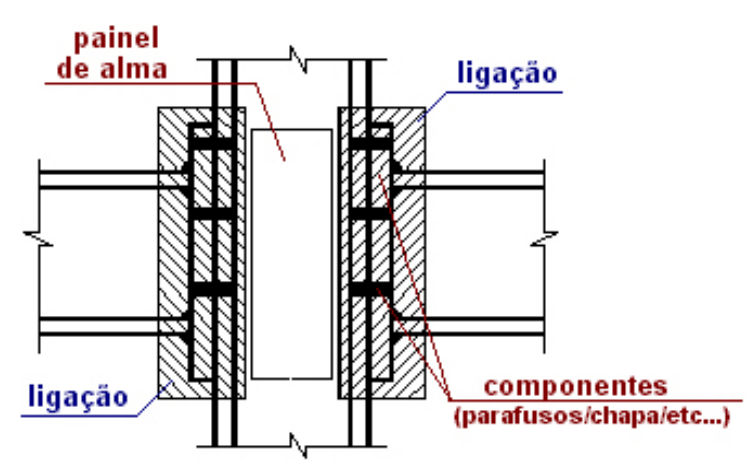

(b) pilar com duas ligações

Figura 2.9 - Ligação viga-coluna com chapa de topo - configuração geral

Levando-se em consideração o princípio da divisão do nó em seus componentes básicos (chapa de topo, parafusos, soldas, etc.), a metodologia empregada para o dimensionamento das ligações com chapa de topo, segundo o EUROCODE-3 (1993), requer verificações específicas de resistência, para cada um dos componentes. 
Tais verificações, 15 no total, são realizadas em função dos esforços que solicitam os elementos componentes da ligação. Segundo o EUROCODE-3 (1993), para cada região da ligação - com base no tipo de esforço a que está submetida originalmente - caracteriza-se a solicitação nos elementos. As verificações necessárias estão apresentadas na tabela II.II e podem ser visualizadas, esquematicamente, na figura 2.10.

Tabela II.II - Verificações de resistência nos elementos da ligação

\begin{tabular}{|c|c|c|}
\hline Região & Ref. Fig. 2.10 & Verificação \\
\hline \multirow{7}{*}{ Tracionada } & a & Tração nos parafusos \\
\hline & $\mathrm{b}$ & Flexão da chapa de topo \\
\hline & c & Flexão da mesa do pilar \\
\hline & d & Tração na alma da viga \\
\hline & e & Tração na alma do pilar \\
\hline & $f$ & Solda mesa/chapa de topo \\
\hline & g & Solda alma/chapa de topo \\
\hline $\begin{array}{c}\text { Cisalhamento } \\
\text { Horizontal }\end{array}$ & $\mathrm{h}$ & $\begin{array}{c}\text { Cisalhamento no painel } \\
\text { de alma do pilar }\end{array}$ \\
\hline \multirow{4}{*}{ Comprimida } & $\mathrm{i}$ & Mesa da viga \\
\hline & j & Solda mesa/chapa de topo \\
\hline & $\mathrm{k}$ & Enrugamento da alma do pilar \\
\hline & 1 & Flambagem da alma do pilar \\
\hline \multirow{3}{*}{$\begin{array}{l}\text { Cisalhamento } \\
\text { Vertical }\end{array}$} & $\mathrm{m}$ & Solda alma/chapa de topo \\
\hline & $\mathrm{n}$ & Cisalhamento nos parafusos \\
\hline & 0 & Pressão de contato (mesa ou chapa) \\
\hline
\end{tabular}

De maneira geral, a filosofia adotada pelo Anexo $\mathrm{J}$ do EUROCODE-3 (1993), baseia-se na hipótese de que a transmissão do momento fletor é realizada, na ligação, por um binário de forças, cujo braço de alavanca $\mathbf{z}$ é determinado pela distância entre o plano médio da mesa comprimida e o ponto médio da distância entre as duas linhas de parafusos mais afastadas daquele plano, na região tracionada, como esquematizado na figura 2.11 . 


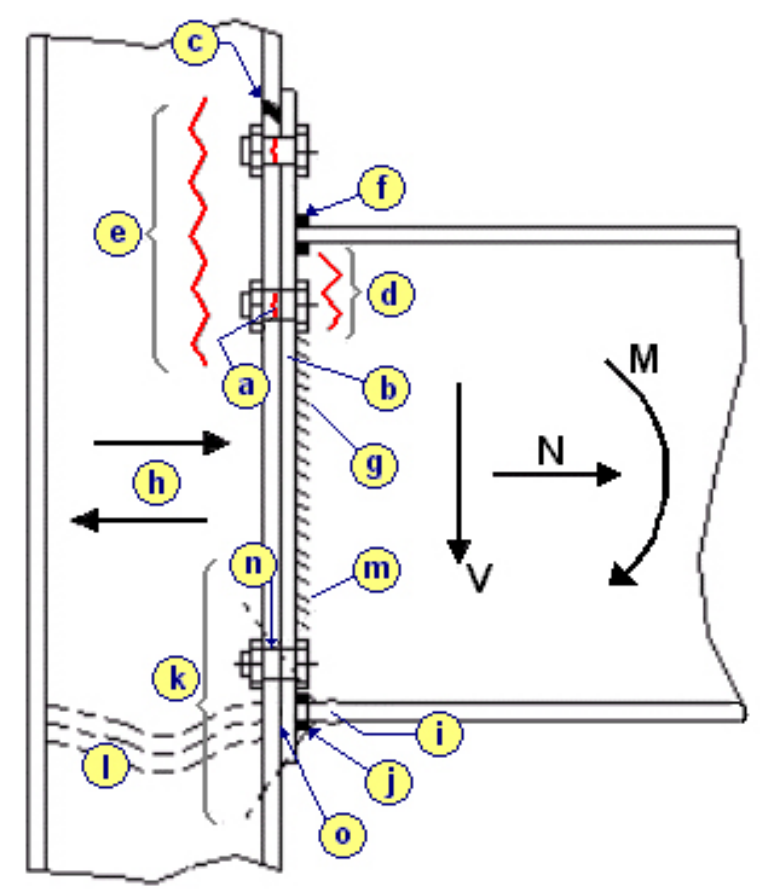

Figura 2.10 - Regiões para verificação da resistência Ligação viga-coluna com chapa de topo
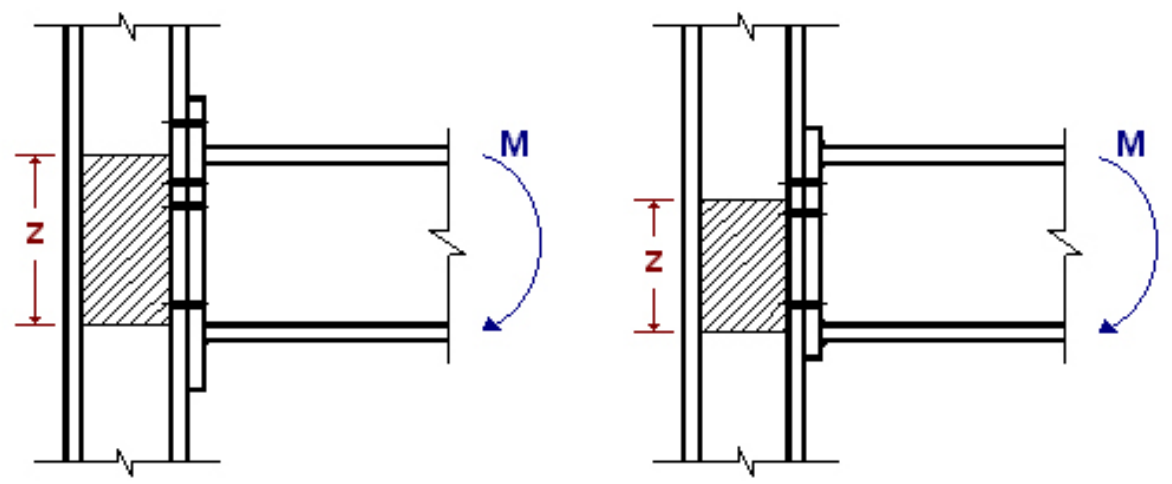

Figura 2.11 - Braço de alavanca do binário tração/compressão

Levando-se em consideração que as linhas de parafusos mais afastadas da mesa comprimida, intuitivamente, atrairão maior esforço, o método também considera que há uma distribuição plástica das forças de tração nos parafusos, abandonando a abordagem tradicional, que considera uma distribuição triangular em direção à região comprimida, como esquematizado na figura 2.12 . 


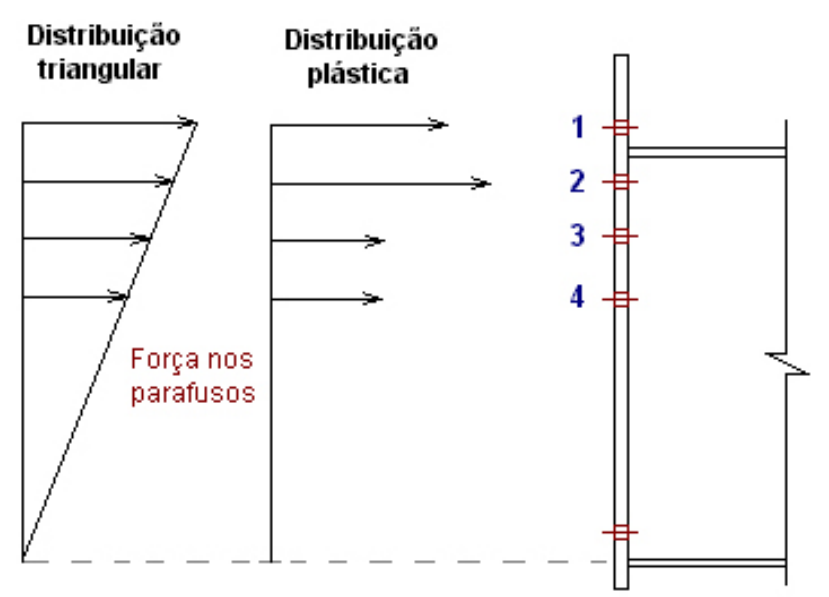

Figura 2.12 - Distribuição plástica das forças nas linhas de parafusos

A filosofia do método de dimensionamento proposto pelo EUROCODE-3 (1993), da maneira como foi colocada acima, assume que a força total permitida para as linhas de parafusos é calculada com base na sua capacidade resistente, e não somente em função de seu braço de alavanca. Essa capacidade resistente é função não só das características dos parafusos, mas é calculada levando-se em consideração todos os elementos resistentes que interagem na região verificada.

A observação feita acima permite concluir que parafusos próximos a pontos de enrijecimento irão atrair uma parcela maior da força de tração. Essa hipótese pode ser visualizada na figura 2.12 para a distribuição plástica, onde é atribuída maior força aos parafusos da linha interna, entre as mesas da viga, numa região enrijecida pela alma da viga.

Com relação à maneira como são empregadas as considerações feitas acima no dimensionamento das ligações com chapa de topo, é necessário se verificar a metodologia proposta pelo EUROCODE-3 (1993) na verificação da capacidade resistente dos elementos componentes da ligação.

Analisando-se, primeiramente, a região tracionada da ligação, o primeiro passo para o dimensionamento é a verificação da capacidade resistente à tração de cada linha de parafusos pertencentes àquela região. 
Uma vez que o método inclui todos os componentes da ligação, a capacidade resistente de cada linha de parafusos é verificada, independentemente, para a flexão da chapa de topo, para a flexão da mesa do pilar, para a capacidade resistente da alma do pilar à tração e para a capacidade resistente, também à tração, da alma da viga, adotando-se o menor valor encontrado.

De maneira geral, para cada estágio de verificação são necessárias duas considerações. A primeira trata da verificação de cada linha isoladamente. A segunda, é a consideração da linha fazendo parte de um grupo.

Seguindo este processo, esquematizado na figura 2.13, a resistência da linha de parafusos mais afastada do centro de compressão (primeira linha) é calculada como se somente ela existisse. Para a verificação da segunda linha, obtém-se a resistência considerando-se sua atuação isolada e também a resistência das linhas 1 e 2, atuando como um grupo, cujo valor, para este caso, é diminuído da capacidade resistente já calculada para a ação isolada da primeira linha. Obtidas desta maneira, adota-se o menor valor para a capacidade resistente da segunda linha. As linhas subsequentes são verificadas seguindo a mesma metodologia de cálculo.

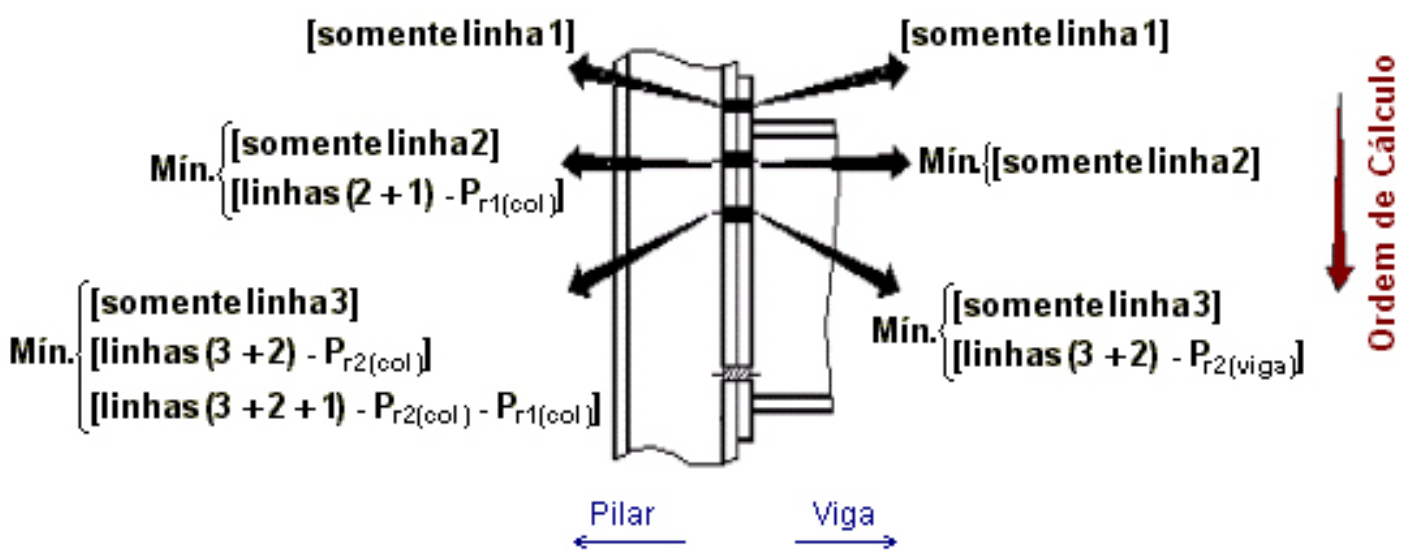

Figura 2.13 - Etapas da verificação da capacidade resistente nas linhas de parafusos 
Uma ressalva a este processo refere-se à existência de enrijecedores tracionados - enrijecedores no pilar ou a presença da mesa da viga - que atuam como divisores das linhas de parafusos. Considerando a atuação das linhas como um grupo, nenhuma linha abaixo do enrijecedor deve ser considerada em combinação com qualquer linha situada acima do mesmo, para o lado correspondente da ligação (pilar ou viga).

Para a ligação apresentada na figura 2.13, observa-se que, para o lado da viga, a segunda linha de parafusos (da região tracionada para a comprimida) não é verificada fazendo o conjunto com a primeira linha, devido à presença da mesa da viga, que separa as duas linhas. No entanto, para o lado do pilar, a verificação de conjunto deve ser feita, pois não existe enrijecedor separando as linhas 1 e 2.

Especificamente quanto à verificação da flexão da chapa de topo e da mesa do pilar, a metodologia proposta pelo Anexo $\mathrm{J}$ do EUROCODE-3 (1993) adota a utilização de perfis "T" equivalentes (equivalent T-stubs) para a consideração do comportamento encontrado em torno dos parafusos, caracterizado pela formação de linhas de escoamento das tensões.

Uma publicação da SCI/BCSA (1996) apresenta diversas tabelas para a caracterização das linhas de escoamento e cálculo dos perfis "T" equivalentes, considerando um comprimento efetivo como apresentado na figura 2.14, para as linhas de parafusos atuando isoladamente ou em grupo.

A capacidade resistente à flexão da mesa do pilar ou da chapa de topo é calculada, então, verificando-se a resistência do perfil "T" equivalente, em função da força de tração atuante em uma linha ou grupo de linhas de parafusos. 

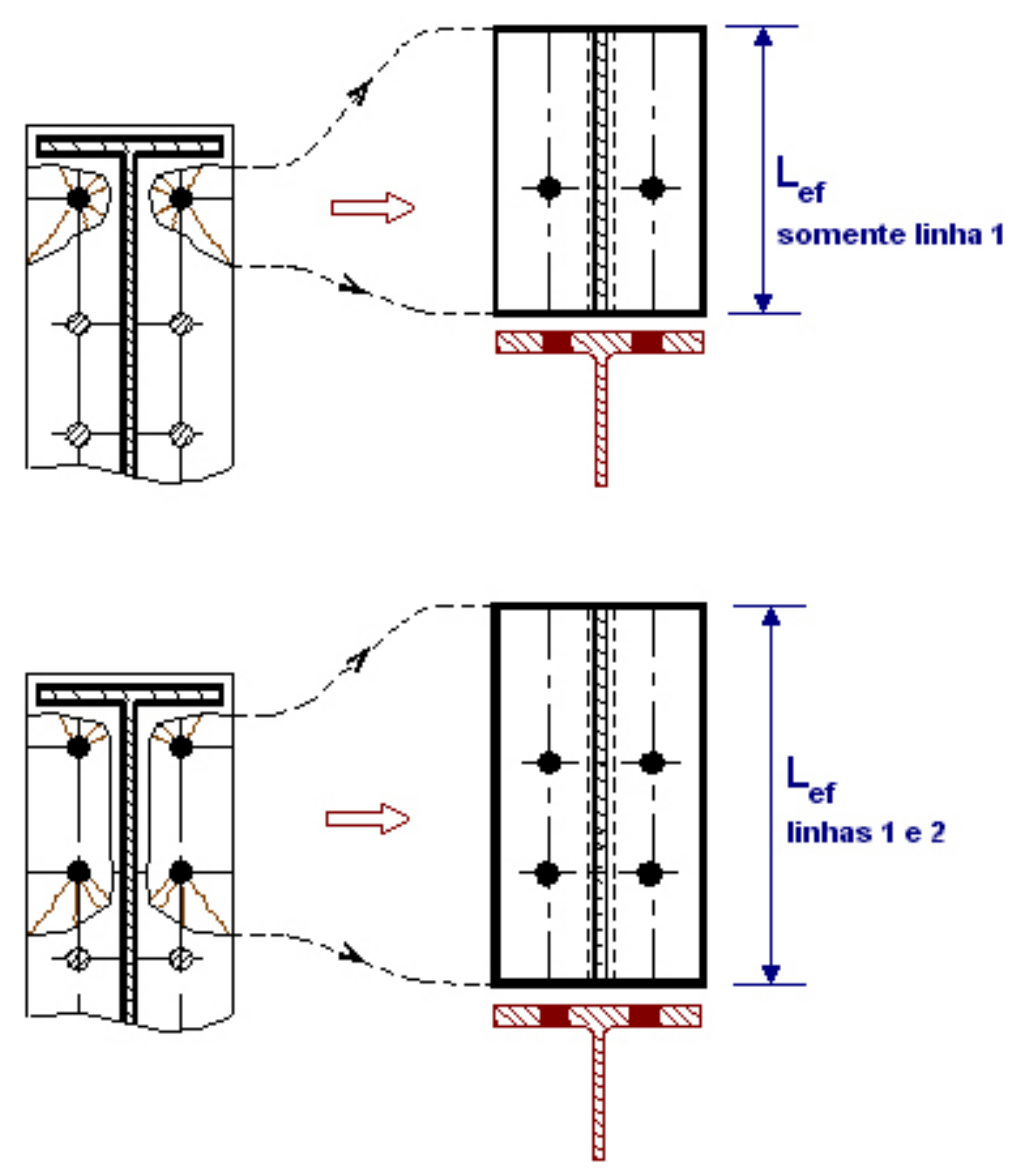

Figura 2.14 - Perfis "T" equivalentes

Neste caso, há três possíveis modos de colapso, apresentados esquematicamente na figura 2.15 , os quais são:

i. Modo 1 - Escoamento total da mesa do pilar ou da chapa de topo;

ii. Modo 2 - Plastificação da mesa do pilar ou da chapa de topo, acompanhado da ruptura dos parafusos;

iii. Modo 3 - Ruptura dos parafusos.

$\mathrm{Na}$ verificação à flexão, para cada linha de parafusos, deve-se adotar o menor valor obtido para a capacidade resistente, considerando-se os três modos acima descritos. 


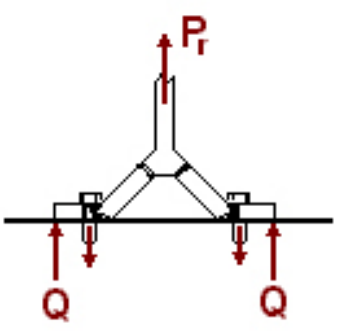

Modo 1

Escoamento total do flange do pilar ou da chapa de topo

Chapa fina,

Parafuso com grande diâmetro

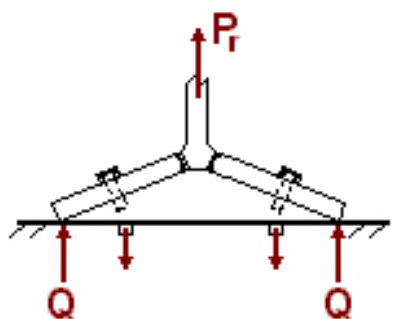

Modo 2

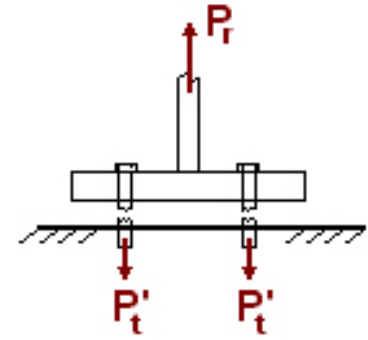

Modo 3
Ruptura do parafuso com escoamento do flange do pilar ou da chapa de topo

Ruptura dos parafusos

Chapa espessa,

Parafuso com pequeno diâmetro

Figura 2.15 - Modos de falha - Flexão da mesa do pilar ou da chapa de topo e resistência dos parafusos

As expressões para o cálculo da capacidade resistente, para cada modo de falha, são apresentadas a seguir.

$$
\begin{aligned}
& \text { i. Modo } 1 \\
& P_{r}=\frac{4 M_{p}}{m}
\end{aligned}
$$

$\operatorname{com} M_{p}=\frac{L_{e f} t^{2} f_{y}}{4}$

\section{ii. Modo 2}

$$
P_{r}=\frac{2 M_{p}+n \sum P_{t}^{\prime}}{m+n}
$$

iii. Modo 3

$$
\mathrm{P}_{\mathrm{r}}=\sum \mathrm{P}_{\mathrm{t}}^{\prime}
$$


onde: $\quad \mathbf{M}_{\mathbf{p}}=$ momento de plastificação total do perfil "T" equivalente, representando a mesa do pilar ou a chapa de topo;

$\mathrm{L}_{\text {ef }} \quad=$ comprimento efetivo da linha de escoamento no perfil "T" equivalente, apresentado em forma de tabelas, de acordo com a posição das linhas ou grupos de linhas de parafusos e da presença ou não de enrijecedores ou da mesa da viga;

t = espessura da mesa do pilar ou da chapa de topo;

$\mathbf{f}_{\mathrm{y}} \quad=$ limite de escoamento do material da mesa do pilar ou da chapa de topo;

$\mathbf{P}_{\mathbf{r}} \quad=$ capacidade resistente da linha ou grupo de linhas de parafusos;

$\mathbf{P}_{\mathbf{t}}{ }^{\prime} \quad=$ limite superior de resistência do parafuso quando o efeito de alavanca é considerado;

$\sum \mathbf{P}_{\mathbf{t}}^{\prime}=$ somatório dos limites superiores de resistência de todos os parafusos de um grupo;

m = distância do centro do parafuso à face da alma do pilar ou da viga, menos $80 \%$ do raio mesa/alma (pilar) ou da dimensão da solda alma/chapa de topo (viga);

n = distância efetiva do centro do parafuso à borda da mesa do pilar ou da chapa de topo, tomada como o valor mínimo entre $\mathbf{e}_{\text {mesa do pilar, }} \mathbf{e}_{\text {chapa de topo e }} \mathbf{1 , 2 5 m}$.

Para o trecho da chapa de topo estendido além da mesa tracionada, são necessárias as dimensões $\mathbf{m}_{\mathbf{x}}$ e $\mathbf{n}_{\mathbf{x}}$, sendo:

$$
\begin{aligned}
\mathbf{m}_{\mathbf{x}}= & \text { distância do centro do parafuso à face da mesa da viga, } \\
& \text { menos } 80 \% \text { da dimensão da solda chapa de topo/mesa } \\
& \text { da viga; } \\
\mathbf{e}_{\mathbf{x}} \quad= & \text { distância do centro do parafuso à extremidade da chapa } \\
& \text { de topo; }
\end{aligned}
$$


$\mathbf{n}_{\mathbf{x}}=$ menor valor entre $\mathbf{e}_{\mathbf{x}}$ e $\mathbf{1 , 2 5 m _ { \mathbf { x } }}$.

As características geométricas necessárias às expressões apresentadas acima, estão detalhadas na figura 2.16.
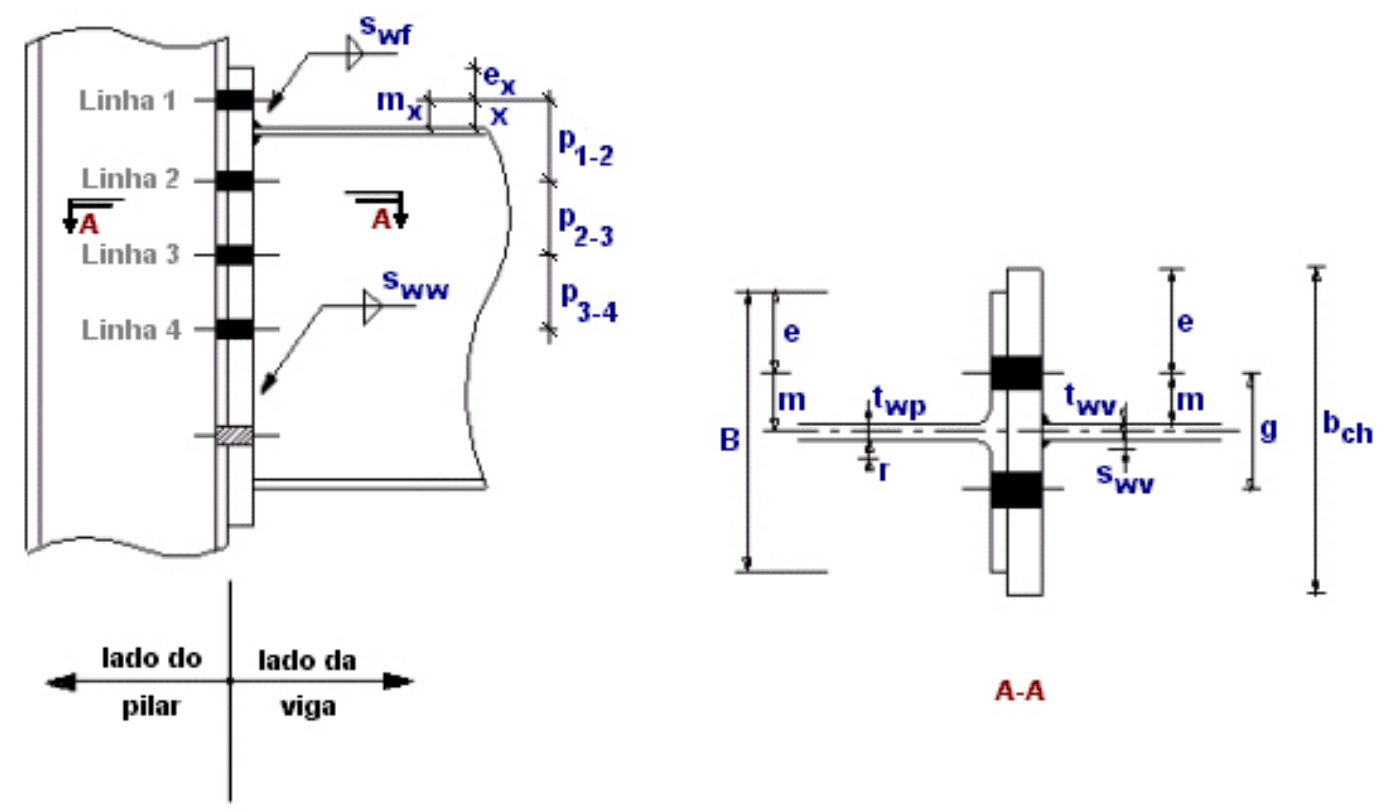

Figura 2.16 - Variáveis geométricas da formulação

Na figura 2.16, as variáveis adicionais são:

g = distância horizontal entre os centros dos parafusos;

e = distância do centro do parafuso à extremidade da mesa do pilar ou da viga;

$\mathbf{x}=$ para a extensão da chapa de topo, distância entre o centro do furo e a face da mesa da viga;

$\mathbf{b}_{\mathrm{ch}}=$ largura da chapa de topo;

$\mathbf{B}$ = largura da mesa do pilar;

$\mathbf{t}_{\mathrm{wv}}=$ espessura da alma da viga;

$\mathbf{t}_{\mathrm{wp}}=$ espessura da alma do pilar;

$\mathbf{s}_{\mathrm{ww}}=$ altura da solda de filete entre chapa e alma da viga;

$\mathbf{S}_{\mathrm{wf}}=$ altura da solda de filete entre chapa e mesa da viga. 
Dando continuidade, é necessário também efetuar a verificação da tração, separadamente, para a alma da viga e do pilar, obtendo-se a capacidade resistente de uma linha ou grupo de linhas de parafusos utilizando-se a expressão

$$
P_{r}=L_{t} t_{w} f_{y}
$$

onde $L_{t} \quad=$ comprimento efetivo da alma (da viga ou do pilar) à tração, admitindo-se um espraiamento máximo de $60^{\circ}$ dos parafusos em relação ao plano médio da alma;

$\mathbf{t}_{\mathrm{w}} \quad=$ espessura da alma da viga $\left(\mathbf{t}_{\mathrm{wv}}\right)$ ou do pilar $\left(\mathbf{t}_{\mathrm{wp}}\right)$;

$\mathbf{f}_{\mathbf{y}} \quad=$ limite de escoamento da alma da viga $\left(\mathbf{f}_{\mathbf{y}, \mathbf{w v}}\right)$ ou do pilar $\left(\mathbf{f}_{\mathrm{y}, \mathrm{wp}}\right)$.

Uma representação esquemática de uma verificação típica da tração na alma da viga ou do pilar pode ser visualizada na figura 2.17.
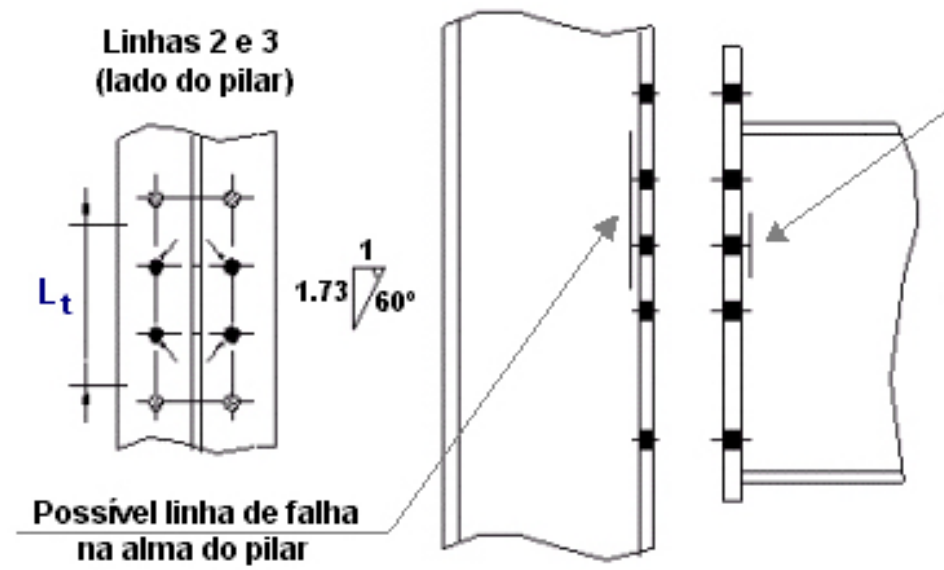

Possível linha de falha na alma da viga

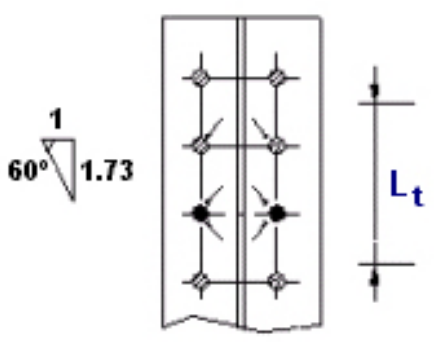

Linhas 2 e 3 (lado da viga)

Figura 2.17 - Verificações típicas para tração na alma

O método proposto pelo EUROCODE-3 (1993) faz uma pequena ressalva, neste ponto, comentando que as tensões na alma do pilar ou da viga não irão governar a determinação da capacidade resistente dos parafusos se, ao longo do comprimento efetivo $L_{t}$, existirem enrijecedores. 
Uma vez conhecida a distribuição plástica das forças entre as linhas de parafusos, é necessário garantir que todas as linhas tenham capacidade de se deformar, de modo a atingirem sua capacidade resistente total.

Se a geometria da ligação impuser um comportamento onde haja pequena capacidade de deformação, como por exemplo, em ligações cujos parafusos são de pequeno diâmetro e a chapa de topo é relativamente espessa, há o risco de que ocorra o colapso dos parafusos das linhas externas, antes mesmo que a capacidade resistente das linhas mais internas seja plenamente alcançada.

Torna-se necessário, então, uma verificação adicional para validar a distribuição de forças obtidas, utilizando-se as seguintes condições:

\section{i. lado da viga}

$$
t_{c h}<\frac{d_{p}}{1,9} \sqrt{\frac{f_{u p}}{f_{y, c h}}}
$$

\section{ii. lado do pilar}

$$
t_{f p}<\frac{d_{p}}{1,9} \sqrt{\frac{f_{u p}}{f_{y, f p}}}
$$

$$
\text { onde } \quad \begin{array}{ll}
\mathbf{t}_{\mathrm{ch}} & =\text { espessura da chapa de topo; } \\
\mathbf{t}_{\mathrm{fp}} & =\text { espessura da mesa do pilar; } \\
\mathbf{d}_{\mathbf{p}} & =\text { diâmetro do parafuso; } \\
\mathbf{f}_{\mathrm{up}} & =\text { resistência última à tração do parafuso; } \\
\mathbf{f}_{\mathbf{y}, \mathrm{ch}} & =\text { limite de escoamento do material da chapa de topo; } \\
\mathbf{f}_{\mathbf{y}, \mathrm{fp}} & =\text { limite de escoamento do material da mesa do pilar. }
\end{array}
$$

As condições expressas pelas equações 2.25 e 2.26 , se não atendidas, limitam a força de tração em qualquer linha de parafusos interna 
às mesas da viga ou aos enrijecedores do pilar ao valor correspondente ao limite proporcionado pela distribuição triangular elástica, como ilustrado na figura 2.18 .

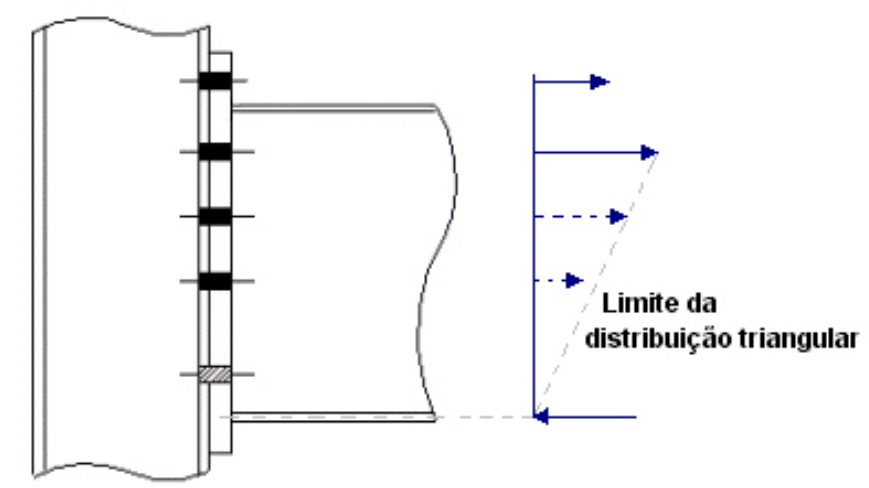

Figura 2.18 - Limite da distribuição triangular para as forças nos parafusos

Analisando-se o procedimento adotado acima, pode-se observar que, se uma linha de parafusos exceder a capacidade limitada pela distribuição triangular, é necessário se transferir a força de tração excedente nessa linha para as linhas inferiores, as quais também devem apresentar reserva de capacidade para resistir à força de tração.

A verificação da capacidade dos parafusos, na região tracionada, apresenta uma importante modificação na maneira de se tratar o efeito conjunto de todos os elementos componentes da ligação, incluída nos modelos do EUROCODE-3 (1993).

Complementando as verificações no que diz respeito aos esforços solicitantes, ainda é necessário analisar a compressão no pilar e na viga, e a absorção de forças cortantes.

Quanto à compressão no pilar, há dois aspectos a serem observados, que são:

i. esmagamento da alma do pilar, considerando-se um espraiamento de $45^{\circ}$ da força transmitida pela mesa comprimida, através da espessura da chapa de topo e de 1/2,5 através da mesa do pilar e do raio de concordância mesa/alma do pilar; e 
ii. flambagem da alma do pilar, considerando-se espraiamento de $45^{\circ}$ da força de compressão transmitida pela mesa da viga, até o eixo do pilar.

A capacidade resistente da alma do pilar, quanto à compressão, é definida por meio da expressão:

$$
P_{c}=M_{c, R d}\left(H-t_{f v}\right)
$$

onde $\quad \mathbf{M}_{\mathbf{c}, \mathbf{R d}}=$ momento resistente de cálculo da seção transversal da viga, tomado como o menor valor entre $\left(\mathbf{W}_{\mathrm{ef}} \mathbf{f}_{\mathrm{y}}\right) / \gamma_{\mathrm{M} 1}$, levando em conta a possibilidade de ocorrência de flambagem local da mesa, e $\left(\mathbf{Z}_{\mathbf{x}} \mathbf{f}_{\mathbf{y}}\right) / \gamma_{\mathbf{m}}$ para seções classe 1, 2 ou 3;

$\mathbf{H} \quad$ = altura da viga;

$\mathbf{t}_{\mathrm{fv}} \quad=$ espessura da mesa da viga;

$\mathbf{W}_{\text {ef }} \quad=$ módulo resistente elástico efetivo da seção da viga;

$\mathbf{Z}_{\mathrm{x}} \quad=$ módulo resistente plástico da seção da viga;

$\mathbf{f}_{\mathrm{y}} \quad=$ limite de escoamento do material da viga;

$\gamma_{\mathrm{M} 0, \mathrm{M} 1}=$ coeficiente de segurança com valor 1,1.

A capacidade resistente da alma do pilar, dada pela equação 2.27, deve ser superior à força de compressão transmitida pela mesa da viga, cujo cálculo é feito em função do somatório das forças transmitidas pelas linhas de parafusos.

Para a mesa da viga, a capacidade resistente à compressão é calculada como sendo

$$
P_{c}=1,4 f_{y, v} t_{f v} b_{f v}
$$

onde $\quad \mathbf{f}_{\mathbf{y}, \mathbf{v}}=$ tensão limite de escoamento do material da viga;

$\mathbf{t}_{\mathrm{fv}}=$ espessura da mesa da viga; 


$$
\mathbf{b}_{\mathrm{fv}}=\text { largura da mesa da viga. }
$$

RIBEIRO (1998) comenta que o acréscimo de 40\% na capacidade resistente da mesa à compressão pode ser justificado por meio de dois efeitos localizados, como resultado do encruamento do material e da dispersão da força de compressão na alma da viga, com uma contribuição de $20 \%$ para cada um.

Para a maioria das ligações, segundo BROWN et al. (1996), esta verificação simplificada mostra que o esmagamento da mesa não é preponderante, mas esse limite pode ser excedido no caso de haver solicitação axial de compressão na viga.

Quanto à verificação à força cortante, o procedimento adotado leva em consideração a capacidade resistente dos parafusos à força cortante, que deve ser obtida pelo somatório das seguintes parcelas:

i. capacidade resistente dos parafusos situados nas linhas de parafusos não solicitados à tração; e

ii. $30 \%$ da capacidade resistente dos parafusos situados nas linhas de parafusos da região tracionada da ligação.

Desta maneira, a condição de resistência à força cortante definida pelo SCI/BCSA (1996), com referência à metodologia empregada pelo EUROCODE-3 (1993), é dada por:

$$
\mathrm{V} \leq \mathrm{n}_{\mathrm{s}} \mathrm{P}_{\mathrm{ss}}+\mathrm{n}_{\mathrm{t}} \mathrm{P}_{\mathrm{ts}}
$$

sendo $\mathbf{V}=$ força cortante na ligação;

$\mathbf{n}_{\mathbf{s}} \quad=$ número de parafusos fora da região tracionada;

$\mathbf{n}_{\mathbf{t}} \quad=$ número de parafusos na região tracionada;

$\mathbf{P}_{\text {ss }}=$ capacidade resistente ao cisalhamento, de um parafuso, tomando-se o menor dos valores calculados para 


$$
\begin{aligned}
& \text { cisalhamento puro no parafuso e para pressão de contato } \\
& \text { na chapa de topo e na mesa do pilar; } \\
\mathbf{P}_{\mathrm{ts}}= & \text { capacidade resistente ao cisalhamento, de um parafuso, } \\
& \text { tomando-se o menor entre os valores correspondentes a } \\
& 40 \% \text { da resistência ao cisalhamento puro no parafuso e à } \\
& \text { resistência à pressão de contato na chapa de topo e na } \\
& \text { mesa do pilar. }
\end{aligned}
$$

O SCI/BCSA (1996) não faz referência, na aplicação da expressão 2.29, ao fato de haver ou não protensão dos parafusos, desconsiderando, também, a hipótese de haverem diferentes solicitações nas linhas de parafusos da região tracionada da ligação.

Não foram abordadas, neste item, as verificações referentes ao painel do pilar - sob cisalhamento - e às soldas, apontando-se como referência as publicações do SCI/BCSA (1996) e ECSC (1997), nas quais são explicadas com detalhes.

O EUROCODE (1992) também apresenta uma classificação para as ligações, onde são considerados aspectos de rigidez (ligações flexíveis, rígidas e semi-rígidas) e aspectos de resistência ao momento fletor (flexíveis, parcialmente resistentes e completamente resistentes). A classificação do EUROCODE (1992) será apresentada no capítulo 3, com mais detalhes.

Adicionalmente, o código também estabelece as condições para a modelagem dos nós (simples, contínuos e semi-contínuos) que implicam na consideração ou não dos efeitos do seu comportamento sobre o comportamento global da estrutura, relacionando a classificação e a modelagem dos nós de acordo com o tipo de análise utilizada (elástica, rígida-plástica ou elasto-plástica).

Inclui também a possibilidade de modelagem do comportamento momento-rotação do nó - que neste caso representa o conjunto de elementos que formam a ligação - por meio de molas de flexão, detalhe que 
merece destaque já que facilita a análise das estruturas pela utilização de programas computacionais.

O procedimento proposto para o dimensionamento das ligações com chapa de topo foi apresentado seguindo o objetivo de abordar aspectos relativos ao modelo adotado pelo EUROCODE-3 (1993), ressaltando as suas principais características.

Dentre elas, pode-se destacar novamente que o método baseia-se na consideração da ligação em função do comportamento estrutural dos seus elementos básicos, incluindo os elementos que constituem o pilar. Desta forma, procura-se avaliar as possíveis influências no comportamento global da ligação.

O procedimento proposto pelo Anexo J do EUROCODE-3 (1993), da maneira com que foi elaborado, permite ainda a análise de qualquer combinação entre as vigas e os pilares, uma vez que apresenta as tabelas de capacidade resistente isoladamente para os pilares e para os conjuntos chapas de topo e viga.

Outro aspecto que deve ser lembrado, e talvez um dos mais importantes, conforme lembrou RIBEIRO (1998), foi a adoção do conceito dos perfis "T" equivalentes para a substituição das diversas configurações de escoamento das tensões, de cujas características depende a determinação da capacidade resistente à flexão da mesa do pilar e da chapa de topo.

Finalmente, é importante comentar que, apesar de levar em consideração os elementos do pilar - mesa, alma, enrijecedores - no cálculo da capacidade resistente dos componentes básicos, a metodologia empregada pelo EUROCODE-3 (1993) não faz menção às possíveis contribuições dadas pela flexibilidade do pilar nas considerações sobre a rigidez das ligações. 


\subsection{COMENTÁRIOS GERAIS}

As metodologias propostas por KRISHNAMURTHY (1978b) e pelo EUROCODE-3 (1993), para o dimensionamento das ligações viga-coluna, com maior relevância no que diz respeito às ligações com chapa de topo, foram apresentadas no item anterior com o objetivo de discutir a sua aplicabilidade e analisar, criticamente, os modelos teóricos que originaram tais propostas.

Cabe aqui ressaltar que a procura de novos métodos de dimensionamento, ou as contribuições para a melhoria dos métodos já existentes, justifica-se pela busca não só da economia de materiais e mãode-obra, mas também do conhecimento dos seus fundamentos, que pode facilitar e até mesmo tornar viável a aplicação das propostas. 


\section{Capítulo}

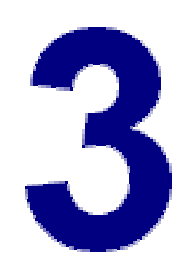

\section{CLASSIFICAÇÃO DAS LIGAÇÕES}

O grande número de observações e estudos feitos com base no comportamento estrutural das ligações entre elementos de estruturas metálicas comprovam, atualmente, a necessidade de se considerar a resposta não linear das estruturas e das ligações como complemento da análise estrutural.

Algumas propostas, mostradas no capítulo 2, correspondendo a esta necessidade, introduziram especificações visando uma adequação dos métodos tradicionais, quando não uma remodelagem de códigos e normas, para que atendam a essa nova filosofia.

Para várias especificações, permite-se já a consideração do comportamento semi-rígido das ligações, sendo uma contribuição aos métodos tradicionais, onde eram considerados apenas comportamentos idealizados, como era o caso das ligações rígidas e flexíveis.

Assim, os mais diversos estudos sobre o comportamento das ligações procuram, enfaticamente, considerar as características que possam classificá-las em termos de resistência, rigidez e ductilidade.

Os sistemas de classificação, neste caso, são arranjados para que possam permitir a inclusão e consideração de novos tipos de comportamentos, idealizados ou não, das ligações.

Este capítulo, dentro desse contexto, tem como objetivo a apresentação e discussão envolvendo algumas propostas de classificação das ligações, levando-se em consideração a existência das ligações semirígidas e a sua influência no comportamento estrutural. 
Serão abordadas as seguintes propostas de classificação:

i. AISC/LFRD (1986);

ii. STARK \& BIJLAARD (1988);

iii. EUROCODE (1992);

iv. BJORHOVDE et al. (1990); e

v. NETHERCOT et al. (1998);

\subsection{COMPORTAMENTO MOMENTO-ROTAÇÃO}

Uma forma de representar o comportamento de uma ligação é relacionar o momento fletor transmitido por ela com a rotação relativa, medida com as linhas elásticas dos elementos conectados.

Essa relação, apresentada graficamente em um diagrama momento-rotação, é uma ferramenta útil para o projeto das ligações e a análise global da estrutura, uma vez que possibilita o estudo da contribuição da semi-rigidez das ligações.

Simplificadamente, a fim de introduzir alguns conceitos básicos, pode-se entender o comportamento semi-rígido de uma ligação por meio da análise dos momentos fletores desenvolvidos nas extremidades dos elementos que a compõem e da rotação relativa desses mesmos elementos.

A figura 3.1 apresenta uma viga com carregamento uniformemente distribuído, onde se pode visualizar duas situações: na figura 3.1(a) consideram-se as ligações como teoricamente rígidas, ou seja, sem rotação relativa entre os elementos e momento máximo nos apoios dado pela expressão

$$
M_{F}=\frac{q L^{2}}{12}
$$

Contudo, levando-se em conta que a ligação não se comporta como perfeitamente rígida, na figura 3.1(b) está representada uma rotação 
nos apoios, a qual provoca uma redução do momento fletor na ligação, expressa por

$$
M_{\theta}=\frac{4 E I \theta}{L}-\frac{2 E I \theta}{L}=\frac{2 E I \theta}{L}
$$

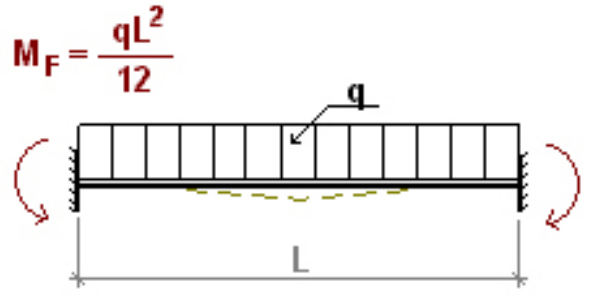

(a)

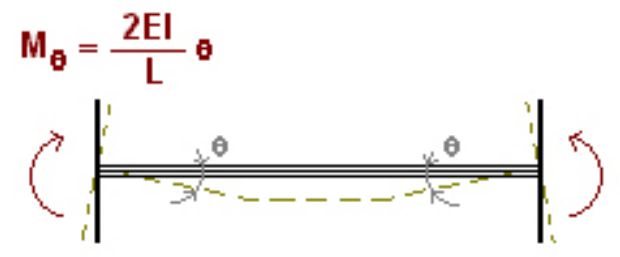

(b)

Figura 3.1 - Ligação rígida teórica e semi-rigidez

Desta maneira, o momento que realmente será transmitido pela ligação será obtido com a soma algébrica dos valores de $\mathbf{M}_{\mathbf{F}}$ e $\mathbf{M}_{\boldsymbol{\theta}}$, ou seja,

$$
M=M_{F}-M_{\theta}=\frac{q L^{2}}{12}-\frac{2 E I \theta}{L}
$$

Considerando a expressão 3.3, para uma ligação teoricamente rígida, $\boldsymbol{\theta}=\mathbf{0}$ e $\mathbf{M}=\mathrm{qL}^{2} / 12$, e para uma ligação teoricamente flexível, $\mathbf{M}=\mathbf{0}$ e $\theta=q^{3} /(24 E \mathrm{E})$, que corresponde à rotação nos apoios de uma viga biapoiada.

Com a formulação básica apresentada acima, observa-se a perda de rigidez de uma ligação, cuja resposta é influenciada pelas propriedades estruturais dos elementos conectados.

O desenvolvimento, então, dos diagramas momento-rotação, tem como objetivo possibilitar uma estimativa do momento fletor que será transmitido pela ligação, levando-se em conta características como a geometria dos elementos conectados, tipo de carregamento e comportamento do material. 
A relação momento-rotação pode ser obtida por meio de ensaios ou com a utilização de modelos analíticos. No segundo caso, considera-se a resistência, a rigidez e a capacidade de deformação das ligações, lembrando também o comportamento predominantemente não linear imposto pelas características do material e pela configuração das mesmas.

\subsection{A RESPOSTA DAS LIGAÇÕES}

A escolha dos critérios a serem utilizados para a classificação das ligações, tanto no que diz respeito aos estados de serviço, quanto aos estados limites últimos, representam uma das maiores dificuldades para os sistemas desenvolvidos de classificação, pelo fato de não apresentarem uma divisão facilmente observada.

No caso do estado em serviço, considerações sobre as deformações e outras características relacionadas com a rigidez das ligações são de fundamental importância.

Para o dimensionamento nos estados limites últimos, parâmetros relacionados à resistência são de maior importância, embora a capacidade de rotação represente um fator que deve ser observado.

Todos esses parâmetros e fatores devem representar escolhas seguras para que possam ser analisados de forma precisa, como resposta das ligações ao carregamento externo, bem como para refletir o comportamento da ligação no comportamento da estrutura como um todo.

\subsection{ORGANIZAÇÃO DOS SISTEMAS DE CLASSIFICAÇÃO}

A importância dos sistema de classificação está justamente em torná-los úteis para que possam ser utilizados de forma segura e coerente no projeto e dimensionamento das estruturas e das ligações. 
Nesse sentido, é de fundamental importância a escolha de categorias, dentro do sistema de classificação, que representem, de forma realística e prática, os tipos de ligações.

Uma vez que já se idealizaram dois tipos de ligações: as flexíveis e as rígidas, torna-se necessário apenas considerar o terceiro tipo, que são as semi-rígidas, com flexibilidade (ou rigidez) intermediária aos dois primeiros tipos.

É importante lembrar que, as ligações idealizadas como rígidas ou flexíveis, no que diz respeito ao comportamento momento-rotação, representam uma pequena parcela quanto à classificação das respostas das ligações.

Para o caso das ligações semi-rígidas, a análise estrutural deve considerar a resposta real da ligação para que a mesma análise conduza a uma representação mais apurada da resposta da própria estrutura. Deve-se também levar em conta os efeitos de segunda ordem produzidos na estrutura, com significante crescimento à medida em que cresce a flexibilidade das ligações.

É importante, também, notar que a representação das características de não linearidade, oriundas do comportamento estrutural das ligações semi-rígidas, deve ser feita de acordo com tal comportamento. Em outras palavras, é extremamente realista pensar em representações não lineares, sejam diagramas ou curvas não lineares da relação momentorotação, como representado na figura 3.2. Para tornar mais prática a utilização, pode-se trabalhar com regiões delimitadas por "curvas" lineares, visualizadas na figura 3.3, desde que levando em conta as aproximações feitas, principalmente quanto ao aspecto de segurança e economia. 


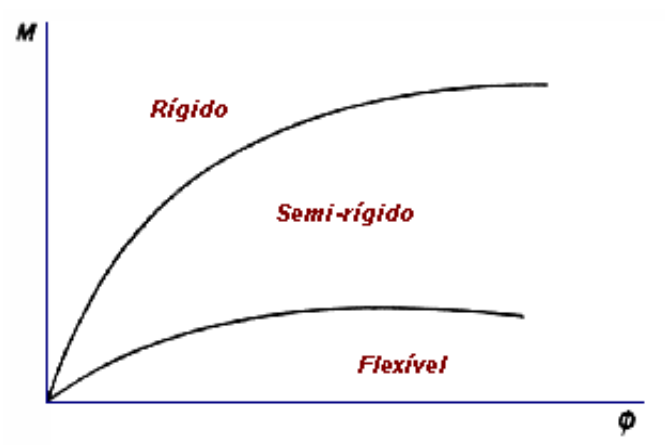

Figura 3.2 - Regiões representativas da resposta não linear

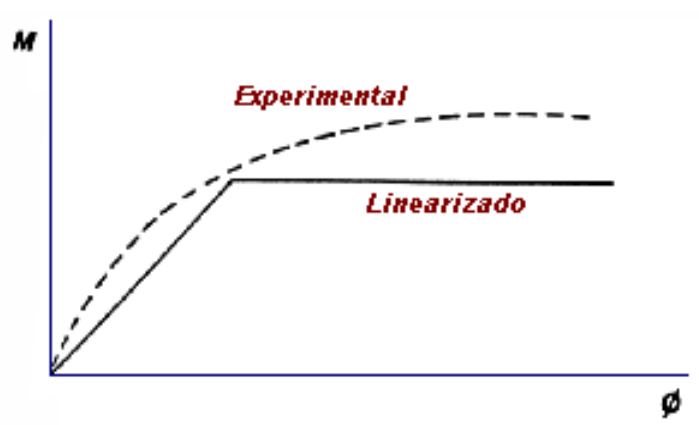

Figura 3.3 - Simplificação da curva momento $x$ rotação

\subsection{PROPOSTAS DE CLASSIFICAÇÃO PARA AS LIGAÇÕES}

\subsubsection{Classificação do AISC(1978) e AISC/LFRD (1986)}

As especificações americanas, publicadas em 1978, classificavam as ligações em três tipos, sendo eles:

i. Tipo 1: ligações rígidas $\rightarrow$ consideradas como aquelas nas quais é garantida a continuidade da estrutura e as rotações relativas são totalmente restringidas, ou admitem restrição no mínimo igual a $90 \%$ da rotação teórica verificada sob condição de rótula ideal; 
ii. Tipo 2: ligações flexíveis $\rightarrow$ consideradas como ligações nas quais as rotações relativas entre os elementos conectados não são restringidas ou admitem uma restrição no máximo igual a $20 \%$ da rotação ideal teórica, verificada sob condição de rótula ideal;

iii. Tipo 3: ligações semi-rígidas $\rightarrow$ ligações cujo comportamento está situado entre os limites estabelecidos pelas ligações rígidas e flexíveis.

Na figura 3.4 estão representados os três tipos de ligações, onde se faz referência ao seu comportamento.

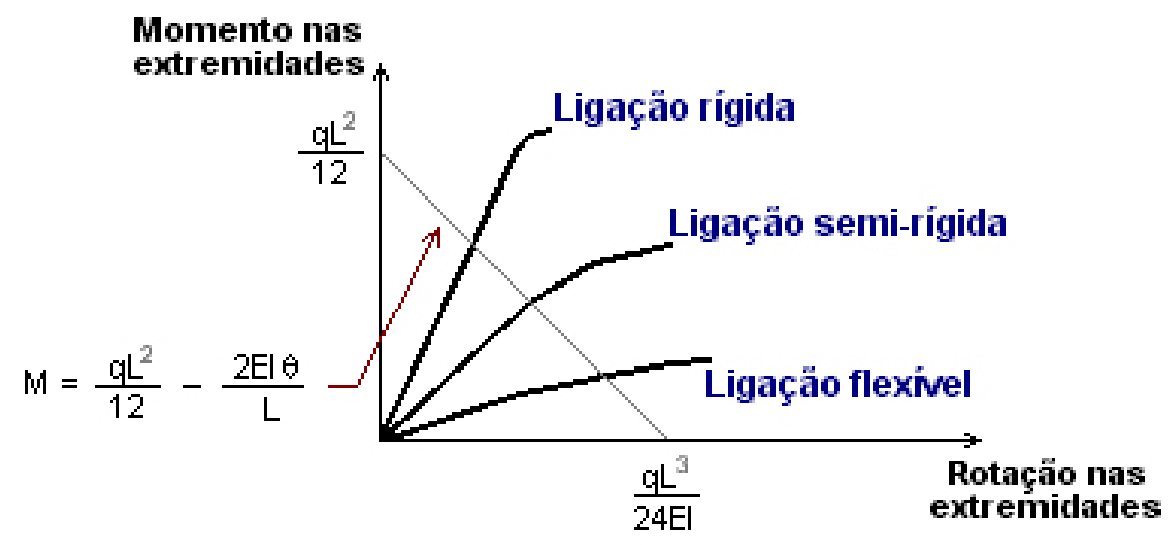

Figura 3.4 - Comportamento da ligação para viga com carregamento uniformemente distribuído

Em 1986, o AISC/LFRD (1986), propôs uma modificação na classificação das ligações na qual considera apenas duas classes:

i. Tipo FR (fully restrained) $\rightarrow$ ligações completamente restringidas; e

ii. Tipo PR (partially restrained) $\rightarrow$ ligações parcialmente restringidas.

As ligações FR mantêm as condições anteriores para ligações rígidas. As ligações $\mathbf{P R}$, no entanto, reúnem todas as ligações cuja rigidez 
considera-se insuficiente para manter inalterado o ângulo original entre os elementos conectados, englobando as ligações antes classificadas como semi-rígidas e flexíveis.

O AISC/LFRD (1986), com base no método dos estados limites, também indica a consideração da rigidez e da resistência da ligação e dos elementos conectados.

\subsubsection{Classificação de STARK \& BIJLAARD (1988)}

A classificação proposta por STARK \& BIJLAARD (1988) depende da metodologia empregada no projeto das ligações quanto à consideração ou não da não linearidade física do material.

Assim, para dimensionamento na fase plástica, as ligações são classificadas como:

i. ligações rotuladas (nominally pinned connections): ligações projetadas para transferir somente forças normais e cortantes, admitindo-se que a ligação tenha uma capacidade de rotação que permita a formação de todas as rótulas plásticas necessárias ao estabelecimento do mecanismo de colapso;

ii. ligações completamente resistentes (full strength connections): ligações que apresentam capacidade de resistir a momentos fletores superiores aos momentos de plastificação dos elementos conectados, resultando na formação de rótula plástica em um elemento adjacente à ligação. Para essa consideração, não é necessário que a ligação apresente, teoricamente, capacidade de rotação;

iii. ligações parcialmente resistentes (partial strength connections): ligações que apresentam capacidade de resistir a momentos fletores inferiores aos momentos de plastificação dos elementos conectados. Neste caso, é necessária uma 
capacidade rotacional adequada, visto que a rótula plástica terá sua formação na ligação.

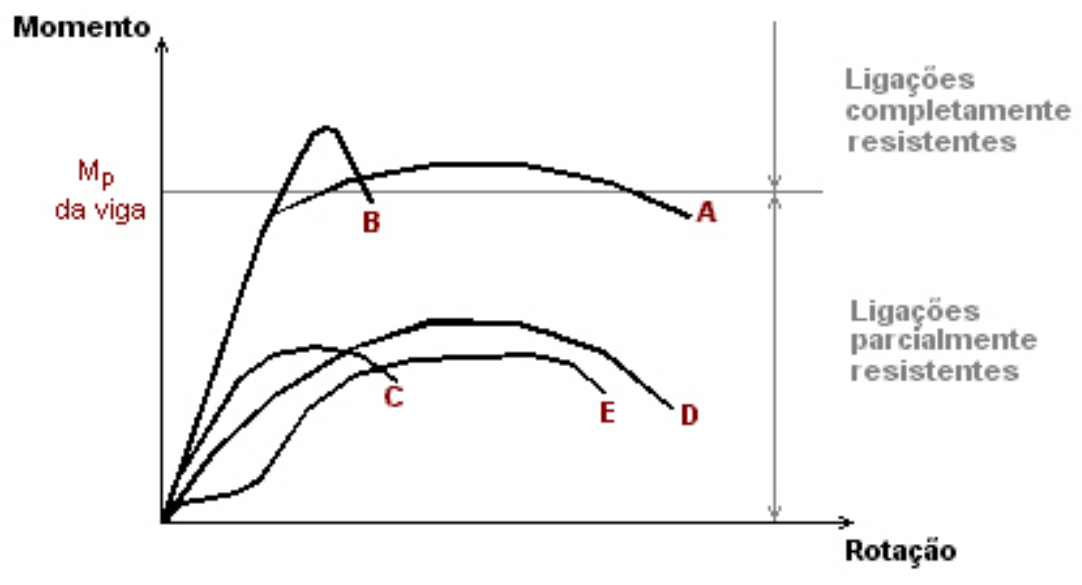

Figura 3.5 - Tipos de ligação na análise plástica

As ligações A e $\mathbf{B}$, apresentadas na figura 3.5, podem ser classificadas como completamente resistentes (ii), sendo que a ligação B deve ser dimensionada, segundo lembrou RIBEIRO (1998), prevendo-se uma reserva de resistência para se considerar a possibilidade de redistribuição plástica dos esforços após a formação da primeira rótula plástica, visto que tal ligação possui pequena capacidade rotacional.

As ligações parcialmente resistentes (iii) estão representadas pelas curvas C, D e E na figura 3.5, observando-se que a curva C representa uma ligação com pequena capacidade rotacional, o que pode ser inadequado levando-se em conta a plastificação da ligação.

Para o projeto na fase elástica, a classificação proposta por STARK \& BIJLAARD (1988) também divide as ligações em três tipos, que são:

i. ligações flexíveis: são as capazes de transmitir somente força cortante e, eventualmente, força normal. Considera-se que sofrem rotações sem absorver momentos fletores de valor significativo;

ii. ligações rígidas: são as capazes de transmitir momentos fletores, além de forças normais e cortantes. Devem apresentar 
elevada rigidez, de modo que se possa considerar desprezível qualquer mudança na distribuição de momentos e nos deslocamentos;

iii. ligações semi-rígidas: considera-se, neste grupo, as ligações que proporcionam um certo grau de interação entre os elementos conectados para a absorção dos esforços. Essa interação tem base nas características da curva momentorotação.

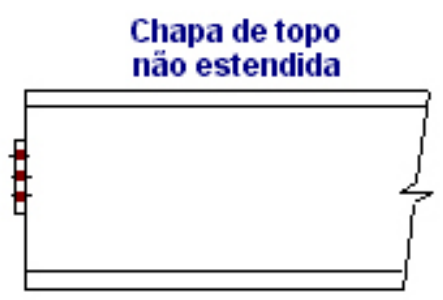

Cantoneira de alma

Figura 3.6 - Ligações tipicamente flexíveis
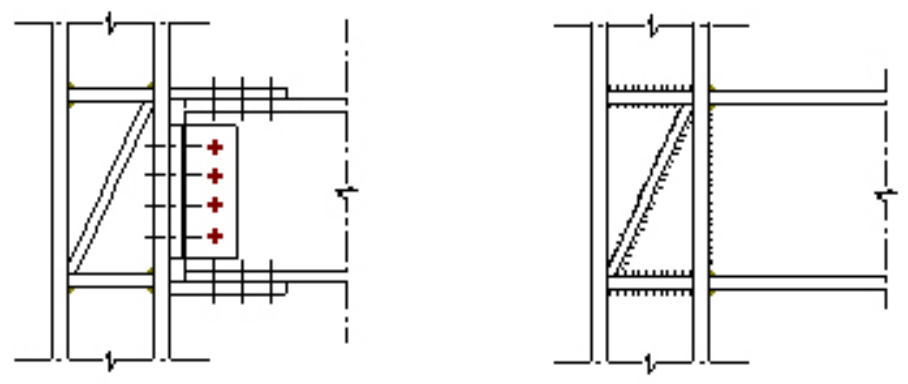

Figura 3.7 - Ligações tipicamente rígidas
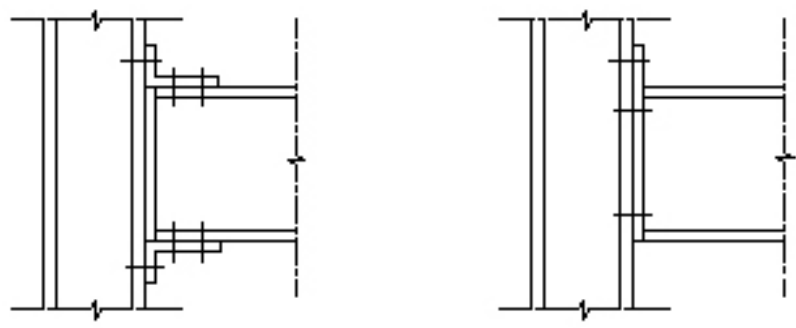

Figura 3.8 - Ligações semi-rígidas 
A figura 3.6 apresenta ligações que, tipicamente, são consideradas flexíveis, segunda a classificação proposta por STARK \& BIJLAARD (1988). Exemplos de ligações rígidas são apresentados na figura 3.7 e exemplos de ligações semi-rígidas estão esquematizadas na figura 3.8, ressalvando-se que as ligações com chapa de topo podem ser classificadas como rígidas em função da variação de suas características geométricas.

\subsubsection{Classificação do EUROCODE-3 (1992)}

A classificação proposta no EUROCODE-3 (1992) é baseada na capacidade de carga dos elementos estruturais, levando-se em conta o comportamento global da estrutura, sendo que a rigidez das ligações é expressa como uma fração da rigidez do elemento que está sendo conectado.

Seguindo este enfoque, as ligações não são tratadas isoladamente, sendo que tanto a rigidez como a resistência da ligação, quando comparadas à rigidez do elemento que está ligando, consideram na estrutura o efeito do comportamento não linear.

Desta maneira, o sistema de classificação proposto utiliza parâmetros de rigidez e resistência separadamente.

Quanto à rigidez, quando comparadas à rigidez do elemento ligado, as ligações podem ser:

i. rígidas;

ii. semi-rígidas;

iii. flexíveis.

Quanto à resistência, as categorias dependem da capacidade das ligações em absorver momentos fletores, sendo estas classificadas em: 
i. completamente resistentes;

ii. parcialmente resistentes;

iii. flexíveis.

A metodologia empregada pelo EUROCODE-3 (1992) para a determinação dos limites correspondentes para cada categoria mostrada acima também considera o tipo de estrutura na qual está inserida a ligação, com ou sem contraventamento.

\subsubsection{Parâmetros utilizados}

Os parâmetros adimensionais utilizados na classificação das ligações são $\overline{\mathrm{m}}$ e $\bar{\theta}$, definidos pelas expressões 3.4 e 3.5, respectivamente.

$$
\begin{aligned}
& \overline{\mathrm{m}}=\mathrm{M} / \mathrm{M}_{\mathrm{p}} \\
& \bar{\theta}=\theta_{\mathrm{r}} / \theta_{\mathrm{p}}
\end{aligned}
$$

onde: $\quad \theta_{p}=M_{p} \mathrm{~L} / \mathrm{El}$

e $\quad \mathbf{I}=$ momento de inércia da seção transversal da viga;

$\mathbf{L}=$ comprimento da viga;

$\mathbf{M}_{\mathbf{p}}=$ momento de plastificação total da seção transversal; e

$\theta_{\mathrm{r}}=$ rotação da ligação para momento $\mathbf{M}$.

O EUROCODE-3 (1992) utiliza o comprimento real da viga para definir a rigidez, sendo que as fronteiras das regiões correspondentes às ligações rígidas e semi-rígidas para estruturas contraventadas e não contraventadas estão apresentadas na figura 3.9. 


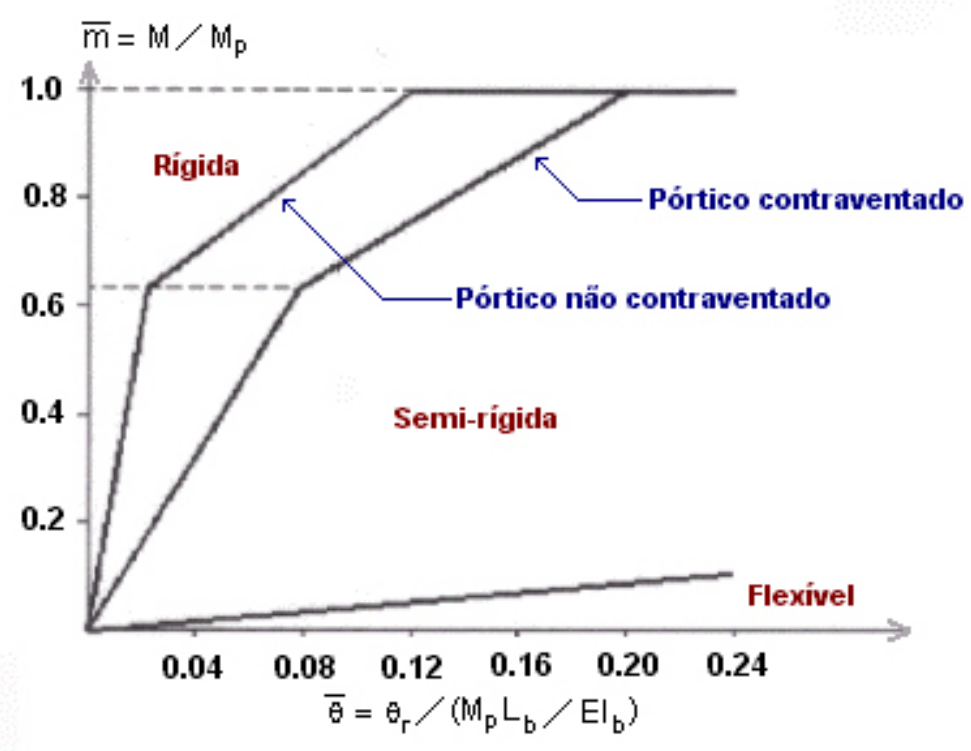

Figura 3.9 - Classificação do EUROCODE-3 (1992)

Assim, analisando-se os limites para a classificação das ligações, tem-se que:

i. estruturas não contraventadas:

$\begin{array}{lll}\text { Se } \bar{m}<2 / 3 & \rightarrow & \bar{m}=25 \bar{\theta} \\ \text { Se } 2 / 3<\bar{m} \leq 1,0 & \rightarrow & \bar{m}=\frac{25 \bar{\theta}+4}{7}\end{array}$

ii. estruturas contraventadas:

$$
\begin{array}{lll}
\text { Se } \overline{\mathrm{m}}<2 / 3 & \rightarrow & \overline{\mathrm{m}}=8 \bar{\theta} \\
\text { Se } 2 / 3<\overline{\mathrm{m}} \leq 1,0 & \rightarrow & \overline{\mathrm{m}}=\frac{20 \bar{\theta}+3}{7}
\end{array}
$$

Sob o aspecto da resistência, o momento de plastificação total da seção transversal é usado como limite máximo, ressaltando-se que o comportamento $\overline{\mathrm{m}} \times \bar{\theta}$ tem como objetivo melhor representar a não 
linearidade de comportamento, verificada através de análises experimentais, para a maioria das ligações semi-rígidas.

Para a caracterização da ligação flexível, complementando a classificação, são estabelecidos os seguintes limites:

\section{i. quanto à rigidez:}

$$
S_{j} \leq \frac{E l}{2 L}
$$

onde: $\quad \mathbf{S}_{\mathbf{j}}=$ rigidez rotacional secante da ligação.

ii. quanto à resistência:

$$
M \leq \frac{M_{p}}{4}
$$

\subsubsection{Observações sobre a proposta do EUROCODE-3 (1992)}

O método proposto pelo EUROCODE-3 (1992) não utiliza, na ligação, uma exigência explícita de rotação. Além disso, como a classificação é feita separadamente quanto à rigidez e quanto à resistência, uma ligação qualquer pode ser de diferentes categorias, como lembrou KISHI et al. (1997).

Seguindo a metodologia apresentada, com a afirmação feita acima, se a ligação tem uma capacidade de resistir momento superior a 95\% da capacidade da viga que está conectando, ela pode ser classificada como uma ligação totalmente resistente, o que implica em dizer que:

i. é possível utilizar, no dimensionamento, a totalidade do momento resistente; 
ii. as deformações que ocorrerão entre os elementos não afetarão as propriedades da ligação.

A aplicação dos conceitos descritos acima, relacionados com a consideração de uma ligação totalmente resistente, pode não ser verdadeira, no entanto, se a rigidez da ligação for relativamente baixa quando comparada com a sua resistência.

Essa consideração poderia invalidar a utilização da totalidade do momento resistente no dimensionamento da ligação, uma vez que esse momento é limitado pela menor rigidez da mesma.

Por outro lado, se a ligação tivesse uma rigidez suficientemente alta, ela seria classificada como rígida, mesmo não apresentando alta resistência.

Uma ligação rígida permite que os elementos da estrutura sejam analisados segundo os métodos tradicionais, ou seja, considerando a total continuidade rotacional e a transmissão total do momento fletor. Todavia, esse tipo de análise não é aceitável para ligações sem resistência adequada, uma vez que poderiam ser considerados momentos resistentes maiores que a real capacidade da ligação.

Visto isso, tal ligação não deveria ser apropriadamente classificada como rígida.

\subsubsection{Classificação de BJORHOVDE et al. (1990)}

BJORHOVDE et al. (1990) utilizaram um grande número de resultados experimentais e resultados teóricos - oriundos da análise de modelos para diferentes tipos de ligações - na formulação do sistema de classificação que será visto adiante.

Os critérios utilizados por BJORHOVDE et al. (1990) levam em consideração o desempenho da ligação, a adoção de um comprimento de 
referência para a viga conectada na definição da rigidez, e parâmetros relativos à capacidade resistente.

No que diz respeito ao desempenho da ligação, considera-se que a rotação é uma medida essencial da deformabilidade no estudo do comportamento das ligações. Desta maneira, é de fundamental importância o conhecimento das leis que regem a curvatura das vigas conectadas.

Neste sentido, o método de classificação utilizado por BJORHVODE et al. (1990) introduz elementos com comprimento de referência específico para o desenvolvimento dos critérios de classificação, utilizado devido à necessidade de correlacionar a rotação da ligação à curvatura na viga conectada, à inclinação inicial da curva momento-rotação e à rigidez da viga.

Uma vez que a rigidez das ligações varia significativamente de um tipo para outro, diferentes comprimentos de referência deveriam ser utilizados, como apresentado na figura 3.10. Como simplificação do método, adotou-se um comprimento de referência único.

Esta simplificação é possível, visto que a maioria das ligações semi-rígidas, através da análise de resultados disponíveis de experimentos, tiveram respostas que se aproximaram da média obtida através dos resultados feitos com o comprimento de referência escolhido.

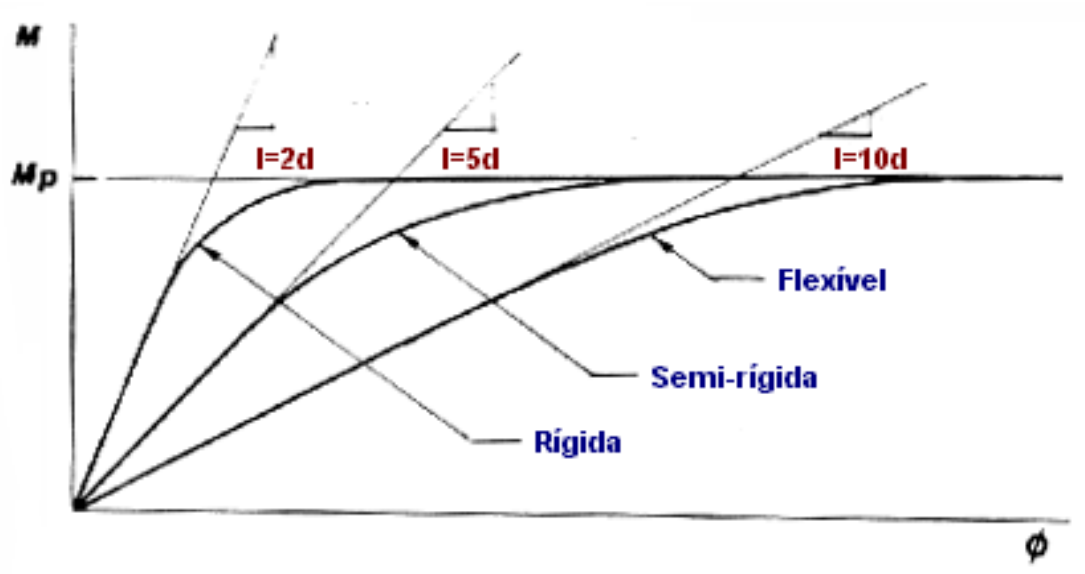

Figura 3.10 - Curvas momento-rotação para diferentes comprimentos de referência 
O comprimento de referência adotado por BJORHOVDE et al. (1990) tem um valor igual a cinco vezes a altura da seção transversal da viga conectada.

Assim como na classificação feita pelo EUROCODE-3 (1992), há a proposição de três categorias de ligação: rígidas, semi-rígidas e flexíveis.

Para definir os limites entre as ligações flexíveis e semi-rígidas, bem como entre as ligações semi-rígidas e as rígidas, procuram-se valores representativos das capacidades resistentes das ligações quanto ao momento fletor, correspondente a um estado limite último.

Um exemplo da análise desses limites pode ser observado na figura 3.11, que mostra apenas percentuais do momento de plastificação relativos às possíveis rotações.

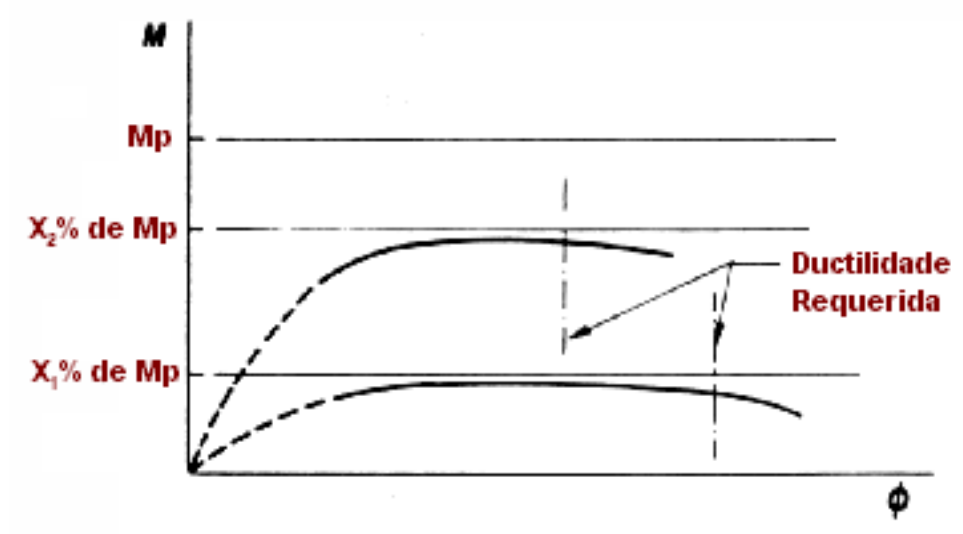

Figura 3.11 - Resistência máxima a níveis associados de ductilidade

Os parâmetros utilizados, adimensionais, são os mesmos utilizados na classificação proposta pelo EUROCODE-3 (1992), apresentados nas expressões 3.4 e 3.5 .

A única consideração a ser feita sobre os parâmetros é $\theta_{p}$, que agora é definido por

$$
\theta_{p}=\frac{5 M_{p} d}{E l}
$$




\subsubsection{Parâmetros utilizados}

Os resultados experimentais analisados por BJORHOVDE et al. (1990), para as ligações viga-coluna, permitiram a escolha de um comprimento de referência para as vigas ensaiadas, de acordo com as simplificações mencionadas no item 3.4.4.

Visto que as respostas dadas pelos vários tipos de ligação, quanto ao aspecto da rigidez, se aproximam em uma região correspondente a um comprimento de referência igual a cinco vezes a altura da viga correspondente, escolheu-se essa referência única como mais apropriada.

Os estudos referidos acima, relacionando os comprimentos de referência e os momentos resistentes para as ligações ensaiadas, estão computados na tabela III.I.

Pode-se perceber que o valor de $\mathrm{I}_{\mathbf{e}}$ que mais se aproxima da média dos valores situados dentro da região que representaria o comportamento semi-rígido, é $\mathrm{I}_{\mathrm{e}} \mathbf{= 5 d}$, onde $\mathbf{d}$ é a altura da viga.

Tabela III.I - Comprimentos de referência para as ligações Resultado da análise de 55 experimentos

\begin{tabular}{|c|c|c|c|}
\cline { 2 - 4 } \multicolumn{1}{c|}{} & \multicolumn{3}{c|}{ Ligações } \\
\cline { 2 - 4 } \multicolumn{1}{c|}{} & Rígida & Semi-rígida & Flexível \\
\hline $\begin{array}{c}\text { Comprimento } \\
\text { de referência } \\
I_{\mathrm{e}}\end{array}$ & $1 d<\mathrm{I}_{\mathrm{e}}<2 d$ & $2 d<\mathrm{I}_{\mathrm{e}}<5 d$ & $\approx 10 d$ \\
\hline $\begin{array}{c}\text { Momento } \\
\text { resistente } \\
\text { último }\end{array}$ & $\approx 0,9 \mathrm{M}_{\mathrm{p}}$ & $\approx 0,7 \mathrm{M}_{\mathrm{p}}$ & $\approx 0.2 \mathrm{M}_{\mathrm{p}}$ \\
\hline
\end{tabular}

Neste caso, escolhido o comprimento de referência, para a divisão entre as ligações rígidas e semi-rígidas adotou-se o comprimento de $\mathbf{2} \mathbf{d}$, e para a divisão entre as ligações semi-rígidas e as flexíveis, um valor de $\mathbf{1 0 d}$.

A localização destes limites, baseados na análise dos resultados mostrados na tabela III.I, estão apresentados na figura 3.12. 


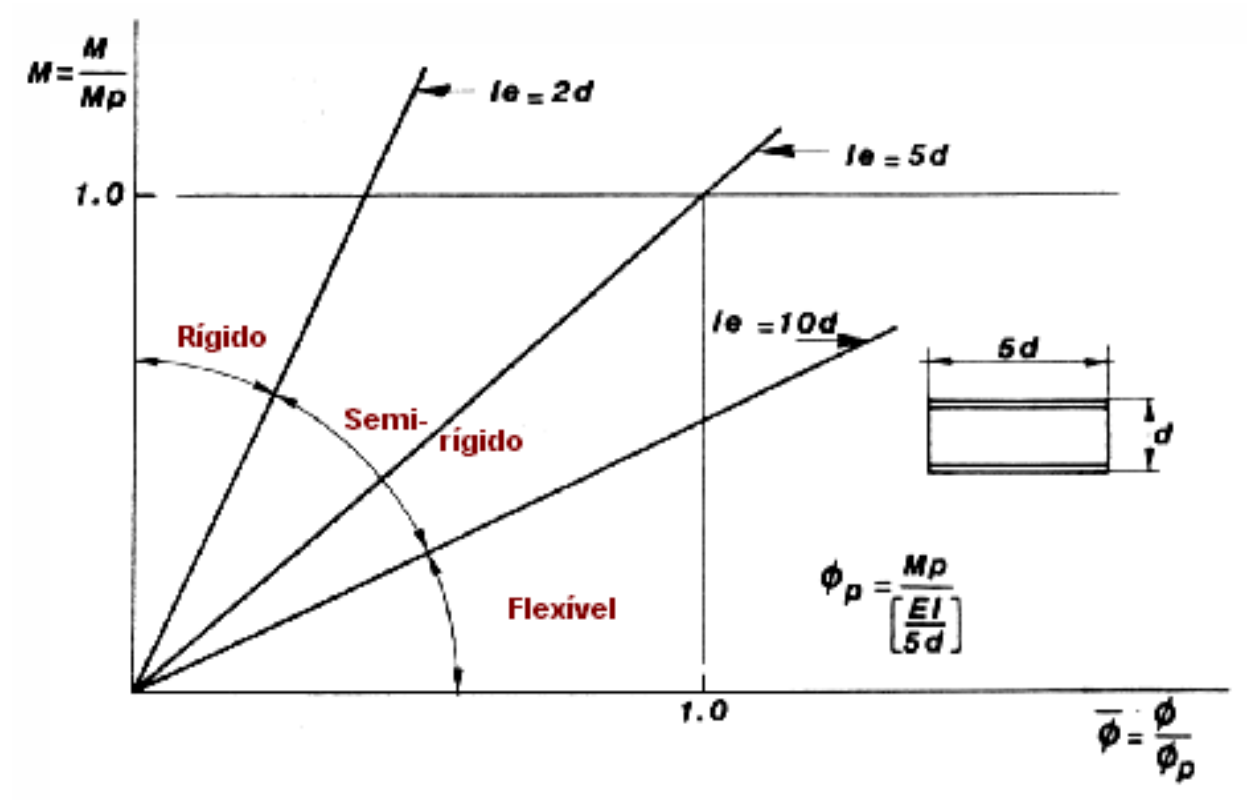

Figura 3.12 - Classificação adimensional - regiões segundo o comprimento de referência

A análise dos dados da tabela III.I também permitem a escolha das máximas capacidades resistentes a serem consideradas. Assim, observa-se que seria coerente a utilização dos valores de $\mathbf{0 , 2} \mathbf{M}_{\mathbf{p}}$ para delimitar as regiões flexível e semi-rígida, e de $\mathbf{0 , 7} \mathbf{M}_{\mathbf{p}}$ para a interface entre as regiões semi-rígida e rígida.

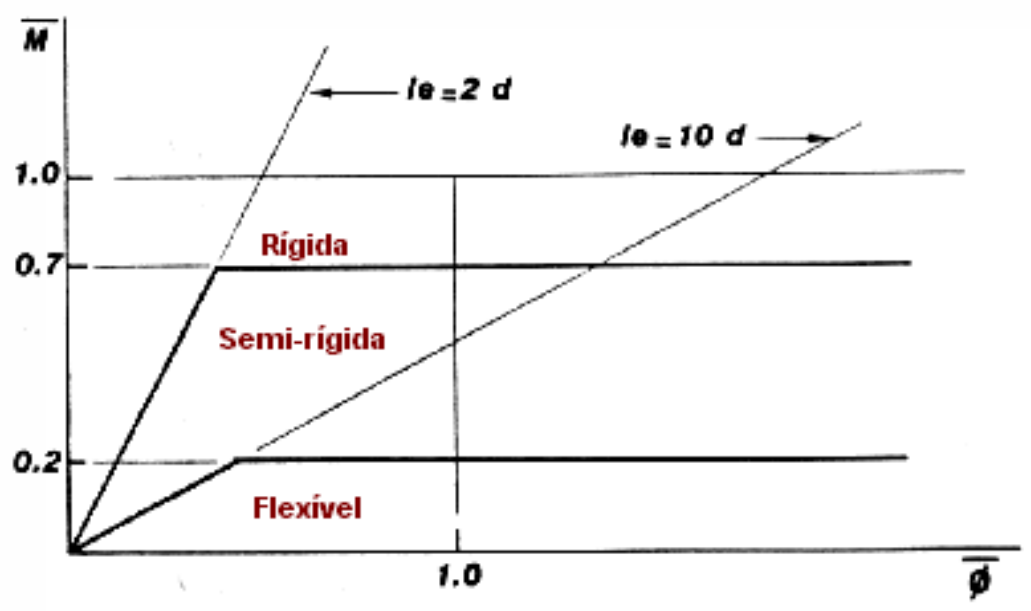

Figura 3.13 - Classificação adimensional para rigidez e resistência máxima das ligações 
A região que representaria as ligações rígidas ainda é delimitada pelo momento de plastificação. Esta consideração é feita segundo os métodos tradicionais de dimensionamento, evitando assim, falhas estruturais fora da região da ligação.

As regiões que são utilizadas para a classificação das ligações estão representadas na figura 3.13.

Em termos das fronteiras das regiões apresentadas nas figuras 3.12 e 3.13 , definem-se as seguintes categorias:

\section{i. ligações rígidas}

$\rightarrow$ quanto à resistência

$$
\overline{\mathrm{m}} \geq 0,7
$$

$\rightarrow$ quanto à rigidez

$$
\overline{\mathrm{m}} \geq 2,5 \bar{\theta}
$$

\section{ii. ligações semi-rígidas}

$\rightarrow$ quanto à resistência

$$
0,7>\bar{m}>0,2
$$

$\rightarrow$ quanto à rigidez

$$
2,5 \bar{\theta}>\bar{m}>0,5 \bar{\theta}
$$




\section{iii. ligações flexíveis}

$\rightarrow$ quanto à resistência

$\overline{\mathrm{m}}<0,2$

$\rightarrow$ quanto à rigidez

$\overline{\mathrm{m}}<0,5 \bar{\theta}$

\subsubsection{Capacidade rotacional da ligação}

O método proposto por BJORHOVDE et. al. (1990) pode ser estendido, segundo considerações do autor, para qualquer tipo de ligação, independentemente da existência de resultados experimentais.

Para isso, é proposta uma equação empírica que descreve o comportamento momento-rotação, expressa simplificadamente por

$$
\overline{\mathrm{m}}=\frac{5,4-2 \bar{\theta}}{3}
$$

Segundo a expressão 3.20 , a capacidade rotacional da ligação é inversamente proporcional à rigidez inicial da ligação, sendo dependente da razão entre a capacidade resistente última da ligação ao momento fletor e o momento de plastificação total da viga correspondente.

A figura 3.14 apresenta os limites das regiões que classificam as ligações e a curva apresentada para a capacidade rotacional da ligação. 


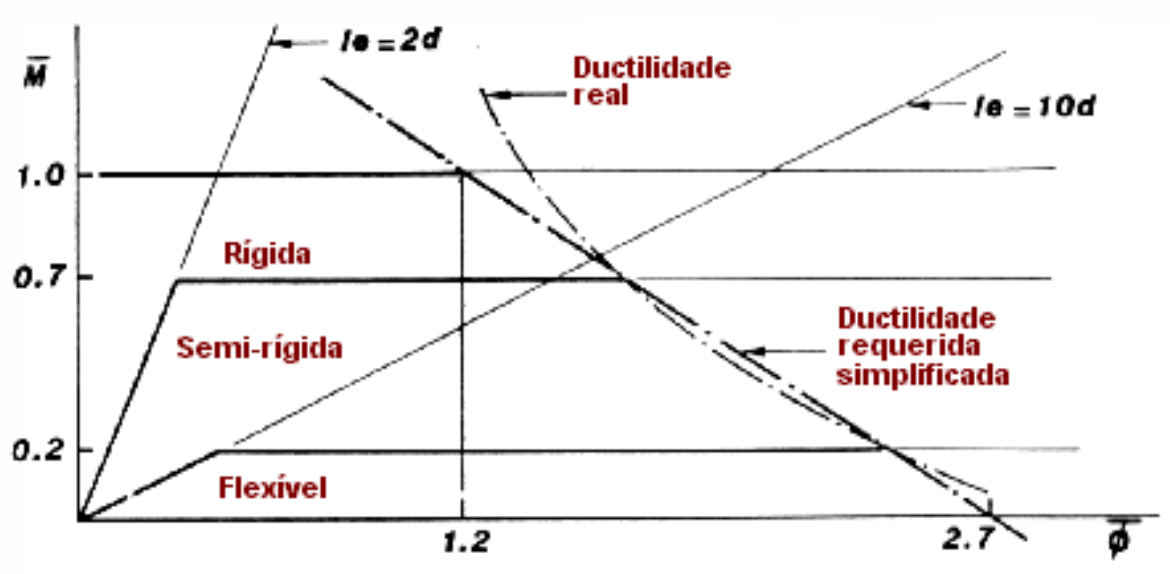

Figura 3.14 - Diagrama com a consideração da capacidade rotacional

O diagrama esquematizado na figura 3.14, representa o sistema de classificação completo.

Como simplificação, pode-se adotar a curva como sendo uma reta, secante à curva, nos pontos de intersecção com os limites de $\mathbf{0 , 7} \mathbf{M}_{\mathbf{p}}$ e $\mathbf{0 , 2} \mathbf{M}_{\mathbf{p}}$.

\subsubsection{Observações - proposta de BJORHOVDE et al. (1990)}

O sistema de classificação das ligações proposto por BJORHOVDE et al. (1990) utiliza os mesmos critérios adotados pelo EUROCODE-3 (1992), ou seja, distinguindo as ligações separadamente, em termos de resistência e em termos da rigidez.

O fato de esse sistema utilizar comprimentos de referência para a comparação entre a rigidez e resistência da ligação e do elemento que está sendo conectado permite observar que toda a metodologia empregada para sua obtenção foi feita para os casos em que não se conhece preliminarmente a estrutura, em termos de distribuição dos elementos, bem como não se conhece a dimensão das peças estruturais.

As ligações são, então, colocadas dentro de três categorias: rígidas, semi-rígidas e flexíveis. 
Neste caso, a rigidez da ligação é representada como uma taxa da rigidez da viga conectada, relativa a um comprimento de referência, sendo esse comprimento um múltiplo da altura da viga.

Se o comprimento de referência para uma ligação é inferior a $2 d$, a ligação é classificada como rígida. Se o comprimento é maior que $10 d$, a ligação é classificada como flexível. Valores intermediários classificam a ligação como semi-rígida.

A capacidade de resistir momentos, para as ligações rígidas, semirígidas e flexíveis, neste sistema, deve ser maior que $70 \%$ de $\mathbf{M}_{\mathbf{p}}$, entre $70 \%$ e $20 \%$ de $\mathbf{M}_{\mathbf{p}}$, e menor que $20 \%$ do $\mathbf{M}_{\mathbf{p}}$, respectivamente, onde $\mathbf{M}_{\mathbf{p}}$ é o momento de plastificação da viga conectada.

Para este sistema de classificação, é possível enquadrar uma ligação em diferentes categorias, nos estados limites últimos e de serviço, considerando a rigidez e a resistência. Além disso, adiciona-se à metodologia de classificação conceitos de capacidade rotacional da ligação, ou seja, uma relação entre a rigidez da ligação e a rotação devido ao carregamento.

Caracteristicamente, o método proposto não considera os efeitos introduzidos pelo comportamento estrutural da ligação no comportamento global da estrutura. Tratando a ligação isoladamente, podem ocorrer erros significativos na classificação das ligações, principalmente se os modelos adotados para a criação dessa proposta diferirem significativamente da estrutura analisada.

Assim como na metodologia descrita pelo EUROCODE-3 (1992), podem haver casos de ligações que são classificadas diferentemente, quanto à rigidez e quanto à resistência.

A figura 3.15 apresenta um caso de comportamento momentorotação, citado por BJORHOVDE et al. (1990), em que há ocorrência de ligações com diferentes classificações. 


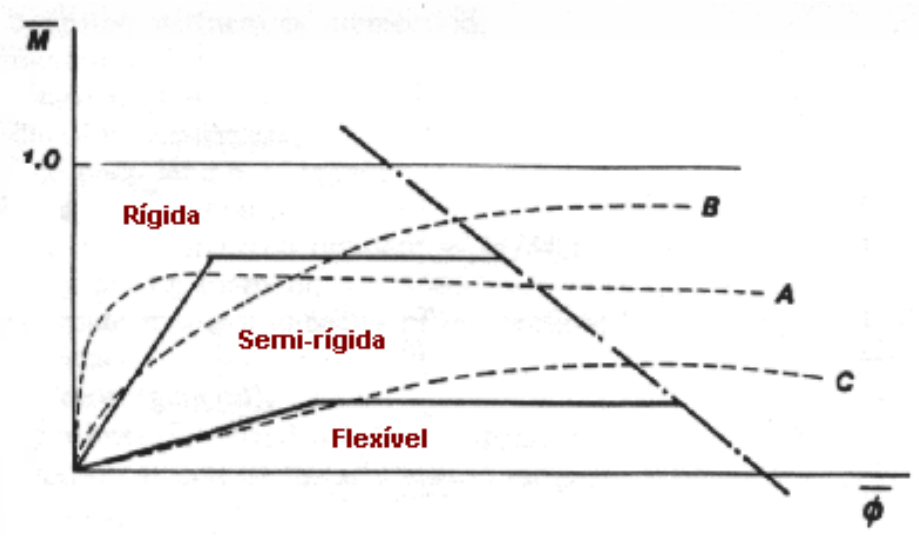

Figura 3.15 - Ligações com diferentes classificações

\begin{abstract}
Ligação A: quanto ao estado limite de utilização (classificação quanto à rigidez), esta ligação é considerada como rígida, sendo semirígida quanto ao momento resistente último;

Ligação B: quanto à rigidez, a ligação é semi-rígida. Para o estado limite último, é classificada como rígida;

Ligação C: a ligação é flexível quanto à rigidez e semi-rígida para o estado limite último.
\end{abstract}

\title{
3.4.5 Classificação de NETHERCOT et al. (1998)
}

NETHERCOT et al. (1998) propuseram um novo sistema de classificação para ligações viga-coluna, no qual as características de rigidez e de resistência das ligações são consideradas simultaneamente.

Neste sistema, as categorias apresentadas referem-se ao comportamento esperado da ligação, cujos termos utilizados são:

i. Totalmente conectadas: devem ter alta resistência e alta rigidez;

ii. Parcialmente conectadas: moderada resistência e rigidez;

iii. Ligações flexíveis: baixa resistência ou baixa rigidez; e

iv. Ligações não-estruturais: as demais, que não se encaixem nas anteriores. 
O método utilizado por NETHERCOT et al. (1998) procura criar um sistema de classificação que elimine resultados ambíguos, quanto às categorias que podem abranger as ligações.

Novamente reconhece que é necessário, para a metodologia empregada, corresponder às respostas dadas pelas ligações aos estados limites de utilização e últimos, analisando o comportamento global da estrutura incluindo o comportamento da ligação.

Segundo as observações feitas por NETHERCOT et al. (1998) sobre a metodologia dos outros sistemas de classificação, a resistência e a rigidez das ligações sob carregamentos axiais e transversais são consideradas suficientemente grandes de modo a não afetar a capacidade resistente e a deformação nos elementos conectados. Desta maneira, essas características não serão consideradas como critérios para a classificação das ligações.

Como já mencionado nos itens 3.4 .3 e 3.4.4, os sistemas de classificação que adotam, separadamente, critérios para a resistência e a rigidez - no que diz respeito aos estados limites últimos e aos estados limites de utilização - podem gerar classificações ambíguas, levando uma ligação a ocupar mais de uma categoria.

Se uma ligação tem uma grande capacidade de absorver momentos, mas uma baixa rigidez, relativamente, não será possível para essa ligação desenvolver sua capacidade máxima, devido às deformações que pode sofrer. Ou seja, se uma ligação não tem rigidez suficiente, sua máxima resistência deve ser observada com cuidado para um dimensionamento adequado.

Seguindo este mesmo raciocínio, se a resistência de uma ligação é pequena, não importará a magnitude da rigidez, uma vez que a ligação pode falhar por ter sido dimensionada como rígida, enquanto não tem capacidade resistente para deixar atuar momentos que estão previstos na categoria das ligações rígidas.

O método proposto por NETHERCOT et al. (1998), considerando simultaneamente a rigidez e a resistência da ligação, faz com que os 
resultados obtidos sejam enquadrados em uma única categoria, representando com melhor consistência as considerações a serem feitas sobre o comportamento da ligação.

A seguir, será apresentado o desenvolvimento do método, levandose em conta os estados limites últimos, para cada tipo de categoria proposta.

\subsubsection{Ligações totalmente conectadas}

As ligações totalmente conectadas, neste método, poderiam permitir a análise tradicional de elementos rígidos, considerando a continuidade rotacional e transmissão total do momento fletor, salvo por algumas observações.

A análise tradicional requer que a capacidade de resistir momentos da ligação deve ser, ao menos, igual a capacidade da viga; e a rigidez da ligação deve ser suficientemente maior para possibilitar que a ligação desenvolva essa capacidade de absorver os momentos.

Uma vez que o máximo momento resistente da viga conectada é conhecido, o critério para a capacidade resistente da ligação já está resolvido.

Já o critério para a rigidez da ligação depende também da rigidez dos elementos que estão sendo conectados, cuja obtenção não é direta.

Assumindo que o momento absorvido na ligação seja maior que 95\% do desenvolvido nos elementos conectados - consideração que vem da análise tradicional - a mínima rigidez requerida, na ligação, para ligações totalmente conectadas pode ser obtida por

$$
K=\frac{38 \alpha}{(2+\alpha)} \frac{E l}{L}
$$

onde: $\mathbf{K}=$ rigidez da ligação;

$\mathbf{E I} / \mathbf{L}=$ rigidez do elemento conectado; $\mathrm{e}$ 
$\propto \quad=$ taxa de rigidez entre elementos conectados.

Para uma ligação cuja rigidez não é inferior à dada pela equação 3.21 e com capacidade de resistir momentos igual à capacidade resistente da viga conectada, a ligação pode ser considerada como totalmente conectada.

A relação entre a rigidez da ligação $(\mathbf{K})$ e a rigidez dos elementos conectados $(\propto)$ está apresentada na figura 3.16.

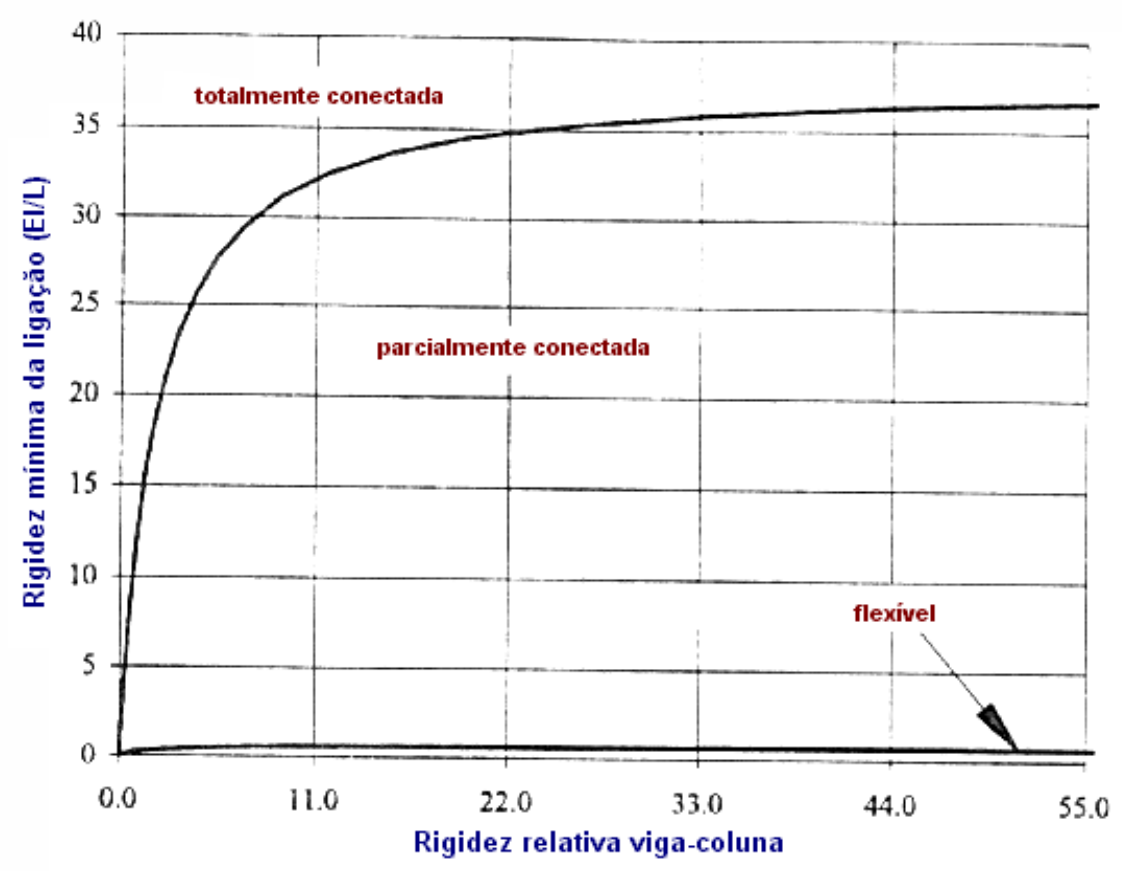

Figura 3.16 - Relação entre a rigidez necessária da ligação e a rigidez relativa entre os elementos conectados

\subsubsection{Ligações flexíveis}

Considerando que as ligações flexíveis não desenvolvem momentos significativos, deve-se limitar a rigidez da ligação ou a capacidade de absorver os momentos. 
Seguindo as classificações anteriormente descritas, a capacidade de absorver momentos deve ser inferior a $25 \%$ do momento oriundo da análise tradicional para elementos rígidos.

Assim, da mesma maneira com que se estabeleceu a relação para a rigidez da ligação e a rigidez relativa entre os elementos conectados para as ligações totalmente conectadas, a expressão para a rigidez da ligação torna-se

$$
K=\frac{0,67 \alpha}{(2+\alpha)} \frac{\mathrm{El}}{\mathrm{L}}
$$

A relação entre $\mathrm{K}$ e $\propto$ também está apresentada na figura 3.16. Analisando-se o gráfico, percebe-se que a rigidez da ligação é muito pequena e quase não é afetada pela relação de rigidez entre viga-coluna.

Assim, uma ligação cuja rigidez é inferior à dada pela expressão 3.22, ou cuja capacidade de absorver momentos é inferior a $25 \%$ da capacidade resistente da viga conectada, é classificada como flexível.

Deve-se notar, como consideração adicional, que para desenvolver um momento inferior a $25 \%$, a ligação deve ter suficiente capacidade de rotação.

Para as ligações flexíveis, NETHERCOT et al. (1995) estima que a mínima capacidade rotacional pode ser obtida por

$$
\theta_{r}=\left[0,344+0,561\left(\frac{M_{d}-M_{y}}{M_{p}-M_{y}}\right)^{2}\right] \frac{M_{d} L}{E l}
$$

onde: $\quad \mathbf{M}_{\mathbf{d}}=$ momento de cálculo;

$$
\begin{aligned}
& \mathbf{M}_{\mathbf{y}}=\text { momento de início do escoamento; e } \\
& \mathbf{M}_{\mathbf{p}}=\text { momento último (plastificação). }
\end{aligned}
$$




\subsubsection{Ligações parcialmente conectadas}

Da análise feita nos itens 3.4.5.1 e 3.4.5.2, qualquer ligação que não satisfaça as condições para uma ligação completamente conectada ou uma ligação flexível, será definida como ligação parcialmente conectada, desde que tenha capacidade rotacional adequada.

Segundo NETHERCOT et al. (1995), para ligações parcialmente conectadas, a capacidade rotacional pode ser obtida por

$$
\theta_{r}=\left[0,344-0,212 \frac{M_{c}}{M_{d}}+0,561\left(\frac{M_{d}-M_{y}}{M_{p}-M_{y}}\right)^{2} \frac{1}{\sqrt{1+M_{c} / M_{d}}}\right] \frac{M_{d} L}{E l}
$$

onde: $\quad \mathbf{M}_{\mathbf{c}}=$ momento de cálculo da ligação;

$\mathbf{M}_{\mathbf{d}}=$ momento de cálculo;

$\mathbf{M}_{\mathbf{y}}=$ momento de início do escoamento; $\mathrm{e}$

$\mathbf{M}_{\mathbf{p}}=$ momento último (plastificação).

\subsubsection{Ligações não-estruturais}

As ligações não-estruturais são aquelas que não podem ser enquadradas naquelas descritas nos itens anteriores. Nos casos mais comuns são ligações que não possuem capacidade rotacional adequada para serem classificadas segundo as categorias já analisadas.

Não são consideradas como estruturais pois, por não possuírem capacidade rotacional suficiente, também não possuem suficiente ductilidade, apresentando rupturas frágeis. 


\subsubsection{Resumo da classificação}

O sistema de classificação apresentado por NETHERCOT et al. (1998), descrito acima para os estados limites últimos, é resumido na figura 3.17 .

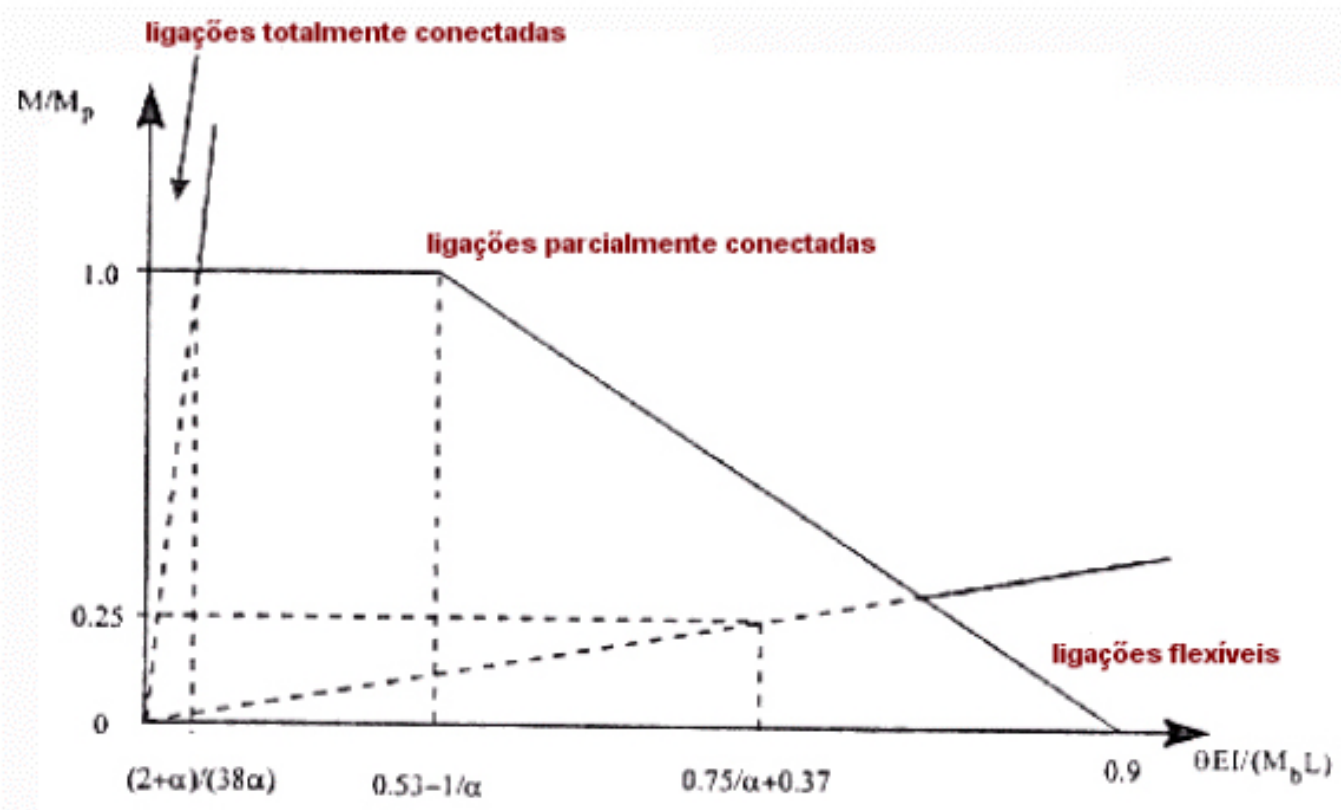

Figura 3.17 - Sistema de classificação unificado NETHERCOT et al. (1998)

\subsubsection{Observações - proposta de NETHERCOT et al. (1998)}

O desenvolvimento de um sistema de classificação unificado, ou seja, considerando as características de rigidez e resistência das ligações simultaneamente, eliminou significativamente a possibilidade de resultados ambíguos na classificação do comportamento estrutural das ligações.

Para as três primeiras categorias mostradas, as limitações foram impostas para a capacidade de absorver momentos, para a mínima e máxima rigidez das ligações, e também considerando a capacidade rotacional dos elementos. Ligações não-estruturais são as que não se enquadram em nenhuma das categorias anteriormente descritas, por não 
apresentarem níveis adequados de capacidade rotacional, principalmente no que se refere às necessidades da estrutura como um todo.

\subsection{COMENTÁRIOS GERAIS}

Fazendo-se uma análise comparativa entre os sistemas de classificação apresentados, pode-se observar uma tendência a se buscar sistemas unificados, onde se procura unir critérios, de modo a obter respostas mais seguras quanto às considerações que devem ser feitas adequadamente a cada comportamento estrutural das ligações.

$\mathrm{Na}$ classificação proposta pelo EUROCODE-3 (1992), todo o sistema é baseado na capacidade resistente dos elementos conectados. A rigidez das ligações é expressa como uma fração da rigidez dos elementos conectados, e dessa maneira, o comportamento global da estrutura também é levado em conta.

Pode-se dizer que este sistema de classificação é mais racional que o proposto por BJORHOVDE et al. (1990), uma vez que as ligações não são tratadas isoladamente, apesar de apresentar uma complexidade maior para a análise da ligação.

O método proposto por BJORHOVDE et al. (1990) foi planejado para os casos em que não existe conhecimento preliminar da estrutura. As ligações têm sua rigidez representada também por uma fração da rigidez da viga conectada, desta vez, relacionada com um comprimento de referência. Todas as conclusões obtidas neste método são oriundas da análise experimental de diversas ligações, proporcionando resultados empíricos.

Neste caso, já é incluída uma análise da capacidade rotacional das ligações, à medida em que surge a necessidade de verificar as ligações flexíveis.

Nestes dois sistemas, pelo fato de se considerarem em separado, os critérios de rigidez e resistência, é possível para uma ligação ser classificada dentro de diferentes categorias. 
O sistema de classificação proposto por NETHERCOT et al. (1998) coloca as ligações dentro de categorias únicas, unificando os critérios de rigidez e resistência das ligações. Neste caso, torna a classificação das ligações mais consistentes.

Por fim, os estudos apresentados anteriormente comprovam que é possível utilizar de modo mais racional as estruturas, de modo a refletir, por meio de suas ligações, melhor desempenho estrutural, seguidos de maior economia, seja no projeto e dimensionamento, seja nas etapas construtivas. 


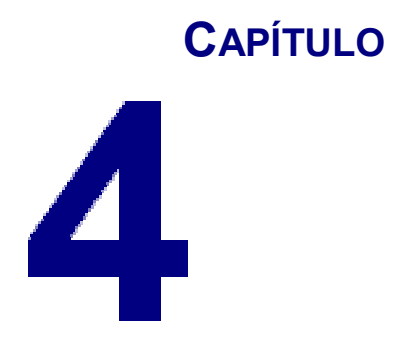

MODELOS NUMÉRICOS

Apresentam-se, neste capítulo, as etapas do desenvolvimento da análise numérica, descrevendo-se a preparação dos modelos numéricos utilizados. Fazem-se, também, algumas observações quanto à análise propriamente dita e se ressaltam as hipóteses e simplificações adotadas.

Os modelos, preparados com a utilização de elementos finitos, foram processados integralmente no software comercial ANSYS, versão 5.5. Visando esclarecimentos adicionais também serão apresentadas as terminologias encontradas no software utilizado, quando necessário e conveniente.

Seguindo os objetivos deste trabalho, como já mencionado anteriormente, os modelos numéricos foram preparados buscando, de forma realística e satisfatória, representar o comportamento das ligações vigacoluna com chapa de topo. Para atender a essa finalidade, as características dos modelos em elementos finitos seguiram as características de protótipos previamente escolhidos, tornando possível a comparação de resultados numéricos e experimentais para a comprovação da confiabilidade da análise numérica.

Assim, utilizou-se como base as características de alguns protótipos ensaiados por RIBEIRO (1998), cujo trabalho envolveu a análise experimental de ligações viga-coluna com chapa de topo.

$\mathrm{Da}$ mesma forma, para tornar representativos os modelos numéricos, tornou-se essencial a definição de algumas características para a análise numérica, as quais são a definição do comportamento do material, 
tipo de análise a ser considerada e tipos de elementos finitos a serem utilizados. Essas características serão detalhadas mais adiante.

Convém salientar que todos os modelos possuem as mesmas considerações no que diz respeito às características da análise e simplificações adotadas, diferenciando-se apenas pelas características geométricas - espessura e dimensões da chapa de topo, diâmetro e dimensões dos parafusos - e valores para representação dos materiais utilizados nos protótipos.

De forma a demonstrar a evolução dos modelos preparados neste trabalho, serão ainda apresentados outros cuja análise preliminar permitiu a definição do modelo final adotado, principalmente os que precederam a consideração da flexibilidade do pilar na análise numérica.

A título de observação, o processamento dos modelos numéricos foi realizado em microcomputadores PC, linha Pentium II, $450 \mathrm{MHz}$, com 512 MB de memória RAM. Com essa configuração, o tempo total para processamento dos modelos finais, em média, foi de 100 horas, o que resulta em aproximadamente 4 dias e meio, para cada modelo processado.

\subsection{CRITÉRIOS GERAIS UTILIZADOS NA ANÁLISE NUMÉRICA}

Observando-se a complexidade do comportamento estrutural do tipo de ligação em estudo e os resultados que se pretende obter, especificamente a rigidez da ligação e estados limites a que está submetida, busca-se uma análise que represente da melhor forma o comportamento real da ligação.

Assim, embora seja possível a representação da ligação num estado plano, como analisado por KRISHNAMURTHY (1975c) e SHERBOURNE \& BAHAARI (1994 e 1996), optou-se pela utilização de modelos tridimensionais que podem, sem dúvida, gerar resultados mais próximos do comportamento real da ligação.

Da mesma forma, deve-se levar em consideração as características de não linearidade. Como a ligação, notoriamente, introduz 
descontinuidades na estrutura, sejam provenientes da geometria ou do material utilizado, tem-se que conduzir a análise segundo critérios que estejam de acordo com as ligações representadas, as quais são objeto desse estudo.

Assim, para a consideração da ligação com chapa de topo, também são feitas algumas considerações de não linearidade, física e geométrica.

\subsubsection{Não linearidade física}

Visando a consideração dos materiais que farão parte dos modelos numéricos, adotou-se um diagrama bi-linear para a representação do comportamento tensão-deformação do material.

Dessa forma, para a análise numérica, considerou-se a utilização de um modelo representativo do diagrama bi-linear, consistente com o material utilizado - aço, e que no software ANSYS recebe a denominação de Bilinear isotropic hardening plasticity (BISO). Este modelo consiste em dois segmentos de retas que dividem o comportamento elástico e plástico do material. A figura 4.1 apresenta, esquematicamente, o modelo mencionado.

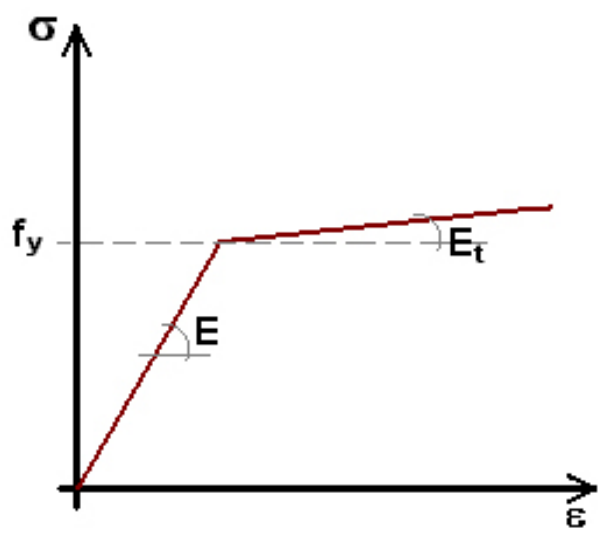

Figura 4.1 - Representação do diagrama bi-linear 
$\mathrm{Na}$ figura 4.1, a reta de maior inclinação representa o comportamento elástico, e a de inclinação menor, o comportamento do material devido à plastificação.

Feita a escolha do modelo, o material é definido pelos valores das seguintes constantes:

$$
\begin{aligned}
& \rightarrow \text { tensão de escoamento }-\mathbf{f}_{\mathbf{y}} \\
& \rightarrow \text { módulo de elasticidade longitudinal (Young) - } \mathbf{E} \\
& \rightarrow \text { módulo de elasticidade após a plastificação }-\mathbf{E}_{\mathbf{t}}
\end{aligned}
$$

Como se procurou utilizar modelos compatíveis com protótipos de ensaio, para posterior comparação dos resultados, as constantes acima definidas foram escolhidas de forma a representar a realidade da análise experimental, que será mencionada adiante.

\subsubsection{Descontinuidade geométrica}

Analisando-se os elementos que compõem a ligação estudada, observa-se que a composição possui como forte característica a descontinuidade na sua geometria.

Quanto à consideração da interação dos elementos componentes da ligação, são utilizados elementos finitos especiais com os quais é possível simular o contato entre parafusos, porcas, chapa de topo e mesa do pilar. Esses elementos serão descritos mais adiante.

Alguns resultados obtidos com a análise numérica, apresentados no Anexo II, indicam que não há influência da consideração de grandes deslocamentos, principalmente para chapas mais grossas. Por essa razão, não foi incluída, na análise, a influência de grandes deslocamentos. Convém salientar, no entanto, que é importante a verificação dessa influência em 
modelos que tendam a apresentar deslocamentos maiores, como no caso de chapas mais finas.

\subsection{RESULTADOS EXPERIMENTAIS ESCOLHIDOS}

Como já citado anteriormente, adotou-se para os modelos numéricos as características de protótipos experimentais com resultados conhecidos, de modo a possibilitar o confronto de resultados e análise da representatividade da análise numérica.

Desta maneira, escolheu-se os resultados da análise experimental realizada por RIBEIRO (1998), cujo trabalho deu origem a uma série de ensaios de ligações viga-coluna com chapa de topo, realizados no Departamento de Estruturas da Escola de Engenharia de São Carlos, USP. Também já citado, RIBEIRO (1998) estudou a rigidez deste tipo de ligação através da análise da influência da espessura da chapa de topo e do diâmetro dos parafusos no comportamento da ligação.

A tabela IV.I apresenta um resumo dos protótipos ensaiados por RIBEIRO (1998). Destes protótipos, foram utilizados 6 para a preparação dos modelos numéricos, variando-se a espessura da chapa de topo e o diâmetro dos parafusos. Os protótipos escolhidos estão destacados na tabela IV.I, a qual também apresenta algumas características geométricas gerais. Salienta-se que, para a análise numérica, escolheu-se apenas os protótipos da série 1 (CT1).

De modo a compatibilizar os modelos numéricos com os protótipos que estão representando, algumas observações quanto à análise experimental realizada por RIBEIRO (1998) são pertinentes, visto às simplificações adotadas para a análise numérica. 
Tabela IV.I - Protótipos das ligações com chapa de topo

\begin{tabular}{|c|c|c|c|c|c|}
\hline Protótipos & Viga & Coluna & $\begin{array}{c}\text { Chapa de } \\
\text { topo } \\
\text { (mm) }\end{array}$ & $\begin{array}{c}\text { Diâmetro } \\
\text { parafusos } \\
\text { (mm) }\end{array}$ & $\begin{array}{l}\text { Comprimento } \\
\text { das vigas } \\
\text { (m) }\end{array}$ \\
\hline CT1A-1 & \multirow{12}{*}{$\begin{array}{c}\text { VS } \\
250 \\
X \\
37\end{array}$} & \multirow{12}{*}{$\begin{array}{c}\text { CVS } \\
350 \\
X \\
105\end{array}$} & 31,5 & 16 & 1,500 \\
\hline CT1B-1 & & & 31,5 & 16 & 1,500 \\
\hline CT1A-2 & & & 25 & 16 & 1,550 \\
\hline CT1B-2 & & & 25 & 19 & 1,550 \\
\hline CT1A-3 & & & 25 & 16 & 1,550 \\
\hline CT1B-3 & & & 25 & 19 & 1,550 \\
\hline CT1A-4 & & & 22,4 & 16 & 1,510 \\
\hline CT1B-4 & & & 22,4 & 19 & 1,510 \\
\hline CT1A-5 & & & 22,4 & 16 & 1,510 \\
\hline CT1B-5 & & & 22,4 & 19 & 1,510 \\
\hline CT1A-6 & & & 19 & 19 & 1,510 \\
\hline CT1B-6 & & & 19 & 19 & 1,510 \\
\hline CT2A-1 & \multirow{13}{*}{$\begin{array}{c}\text { VS } \\
350 \\
X \\
58\end{array}$} & \multirow{13}{*}{$\begin{array}{c}\text { CVS } \\
350 \\
X \\
128\end{array}$} & 37,5 & 22 & 1,495 \\
\hline CT2B-1 & & & 37,5 & 22 & 1,495 \\
\hline CT2C-1 & & & 37,5 & 22 & 1,495 \\
\hline CT2A-2 & & & 31,5 & 22 & 1,500 \\
\hline CT2B-2 & & & 31,5 & 22 & 1,500 \\
\hline CT2A-3 & & & 31,5 & 25 & 1,500 \\
\hline CT2B-3 & & & 31,5 & 25 & 1,500 \\
\hline CT2A-4 & & & 25 & 22 & 1,505 \\
\hline CT2B-4 & & & 25 & 22 & 1,505 \\
\hline CT2A-5 & & & 25 & 25 & 1,505 \\
\hline CT2B-5 & & & 25 & 25 & 1,505 \\
\hline CT2A-6 & & & 22,4 & 25 & 1,505 \\
\hline CT2B-6 & & & 22,4 & 25 & 1,505 \\
\hline
\end{tabular}

Uma diz respeito à configuração adotada por RIBEIRO (1998) para a montagem dos protótipos, na qual cada protótipo contém um par de vigas, ou seja, um par de ligações, de igual geometria. Além de permitir comparação entre os resultados de cada componente do par, essa configuração, ilustrada na figura 4.2 , foi adotada por não necessitar de um dispositivo rígido para promover o contraventamento do sistema, ou seja, travamento do pilar na posição vertical. 


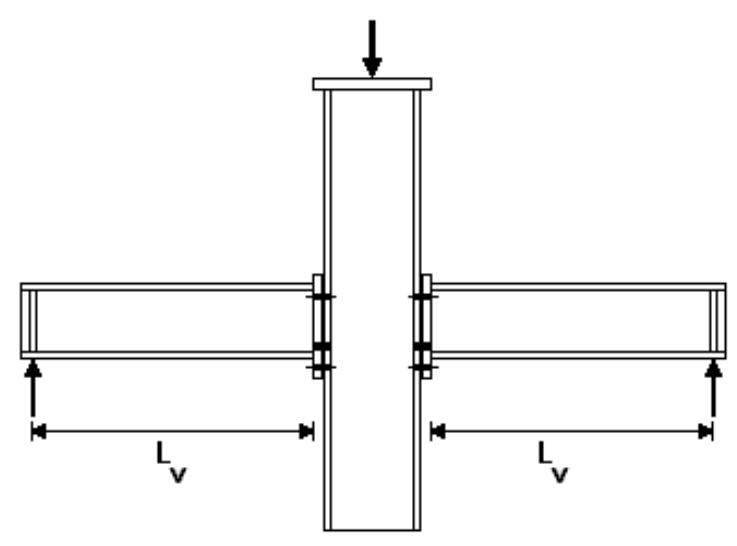

Figura 4.2 - Representação esquemática dos protótipos de ensaio. Protótipo cruciforme

Outra vantagem explícita da utilização de protótipos cruciformes é a possibilidade de aplicação do carregamento através de um único atuador hidráulico, posicionado sobre o pilar central, tendo-se dois apoios posicionados sob as extremidades das vigas.

Note-se que, desta maneira, a aplicação do carregamento nas extremidades das vigas se dá de baixo para cima, razão pela qual a ligação está invertida, simulando então uma viga em balanço.

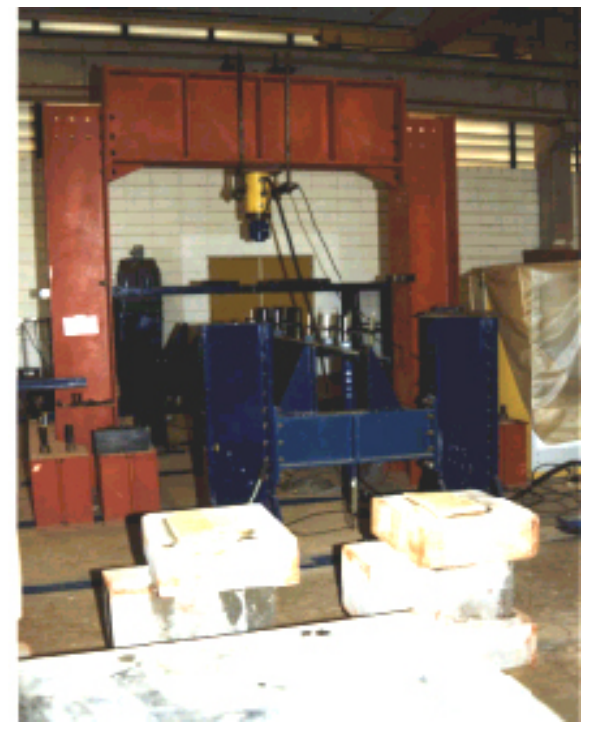

Figura 4.3 - Pórtico de reação Fonte: RIBEIRO (1998)

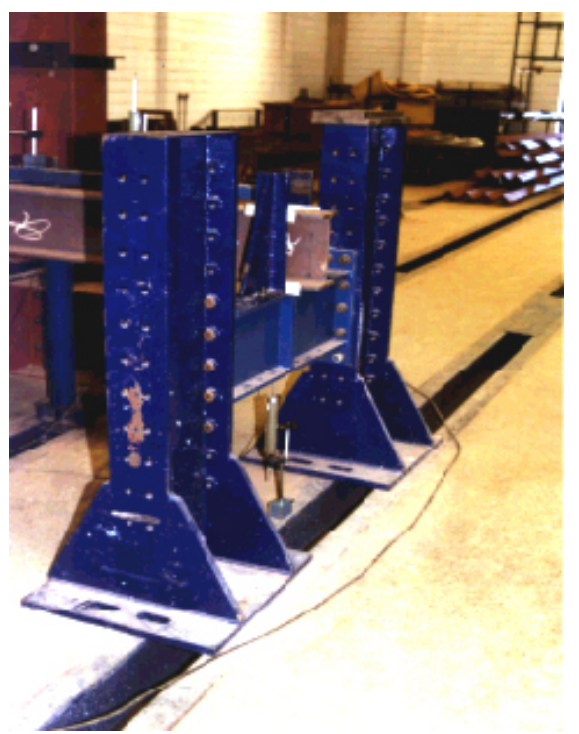

Figura 4.4 - Detalhe dos apoios Fonte: RIBEIRO (1998) 


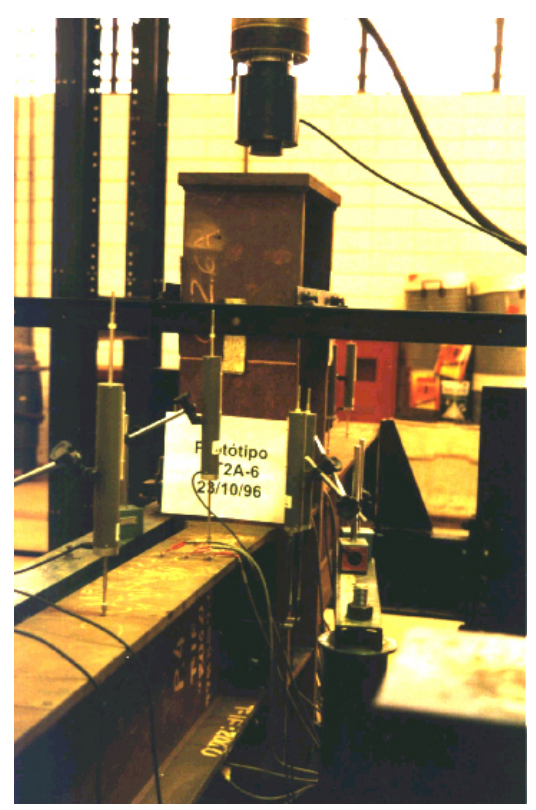

Figura 4.5 - Visão geral do protótipo Fonte: RIBEIRO (1998)

Outra observação é a utilização, no pilar central, de enrijecedores soldados, posicionados nas alturas das mesas tracionada e comprimida.

Escolhidos os protótipos, cuja geometria e características de material serão representadas, faz-se a montagem dos modelos numéricos, cuja descrição é apresentada a seguir.

De forma ilustrativa, a figura 4.3 apresenta o pórtico de reação utilizado para os ensaios, a figura 4.4 um detalhe dos apoios das vigas e, na figura 4.5, tem-se uma visão geral da montagem dos protótipos utilizados por RIBEIRO (1998).

\subsection{PREPARAÇÃO DOS MODELOS NUMÉRICOS}

A montagem dos modelos numéricos, basicamente, consiste de algumas fases distintas que podem ser itemizadas da seguinte forma:

i. Montagem da geometria do modelo;

ii. Escolha dos tipos de elementos finitos a serem utilizados;

iii. Definição das características dos materiais envolvidos; 
iv. Preparação da malha de elementos finitos na geometria;

v. Definição das condições de contorno no modelo; e

vi. Aplicação do carregamento.

Apesar de distintas, todas as fases acima citadas se correlacionam, à medida que interferem umas nas outras. Pode-se citar como exemplo, neste caso, a grande importância que existe na montagem da geometria para a preparação da malha de elementos finitos, onde uma boa escolha do primeiro pode facilitar a execução do segundo.

\subsubsection{Considerações gerais sobre o modelo}

As partes que compõem a ligação estudada são, de maneira geral, viga, chapa de topo soldada à viga, pilar e parafusos, estes utilizados juntamente com porcas para aperto.

Para o estudo da ligação e seu comportamento em particular não é necessária a sua colocação interna a uma estrutura global. Desta maneira, constituindo uma simplificação no modelo, exclui-se a representação do pilar como um todo, a não ser pela modelagem da sua mesa (flange) aonde está conectada a chapa de topo, juntamente com a viga. A compatibilização do modelo numérico, devido a essa simplificação, com o protótipo experimental será mostrada adiante, ressaltando-se que a análise numérica considerou a flexibilidade da mesa do pilar.

Visando uma otimização do modelo numérico, também se aproveitou a simetria proveniente da geometria, segundo o plano médio da alma da viga. Alguns detalhes a respeito do comentado acima serão apresentados adiante, quando mais conveniente. 


\subsubsection{Características geométricas dos modelos numéricos}

Visando, principalmente, possibilitar a comparação entre resultados numéricos e experimentais, tomou-se como base para os modelos numéricos a geometria dos protótipos referidos no item 4.2.

Assim, é necessário se definir a geometria da viga, da chapa de topo, dos parafusos e da mesa do pilar, para cada modelo.

Todos os modelos analisados representaram a série 1 dos protótipos ensaiados por RIBEIRO (1998), cujas dimensões das peças componentes são detalhadas a seguir.

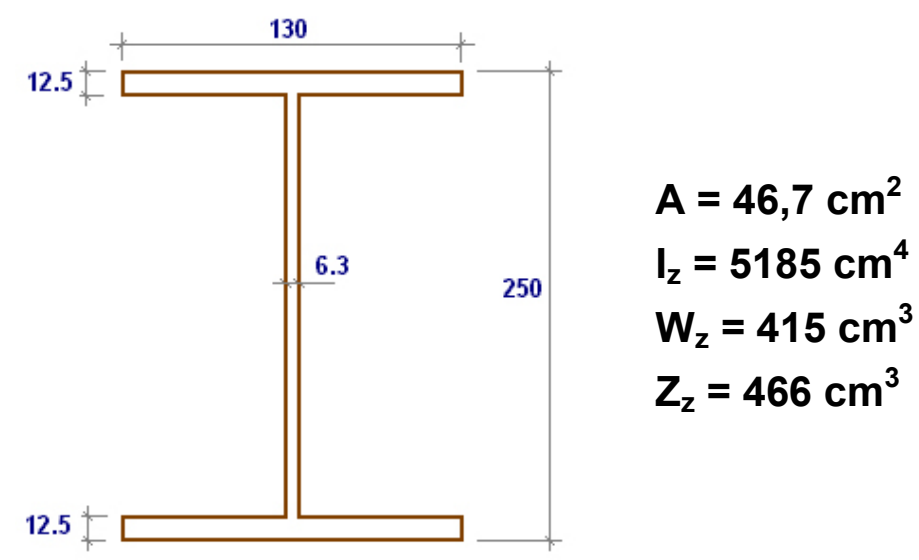

Figura 4.6 - Dimensões da seção transversal da viga Perfil VS 250×37

A figura 4.6 ilustra a seção transversal da viga, com suas respectivas dimensões. Todos os protótipos representados utilizaram vigas tipo VS 250x37. Para os modelos numéricos o vão considerado para a viga em balanço foi $L_{v}=1,50 \mathrm{~m}$, embora haja algumas pequenas variações de vão para os protótipos, observadas na tabela IV.I. Considerando que essa variação é muito pequena, levando em conta as dimensões do protótipo, adotou-se um comprimento único para os modelos numéricos fazendo-se as devidas correções para o momento fletor na ligação.

As espessuras das chapas de topo para cada modelo correspondente estão apresentadas na tabela IV.II. Como a geometria da 
chapa de topo depende, basicamente, do diâmetro do parafusos utilizado na ligação, as dimensões gerais estão ilustradas na figura 4.7 e são representadas duas chapas de topo para os parafusos de $16 \mathrm{~mm}$ e $19 \mathrm{~mm}$, esquematizadas respectivamente nas figuras $4.8 \mathrm{a}$ e $4.8 \mathrm{~b}$.
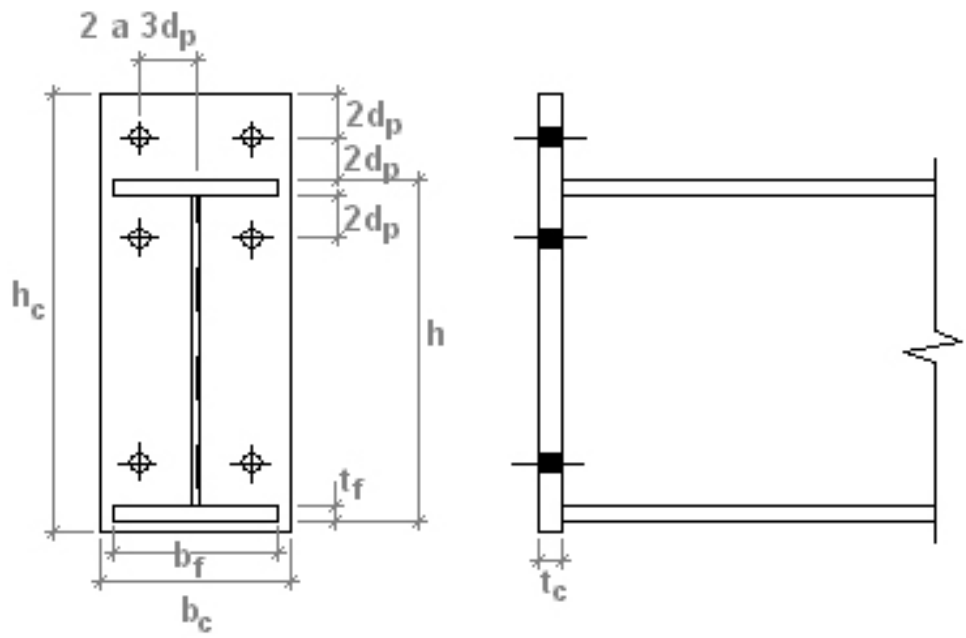

Figura 4.7 - Geometria esquemática das chapas de topo

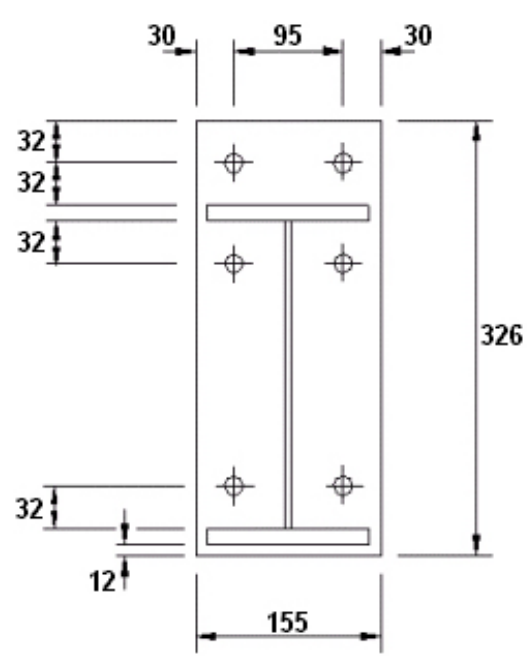

(a) $\phi_{\mathrm{p}}=16 \mathrm{~mm}$

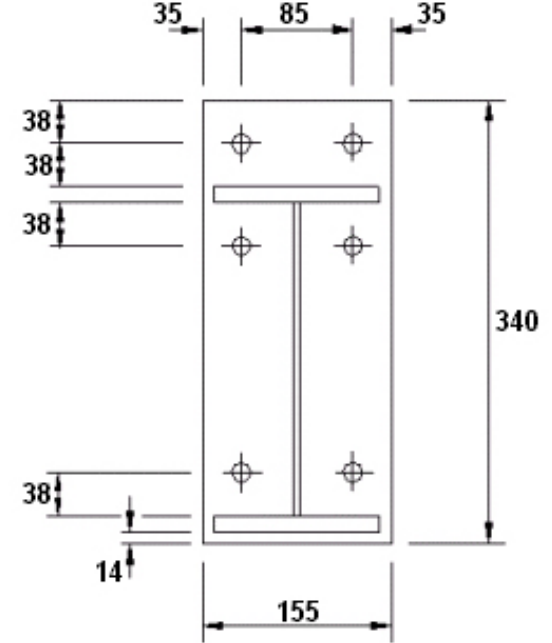

(b) $\phi_{\mathrm{p}}=19 \mathrm{~mm}$

Figura 4.8 - Gabaritos das chapas de topo Dimensões em mm

Tabela IV.II - Espessuras das chapas de topo

\begin{tabular}{|c|c|c|c|c|c|c|}
\hline Protótipo & CT1A-1 & CT1A-2 & CT1A-4 & CT1B-2 & CT1B-4 & CT1B-6 \\
\hline $\left.\mathbf{t}_{\mathbf{c}} \mathbf{( m m}\right)$ & 31,5 & 25,0 & 22,4 & 25,0 & 22,4 & 19,0 \\
\hline
\end{tabular}


Os protótipos experimentais da série 1 utilizaram como apoio da ligação um pilar CVS 350x105, cujas dimensões pertinentes estão apresentadas na figura 4.9. Na montagem dos modelos numéricos, como já mencionado anteriormente, representa-se apenas a mesa do pilar.

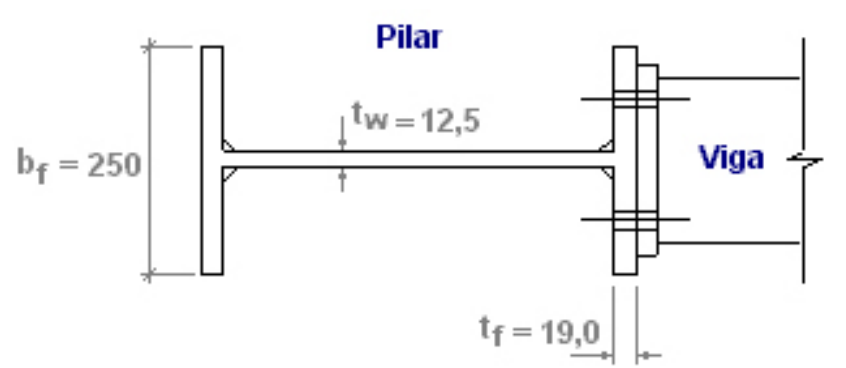

Figura 4.9 - Dimensões do pilar (mm)

A ligação dos protótipos foi feita utilizando-se parafusos de alta resistência, ASTM-A325, cujas dimensões segundo as especificações estão apresentadas na tabela IV.III e podem ser visualizadas, esquematicamente, na figura 4.10 .

Tabela IV.III - Dimensões dos parafusos e porcas (mm)

\begin{tabular}{|c|c|c|c|c|c|c|}
\hline \multirow[b]{2}{*}{$\phi_{p}$} & \multicolumn{4}{|c|}{ Parafuso } & \multicolumn{2}{|c|}{ Porca } \\
\hline & $F$ & $\mathbf{H}_{\mathrm{b}}$ & Protótipo & $L_{b}$ & $\mathbf{W}$ & $H_{n}$ \\
\hline \multirow{3}{*}{16} & \multirow{3}{*}{27,0} & \multirow{3}{*}{10,0} & CT1A-1 & 50,5 & \multirow{3}{*}{27,0} & \multirow{3}{*}{16,0} \\
\hline & & & CT1A-2 & 44,0 & & \\
\hline & & & CT1A-4 & 41,4 & & \\
\hline \multirow{3}{*}{19} & \multirow{3}{*}{31,75} & \multirow{3}{*}{12,0} & CT1B-2 & 44,0 & \multirow{3}{*}{31,75} & \multirow{3}{*}{18,2} \\
\hline & & & CT1B-4 & 41,4 & & \\
\hline & & & CT1B-6 & 38,0 & & \\
\hline
\end{tabular}

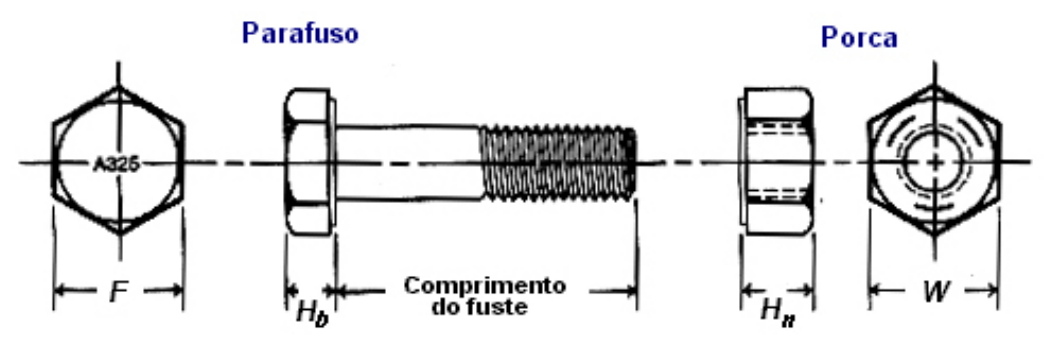

Figura 4.10 - Dimensões padronizadas dos parafusos ASTM-A325 
A simulação do parafuso e da porca foi feita considerando-se o conjunto atuando como um único elemento, sendo o comprimento do fuste do parafuso igual ao somatório das espessuras da chapa de topo e mesa do pilar. As dimensões da cabeça do parafuso e da porca de aperto seguiram as especificações apresentadas na figura 4.11 .

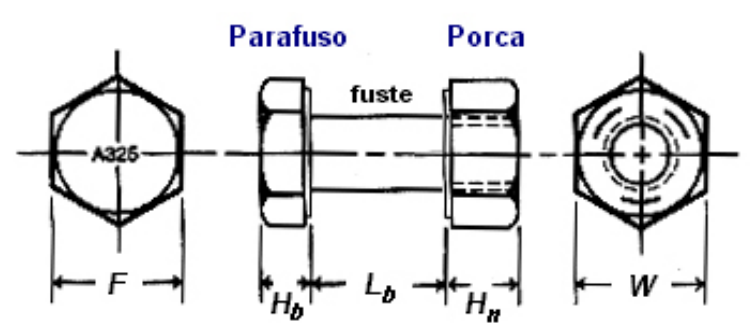

Figura 4.11 - Esquema da simulação do parafuso

\subsubsection{Elementos finitos utilizados}

A escolha dos tipos de elementos finitos utilizados na preparação dos modelos depende, principalmente, das características da geometria e das considerações a serem feitas na representação da ligação.

Além disso, torna-se fundamental uma boa escolha, visto a necessidade de precisão nos resultados, juntamente com a otimização do modelo. Em outras palavras, procura-se uma razão eficiente entre qualidade de resultados e economia computacional, principalmente no que se refere a tempo de processamento.

Desta maneira, e observando as características das ligações, escolheu-se dois tipos de elementos. Um tipo, volumétrico, para a representação da geometria do modelo e outro, de "contato" para a representação das descontinuidades geométricas, característica da ligação. 


\subsubsection{Elemento volumétrico}

A modelagem da malha de elementos finitos para todos os componentes da geometria foi feita com elementos sólidos, volumétricos.

No ANSYS, existe uma grande variedade de elementos, para os mais diversos fins. O escolhido para essa análise foi o elemento finito denominado SOLID45. Uma representação esquemática do elemento está ilustrada na figura 4.12 .

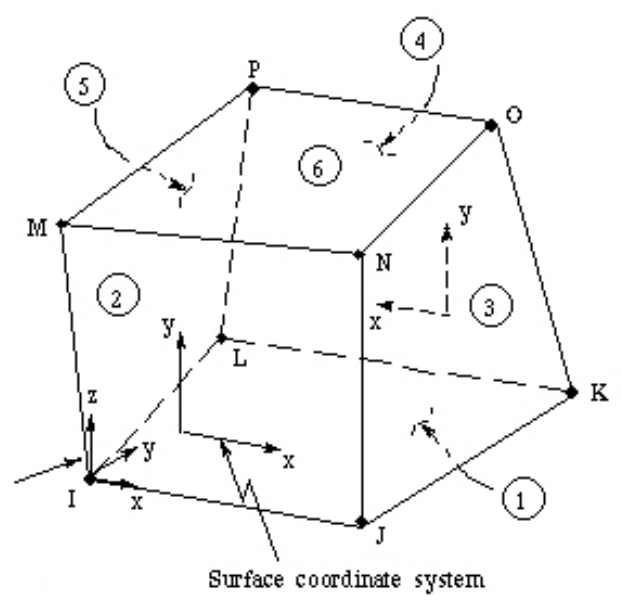

Figura 4.12 - Elemento volumétrico SOLID45 Fonte: ANSYS Help System

Esse elemento possui 8 nós, cada nó com graus de liberdade de translação nas direções $\mathrm{X}, \mathrm{Y}$ e Z. Possui também características de plasticidade, admitindo a utilização do diagrama bi-linear para representação do material utilizado, o que condiz com os objetivos desta análise.

Apesar de existirem elementos finitos mais refinados, com a existência de nós intermediários e maior número de graus de liberdade, optou-se pelo SOLID45 uma vez que a geometria do modelo numérico é regular - o que viabiliza a utilização de elementos sem nós intermediários e os resultados de rotações podem ser calculados através dos resultados

\footnotetext{
1 ANSYS Help System Release 5.5. Elements Manual. Elements 4.45 SOLID45 3-D Structural Solid.
} 
fornecidos pelas translações dos nós, não havendo necessidade de graus de liberdade que representem as rotações nos elementos.

Outra observação importante diz respeito à utilização do elemento volumétrico em detrimento do elemento de casca. Apesar dos elementos de casca produzirem uma boa representação do modelo com uma quantidade menor de elementos - o que produziria uma economia no tempo de processamento - a sua representatividade quanto à simulação da espessura da chapa de topo e da mesa do pilar fica comprometida, principalmente pela consideração dos parafusos. Uma vez que os parafusos são protendidos, como será apresentado adiante, é necessário considerar a distribuição de tensões ao longo da espessura da chapa de topo, o que não é possível com a utilização de elementos de casca.

\subsubsection{Elemento de contato}

A ligação viga-coluna, responsável pela transmissão dos momentos fletores e forças cortantes da viga para o pilar, possui um comportamento previsível em termos da identificação das regiões em que há compressão da chapa de topo contra a mesa do pilar (região comprimida da viga) e de regiões em que há um descolamento da chapa de topo com relação ao pilar (região tracionada). Nessas regiões, devido às forças de tração, a chapa de topo é mantida presa à mesa do pilar através da atuação dos parafusos e porcas de conexão.

Uma das formas de modelar essas regiões, uma vez que não devem haver restrições quanto ao deslocamento da chapa de topo, principalmente na direção das forças de tração e compressão devido ao momento fletor, é a utilização de elementos de contato entre as regiões que literalmente estão em "contato" umas com as outras.

Os elementos finitos de contato estabelecem novos termos na matriz de rigidez fornecendo informações ao processo da análise numérica quanto a pontos ou regiões distintas que deverão gerar pressões quando 
comprimidas umas contra as outras, ou níveis de abertura quando houver separação. Assim, o elemento de contato possui a característica de apresentar rigidez na compressão e nenhuma rigidez na tração.

Para a análise numérica do modelo escolheu-se um elemento de contato denominado, no ANSYS, de CONTAC49, que estabelece a interação entre superfícies. A figura 4.13 ilustra, de forma também esquemática, um elemento finito CONTAC49.

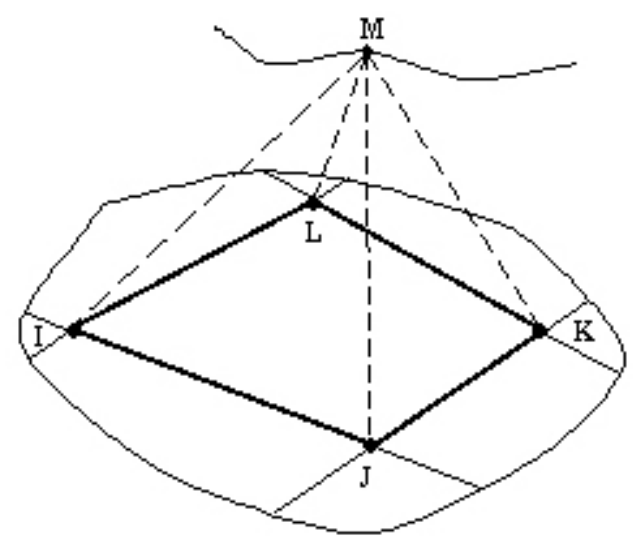

Figura 4.13 - Elemento de contato CONTAC49 Fonte: ANSYS Help System ${ }^{2}$

Na figura 4.13 pode-se ver, representativamente, um elemento de contato unindo o nó $\mathbf{M}$ à superfície $\mathbf{I J K L}$. Definido esse elemento, se o nó $\mathbf{M}$ interagir com a superfície IJKL, forças de contato se desenvolverão.

Tais forças são produzidas através da consideração de rigidezes definidas pelas constantes $\mathbf{K N}$ e KT, que são, respectivamente, a rigidez normal e a rigidez transversal do contato, com unidade de força/comprimento. Tais rigidezes podem ser visualizadas, com certo cuidado, como sendo molas, assim como está representado na figura 4.14.

2 ANSYS Help System Release 5.5. Elements Manual. Elements 4.49 CONTAC49 3-D Point-to-surface Contact. 


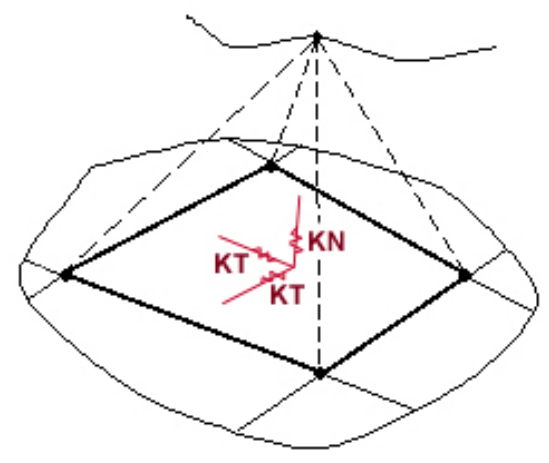

Figura 4.14 - Visualização das rigidezes do contato

A análise aqui proposta desconsiderou qualquer tipo de atrito, visto que também não foram consideradas as folgas nas regiões dos furos, para os parafusos. Desta maneira, adotou-se, após testes de calibragem para essas constantes, um valor de $\mathrm{KN}=1 \times 10^{7} \mathrm{kN} / \mathrm{cm}$ e $\mathrm{KT}=1 \times 10^{-4} \mathrm{kN} / \mathrm{cm}$. Um valor suficiente baixo para KT foi adotado de modo a não permitir a influência desse parâmetro na análise do modelo.

\subsubsection{Características dos materiais}

Foram utilizados, na análise numérica, 4 tipos de materiais, de forma a representar os componentes da ligação.

Dessa forma, utilizou-se do diagrama bi-linear, comentado no item 4.1.1, para a caracterização do comportamento dos materiais da viga, mesa do pilar, chapa de topo e parafusos.

As constantes que definem tal comportamento, também apresentadas no item 4.1.1, para cada modelo e parte da ligação, estão apresentados na tabela IV.IV.

Para possibilitar, novamente, melhores comparações entre os resultados numéricos e experimentais, adotou-se para as constantes tensão de escoamento $\left(\mathbf{f}_{\mathbf{y}}\right)$ e módulo de elasticidade longitudinal $(\mathbf{E})$, valores semelhantes aos obtidos pela caracterização dos materiais realizada por RIBEIRO (1998), para as chapas de topo. 
Para a viga, mesa do pilar e parafusos, adotou-se os valores convencionais para o aço, encontrados na bibliografia consultada.

A escolha do módulo plástico $\left(E_{t}\right)$ também foi feita segundo recomendações da bibliografia consultada que utiliza, normalmente, um valor de $10 \%$ do módulo de elasticidade longitudinal para representar o comportamento plástico do material, não fugindo também do encontrado nas características dos materiais dos protótipos.

\section{Tabela IV.IV - Características dos materiais $f_{y}, E, E_{t}$ em $k N / c^{2}$}

\begin{tabular}{|c|c|c|c|c|c|c|c|c|c|}
\hline \multirow{2}{*}{ Protótipos } & \multicolumn{4}{|c|}{ Viga e mesa do pilar } & \multicolumn{3}{|c|}{ Chapa de topo } & \multicolumn{3}{c|}{ Parafuso e porca } \\
\cline { 2 - 10 } & $\mathbf{f}_{\mathbf{y}}$ & $\mathbf{E}$ & $\mathbf{E}_{\mathbf{t}}$ & $\mathbf{f}_{\mathbf{y}}$ & $\mathbf{E}$ & $\mathbf{E}_{\mathbf{t}}$ & $\mathbf{f}_{\mathbf{y}}$ & $\mathbf{E}$ & $\mathbf{E}_{\mathbf{t}}$ \\
\hline CT1A-1 & 25,0 & 20500 & 2050 & 26,0 & 20030 & 2003 & 63,5 & 20500 & 2050 \\
\hline CT1A-2 & 25,0 & 20500 & 2050 & 26,0 & 20090 & 2009 & 63,5 & 20500 & 2050 \\
\hline CT1A-4 & 25,0 & 20500 & 2050 & 28,8 & 20320 & 2032 & 63,5 & 20500 & 2050 \\
\hline CT1B-2 & 25,0 & 20500 & 2050 & 26,0 & 20090 & 2009 & 63,5 & 20500 & 2050 \\
\hline CT1B-4 & 25,0 & 20500 & 2050 & 28,8 & 20320 & 2032 & 63,5 & 20500 & 2050 \\
\hline CT1B-6 & 25,0 & 20500 & 2050 & 27,6 & 20560 & 2056 & 63,5 & 20500 & 2050 \\
\hline
\end{tabular}

Um quarto tipo de material foi utilizado para representar os elementos de contato. Essa consideração deve ser feita de modo a atender as características do elemento finito escolhido para representar a interação entre os componentes da ligação. Segundo orientação do ANSYS, pode-se utilizar um material linear, considerando como módulo de elasticidade longitudinal um valor semelhante ao dos outros materiais envolvidos. Assim, adotou-se para os elementos de contato um material com $\mathbf{E}=\mathbf{2 0 5 0 0}$ $\mathrm{kN} / \mathrm{cm}^{2}$.

A conveniência da escolha de diagramas simplificados, à exceção de pequenas diferenças com as características reais dos materiais, se dá em estabelecer parâmetros de comparação que possam ser estudados, posteriormente, sem a interferência das características do material, que está de certa forma padronizado. 


\subsubsection{Definição da malha de elementos finitos}

A definição da malha de elementos finitos é parte essencial da análise, na qual a geometria é moldada com os elementos finitos previamente escolhidos.

Neste item serão apresentados alguns detalhes das malhas geradas para os componentes da ligação e referentes aos elementos de contato.

\subsubsection{Viga e chapa de topo}

A malha de elementos finitos que compõe a viga e a chapa de topo está apresentada na figura 4.15. Os nós de intersecção entre a viga e a chapa de topo pertencem aos dois componentes, visto que a chapa de topo é soldada à viga, formando um bloco único.

Para a análise, como já mencionado, utilizou-se do comprimento total do vão dos protótipos.

Para facilitar a descrição dos modelos, bem como a análise dos resultados da análise numérica nos próximos capítulos, serão feitas referências aos modelos numéricos com a mesma denominação dada por RIBEIRO (1998) aos protótipos experimentais. Assim, ao se fazer referência ao modelo numérico CT1A-1, está-se representando o protótipo de mesmo nome.

Como o intuito desta descrição é mostrar a configuração da malha de elementos finitos, omitiu-se as dimensões do modelo nas figuras, as quais estão de acordo com a geometria dos protótipos descritos no item 4.2.

Como já comentado anteriormente, utilizou-se da simetria do modelo com relação ao eixo da viga (plano $X-Y$ ). 


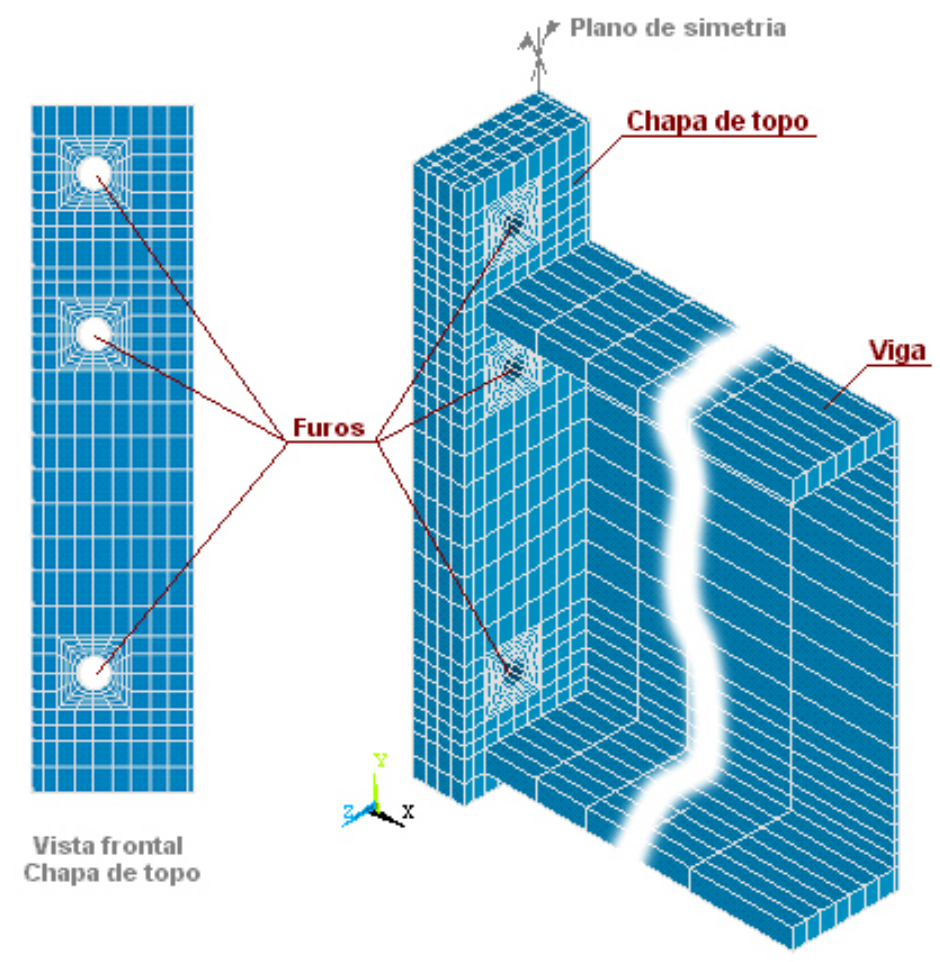

Figura 4.15 - Malha de elementos finitos para a viga e chapa de topo Modelo CT1A-1

Na figura 4.16 apresenta-se um detalhe do furo na chapa de topo. Como não foram consideradas as folgas, previstas para a montagem, o diâmetro dos furos é igual ao diâmetro dos parafusos considerados.

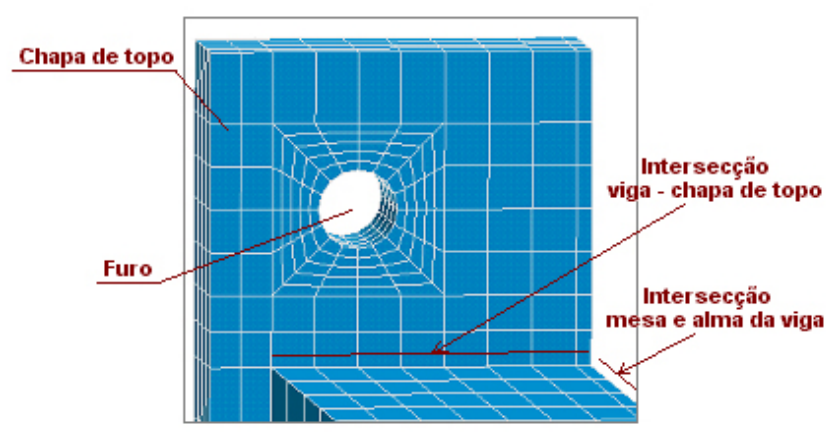

Figura 4.16 - Detalhe do furo e malha nas intersecções Modelo CT1A-1

A figura 4.16 também detalha a distribuição do tamanho dos elementos que formam a mesa da viga. Na formação da malha, tomou-se o cuidado de não provocar mudanças muito bruscas no tamanho dos 
elementos, principalmente próximo às intersecções entre as mesas e a alma, visto a diferença de espessura entre as partes da viga.

\subsubsection{Mesa do pilar}

Para os modelos, o pilar não foi representado por inteiro, participando da análise como apoio da ligação, onde se fará o contato com a chapa de topo.

Desta maneira, simulou-se apenas a mesa do pilar, levando-se em conta a sua espessura e largura. Esta consideração, juntamente com o tipo de modelagem feita nos parafusos, permitiu à análise a inclusão da contribuição da flexibilidade da mesa do pilar no comportamento da ligação.

Nos modelos, a altura da mesa do pilar foi estendida, para ambos os lados, além da altura da chapa de topo, como apresentado na figura 4.17. Detalhes sobre a consideração do apoio e suas vinculações serão abordados no item referente às condições de contorno e carregamento.

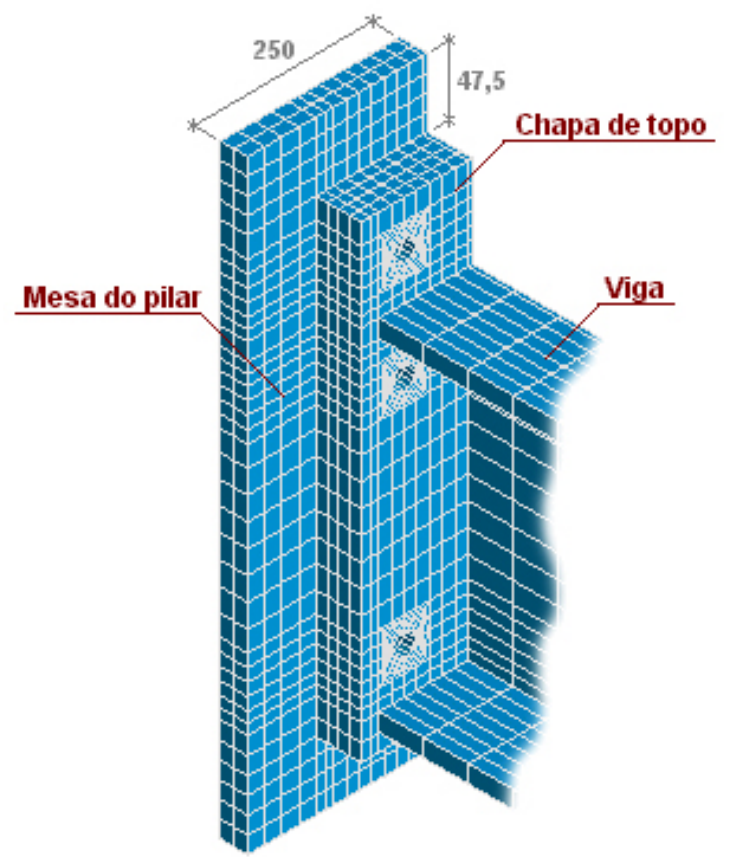

Figura 4.17 - Malha da mesa do pilar Modelo CT1A-1 
Seguindo a configuração da chapa de topo, a mesa do pilar também possui os furos correspondentes, na mesma posição.

\subsubsection{Parafusos}

A análise numérica, com base na geometria esquematizada na figura 4.11, considerou os parafusos e porcas como sendo elementos únicos. Essa consideração é possível devido à natureza do carregamento que se pretende aplicar e ao comportamento do conjunto parafuso/porca, o qual será analisado nos próximos capítulos.

Considerando os dados expostos na tabela IV.III, para cada modelo tem-se um parafuso com comprimento específico de fuste. De modo geral, a malha do conjunto parafuso/porca pode ser visualizada na figura 4.18.
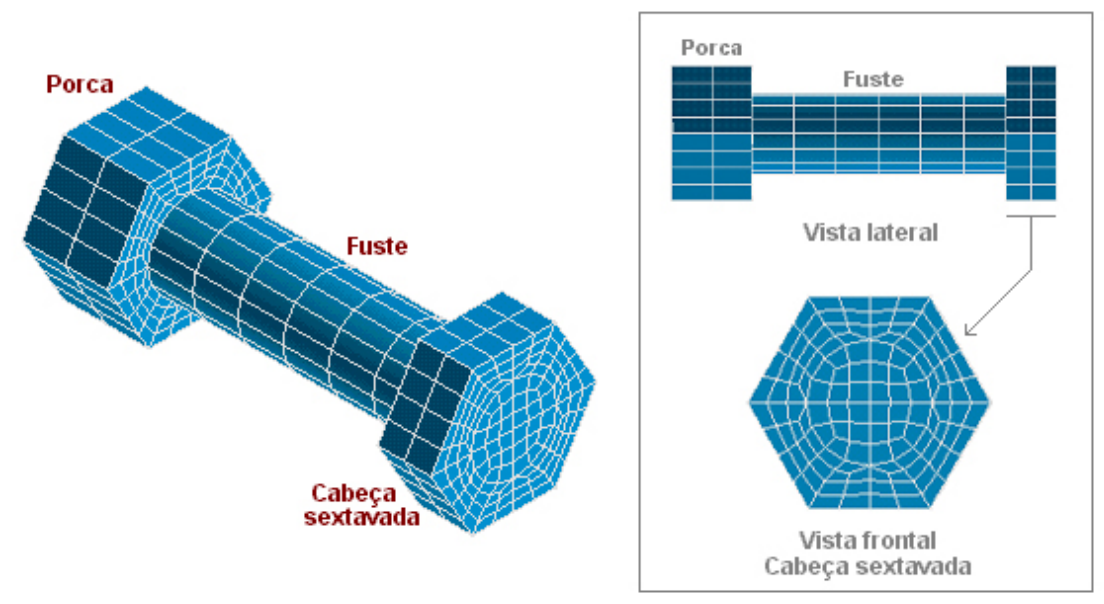

Figura 4.18 - Malha do conjunto parafuso/porca Modelo CT1A-1

\subsubsection{Elementos de contato}

Os elementos de contato foram colocados para representar todas as possíveis interações entre os componentes da ligação, representados no 
modelo numérico. Pode-se resumir, então, os seguintes pares de contato entre superfícies.

1. contato entre a superfície posterior da chapa de topo e a superfície anterior do apoio;

2. contato entre a superfície posterior da cabeça do parafuso com a superfície anterior da chapa de topo;

3. contato entre a superfície anterior da porca com a superfície posterior da mesa do pilar;

4. contato entre a superfície do fuste do parafuso com as superfícies exteriores dos furos na chapa de topo e mesa do pilar.

Seguindo a numeração apresentada nos itens acima, a figura 4.19 apresenta a localização das superfícies, numa vista lateral do modelo.

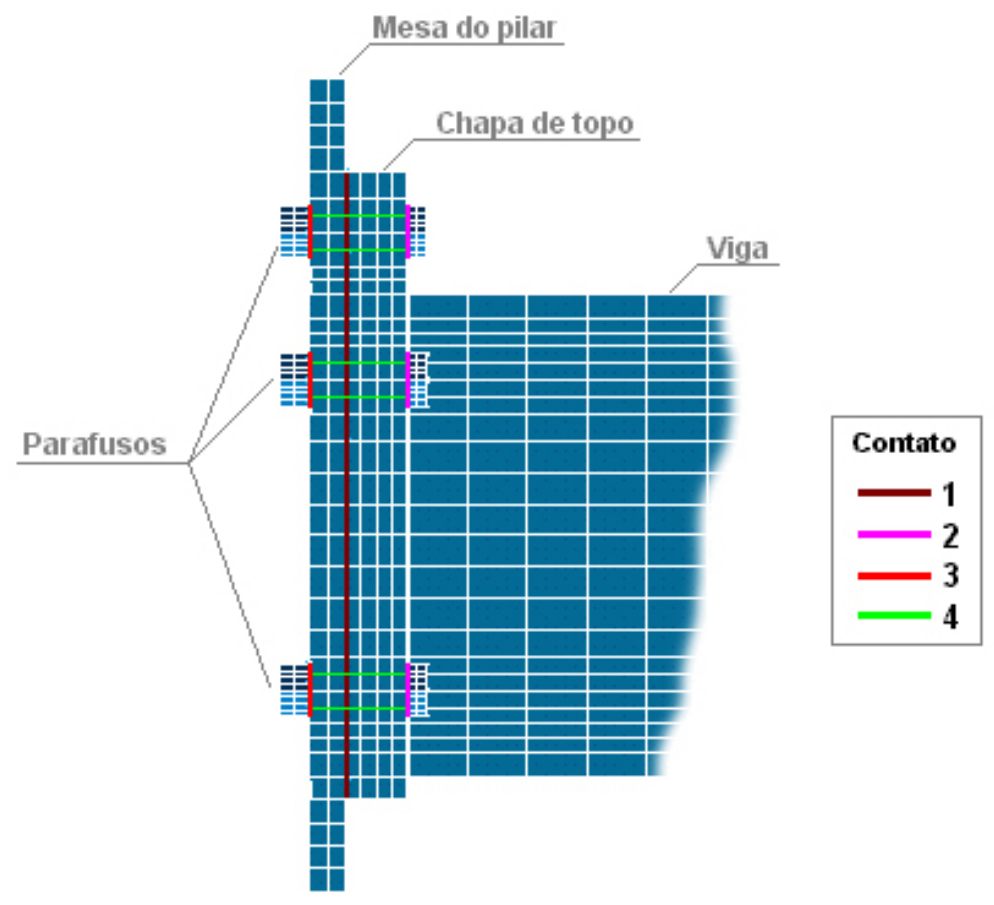

Figura 4.19 - Posicionamento dos elementos de contato Modelo CT1A-1 
Convém salientar que, apesar de terem sido apresentadas as características geométricas do modelo $\mathbf{C T 1 A - 1}$ na figuras acima, as considerações feitas valem para todos os modelos numéricos.

\subsubsection{Condições de contorno}

Para a simulação do apoio da ligação utilizou-se a representação da mesa do pilar, na qual está conectada a chapa de topo e a viga, por meio dos parafusos.

Como, na análise, inclui-se a contribuição da flexibilidade do apoio da ligação, é necessário representar, na mesa do pilar, as regiões enrijecidas, restringindo o seu deslocamento.

Desta maneira, tem-se que considerar, no apoio, a presença da alma do pilar e dos enrijecedores utilizados nos protótipos de RIBEIRO (1998). Identificadas essas regiões, os nós a elas pertencentes são impedidos de transladar nas três direções. Dessa forma, substitui-se a alma e os enrijecedores por vínculos, cuja configuração pode ser visualizada na figura 4.20 .

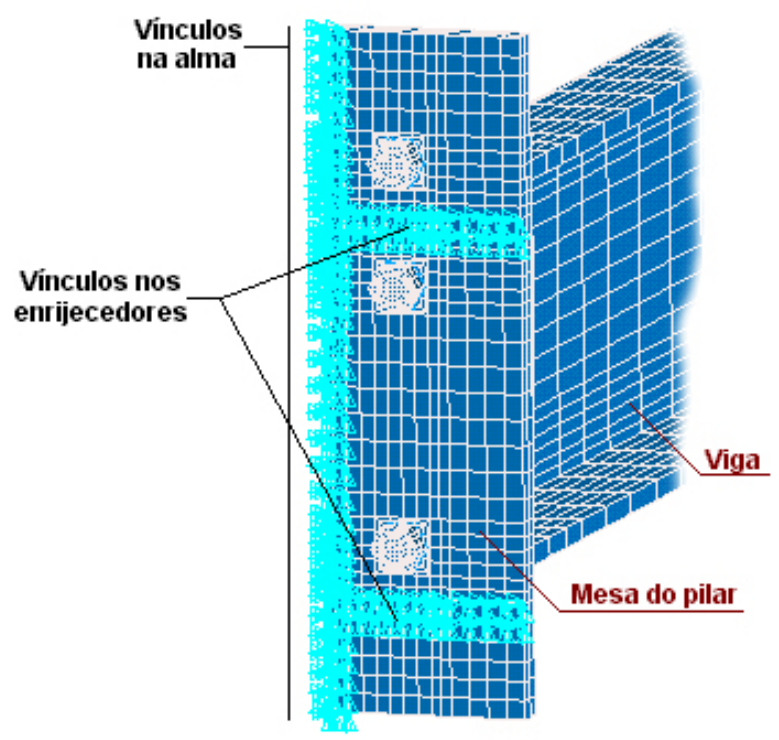

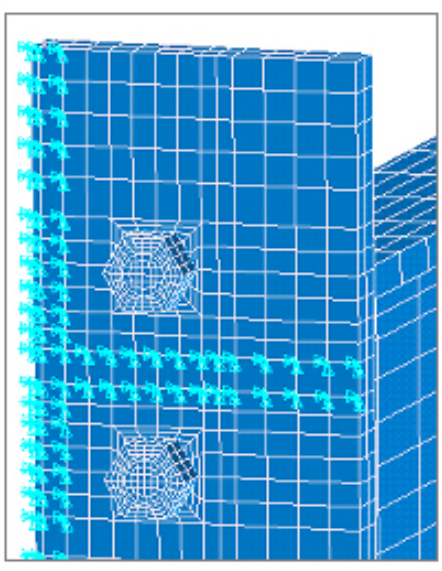

Detalhe do posicionamento

Figura 4.20 - Posicionamento dos vínculos dos enrijecedores e alma do pilar - Modelo CT1A-1 
Visto as características da montagem dos protótipos, pela utilização da configuração cruciforme (item 4.2), o uso dessas restrições é admissível uma vez que o pilar central do protótipo não se desloca horizontalmente.

Os enrijecedores, no apoio dos protótipos, foram posicionados na altura das mesas - superior e inferior - da viga. No modelo numérico são considerados os nós correspondentes a essas posições.

Outra vinculação feita nos modelos foi o impedimento do deslocamento horizontal, segundo a direção transversal da viga, no plano médio de sua alma, para considerar a simetria do modelo.

É importante também observar que a viga e a chapa de topo não possuem restrições quanto ao deslocamento. Tais restrições serão dadas pelo contato com os parafusos e com a mesa do pilar, visto a natureza dos carregamentos, que serão mostrados no próximo item.

\subsubsection{Carregamento}

Existem duas fases de carregamento para o modelo, que são:

i. protensão dos parafusos; e

ii. carregamento da viga.

Na primeira fase é feita a protensão, simulando o aperto dado aos parafusos dos protótipos experimentais. Devido às características da análise e à configuração adotada para os parafusos e vínculos do apoio, a protensão é feita através de um carregamento auxiliar, aplicando-se uma variação negativa de temperatura nos elementos que compõem o fuste dos parafusos.

Como os parafusos, pela aplicação desse carregamento, tendem a encurtar, sendo impedidos pela chapa de topo e pela mesa do pilar, simula- 
se o comportamento devido à protensão, ou seja, tensões positivas no fuste e aparecimento de pressões de contato entre a chapa de topo e a mesa do pilar.

O valor da variação de temperatura a ser empregada foi escolhido de maneira a resultar uma força de protensão equivalente a $85 \mathbf{~ k N}$ para os parafusos de $16 \mathrm{~mm}$ de diâmetro, e $125 \mathrm{kN}$ para os de $19 \mathrm{~mm}$. As forças de protensão são recomendadas pela NBR-8800 (1986) e a variação de temperatura adotada para cada parafuso está apresentada na tabela IV.V.

Tabela IV.V - Variação de temperatura e força de protensão

\begin{tabular}{|c|c|c|}
\hline $\begin{array}{c}\text { Diâmetro do } \\
\text { parafuso }\end{array}$ & $\begin{array}{c}\text { Força de } \\
\text { protensão }\end{array}$ & $\begin{array}{c}\text { Variação de } \\
\text { temperatura }\end{array}$ \\
\hline $16 \mathrm{~mm}$ & $85 \mathrm{kN}$ & $-290^{\circ} \mathrm{C}$ \\
\hline $19 \mathrm{~mm}$ & $125 \mathrm{kN}$ & $-320^{\circ} \mathrm{C}$ \\
\hline
\end{tabular}

É necessário observar, neste ponto, que a protensão simulada nos modelos oferece as restrições necessárias à viga e à chapa de topo, através dos elementos de contato.

Terminada a fase de protensão, inicia-se o carregamento da viga, através da aplicação de forças na extremidade livre. Nessa segunda fase, o carregamento é aplicado verticalmente, de cima para baixo, e distribuído ao longo da largura da mesa superior.

Seu valor foi escolhido de modo a gerar na ligação um momento fletor total $30 \%$ superior ao momento de plastificação teórico da seção transversal, de modo a se acompanhar a plastificação dos elementos que compõem a ligação.

O momento de plastificação teórico é calculado por

$$
M_{p}=Z_{z} f_{y}
$$

Utilizando os dados de material e da geometria da seção transversal tem-se 


$$
M_{p}=466 \times 25=11650 \mathrm{kN} . \mathrm{cm}
$$

Desta maneira, aplicou-se um carregamento total de $100 \mathrm{kN}$ na extremidade livre para que o momento total na ligação - obtido na intersecção da viga com a chapa de topo - fosse igual à $M_{t}=15000 \mathrm{kN} . \mathrm{cm}$, ou seja, aproximadamente $1,3 \mathrm{M}_{\mathrm{p}}$. A distribuição das forças na extremidade está detalhada na figura 4.21 .

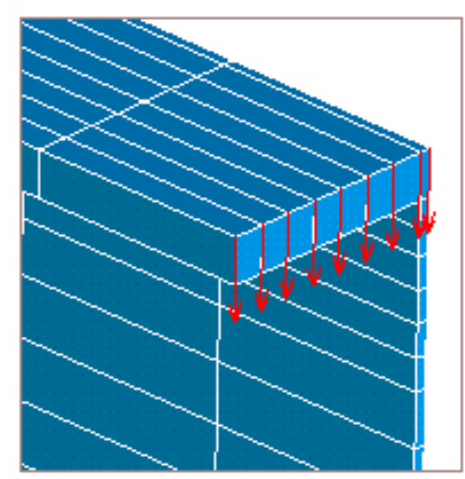

Figura 4.21 - Carregamento na extremidade livre da viga

Convém lembrar que, por se estar utilizando a simetria da viga segundo seu eixo longitudinal, o carregamento aplicado no modelo também é simétrico, ou seja, metade do mencionado acima. O valor total do carregamento, de $100 \mathbf{~ k N}$, deve ser utilizado apenas para o cálculo do momento aplicado na ligação.
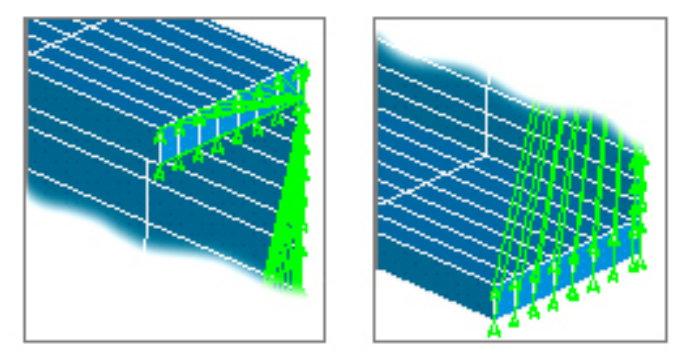

Figura 4.22 - Acoplamento dos nós da extremidade livre da viga

Devido ao tipo de carregamento adotado, uma característica adicional foi a utilização do acoplamento de graus de liberdade nos nós da 
extremidade livre. Visando evitar distorções na mesa superior devido às cargas concentradas, todos os nós da extremidade livre da viga foram acoplados, como ilustrado na figura 4.22, de modo a terem o mesmo deslocamento vertical (UY).

Uma visão geral do modelo CT1A-1 é apresentada na figura 4.23, onde estão representados todos os componentes da ligação.

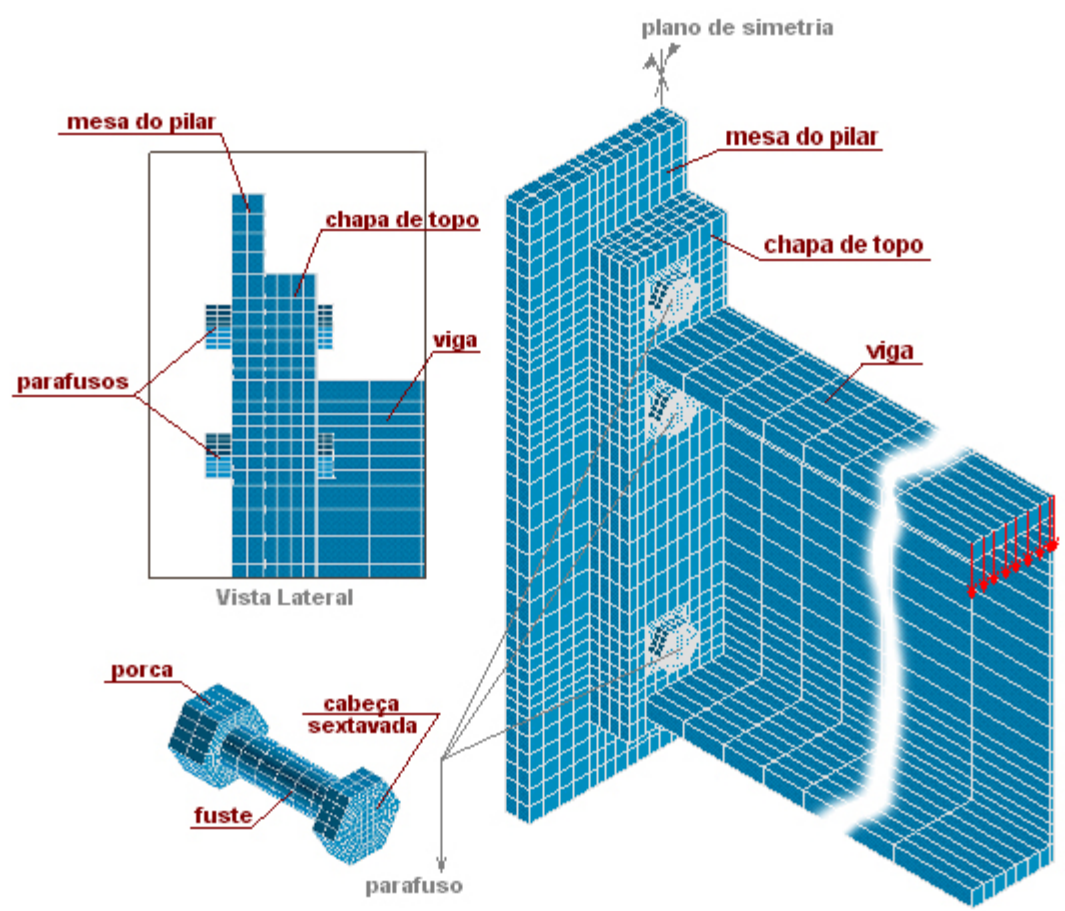

Figura 4.23 - Visão geral do modelo numérico CT1A-1

\subsection{MODELOS PRELIMINARES - APOIO RÍGIDO}

A consideração da flexibilidade da mesa do pilar no estudo da ligação representou uma sofisticação da análise numérica, cujos modelos foram precedidos pela análise de outros onde se desconsidera essa flexibilidade do apoio.

Por razão de futuras comparações na apresentação dos resultados, nos próximos capítulos, os modelos com apoio rígido serão 
brevemente descritos neste item, em particular o referente ao protótipo CT1A-1, que será denominado, deste ponto em diante, de CT1A-1R.

\subsubsection{Geometria e malha de elementos finitos}

A principal diferença entre o modelo com apoio rígido e os modelos considerando a flexibilidade da mesa do pilar está na representação do parafuso. A figura 4.24 apresenta a geometria do parafuso utilizado no modelo CT1A-1R, onde se verifica apenas a representação do fuste e da cabeça do parafuso. A figura 4.25 apresenta um detalhe lateral do mesmo modelo, com os parafusos da região tracionada da viga (mesa superior).

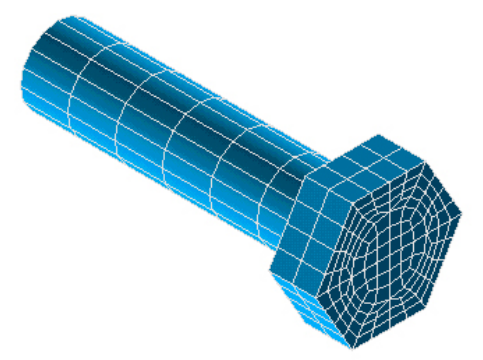

Figura 4.24 - Parafuso do modelo CT1A-1R

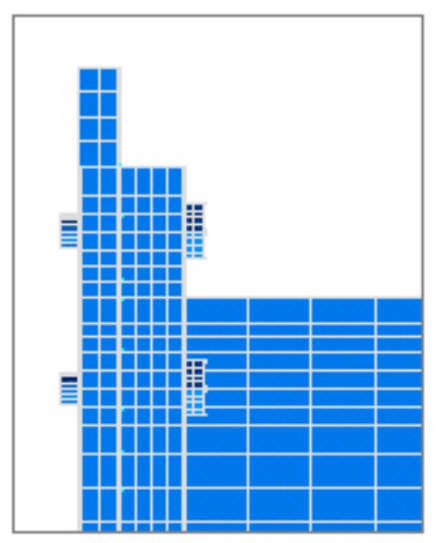

Figura 4.25 - Detalhe da geometria dos parafusos no modelo CT1A-1R

A malha da viga, chapa de topo e mesa do pilar não tiveram modificações. Os elementos de contato também são os mesmos com exceção do contato entre porca e mesa do pilar que não existe, visto a não representação da porca para este modelo. 


\subsubsection{Condições de contorno}

Para a simulação do apoio, neste caso, admite-se a mesa do pilar como completamente rígida, impedindo-se qualquer translação da sua região posterior.

Como já mencionado, os ensaios realizados no trabalho experimental de RIBEIRO (1998) utilizaram enrijecedores nos pilares, na altura das mesas das vigas, o que permitiu a adoção desta simulação para a mesa do pilar, que se não é verdadeira é admissível pelos cuidados tomados na configuração dos protótipos. A figura 4.26 ilustra a vinculação da mesa do pilar.

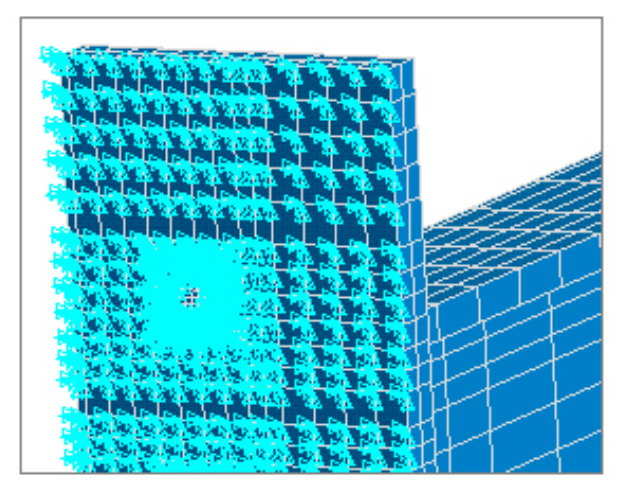

Figura 4.26 - Mesa do pilar como apoio totalmente rígido Detalhe dos vínculos

Para os modelos com apoio rígido também utilizou-se as condições de simetria.

\subsubsection{Carregamento}

Da mesma forma, aplicou-se o carregamento em duas fases, sendo a primeira a protensão dos parafusos. Para o modelo CT1A-1R, esse carregamento foi introduzido por meio da imposição de deslocamento da ponta do fuste do parafuso, que é "puxado" segundo seu eixo longitudinal, 
empurrando a chapa de topo contra a mesa do pilar. Essa direção do deslocamento prescrito pode ser observada na figura 4.27.

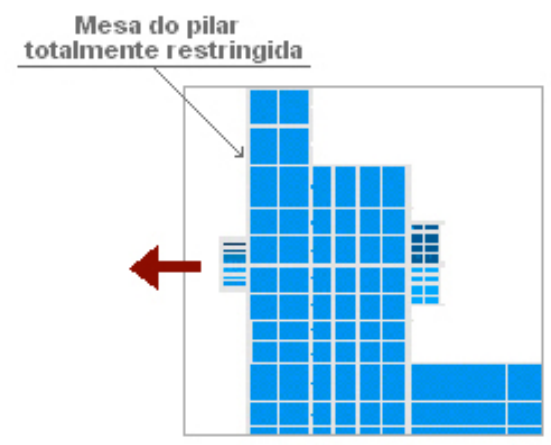

Figura 4.27 - Direção do deslocamento prescrito para a protensão dos parafusos

Como se está considerando o apoio como rígido, ou seja, impedido de transladar em todas as direções, pode-se simular dessa maneira o efeito das porcas, uma vez que o parafuso é restringido na posição deslocada antes de se efetuar o carregamento na viga.

O deslocamento prescrito à ponta do parafuso foi imposto de tal maneira a dar uma força equivalente à de protensão mínima recomendada pela Norma. Para o modelo CT1A-1R, que utiliza parafusos de $16 \mathrm{~mm}$ de diâmetro, aplicou-se um deslocamento negativo (contra a direção positiva do eixo longitudinal da viga) de $0,016 \mathrm{~cm}$, gerando uma força equivalente de aproximadamente $85 \mathrm{kN}$, força esta recomendada para esse diâmetro de parafuso.

O carregamento da viga foi aplicado da mesma forma já descrita no item 4.3.7.

\subsection{PROCESSAMENTO DOS MODELOS NUMÉRICOS}

Em geral, os modelos numéricos foram processados considerandose as não linearidades física e geométrica, como já mencionado nos critérios da análise numérica. 
Para o processamento de alguns modelos, no entanto, escolheu-se tipos diferentes de análise, principalmente para possibilitar a verificação dos resultados, citando-se como exemplo a distribuição de tensões nas mesas e alma e o acompanhamento da plastificação dos elementos finitos.

Assim, especificamente para o modelo CT1A-1R, utilizou-se primeiramente uma análise considerando comportamento linear do material e, posteriormente, utilizando os modelos de materiais descritos no item 4.3.4, com consideração da plastificação. Para o modelo CT1A-1R ainda utilizou-se uma terceira análise com a consideração de grandes deslocamentos.

Nas análises não lineares utilizou-se o controle de deslocamentos para verificação da convergência por meio de norma de energia. Ressalta-se que, com a adoção do diagrama bilinear para a representação do material, o processamento só é interrompido se o critério de convergência citado acima não for atingido após um limite máximo de 200 iterações.

De maneira geral, para todos os modelos, as fases de carregamento juntamente com os incrementos de carga adotados são apresentados na tabela IV.VI.

Tabela IV.VI - Fases do carregamento e incrementos de carga

\begin{tabular}{|l|c|c|c|}
\hline \multirow{2}{*}{ Modelos } & \multicolumn{3}{|c|}{ Total de incrementos para cada fase do carregamento } \\
\cline { 2 - 4 } & Protensão & $\begin{array}{c}\text { Carga de } 70 \mathrm{kN} \\
\text { (antes da plastificação) }\end{array}$ & $\begin{array}{c}\text { Carga total } \\
\mathbf{+ 3 0}=\mathbf{1 0 0} \mathrm{kN}\end{array}$ \\
\hline $\begin{array}{l}\text { CT1A-1 } \\
\text { CT1A-2 }\end{array}$ & & \\
CT1A-4 & 20 & +20 & +30 \\
CT1B-2 & & & \\
CT1B-4 & & & \\
CT1B-6 & & & \\
\hline
\end{tabular}

Os resultados utilizados na verificação da análise numérica, bem como a comparação entre resultados numéricos e experimentais serão abordados nos próximos capítulos. 


\section{Capítulo}

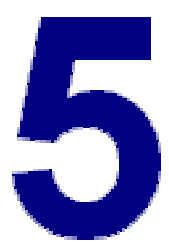

\section{RESULTADOS DA ANÁLISE NUMÉRICA}

Apresenta-se, neste capítulo, os resultados referentes à análise numérica.

Tendo em vista que não é possível nem conveniente apresentar todos os resultados obtidos numericamente, foram escolhidos os mais representativos, de modo a possibilitar a análise das ligações representadas, tendo em vista a verificação do seu comportamento - principalmente sobre o aspecto da rigidez - e dos fatores que o influenciam, em particular observando-se a influência da variação da espessura da chapa de topo e do diâmetro dos parafusos.

Seguindo este enfoque, serão apresentados e discutidos os resultados referentes aos deslocamentos relativos entre chapa de topo e mesa do pilar, rotações e distribuições de tensão na chapa, forças de tração e deformação nos parafusos e as distribuições de tensões na viga.

Para possibilitar a comparação dos resultados entre os modelos numéricos, avaliando-se assim a influência da variação da geometria dos elementos que compõem a ligação, utilizou-se como parâmetro de referência o momento fletor na ligação, calculado como sendo o produto entre a força aplicada na extremidade livre da viga e a distância da extremidade livre à intersecção da viga com a chapa de topo.

Além disso, na apresentação dos resultados dos modelos numéricos serão adicionados, quando conveniente, resultados analíticos provenientes das teorias clássicas de resistência dos materiais e das hipóteses básicas de cálculo convencionalmente adotadas para 0 
dimensionamento das ligações parafusadas com chapa de topo, as quais serão devidamente comentadas.

A titulo de observação, o valor total do carregamento aplicado em cada modelo numérico teve como objetivo representar uma solicitação na ligação superior em $\mathbf{3 0} \%$ o valor do momento teórico de plastificação total da seção transversal, ou seja, $M_{t}=1,3 \cdot M_{p}=15000 \mathrm{kNcm}$, sendo $M_{p}=11650$ kNcm.

Ressalta-se ainda que este capítulo tem como objetivo comentar os resultados obtidos especificamente da análise numérica. Comparações entre os resultados numéricos e os resultados experimentais obtidos por RIBEIRO (1998), juntamente com as considerações sobre as propostas de dimensionamento, serão apresentados no capítulo 6.

\subsection{DISTRIBUIÇÕES DE TENSÕES NA VIGA}

A análise dos resultados de tensões na viga tem como objetivo fundamental comparar os valores obtidos nos modelos numéricos com os valores analíticos esperados, obtidos por meio da teoria de flexão simples, como forma de analisar a confiabilidade dos resultados numéricos.

Adicionalmente, também é possível verificar os mecanismos de plastificação das seções transversais da viga.

Para tanto, serão apresentados os resultados referentes à distribuição de tensões longitudinais (devidas ao momento solicitante) nas mesas e alma e a distribuição das tensões transversais na alma da viga.

\subsubsection{Distribuição de tensões longitudinais}

A distribuição de tensões na mesa superior, na intersecção da viga com a chapa de topo e na seção $H / 2$, conforme ilustra a figura 5.1 , estão apresentadas abaixo e tem como objetivo ilustrar as concentrações de tensão na região da ligação. 


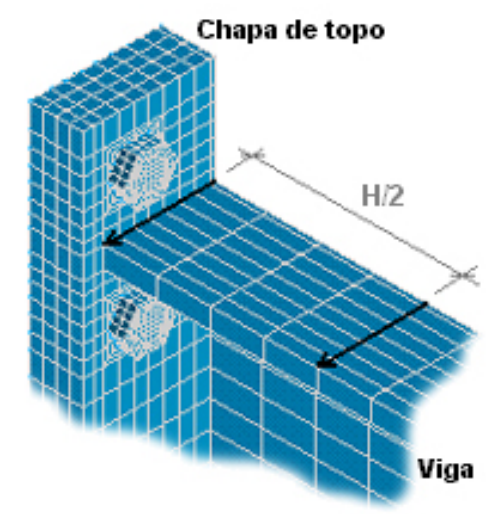

Figura 5.1 - Posição das seções transversais na viga

Os valores obtidos para a seção de intersecção viga/chapa de topo estão apresentados na figura 5.2, e representam a distribuição de tensões longitudinais observadas na mesa superior, tracionada, do modelo CT1A-1 $\left(t_{c h}{ }^{\natural}=31,5 \mathrm{~mm} ; d_{p}^{D}=16 \mathrm{~mm}\right)$.

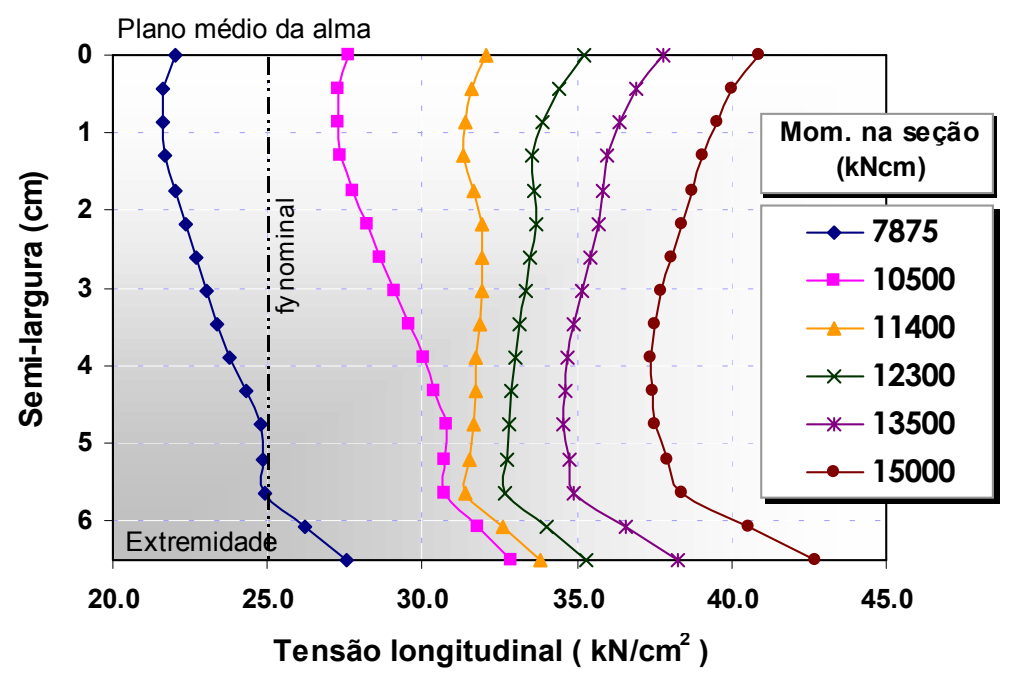

Figura 5.2 - Distribuição de tensões longitudinais Seção de intersecção viga/chapa de topo - modelo CT1A-1

Nota-se, na figura 5.2, valores maiores da tensão longitudinal nas proximidades da extremidade da mesa, conseqüência do enrijecimento causado pela presença da chapa de topo.

${ }^{1}$ O símbolo $\mathbf{t}_{\text {ch }}$ será utilizado para especificar a espessura da chapa de topo no modelo.

${ }^{2} \mathrm{O}$ símbolo $\mathbf{d}_{\mathbf{p}}$ será utilizado para especificar o diâmetro dos parafusos no modelo. 
Comportamento inverso é observado para a distribuição de tensões longitudinais na seção $H / 2$, apresentada na figura 5.3 , com tensões maiores na região do plano médio da alma.

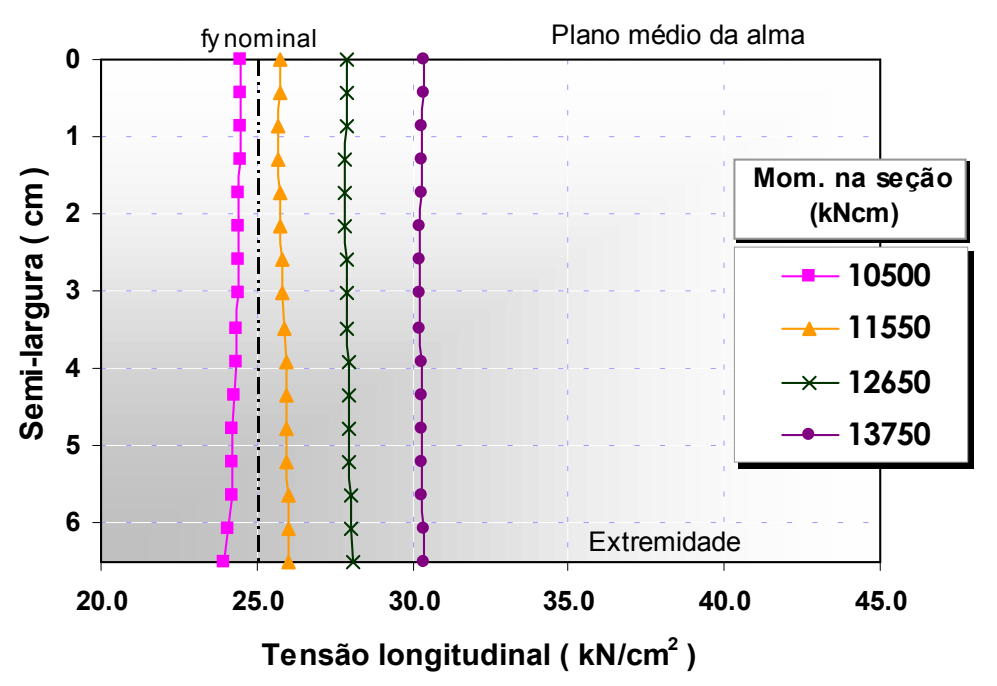

Figura 5.3 - Distribuição de tensões longitudinais Seção H/2 - modelo CT1A-1

Para a seção H/2, a distribuição de tensões longitudinais apresenta um comportamento mais uniforme, tendendo a uma linearização após alcançado o valor de $\mathbf{M}_{\mathbf{p}}$ na seção transversal.

As tensões médias para a seção $\mathrm{H} / 2$, observadas na figura 5.4 , são coincidentes com a tensão teórica calculada pela teoria da flexão simples até o início da plastificação da mesa superior, notando-se claramente a diminuição da sua magnitude a partir do momento fletor igual a $\mathbf{M}=10000$ $\mathbf{k N c m}$, inferior ao valor de $\mathbf{M}_{\mathbf{p}}$.

A partir da seção $H / 2$, a distribuição de tensões longitudinais ao longo da mesa superior torna-se praticamente uniforme para todos os níveis de solicitação. 


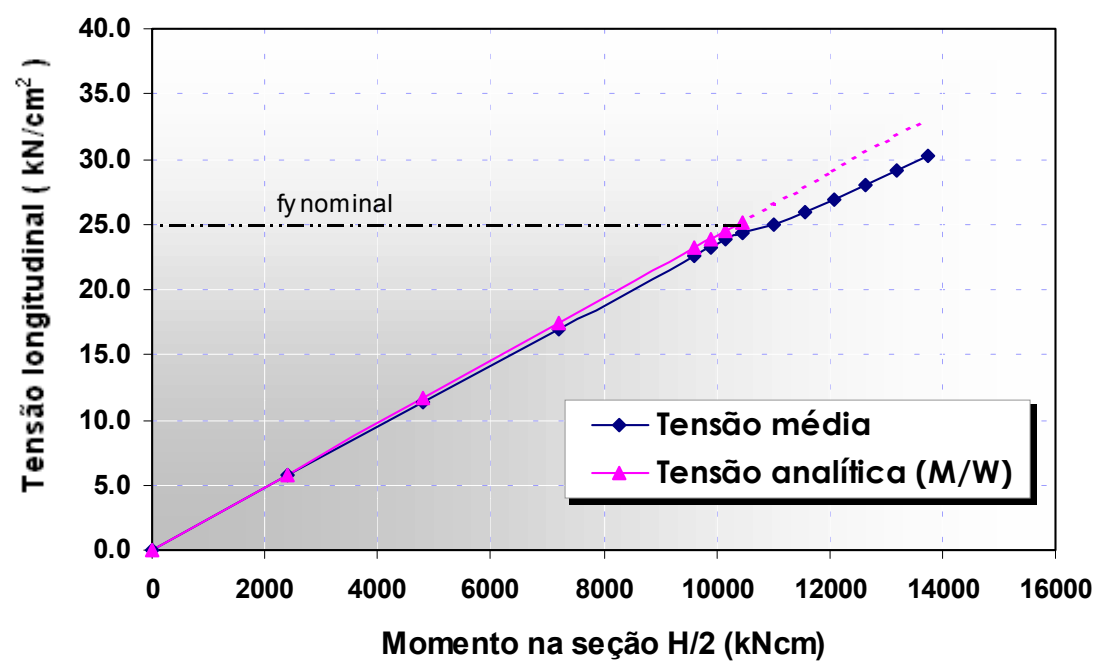

Figura 5.4 - Tensões longitudinais médias na mesa superior Seção H/2 - modelo CT1A-1

Examinando-se a questão da influência da variação da espessura da chapa de topo na distribuição de tensões, toma-se para comparação os modelos CT1A-1 e CT1A-4, os quais possuem chapas com espessura de 31,5 e $22,4 \mathrm{~mm}$, respectivamente.

A figura 5.5 apresenta as tensões médias na mesa superior para a seção $\mathbf{H} / 2$ dos modelos citados acima.

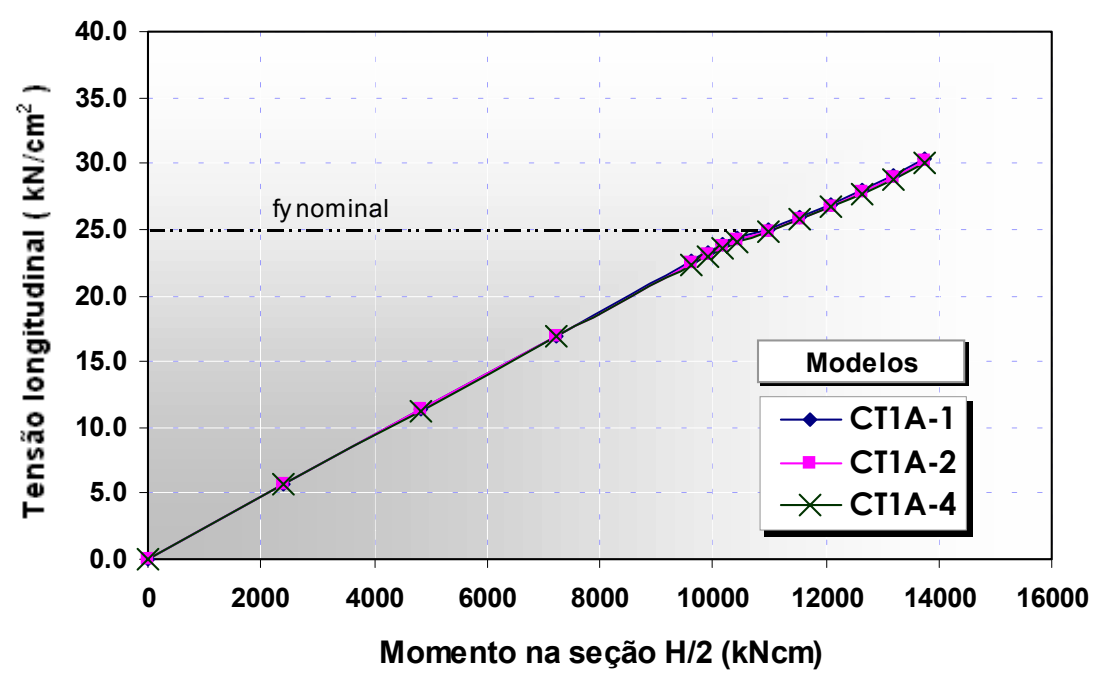

Figura 5.5 - Tensões longitudinais médias na seção $\mathrm{H} / 2$ Variação da espessura da chapa de topo 
Na figura 5.5 é possível observar que, para a seção $H / 2$, os valores médios da tensão longitudinal são praticamente idênticos para os modelos citados, em qualquer nível de solicitação.

Pode-se afirmar que não há influência da espessura da chapa de topo nas tensões longitudinais na seção $\mathbf{H} / 2$, pois em ambos os casos a viga atingiu a plastificação, com redistribuição das tensões de maneira praticamente idêntica.

O mesmo ocorre levando-se em consideração a variação do diâmetro do parafuso, o que pode ser observado na figura 5.6, que apresenta as tensões longitudinais médias na seção $H / 2$, para os modelos CT1A-4 e CT1B-4, ambos com chapa de $\mathbf{2 2 , 4} \mathrm{mm}$ de espessura e parafusos de diâmetros 16 e $19 \mathrm{~mm}$, respectivamente.

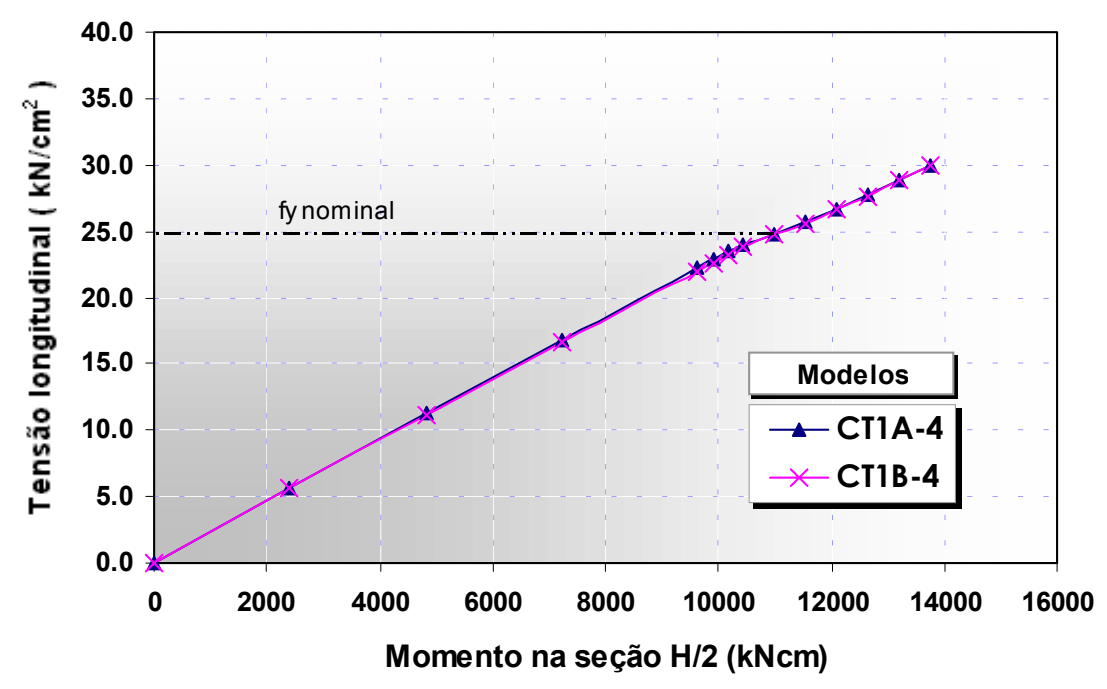

Figura 5.6 - Tensões longitudinais médias na seção H/2 Variação do diâmetro dos parafusos

Utilizando-se como referência os gráficos apresentados nas figuras 5.5 e 5.6, verifica-se que tanto a variação da espessura da chapa quanto do diâmetro dos parafusos, para os modelos numéricos, não influenciam de forma significativa os valores médios de tensão obtidos segundo as distribuições observadas na mesa superior. 
A exemplo do que se verifica nas mesas, também é interessante obter a distribuição de tensões longitudinais na alma da viga, ao longo de sua altura.

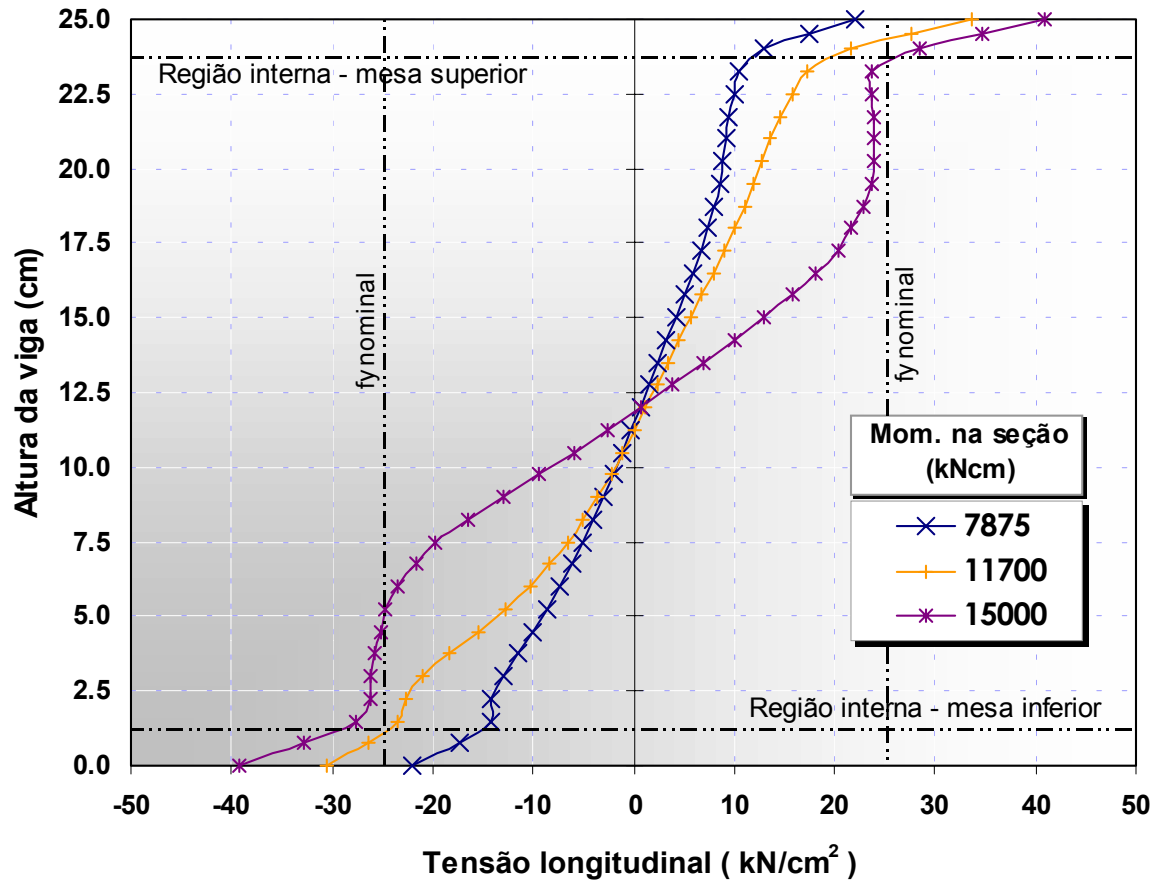

Figura 5.7 - Distribuição de tensões longitudinais na alma da viga Seção de intersecção viga/chapa de topo - modelo CT1A-1

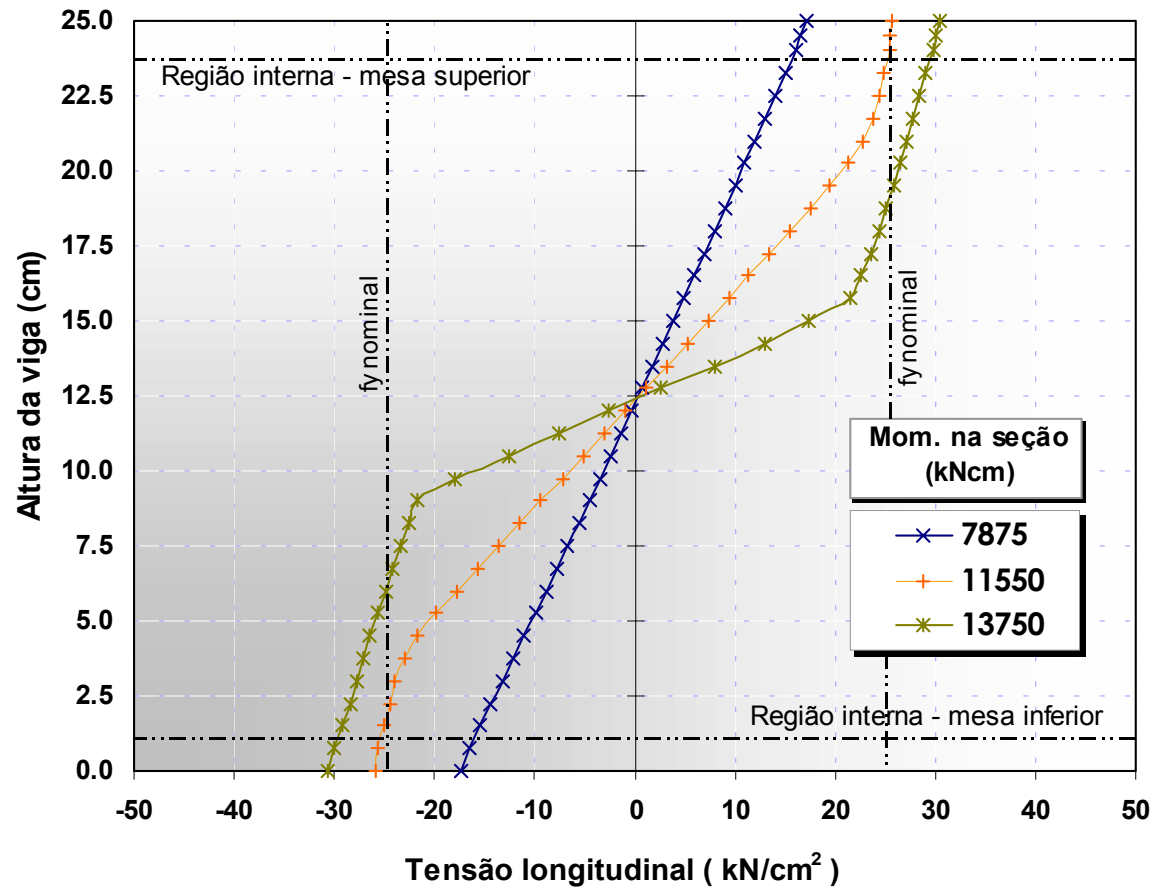

Figura 5.8 - Distribuição de tensões longitudinais na alma da viga Seção H/2 - modelo CT1A-1 
Observando-se as figuras 5.7 e 5.8, as quais apresentam as tensões longitudinais nas seções de intersecção viga/chapa de topo e H/2, respectivamente, verifica-se a evolução dos valores de tensão à medida em que a solicitação cresce, sendo possível o acompanhamento da plastificação da alma, para o modelo CT1A-1 $\left(t_{c h}=31,5 \mathrm{~mm} ; d_{p}=16 \mathrm{~mm}\right)$.

Para momentos inferiores à plastificação, observa-se que as tensões na alma são praticamente lineares para ambas as seções, ocorrendo uma pequena variação nos seus valores para a seção de intersecção viga/chapa de topo, nas regiões próximas às mesas.

Para $\mathbf{M}=11700 \mathbf{k N c m}$, equivalente a $\mathbf{M}_{\mathrm{p}}$, há uma diminuição na taxa de crescimento das tensões na figura 5.7, para as regiões próximas às mesas. Para a seção H/2 essa diminuição é melhor visualizada, na figura 5.8, para $\mathbf{M}=11550 \mathbf{~} \mathbf{N c m}$, representando a plastificação da alma ao longo da altura da viga.

Para a solicitação máxima em ambas as seções, tal condição de plastificação é confirmada, apresentando um comportamento típico da distribuição de tensões longitudinais ao longo da alma da viga.

RIBEIRO (1998) comenta que, em sua análise numérica, a distribuição de tensões longitudinais na alma apresentou um comportamento atípico, uma vez que para alguns níveis de solicitação as tensões tiveram valores negativos em quase toda a extensão da altura. Segundo o autor citado, nas diversas pesquisas que utilizaram elementos finitos com segmentos curtos de viga, como os trabalhos de KRISHNAMURTHY (1974a, 1978b, 1975b, 1980c e 1983) e SHERBOURNE \& BAHAARI (1994, 1996, 1997a, 1997b), não houve preocupação com a questão da distribuição de tensões na viga, o que pode ser influenciado pelo tipo de carregamento utilizado e do vão considerado nos modelos.

Outro aspecto interessante, observado no gráfico da figura 5.7, refere-se à posição da linha neutra, cujo valor na seção de intersecção viga/chapa de topo teve uma pequena variação em relação ao valor médio da altura da viga. 
A variação da espessura da chapa de topo e do diâmetro dos parafusos utilizados nos modelos numéricos, assim como para as mesas, não modificou a distribuição de tensões longitudinais para a alma.

De maneira geral, a figura 5.9 apresenta as distribuições para os modelos CT1A-1, CT1A-4 e CT1B-4 para a seção H/2, com momento fletor $M=11550 \mathrm{kNcm}$.

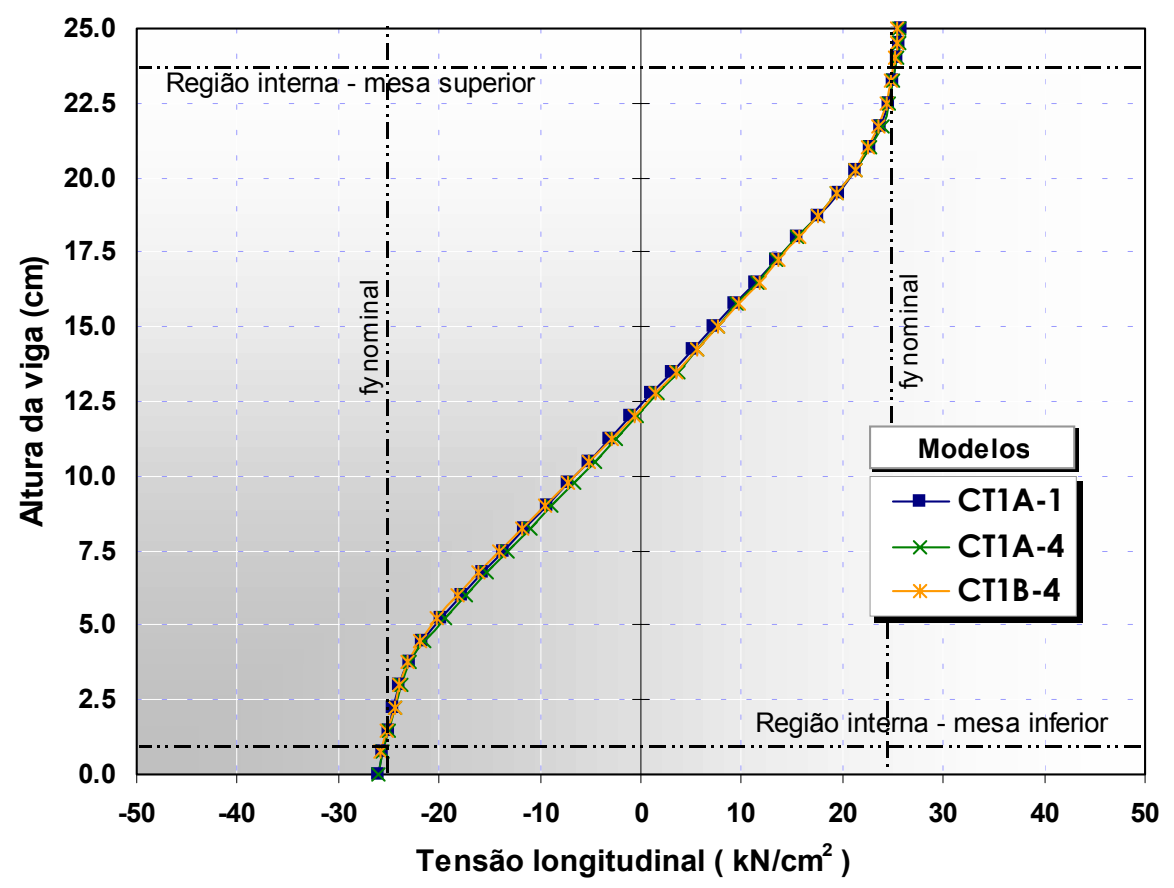

Figura 5.9 - Tensões longitudinais na alma da viga $-M=11700 \mathrm{kNcm}$ Variação da espessura da chapa de topo e diâmetro dos parafusos Seção H/2

Ilustrativamente, pode-se observar o estado de tensão longitudinal nas mesas e alma da viga na figura 5.10, a qual apresenta a viga do modelo CT1A-1 para solicitação, na ligação, igual à $11700 \mathrm{kNcm}$, equivalente ao valor de $\mathbf{M}_{\mathbf{p}}$.

Uma vez que não foram observadas mudanças significativas no comportamento da distribuição de tensões com a variação da espessura da chapa de topo e do diâmetro dos parafusos, a figura 5.10 apresenta um estado de tensões típico para as vigas de todos os modelos numéricos. 


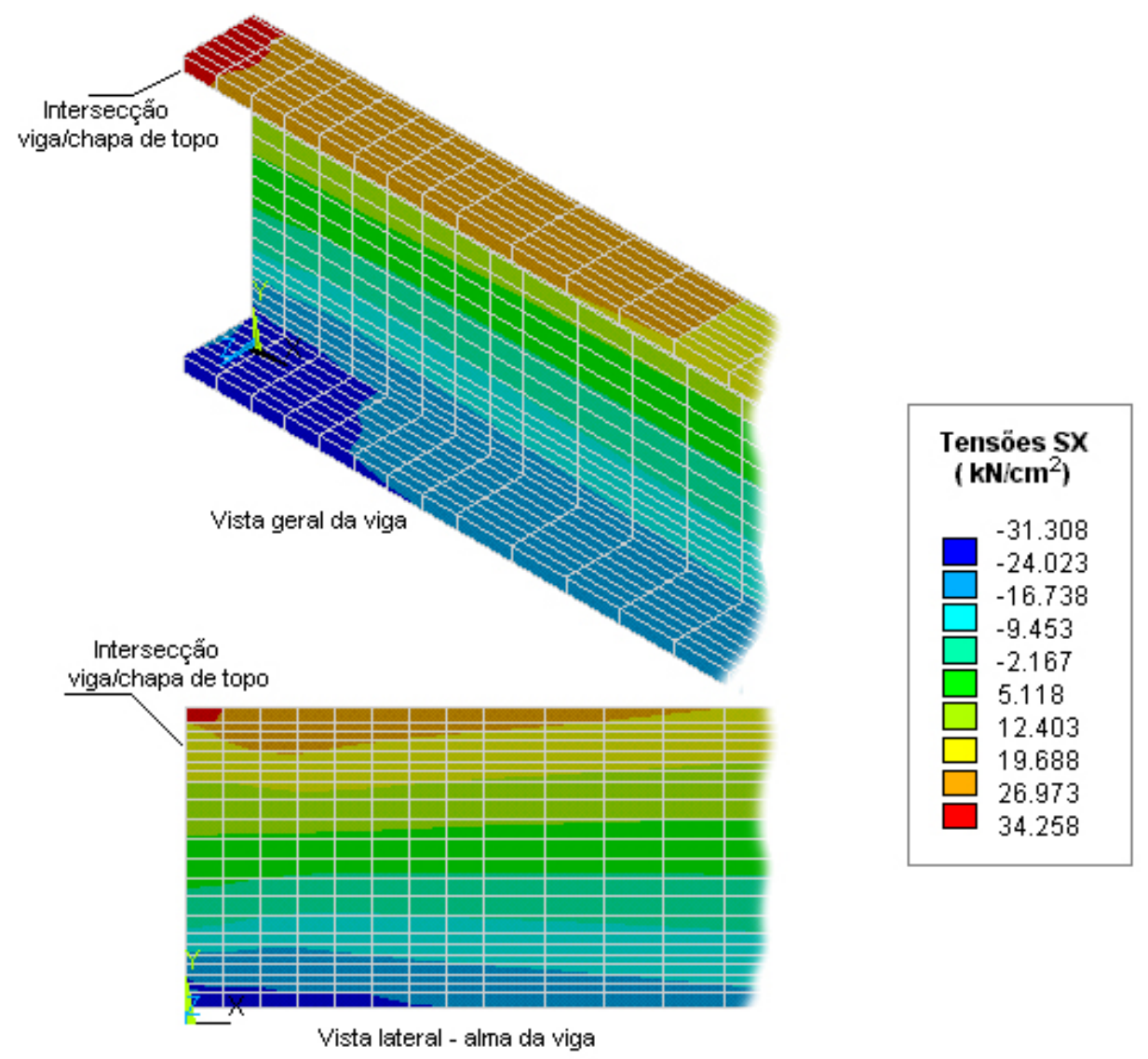

Figura 5.10 - Tensões longitudinais nas mesas e alma da viga do modelo CT1A-1

\subsubsection{Distribuição de tensões transversais de cisalhamento}

Em virtude do tipo de carregamento utilizado nos modelos numéricos, pela aplicação de forças verticais na extremidade da viga, também é possível observar o desenvolvimento de tensões transversais devido à força cortante, principalmente ao longo da altura da alma.

A figura 5.11 apresenta, para algumas seções da viga do modelo CT1A-1, a distribuição de tensões transversais para uma força aplicada, na extremidade da viga, de $78 \mathbf{k N}$. Tal força produz um momento fletor, na ligação (intersecção viga/chapa), igual a $11700 \mathbf{k N c m}$, próximo a $\mathbf{M}_{\mathbf{p}}$. Os momentos que solicitam as demais seções estão indicados na figura, em kNcm. 


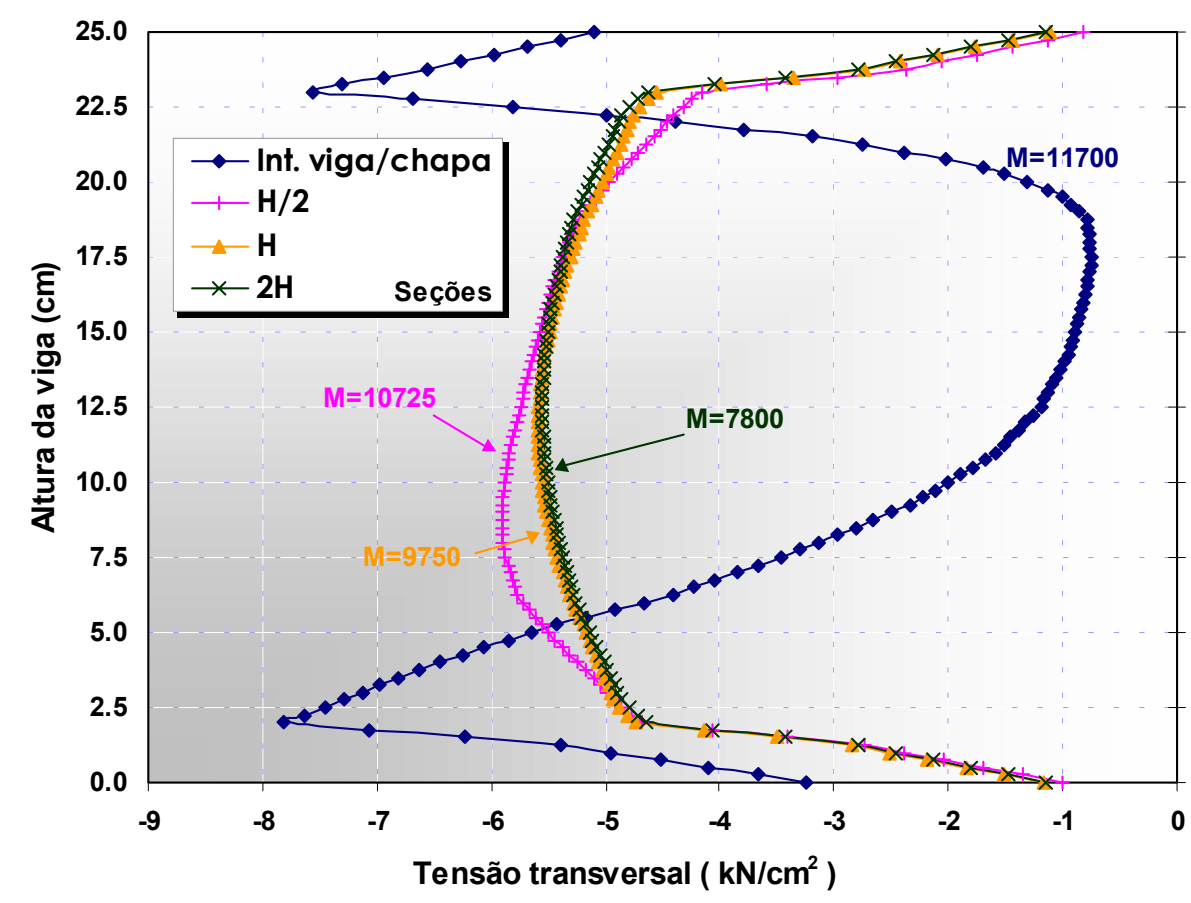

Figura 5.11 - Distribuição de tensões trasversais na alma da viga Modelo CT1A-1 - Momentos em kNcm

Analisando-se a figura 5.11 é possível observar uma grande distorção de comportamento para a seção de intersecção viga/chapa de topo. À medida em que as seções se afastam da chapa, a distribuição de tensões transversais tende a um comportamento clássico, apresentando valores máximos na altura média da viga $(12,5 \mathrm{~cm})$.

A partir da seção $\mathbf{H}$, nota-se que a distribuição de tensões transversais apresenta um comportamento como previsto na teoria clássica da resistência dos materiais, assim permanecendo ao longo do vão da viga.

Tomando-se a média das tensões transversais na seção $\mathbf{H}$, para a distribuição apresentada na figura 5.11, obtém-se um valor de $-6,20 \mathrm{kN} / \mathrm{cm}^{2}$, ao longo da altura da alma. Esse valor, multiplicado pela área total da seção transversal da alma $(25 \times \mathbf{0 , 6 3} \mathrm{cm})$, resulta numa força de $\mathbf{- 9 7 , 6 5} \mathbf{k N}$, que representa, aproximadamente, a força cortante na seção transversal. Uma vez que o carregamento aplicado deveria originar uma força cortante teórica constante no valor de $-100 \mathbf{k N}$, a diferença é de $2,5 \%$, o que valida os resultados obtidos quando comparados com o diagrama de cortante esperado. 


\subsection{CHAPA DE TOPO}

As figuras que compõem a tabela V.I, apresentada abaixo, ilustram a deformada da chapa de topo para os seis modelos numéricos, para momento máximo, na ligação, de $\mathbf{M}=15000 \mathbf{k N c m}$. Os deslocamentos foram aumentados em 25 vezes, para melhor visualização.

Tabela V.I - Deformada da chapa de topo para os modelos numéricos

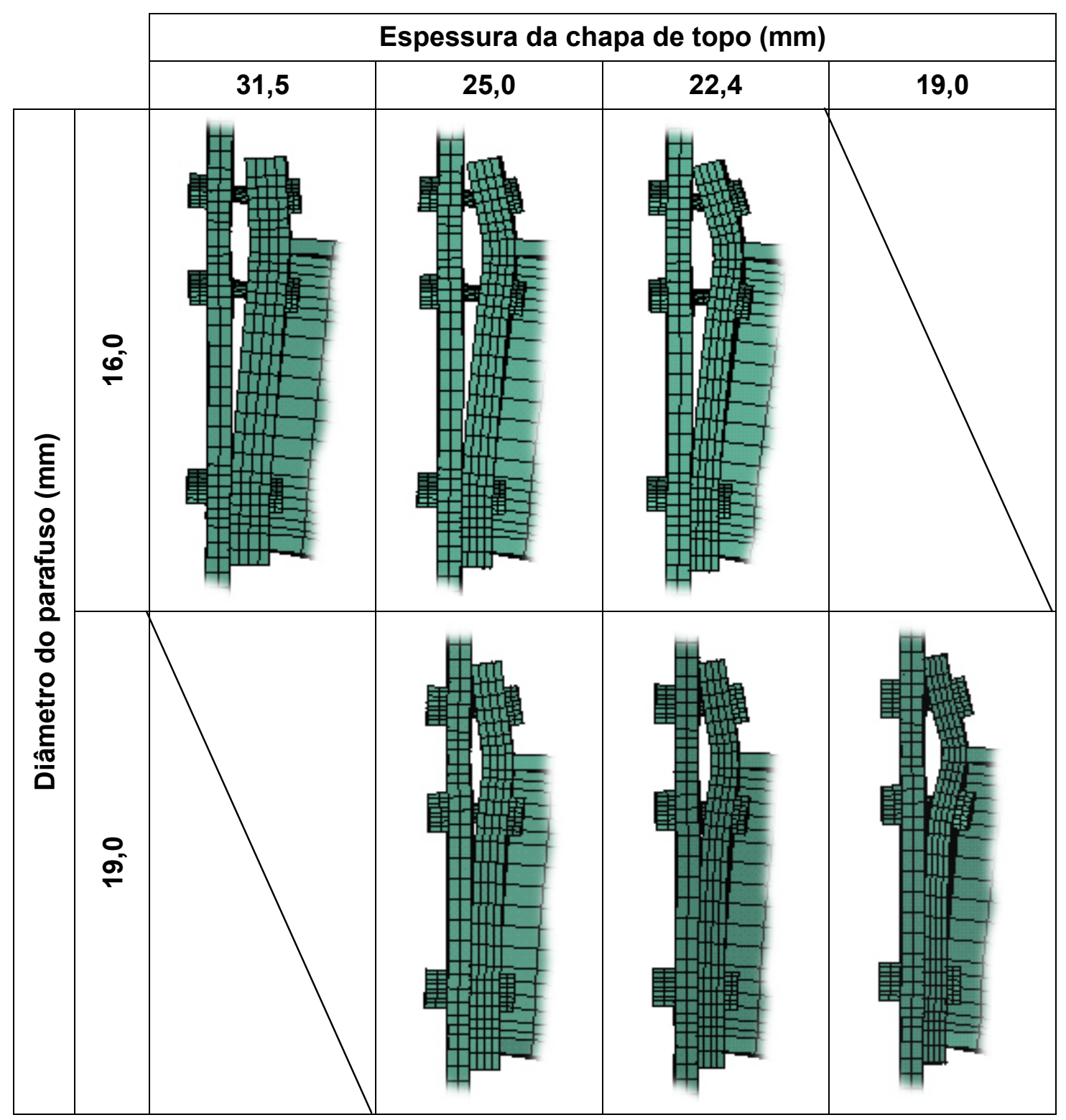


Para se quantificar o comportamento observado na tabela V.I, algumas seções da chapa de topo, esquematizadas na figura 5.12, foram escolhidas a fim de representar os deslocamentos da chapa com relação à mesa do pilar.

Vale salientar que estes resultados são importantes não só para visualização do comportamento da ligação, mas também como parâmetro para critérios de dimensionamento, podendo-se citar o EUROCODE (1993), que define estes comportamentos.

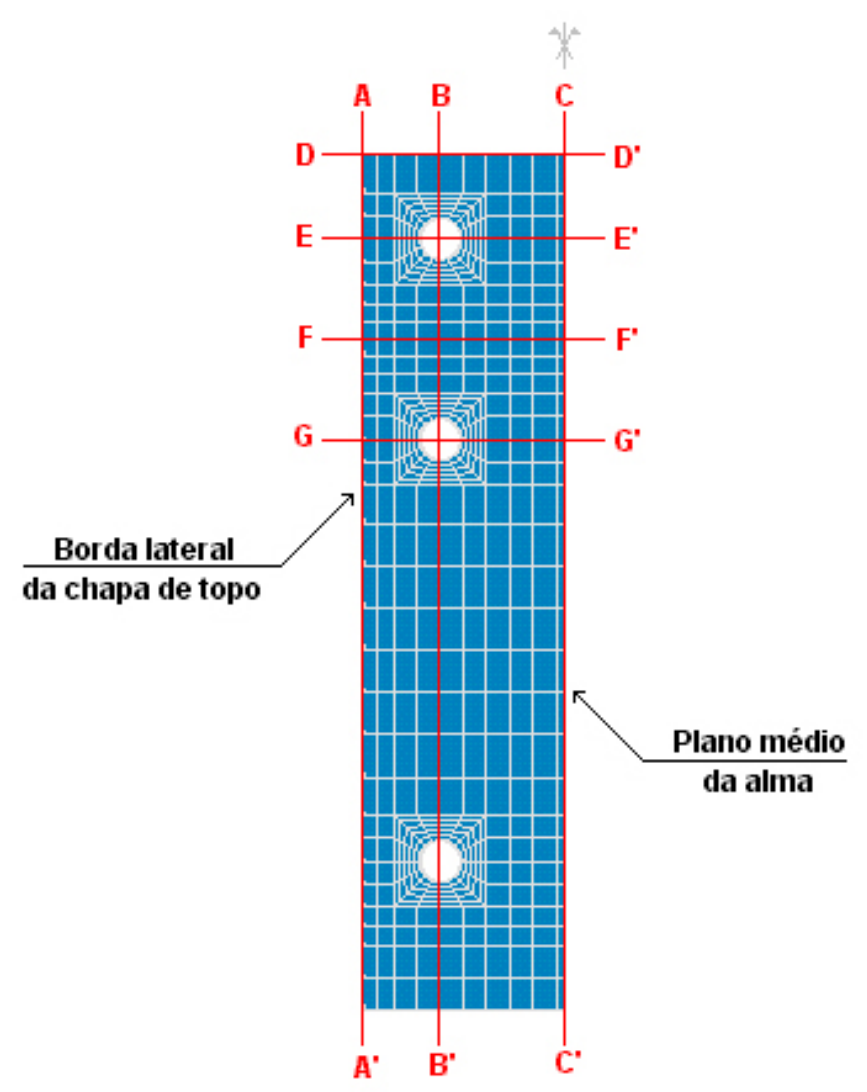

Figura 5.12 - Seções na chapa de topo

Inicialmente, para o modelo CT1A-1 $\left(t_{c h}=31,5 \mathrm{~mm} ; d_{p}=16 \mathrm{~mm}\right)$, as figuras $5.13,5.14$ e 5.15 apresentam os deslocamentos relativos chapa/pilar para as seções AA', BB' e CC', respectivamente, para diversos níveis de solicitação.

Ressalta-se que, para os gráficos apresentados, são incluídos os resultados referentes à solicitação equivalente à $\mathbf{M}_{\mathrm{p}}(\mathbf{M}=11700 \mathrm{kNcm})$, e 
para o momento total aplicado à ligação de todos os modelos, $\mathbf{M}=15000$

\section{$\mathrm{kNcm}$.}

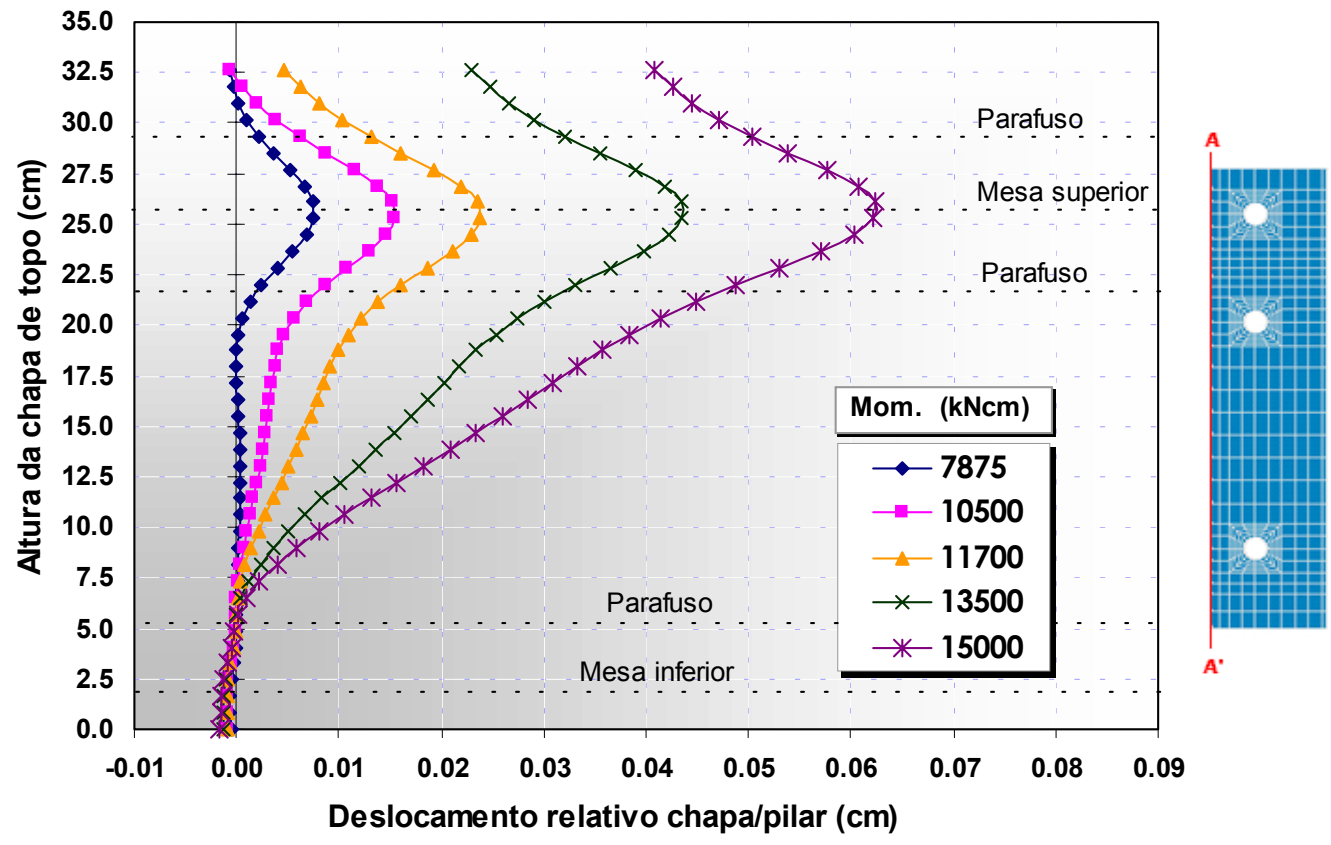

Figura 5.13 - Deslocamento relativo chapa/pilar Seção AA' - modelo CT1A-1

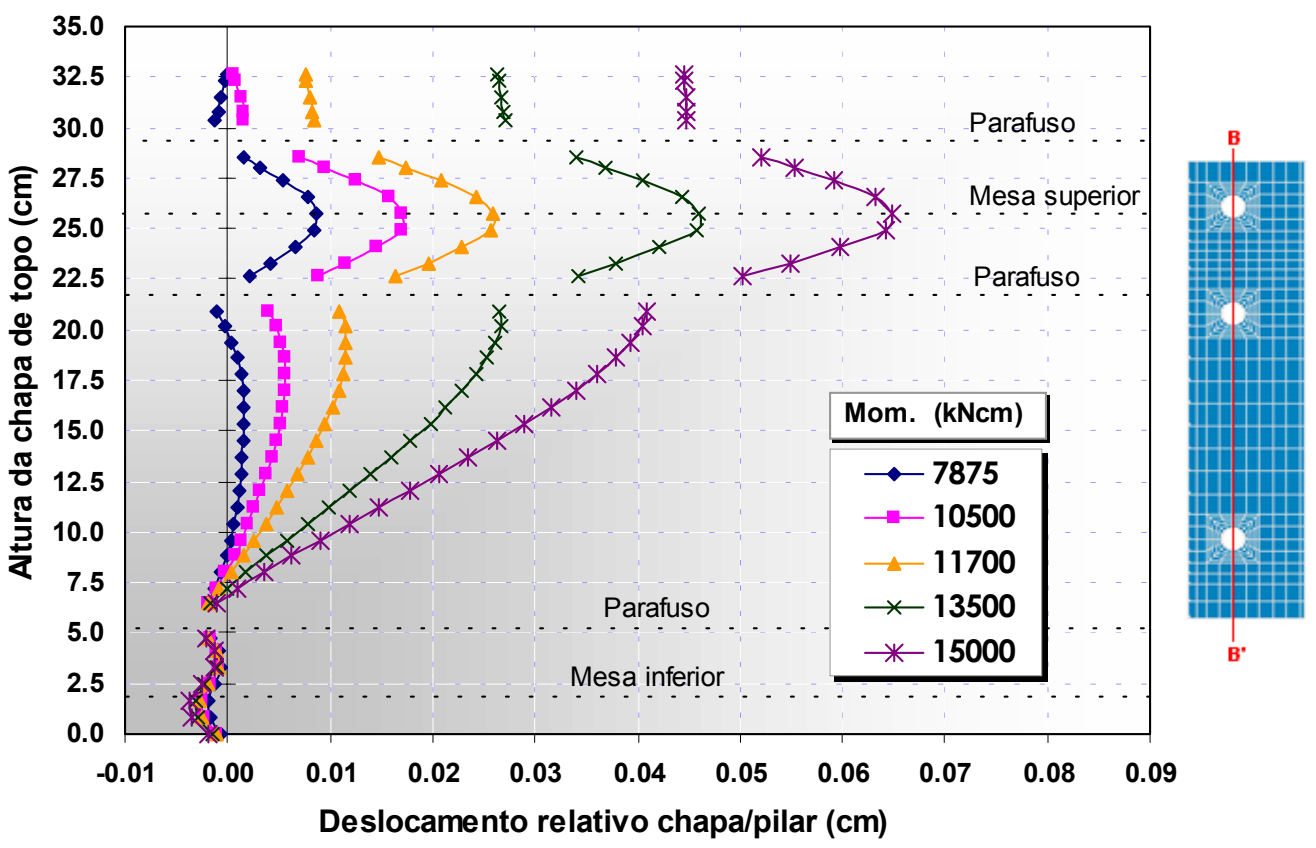

Figura 5.14 - Deslocamento relativo chapa/pilar Seção BB' - modelo CT1A-1 


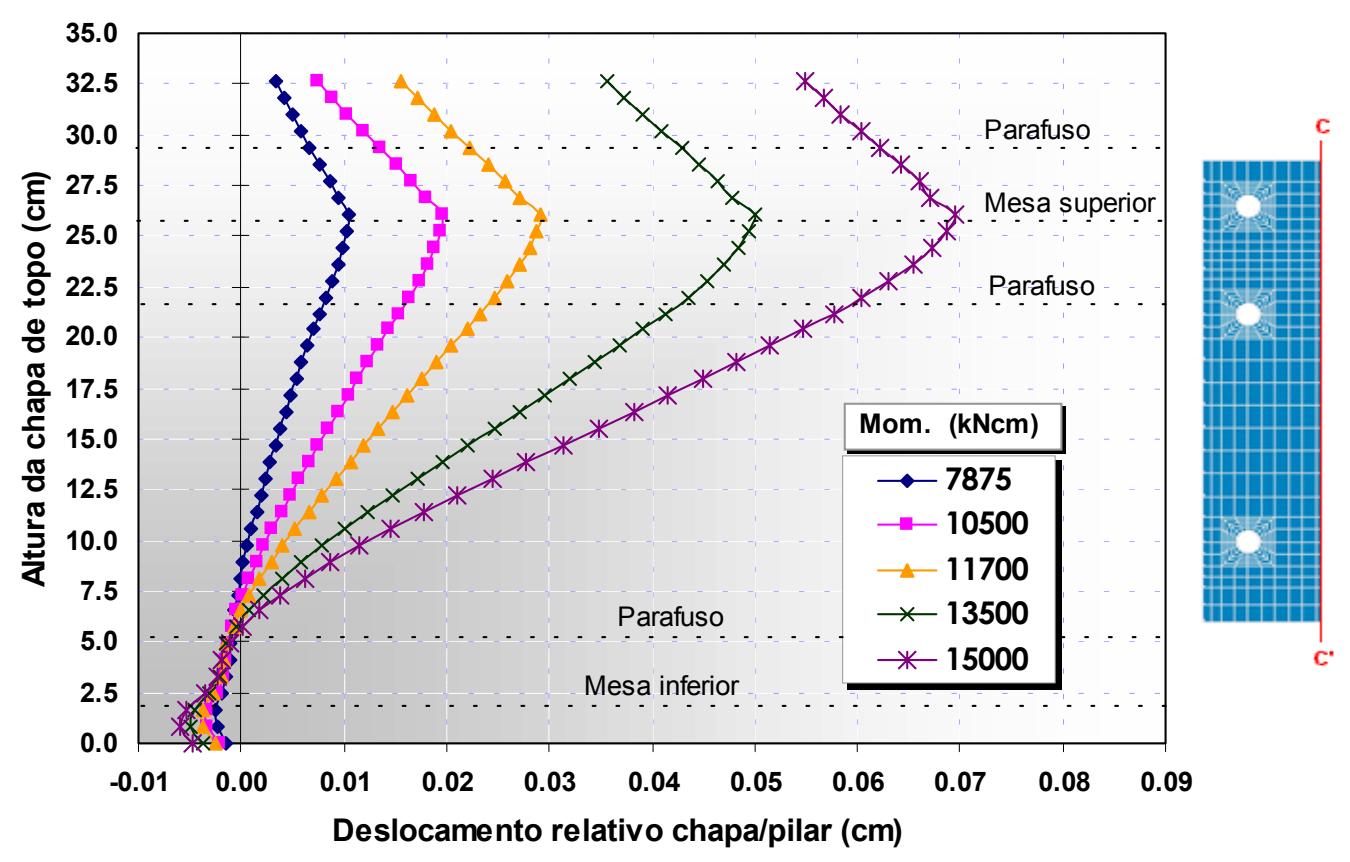

Figura 5.15 - Deslocamento relativo chapa/pilar Seção CC' - modelo CT1A-1

Com relação ao modelo CT1A-1, o primeiro aspecto verificado com relação ao seu comportamento refere-se ao descolamento da chapa de topo na região tracionada.

Devido à sua espessura, a chapa possui grande rigidez à flexão, rotacionando como se fosse um corpo rígido, ou seja, as deformações da chapa são muito pequenas. Sob outro ponto de vista, os deslocamentos chapa/pilar são atribuídos à deformação dos parafusos.

Dessa maneira, para as seções AA' e BB', há uma perda total de contato entre a região superior da chapa e a mesa do pilar para solicitações a partir de $\mathbf{M}_{\mathbf{p}}$, e para a seção $\mathbf{C} \mathbf{C}^{\prime}$ os valores de afastamento são pouco maiores, ocorrendo a perda de contato para solicitações inferiores à $\mathbf{M}_{\mathbf{p}}$.

Além disso, pode-se afirmar que não há simetria do afastamento chapa/pilar para os pontos situados nas linhas externa e interna de parafusos, com relação à mesa tracionada, exceto para níveis menores de solicitação. 
De forma semelhante, apresenta-se nas figuras 5.16 a 5.19 os gráficos referentes ao deslocamento relativo chapa/pilar para as seções DD', EE', FF' e GG', respectivamente, para o modelo CT1A-1.

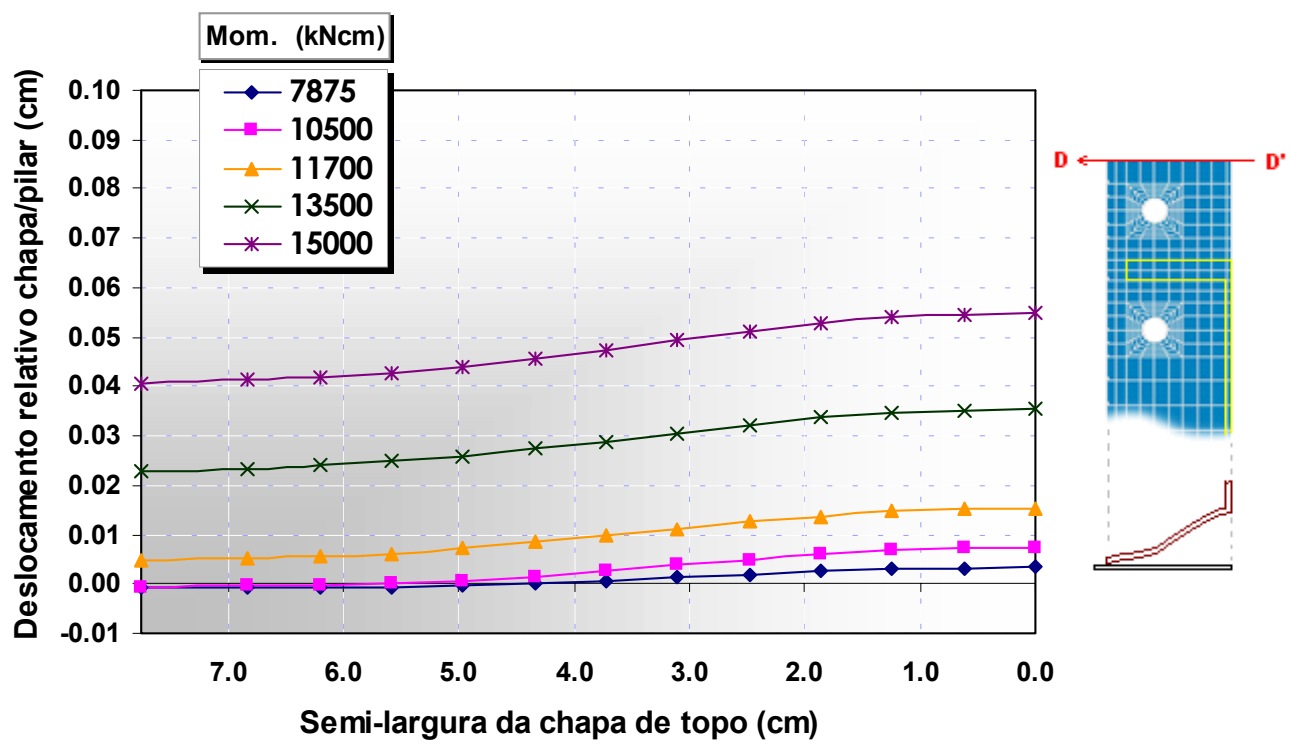

Figura 5.16 - Deslocamento relativo chapa/pilar Seção DD' - modelo CT1A-1

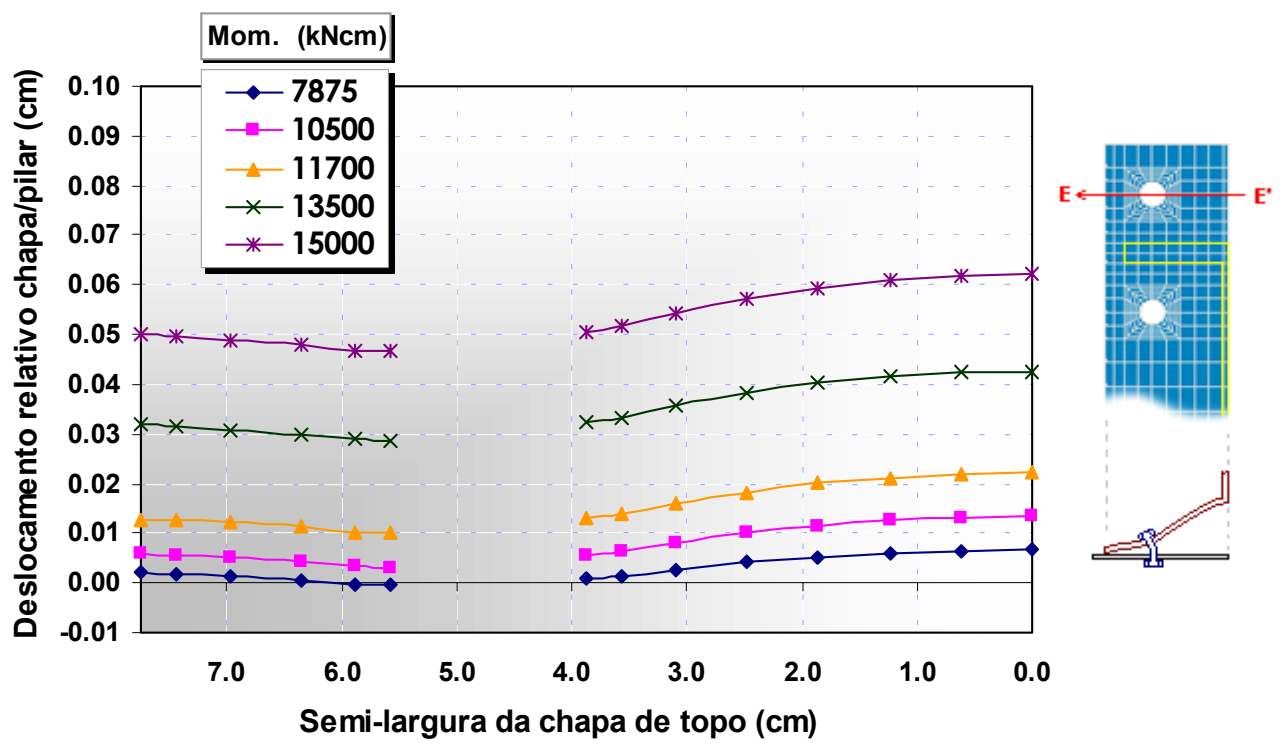

Figura 5.17 - Deslocamento relativo chapa/pilar Seção EE' - modelo CT1A-1 


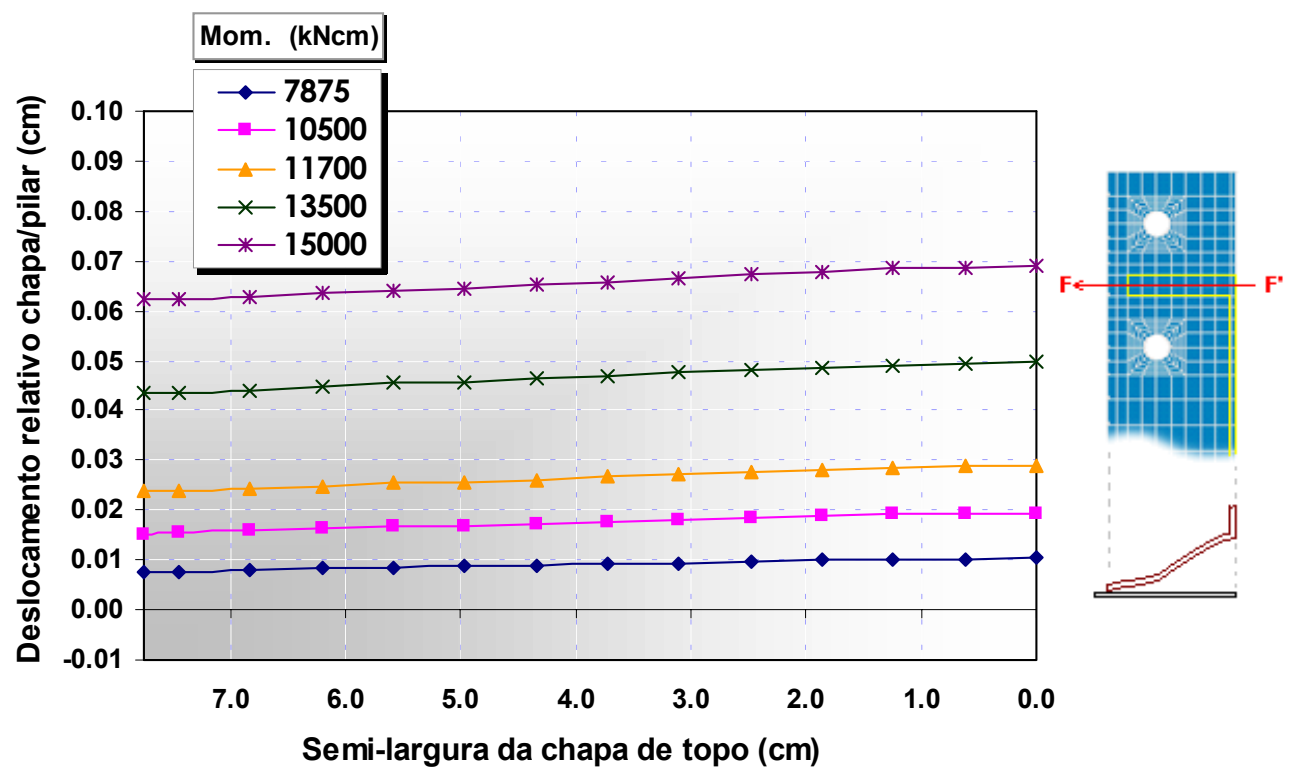

Figura 5.18 - Deslocamento relativo chapa/pilar Seção FF' - modelo CT1A-1

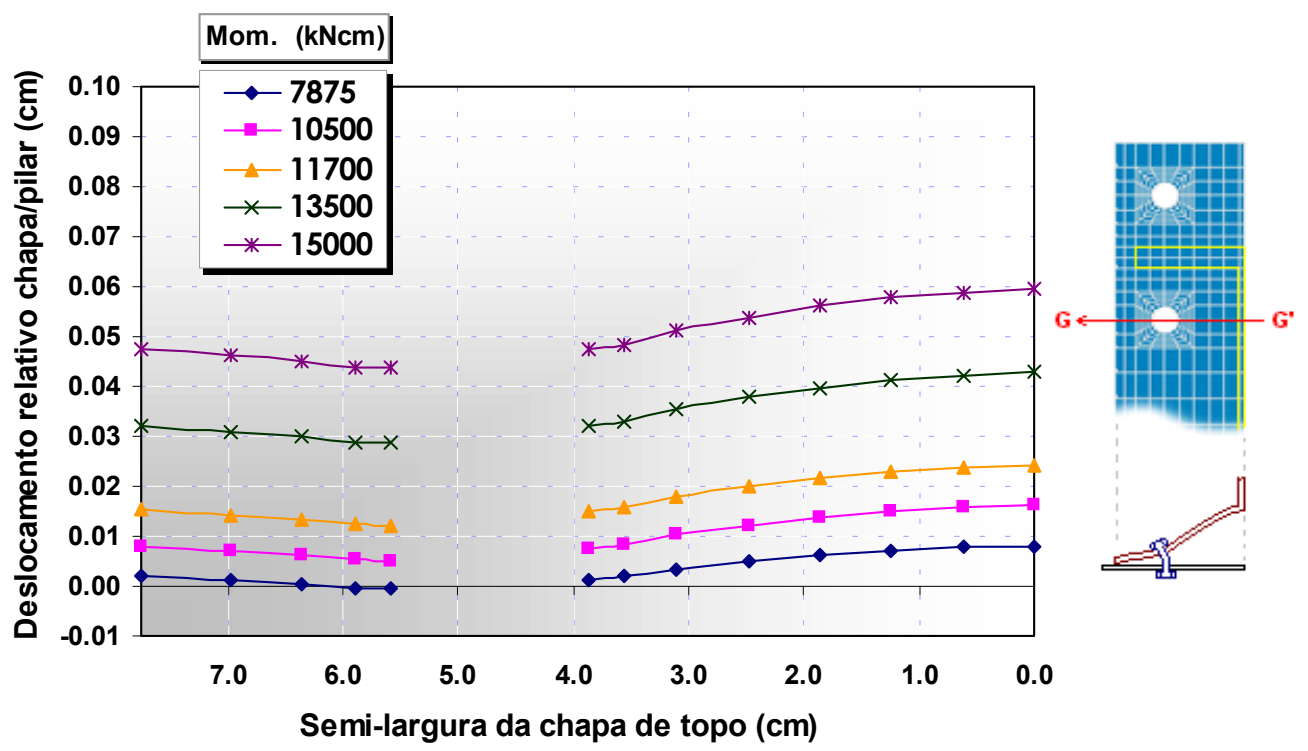

Figura 5.19 - Deslocamento relativo chapa/pilar Seção GG' - modelo CT1A-1

Analisando-se os gráficos apresentados nas figuras 5.13 a 5.19 , observa-se que a chapa de topo está sujeita à flexão segundo dois planos, com afastamentos máximos localizados no plano médio da alma da viga.

Para possibilitar a avaliação da influência exercida pela variação da espessura da chapa de topo no comportamento da ligação, com relação aos 
deslocamentos relativos viga/pilar, apresenta-se uma comparação entre os resultados do modelo CT1A-4 $\left(t_{c h}=22,4 \mathrm{~mm} ; d_{p}=16,0 \mathrm{~mm}\right)$ com os obtidos para o modelo CT1A-1 $\left(t_{c h}=31,5 \mathrm{~mm} ; d_{p}=16,0 \mathrm{~mm}\right)$, nas figuras 5.20 e 5.21, para as seções AA' e DD' respectivamente, em dois níveis de carregamento.

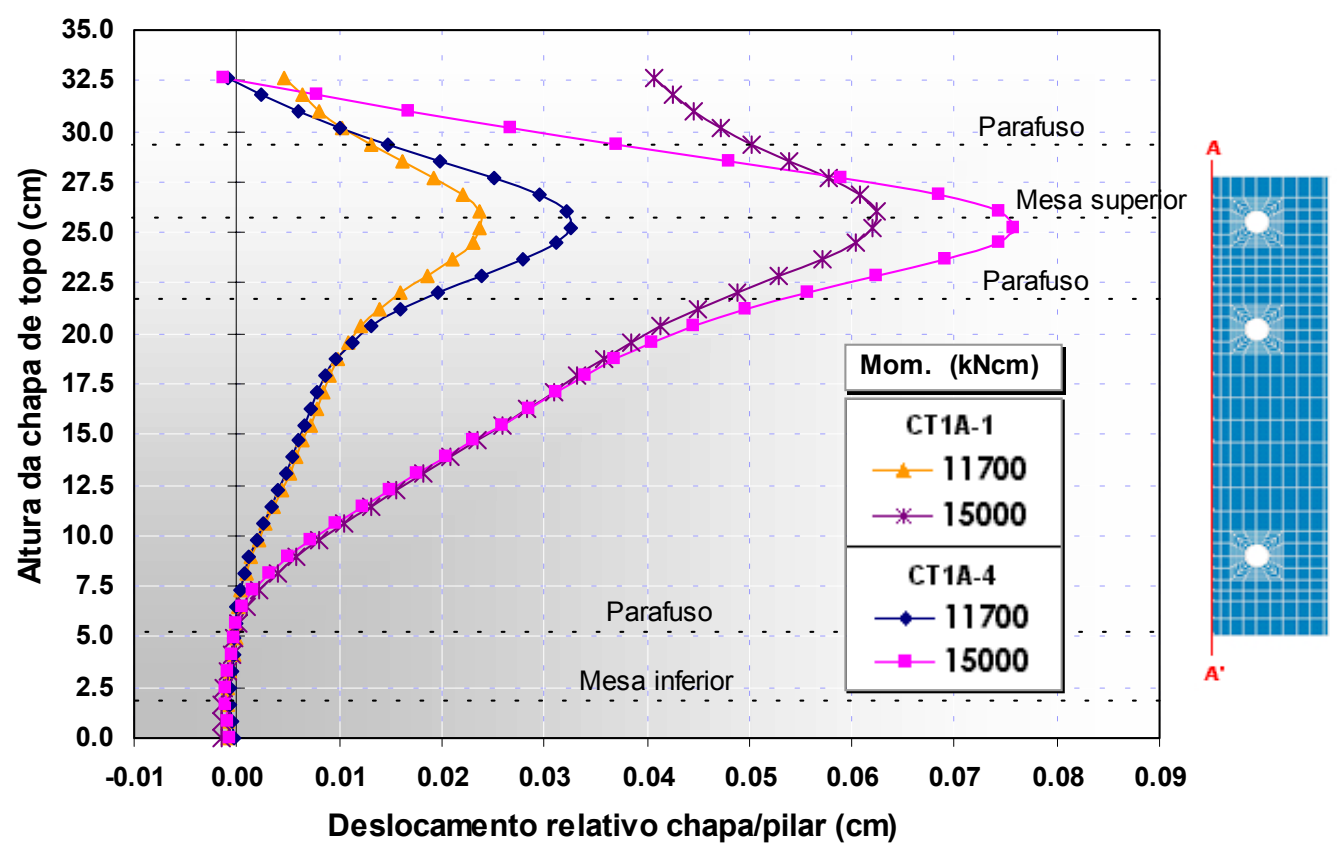

Figura 5.20 - Deslocamento relativo chapa/pilar - seção AA' Variação da espessura da chapa de topo

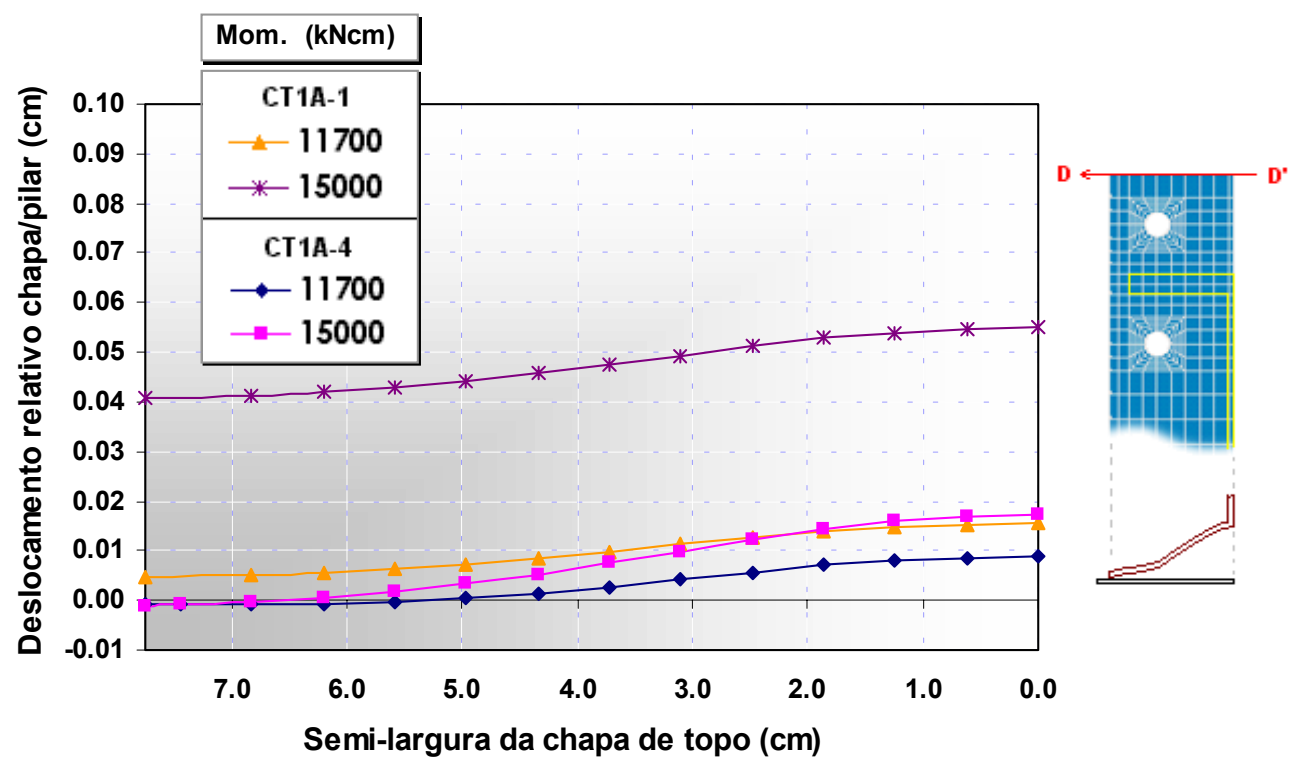

Figura 5.21 - Deslocamento relativo chapa/pilar - seção DD' Variação da espessura da chapa de topo 
A observação das figuras 5.20 e 5.21 permite constatar que a diminuição da espessura da chapa de topo modifica, significativamente, o aspecto geral da curva dos afastamentos chapa/pilar.

Deste modo, há uma modificação no comportamento da ligação, que pode ser verificado analisando-se os deslocamentos da extremidade superior da chapa de topo, principalmente na região da borda. Ao contrário da chapa do modelo CT1A-1 $\left(\mathbf{t}_{\mathrm{ch}}=\mathbf{3 1 , 5} \mathrm{mm}\right)$, mesmo para a solicitação máxima de $15000 \mathrm{kNcm}$, a chapa do modelo CT1A-4 $\left(\mathbf{t}_{\mathrm{ch}}=22,4 \mathrm{~mm}\right)$ permanece em contato com a mesa do pilar. Ao mesmo tempo, observa-se que o afastamento chapa/pilar na altura da mesa superior sofre um acréscimo para o modelo de chapa mais fina, em ambos os níveis de solicitação considerados.

A partir da constatação realizada acima, é possível afirmar que a diminuição da espessura da chapa de topo tem como conseqüência um aumento na flexão da chapa, aumentando os deslocamentos relativos chapa/pilar. Dessa forma, a flexão da chapa passa a interagir mais intensamente com a deformação dos parafusos.

Além disso, a consideração do contato entre a extremidade superior da chapa de topo e a mesa do pilar, observado no modelo CT1A-4, torna-se importante na determinação dos esforços na região tracionada, uma vez que a mesa do pilar irá adicionar forças de reação à chapa. Tais forças são provenientes do chamado "efeito alavanca" ou "prying action", que será melhor visualizado no item referente aos parafusos.

As considerações feitas acima também são válidas para o aumento do diâmetro dos parafusos.

As figuras 5.22 e 5.23 apresentam uma comparação entre os modelos CT1A-4 $\left(t_{c h}=22,4 \mathrm{~mm} ; d_{p}=16,0 \mathrm{~mm}\right)$ e CT1B-4 $\left(t_{c h}=22,4 \mathrm{~mm}\right.$; $d_{p}=19,0 \mathrm{~mm}$ ), para as seções DD' e EE', respectivamente, também para momentos fletores $\mathbf{M}=11700 \mathbf{k N c m}\left(\approx M_{p}\right)$ e $\mathbf{M}=15000 \mathbf{k N c m}$. 


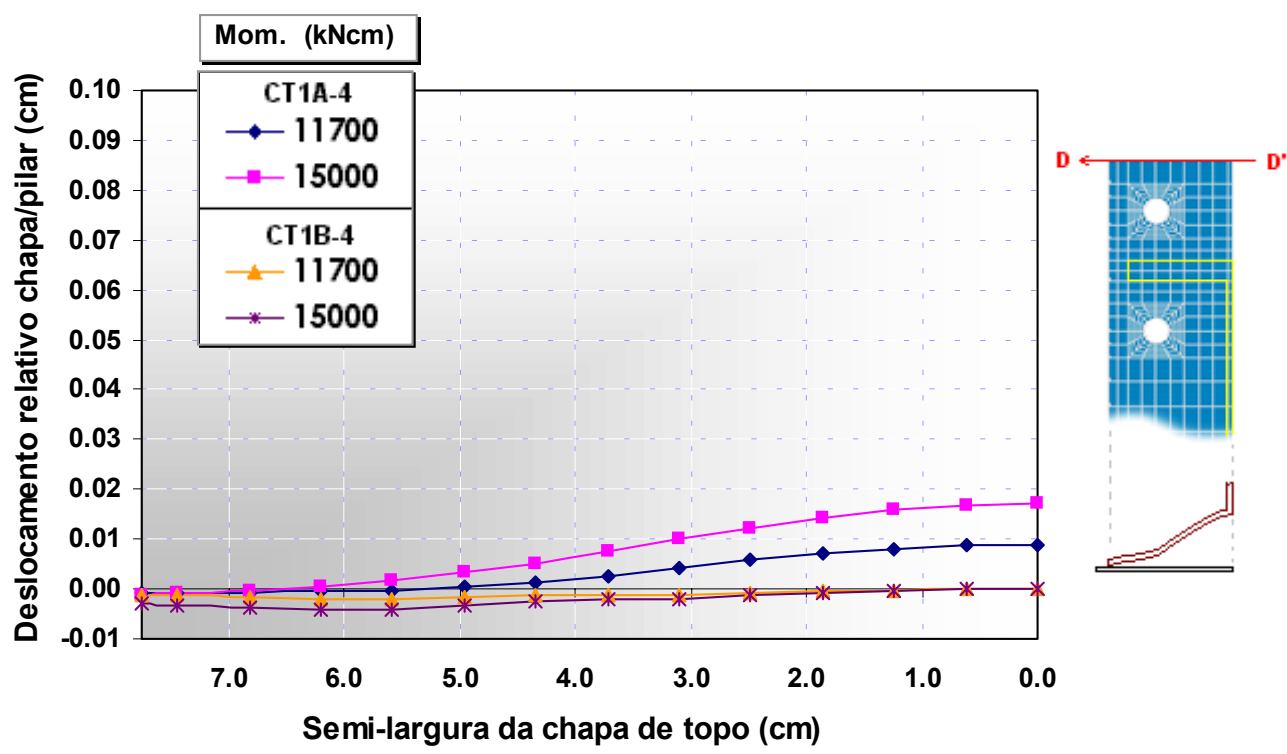

Figura 5.22 - Deslocamento relativo chapa/pilar - seção DD' CT1A-4 $\left(d_{p}=16,0 \mathrm{~mm}\right)$ e CT1B-4 $\left(d_{p}=19,0 \mathrm{~mm}\right)$ Variação do diâmetro dos parafusos

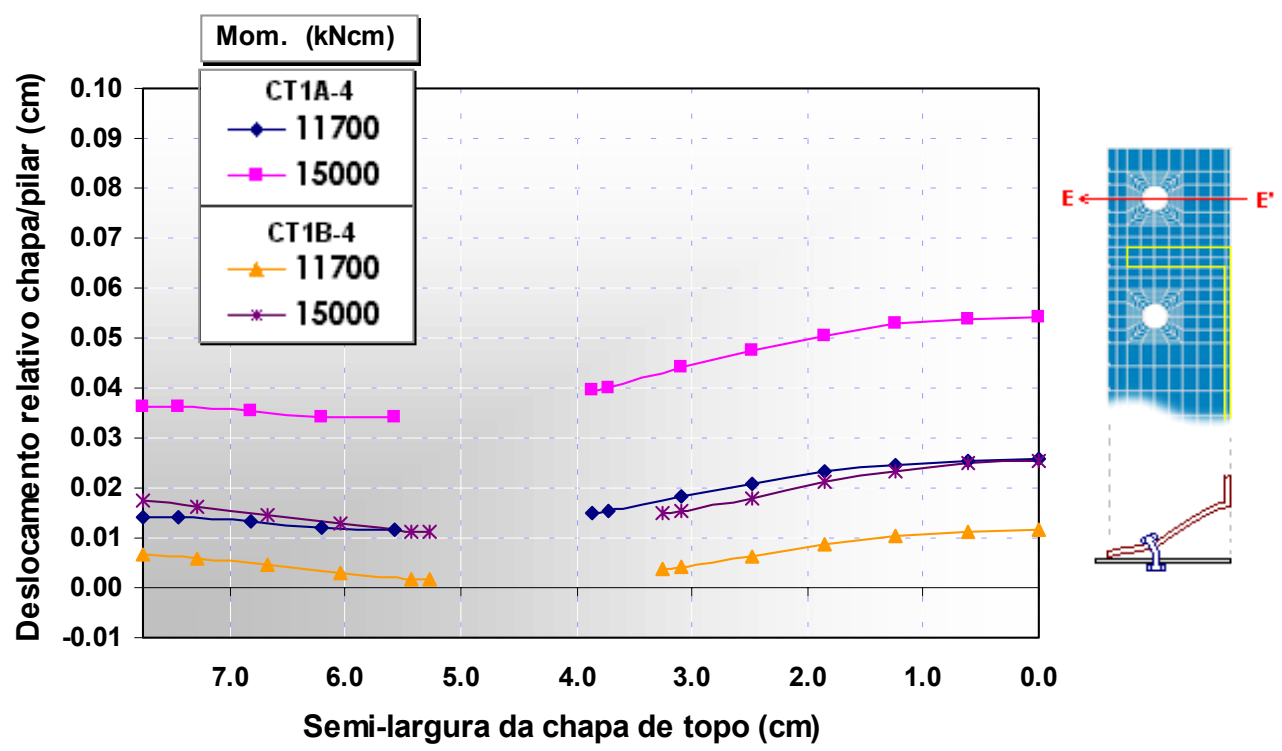

Figura 5.23 - Deslocamento relativo chapa/pilar - seção EE' CT1A-4 $\left(d_{p}=16,0 \mathrm{~mm}\right)$ e CT1B-4 $\left(d_{p}=19,0 \mathrm{~mm}\right)$ Variação do diâmetro dos parafusos

Para a seção DD', no modelo CT1B-4, observa-se que o contato entre a extremidade superior da chapa de topo com a mesa do pilar é mantido para toda a sua largura, inclusive para o momento máximo $\mathbf{M}=$ $15000 \mathrm{kNcm}$. 
Além disso, devido ao aumento do diâmetro do parafuso, reduzemse os afastamentos chapa/pilar, de um modo geral.

Ainda com relação aos gráficos apresentados, um comentário é necessário devido ao aparecimento de valores negativos para 0 deslocamento relativo chapa/pilar. Analisando-se o modelo numérico e a simulação do contato entre a chapa e a mesa do pilar, pode-se dizer que tais valores são decorrentes da penetração dos pontos da superfície da chapa de topo na superfície da mesa do pilar, conseqüência da rigidez utilizada para os elementos de contato entre as duas superfícies.

Além dos afastamentos chapa/pilar, outra característica importante para a análise dos resultados numéricos é a distribuição de tensões decorrentes das forças longitudinais aplicadas à chapa pela viga e das tensões na direção da maior flexão da chapa de topo (direção $Y$ ).

As tabelas V.II e V.III apresentam, respectivamente, o estado de tensões encontrado na chapa de topo segundo a direção do eixo longitudinal da viga $\left(\sigma_{x}\right)$ para os modelos CT1A-1 $\left(t_{c h}=31,5 \mathrm{~mm} ; d_{p}=16,0 \mathrm{~mm}\right) \mathrm{e}$ CT1A-4 $\left(t_{c h}=22,4 \mathrm{~mm} ; d_{p}=19,0 \mathrm{~mm}\right)$, para quatro estágios de carregamento, incluindo $\mathbf{M}=11700 \mathbf{k N c m}\left(\approx \mathbf{M}_{\mathbf{p}}\right)$ e o momento máximo solicitante $\mathbf{M}=15000 \mathrm{kNcm}$.

Em quase toda a extensão da chapa de topo, é possível observar que as tensões $\sigma_{\mathbf{x}}$ permanecem com valores próximos de zero para todos os níveis de solicitação apresentados, em ambos os modelos.

Esses valores só se alteram em regiões específicas da chapa, as quais estão localizadas nas proximidades dos furos, nas alturas das mesas tracionada e comprimida e próximo à alma.

Observando-se, primeiramente, os furos na chapa de topo, verificase que existe uma concentração de tensões de compressão exatamente na região onde está localizada a cabeça dos parafusos. 


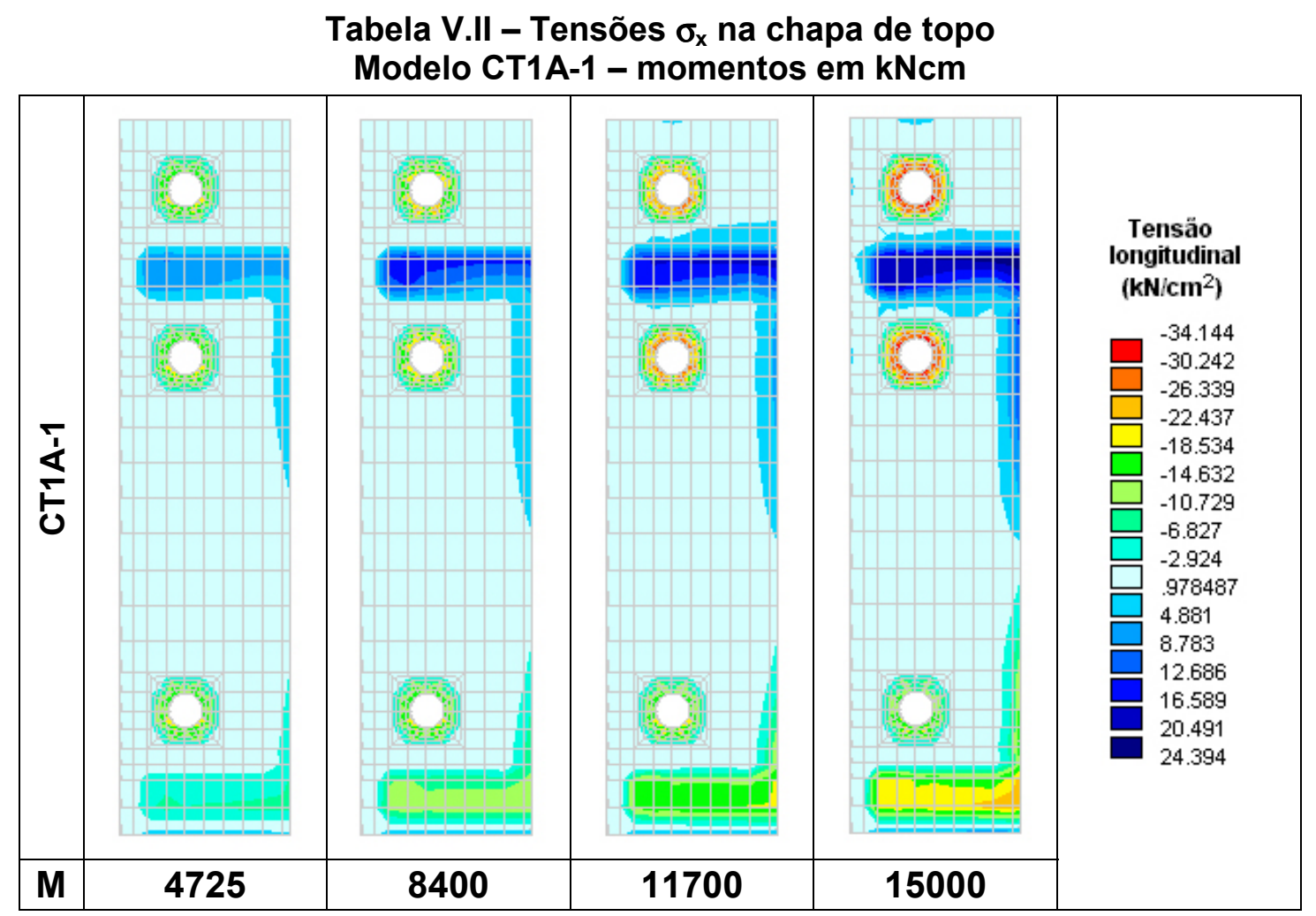

Tabela V.III - Tensões $\sigma_{\mathrm{x}}$ na chapa de topo

Modelo CT1A-4 - momentos em kNcm

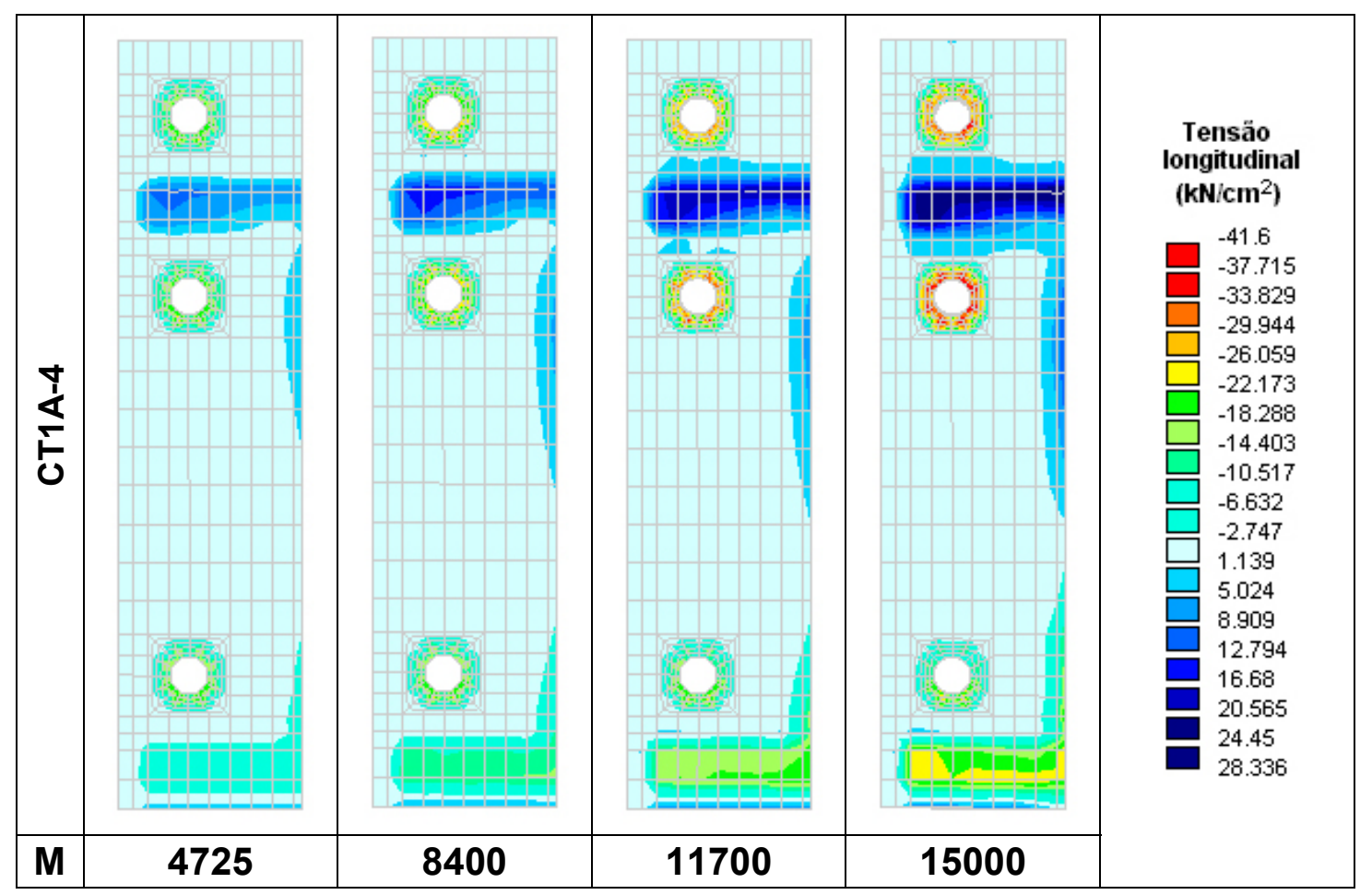


Além disso, nota-se que o estado de tensões é diferente para a linha de parafusos situada na região comprimida. Enquanto as tensões de compressão nos furos da região tracionada sofrem um acréscimo juntamente com o aumento da solicitação, as tensões de compressão para os furos da região comprimida possuem valores praticamente constantes.

Para a intersecção da chapa com a viga, observa-se nitidamente a distribuição de tensões de tração e compressão nas regiões onde estão localizadas as mesas da viga.

Seguindo a altura da chapa de topo, na região próxima à alma da viga, observa-se ainda a transição entre as tensões de compressão e de tração e suas respectivas distribuições.

Observando-se as tensões apresentadas nas tabelas V.II e V.III, nota-se que há uma variação da linha neutra com relação à altura média da viga, aproximando-se da mesa comprimida. Essa variação pode ser atribuída à deformabilidade da chapa de topo, que por sua vez tem relação com a solicitação imposta à ligação e a distribuição de tensões longitudinais na viga.

Devido a esse "abaixamento" da linha neutra, uma conseqüência direta é o aumento das tensões de tração na mesa superior, juntamente com a diminuição dos valores das tensões de compressão na mesa oposta.

Com relação às tensões devido à flexão da chapa de topo, a tabela V.IV apresenta as distribuições de tensão na direção $Y\left(\sigma_{\mathbf{y}}\right)$ para o modelo CT1A-1 $\left(t_{c h}=31,5 \mathrm{~mm} ; d_{p}=16,0 \mathrm{~mm}\right)$, também para quatro estágios de carregamento.

Com as figuras da tabela V.IV é possível observar nitidamente as tensões que solicitam a chapa de topo, notando-se a complexidade da determinação do comportamento de tal distribuição para a região próxima aos parafusos.

Com relação ao dimensionamento da chapa de topo, é interessante comentar que o EUROCODE-3 (1993) considera tal distribuição verificando a capacidade resistente de perfis "T" equivalentes às linhas de escoamento 
formadas nas proximidades dos parafusos. No entanto, o comportamento encontrado nas chapa dos modelos, à primeira vista, não representa tais substituições.

Tabela V.IV - Tensões $\sigma_{\mathrm{y}}$ na chapa de topo Modelo CT1A-1 - momentos em kNcm

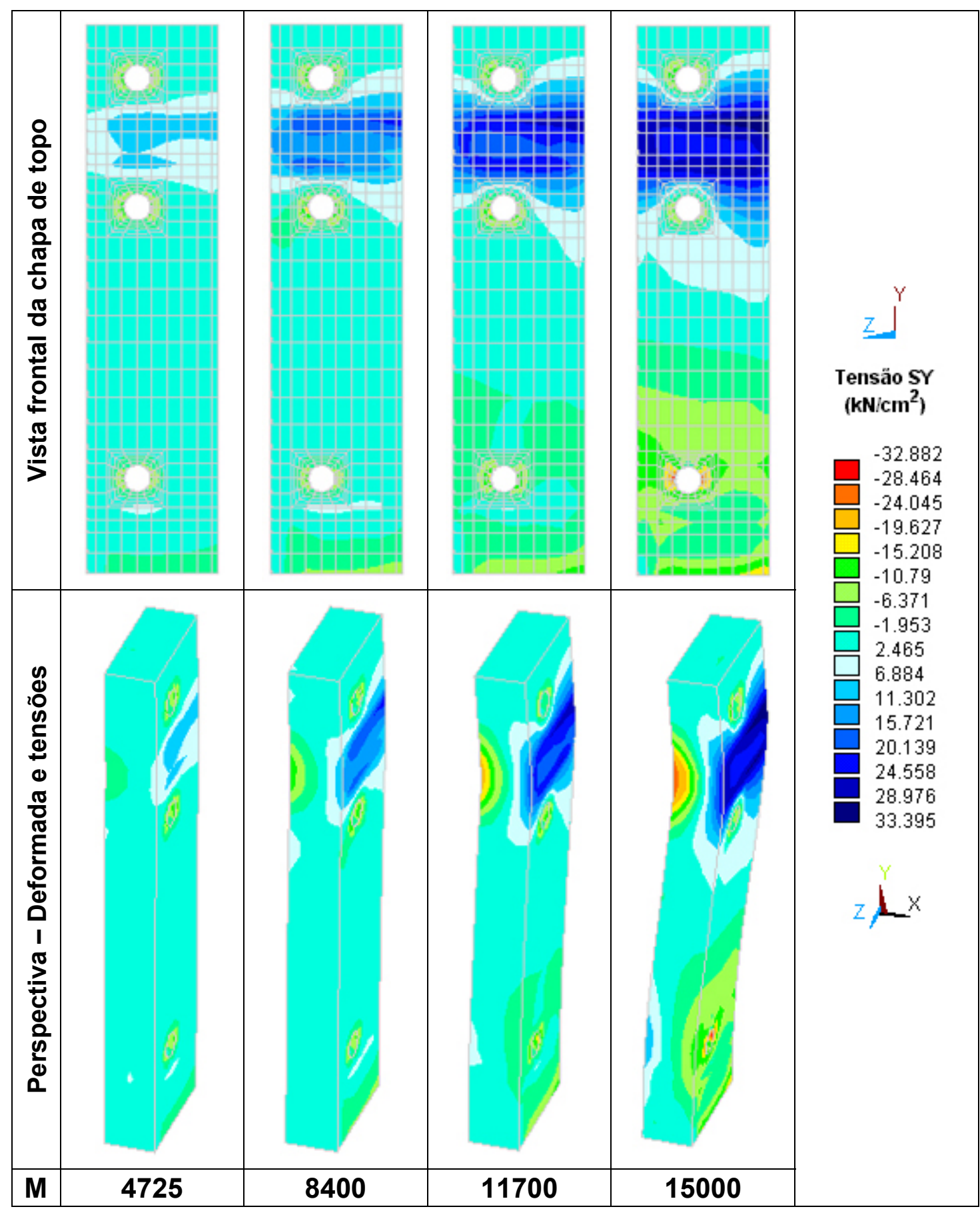


Se por um lado foi possível observar o comportamento da chapa de topo com os resultados referentes ao afastamento chapa/pilar e às distribuições de tensões, ainda é necessário se verificar o aspecto de rigidez para as ligações representadas nos modelos numéricos.

Dessa maneira, a rotação da chapa de topo torna-se importante para a avaliação do comportamento da ligação em função da variação dos parâmetros estudados neste trabalho, relativos à espessura da chapa de topo e diâmetro dos parafusos.

Inicialmente, cabe ressaltar que, convencionalmente, a rotação de uma ligação é calculada pela divisão do afastamento chapa/pilar - medido na altura do plano médio da mesa tracionada - pela distância entre os planos médios das mesas da viga, ou seja, $\left(\mathbf{H}-\mathbf{t}_{\mathbf{f}}\right)$, onde $\mathbf{H}$ é a altura da viga e $\mathbf{t}_{\mathbf{f}}$ a espessura das mesas. Essa relação considera, basicamente, que a intersecção entre a chapa de topo e a mesa do pilar, na altura do plano médio da mesa comprimida, seja o eixo de rotação da chapa de topo.

Para a comparação entre os modelos numéricos, a distância (H $\mathbf{t}_{\mathbf{f}}$ ) é utilizada como um parâmetro de referência, e está esquematizada na figura 5.24 .

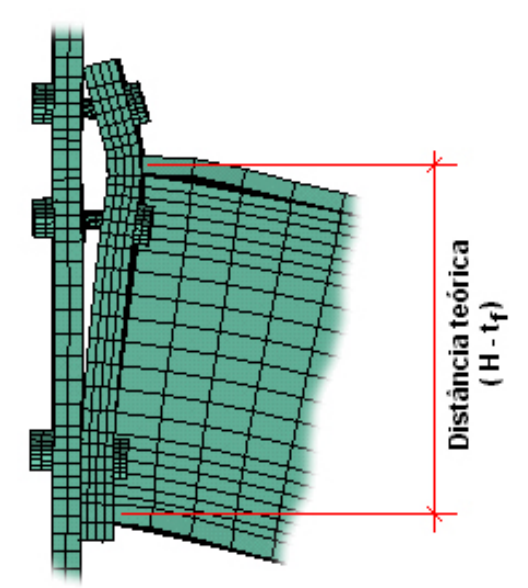

Figura 5.24 - Distância teórica $\left(H-t_{f}\right)$

Paralelamente à discussão sobre a variação de rigidez para as ligações do modelo, é conveniente relacionar as rotações da chapa de topo para algumas seções, em função da variação dos afastamentos chapa/pilar da borda da chapa para a região do plano médio da alma. Dessa maneira, 
foram escolhidos os pontos P1, P2 e P3, na intersecção entre as seções A'', BB' e CC', com a seção FF', respectivamente, como esquematizado na figura 5.25 .

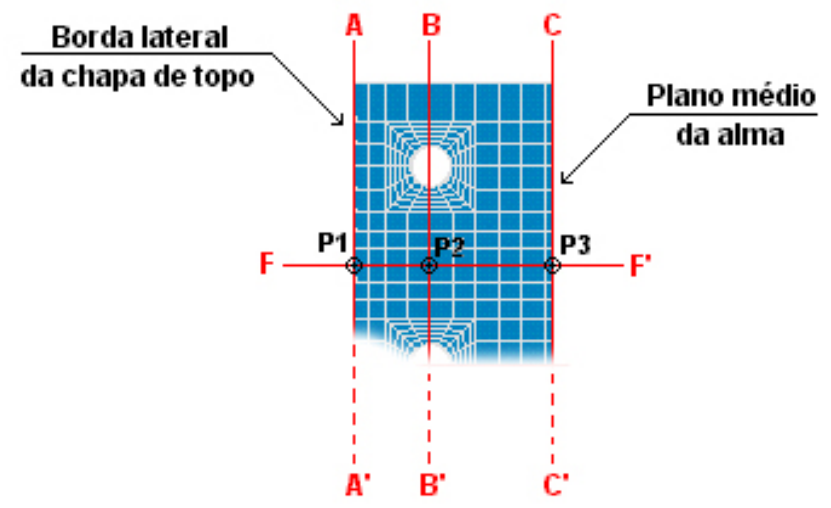

Figura 5.25 - Pontos para medição do afastamento chapa/pilar

Dessa maneira, a figura 5.26 apresenta as rotações teóricas para o modelo CT1A-1 $\left(\mathbf{t}_{\mathrm{ch}}=\mathbf{3 1 , 5} \mathrm{mm} ; \mathbf{d}_{\mathrm{p}}=16,0 \mathrm{~mm}\right)$ para os pontos descritos acima.

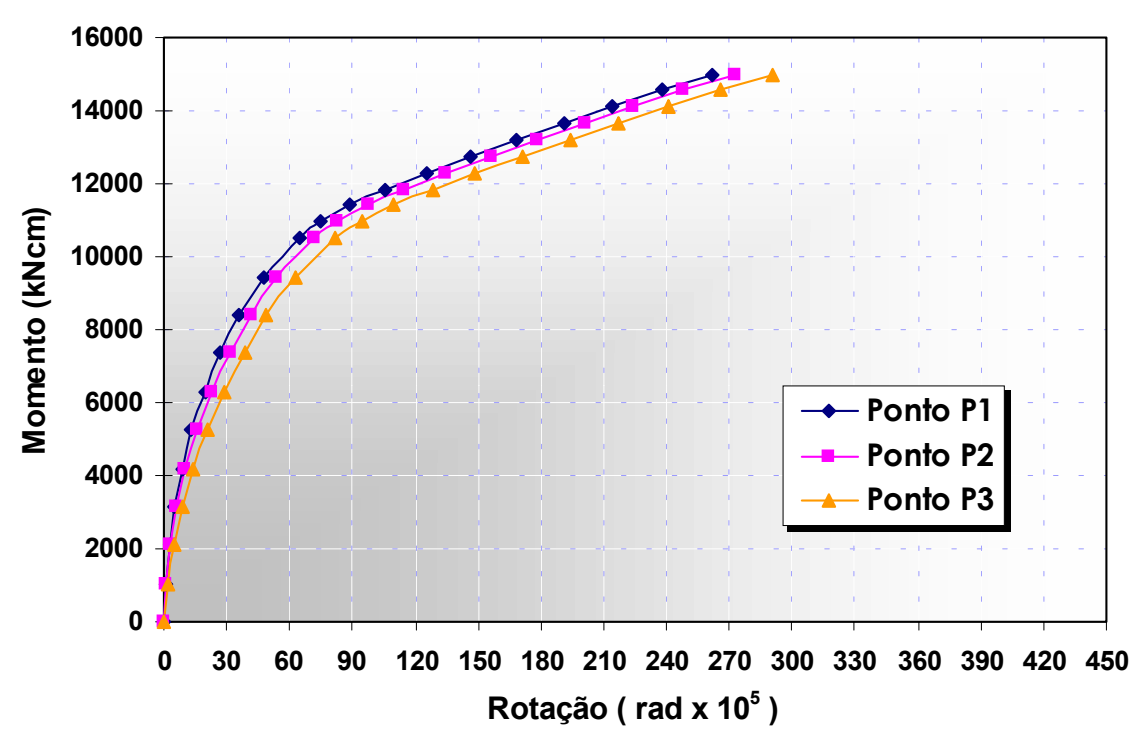

Figura 5.26 - Curva momento-rotação teórica - modelo CT1A-1

Considerando-se que os afastamentos aumentam à medida em que o ponto considerado se aproxima do plano médio da alma, também há um acréscimo na rotação. No entanto, o comportamento momento-rotação 
para os pontos considerados é semelhante, a menos de pequenas diferenças em seus valores.

Neste caso, adotou-se a rotação da chapa de topo como sendo a média dos valores encontrados para os três pontos considerados.

Analisando a influência da variação da espessura da chapa, são apresentados, na figura 5.27 , as curvas de rotação média teórica para os modelos CT1A-1 $\left(t_{c h}=31,5 \mathrm{~mm}\right)$, CT1A-2 $\left(t_{c h}=25,0 \mathrm{~mm}\right)$ e CT1A-4 $\left(t_{c h}=\right.$ 22,4 mm), todos com parafusos de 16,0 mm de diâmetro.

Da mesma forma, apresenta-se, na figura 5.28, as curvas para os modelos CT1B-2 $\left(t_{c h}=25,0 \mathrm{~mm}\right)$, CT1B-4 $\left(t_{c h}=22,4 \mathrm{~mm}\right)$ e CT1B-6 $\left(t_{c h}=\right.$ $19,0 \mathrm{~mm}$ ), para os quais foram utilizados parafusos maiores, de $19,0 \mathrm{~mm}$ de diâmetro.

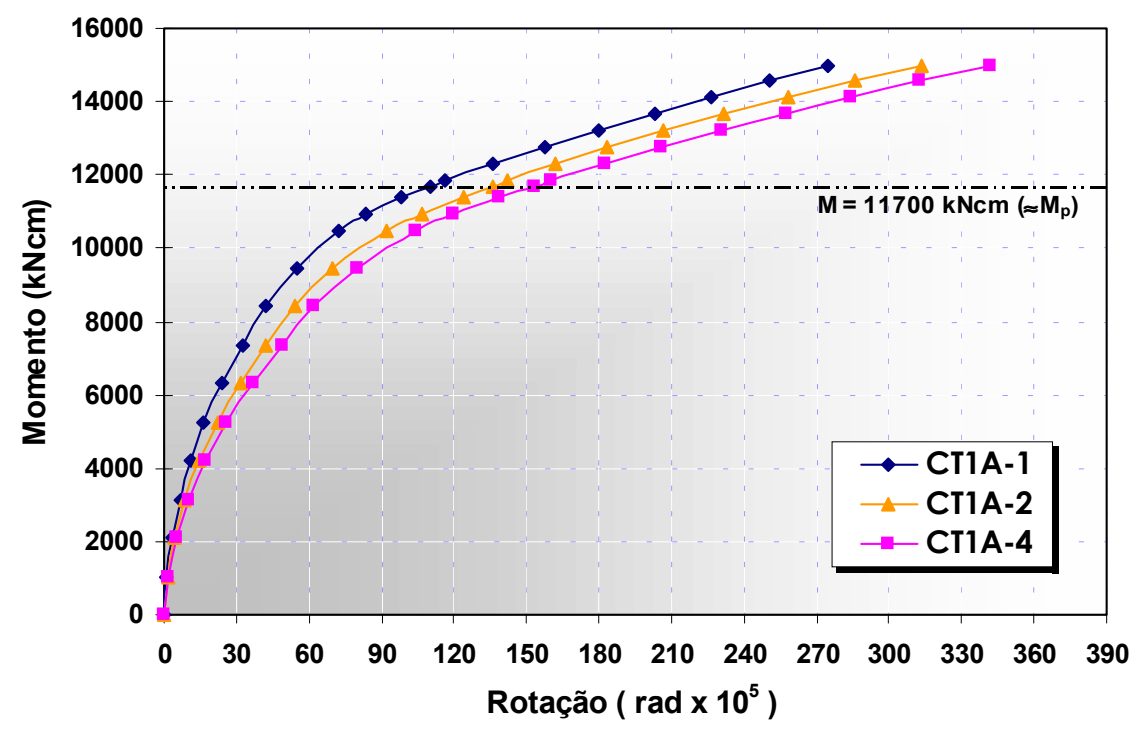

Figura 5.27 - Curvas momento-rotação teóricas médias Variação da espessura da chapa de topo $-d_{p}=16,0 \mathrm{~mm}$

É possível observar que a redução da espessura da chapa, mantendo-se constante o diâmetro do parafuso, traz como conseqüência um acréscimo nos valores de rotação, com exceção para solicitações muito baixas na ligação $(\mathbf{M}=\mathbf{2 0 0 0} \mathbf{k N c m})$, mantendo-se constante a forma da curva para todos os modelos. 


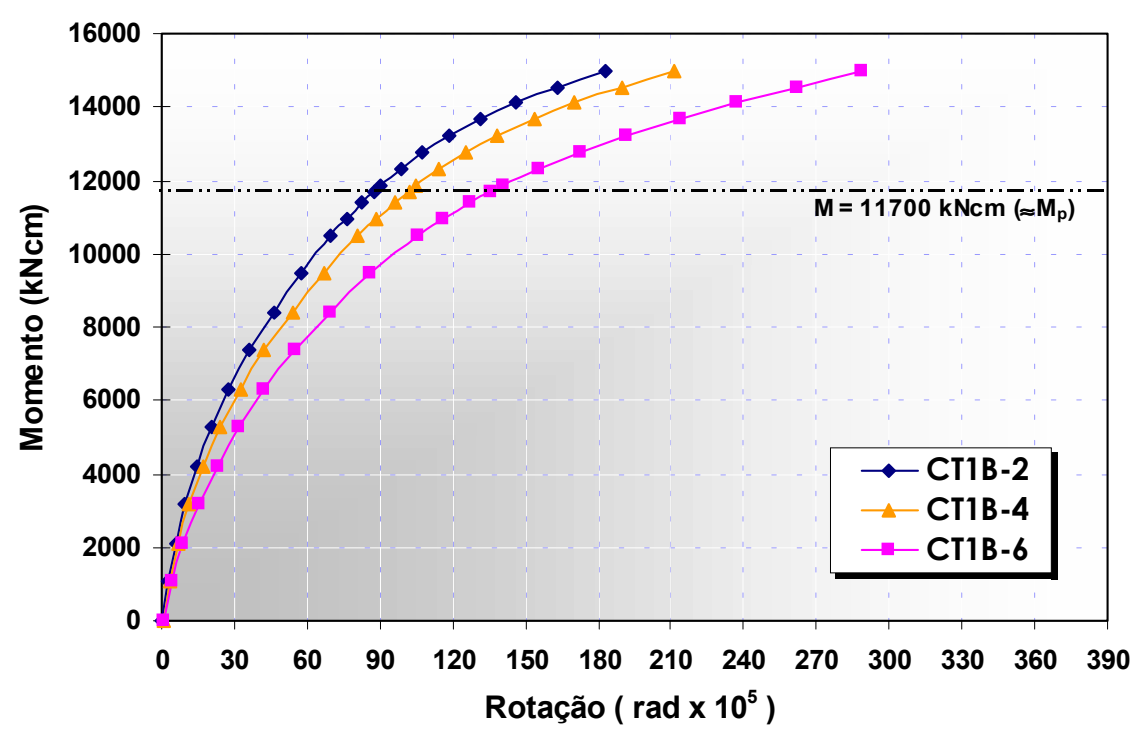

Figura 5.28 - Curvas momento-rotação teóricas médias Variação da espessura da chapa de topo $-d_{p}=19,0 \mathrm{~mm}$

Utilizando como parâmetro de referência o momento fletor, na ligação, igual à $11700 \mathrm{kNcm}\left(\approx \mathrm{M}_{\mathrm{p}}\right)$, para os modelos com parafusos de 16,0 $\mathrm{mm}$ de diâmetro, o decréscimo na espessura da chapa, de $31,5 \mathrm{~mm}$ para $\mathbf{2 5 , 0} \mathbf{m m}$ (redução de $\mathbf{2 1 \%}$ na espessura) resulta num acréscimo de $\mathbf{2 3} \%$ para os valores de rotação.

Para a variação da chapa de $\mathbf{2 5 , 0} \mathrm{mm}$ para a chapa de $\mathbf{2 2 , 4} \mathrm{mm}$ (redução de $10 \%$ na espessura), o acréscimo na rotação é de, aproximadamente, $12 \%$.

Quantitativamente, tais diferenças indicam que, para as curvas apresentadas na figura 5.27 , há uma certa proporcionalidade entre a diminuição da espessura da chapa de topo e o aumento da sua rotação.

A afirmação acima não é verificada para os modelos com parafuso de $19,0 \mathrm{~mm}$, cujas curvas momento-rotação estão apresentadas na figura 5.28. Para a variação da espessura da chapa de $25,0 \mathrm{~mm}$ para $22,4 \mathrm{~mm}$ (redução de $10 \%$ ), há um aumento de $16 \%$ na rotação. Variando-se a espessura da chapa de $22,4 \mathrm{~mm}$ para $19,0 \mathrm{~mm}$ (redução de $15 \%$ ), esse aumento é de $33 \%$.

\footnotetext{
${ }^{3}$ Os valores apresentados são obtidos para a solicitação de momento fletor igual à 11700 $\mathbf{k N c m}$, equivalente à $\mathbf{M}_{\mathbf{p}}$.
} 
A não proporcionalidade observada para os modelos com parafusos de $19,0 \mathrm{~mm}$ pode ser atribuída a uma mudança no comportamento da chapa de topo, em virtude da variação da rigidez dos elementos componentes da ligação. Para ilustrar a consideração feita acima, a figura 5.29 apresenta a deformada da região da ligação para os modelos CT1A-4 $\left(d_{p}=16,0 \mathrm{~mm}\right)$ e CT1B-4 $\left(d_{p}=19,0 \mathrm{~mm}\right)$, ambos com chapa de $22,4 \mathrm{~mm}$, para momento máximo na ligação de $\mathbf{M}=15000 \mathrm{kNcm}$.

Para o modelo CT1A-4, é possível observar que a flexão da chapa de topo contribui significativamente para o afastamento chapa/pilar. No entanto, há também uma contribuição da deformação dos parafusos. Podese dizer, então, que há uma interação entre a chapa de topo e os parafusos na consideração da capacidade resistente da ligação.

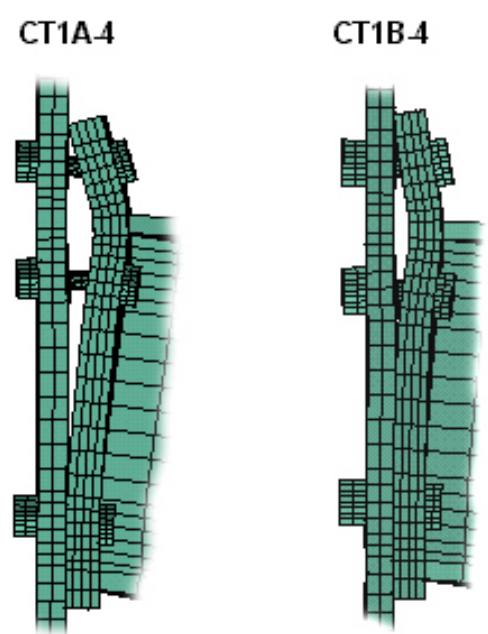

Figura 5.29 - Deformadas da chapa de topo

Para o modelo CT1B-4, o aumento do diâmetro dos parafusos diminui a sua contribuição para os valores de afastamento chapa/pilar, ou seja, as deformações dos mesmos é menor, o que pode ser visualizado na figura 5.29 pela restrição imposta à chapa.

Desta maneira, há uma concentração do afastamento chapa/pilar na região situada entre as linhas externa e interna de parafusos, com conseqüente acréscimo da flexão na chapa, que passa a ser, isoladamente, um possível modo de colapso para a ligação. 
Assim, pode-se dizer que o comportamento das ligações está intimamente ligado à "rigidez" relativa entre os elementos que as compõem.

Outra comparação pertinente refere-se à variação do diâmetro do parafuso, mantendo-se constante a espessura da chapa de topo. Assim, a figura 5.30 apresenta as curvas momento-rotação comparando-se os modelos CT1A-2 $\left(d_{p}=16,0 \mathrm{~mm}\right)$ e CT1B-2 $\left(d_{p}=19,0 \mathrm{~mm}\right)$, ambos com chapa de $\mathbf{2 5 , 0} \mathbf{m m}$ de espessura, juntamente com os modelos CT1A-4 $\left(\mathbf{d}_{\mathrm{p}}=\right.$ 16,0 $\mathrm{mm}$ ) е CT1B-4 $\left(d_{p}=19,0 \mathrm{~mm}\right)$, com chapa de 22,4 mm.

Devido ao acréscimo no diâmetro do parafuso, a rotação da chapa de topo para os modelos com parafusos de $19,0 \mathrm{~mm}$ diminui quando comparada com os modelos com parafusos de $16,0 \mathrm{~mm}$.

Uma característica interessante quanto ao comportamento da chapa de topo, a exemplo da variação da sua espessura, é a proporção do decréscimo dos valores da rotação para o aumento do diâmetro dos parafusos.

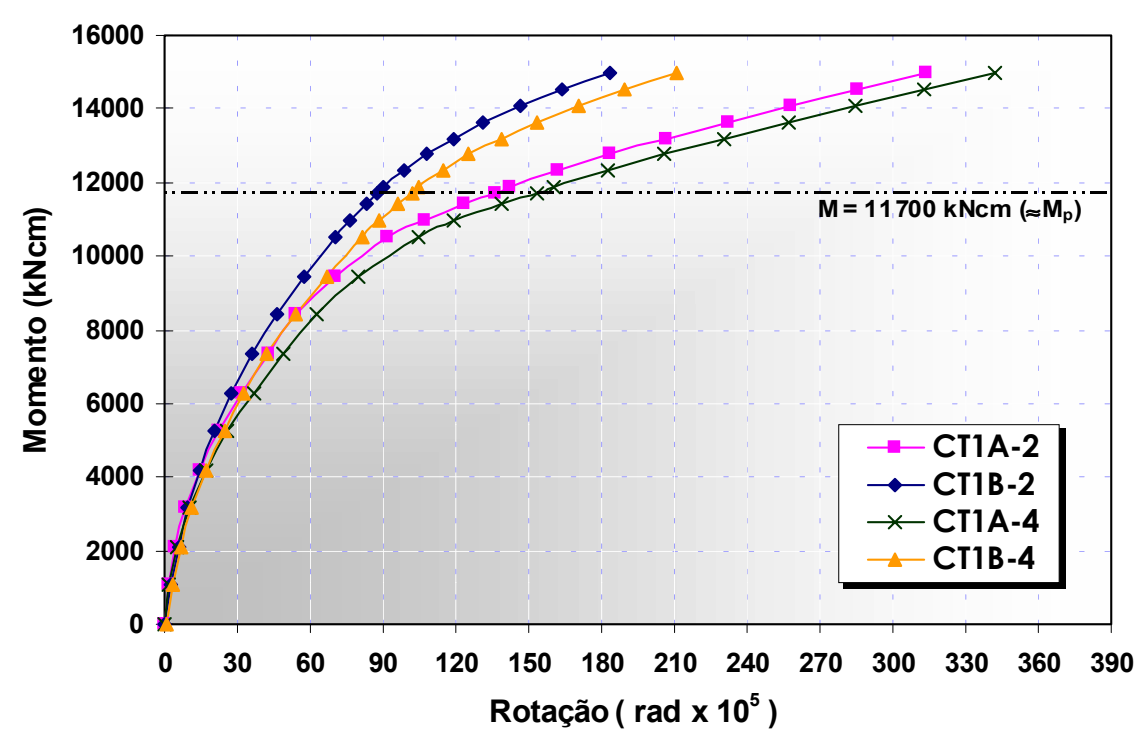

Figura 5.30 - Curvas momento-rotação teóricas médias Variação do diâmetro dos parafusos

Tomando-se, novamente, a solicitação de $11700 \mathrm{kNcm}$ como referência, para o modelo CT1B-2 a rotação da chapa é $35 \%$ inferior ao 
valor do modelo CT1A-2. Entre os modelos CT1B-4 e CT1A-4, essa redução é de $\mathbf{3 4 \%}$, bem próxima ao encontrado anteriormente.

Pode-se concluir que a interdependência da solicitação no parafuso e a espessura da chapa é clara, salientando-se também que a capacidade última do parafuso é um estado limite a ser considerado. Passa a ser, então, essencial classificar e quantificar a influência da chapa de topo na solicitação dos parafusos que ocorre por meio de um maior ou menor efeito alavanca ("prying action").

\subsection{PARAFUSOS}

A grande complexidade do comportamento das ligações com chapa de topo e das ligações em geral, deve-se ao grande número de fatores que o influenciam. Entre eles, com grande importância, inclui-se o comportamento dos parafusos.

De forma geral, pode-se verificar que as hipóteses básicas adotadas para o dimensionamento das ligações tendem a não considerar a complexidade destes componentes, apresentando diversas simplificações para o seu comportamento.

Pode-se citar, neste caso, a consideração teórica de que as forças são transmitidas à ligação somente pelas mesas da viga, e que, até poucos anos, a distribuição de forças na região tracionada se dá igualmente para todos os parafusos, considerando modelos elásticos.

Outro aspecto é a consideração de que os parafusos estão solicitados somente à tração na direção do seu eixo longitudinal, ignorandose as solicitações de flexão a que estão submetidos.

Com finalidade meramente ilustrativa, a figura 5.31 apresenta uma deformada da região tracionada no modelo CT1A-1, para a qual é possível se verificar o comportamento da ligação, destacando-se a flexão dos parafusos. 


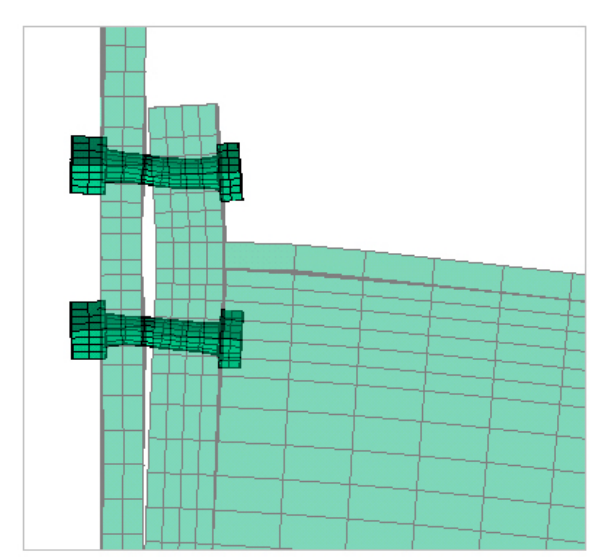

Figura 5.31 - Deformada típica dos parafusos

Dessa maneira, a inclusão dos parafusos nos modelos numéricos é de grande importância, não só pela possibilidade de se obter resultados representativos do seu comportamento, mas por representar uma melhoria para o comportamento global dos modelos numéricos.

Neste caso, inicialmente, é interessante analisar a distribuição de tensões nos parafusos dos diversos modelos numéricos, visando a identificação e quantificação dos esforços a que estão submetidos.

Verificando-se, então, as distribuições de tensões longitudinais na direção do eixo do parafuso - apresenta-se na tabela V.V um comparativo entre os parafusos da região tracionada dos modelos CT1A-1, CT1A-4, CT1B-4 e CT1B-6 para diversos níveis de carregamento, incluindo a configuração da fase final da protensão. 
Tabela V.V - Tensões longitudinais e deformadas dos parafusos

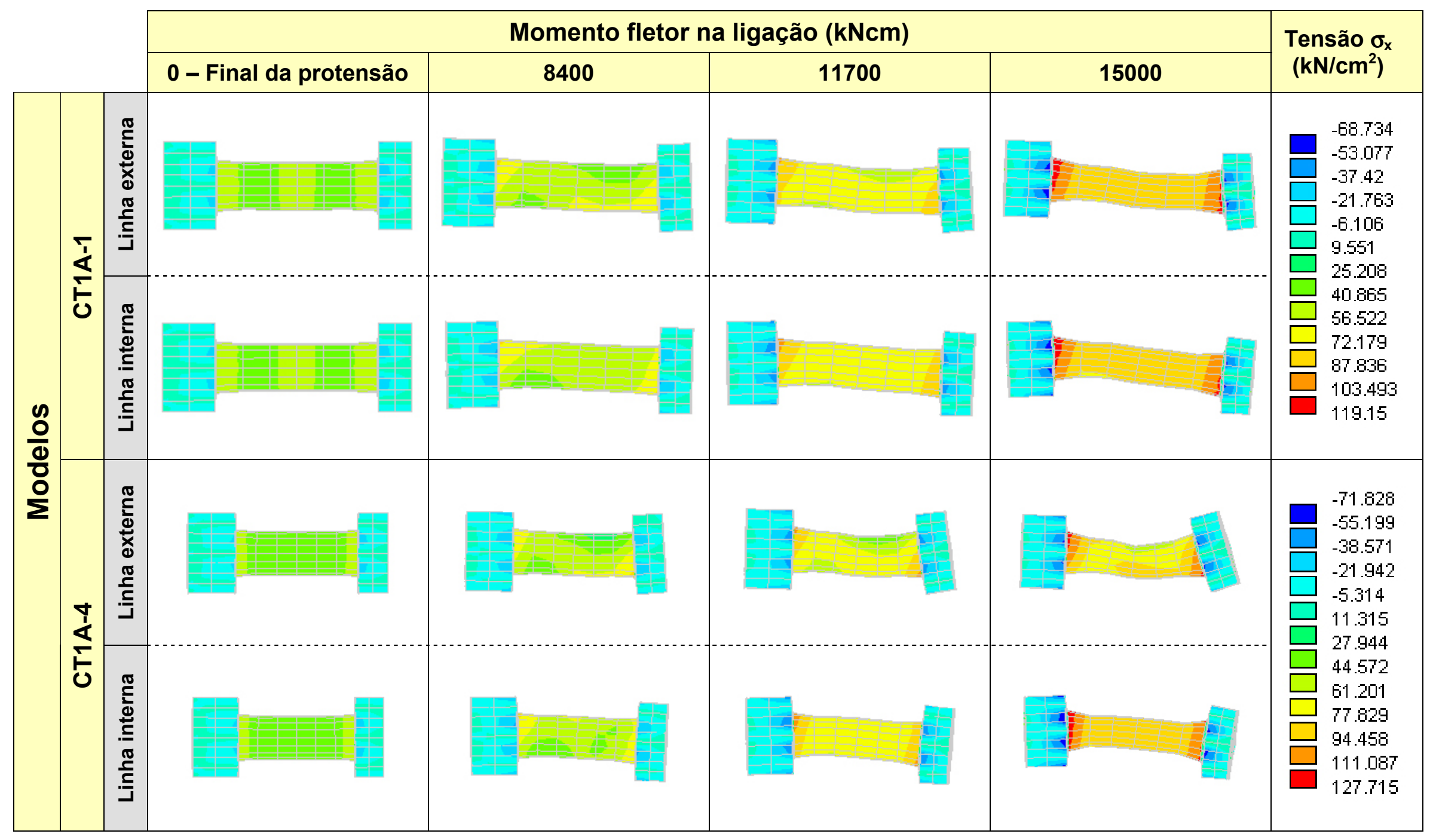




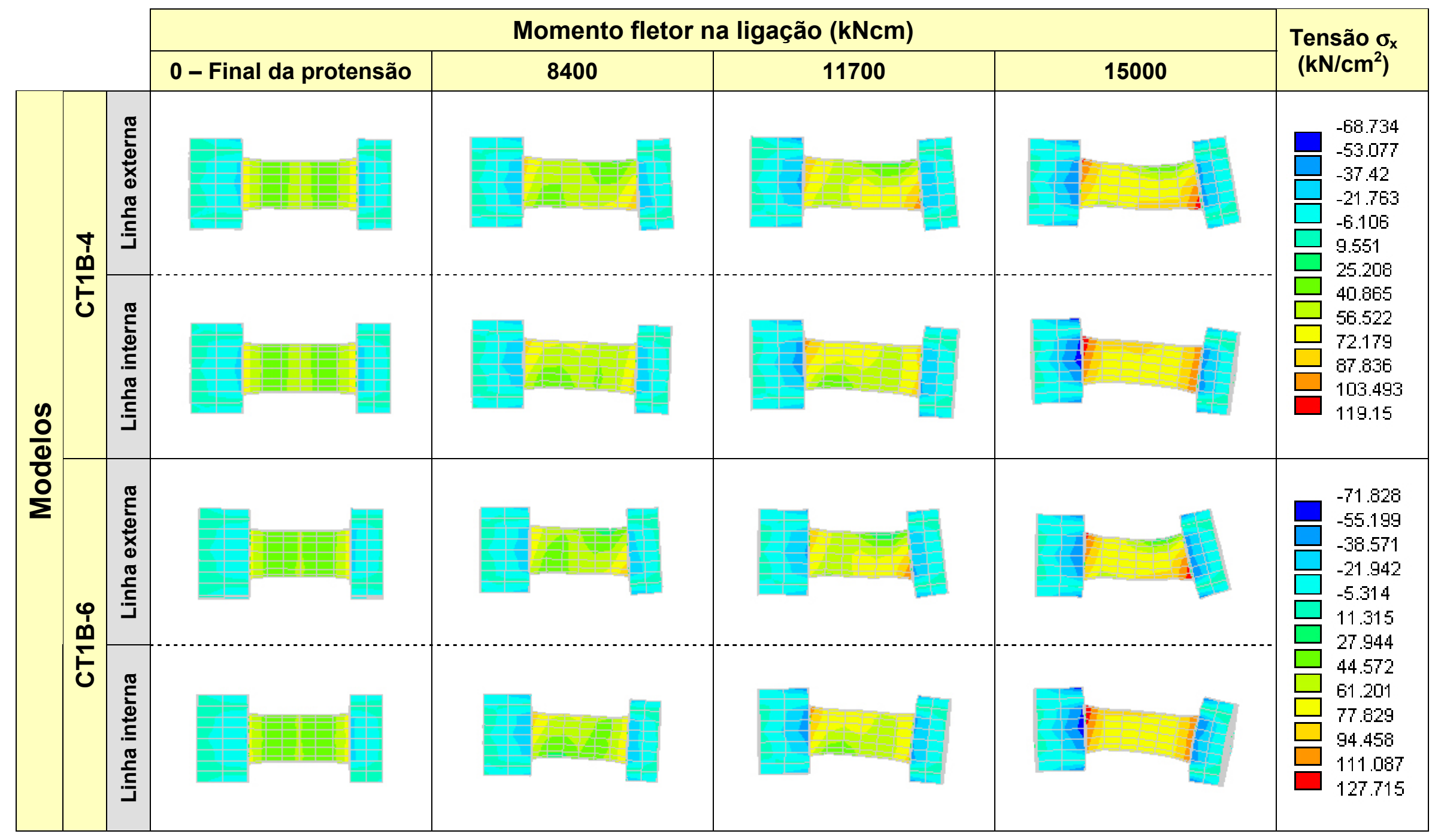


A visualização dos esforços que ocorrem nos parafusos pode ser feita facilmente, uma vez que, à medida em que aumenta a solicitação, as fibras superior e inferior do fuste possuem uma variação no valor da tensão longitudinal.

Visto que há regiões com grandes concentrações de tensão, principalmente nas extremidades do fuste, e que tal distribuição pode se tornar extremamente complexa, a análise dos resultados referentes aos parafusos será feita considerando-se os valores médios de tensão e deformação para a região central do fuste, onde a distribuição de tensões é mais bem comportada.

Vale salientar que 0 modelo do comportamento tensão $x$ deformação adotado para os parafusos não permite atingir o seu colapso, total ou parcial. Esta observação é particularmente importante pois não é possível, desta forma, obter o Estado Limite Último para o parafuso.

Para facilitar a verificação dos resultados, os parafusos serão analisados separadamente para cada um dos modelos numéricos apresentados na tabela V.V, a menos de algumas comparações, quando pertinente.

Analisando-se a questão dos esforços atuantes nos parafusos, apresenta-se, na figura 5.32, a variação das forças de tração nos parafusos das linhas externa e interna da região tracionada do modelo CT1A-1 $\left(\mathbf{t}_{\mathrm{ch}}=\right.$ $31,5 \mathrm{~mm} ; d_{p}=16,0 \mathrm{~mm}$ ).

A figura 5.32 também apresenta os valores da força $F^{*}$, que representa a força de tração para cada parafuso proveniente da solicitação na viga, calculada pela consideração de transmissão do momento fletor por um binário atuando somente nas suas mesas (hipótese teórica) e distribuída igualmente para todos os parafusos da região tracionada da ligação. Os valores da força $\mathbf{F}^{*}$ inferiores ao valor da força de protensão aplicada, estão tracejados por não representarem, teoricamente, nenhum acréscimo na força de tração de cada parafuso. 


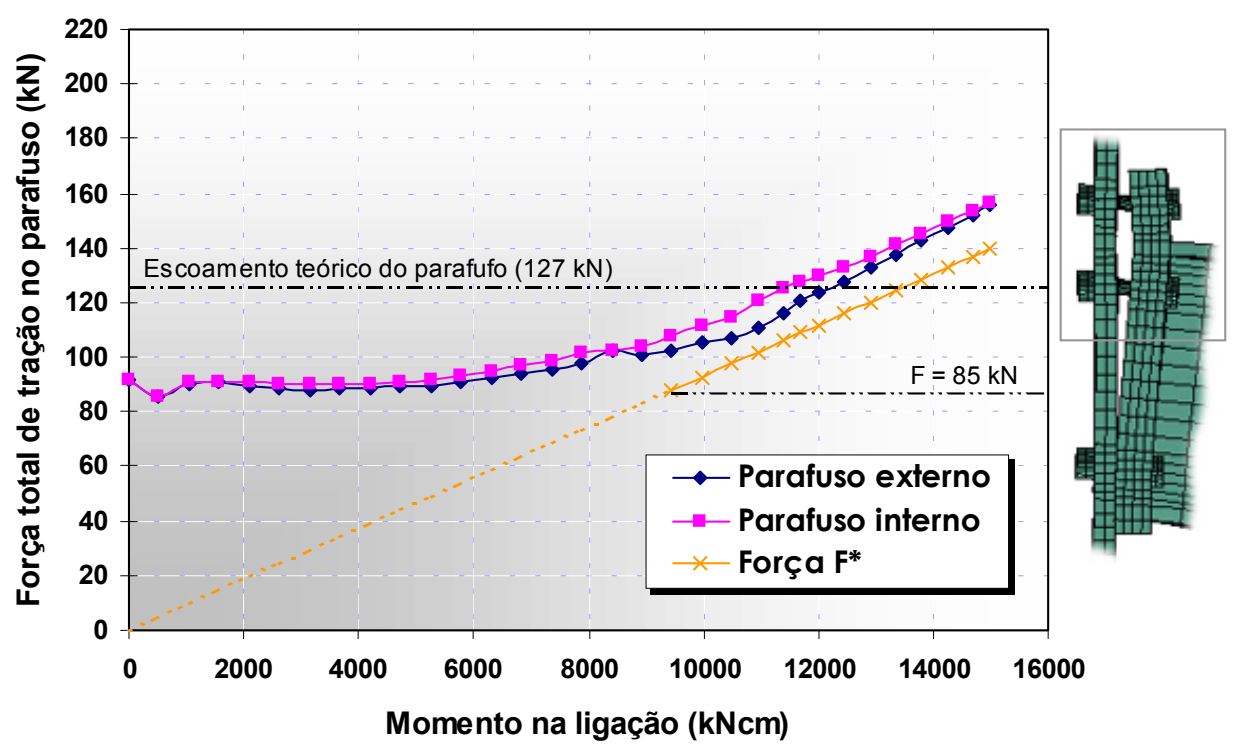

Figura 5.32 - Forças de tração nos parafusos - modelo CT1A-1 $\mathrm{F}=\mathbf{8 5} \mathrm{kN} \rightarrow$ Força de protensão

Para o modelo CT1A-1 pode-se observar que entre as linhas de parafusos (externa e interna), as forças de tração não apresentam grandes variações. Na verdade, há algumas diferenças na região compreendida entre as solicitações de $10000 \mathrm{kNcm}$ e $12000 \mathrm{kNcm}$. No entanto, para a solicitação total de $15000 \mathbf{~ k N c m}$, tais diferenças tendem a desaparecer, o que reafirma o comportamento de "corpo rígido" da chapa de topo na região tracionada.

Assim, a distribuição da força total de tração é feita com certa uniformidade para as duas linhas de parafusos.

Essa uniformidade não é observada no modelo CT1A-4 $\left(\mathbf{t}_{\mathrm{ch}}=\mathbf{2 2 , 4}\right.$ $\mathrm{mm} ; \mathrm{d}_{\mathrm{p}}=16,0 \mathrm{~mm}$ ), cujas forças de tração para cada linha de parafusos estão apresentadas na figura 5.33.

Neste caso, verifica-se que a linha interna de parafusos é mais solicitada que a linha externa, sendo que tais diferenças iniciam-se a partir de níveis baixos de solicitação, aproximadamente 4000 kNcm.

De certa forma, pode-se dizer que a diminuição da espessura da chapa de topo tem como conseqüência um aumento da solicitação nos parafusos da linha interna, com relação aos parafusos da linha externa, o 
que é coerente observando-se o comportamento da chapa de topo quando há uma variação da sua espessura.

Assim como para o modelo CT1A-1, a solicitação nos parafusos do modelo CT1A-4 é função do comportamento da chapa de topo, que introduz forças adicionais de tração nos parafusos, como esquematizado na figura 5.34 .

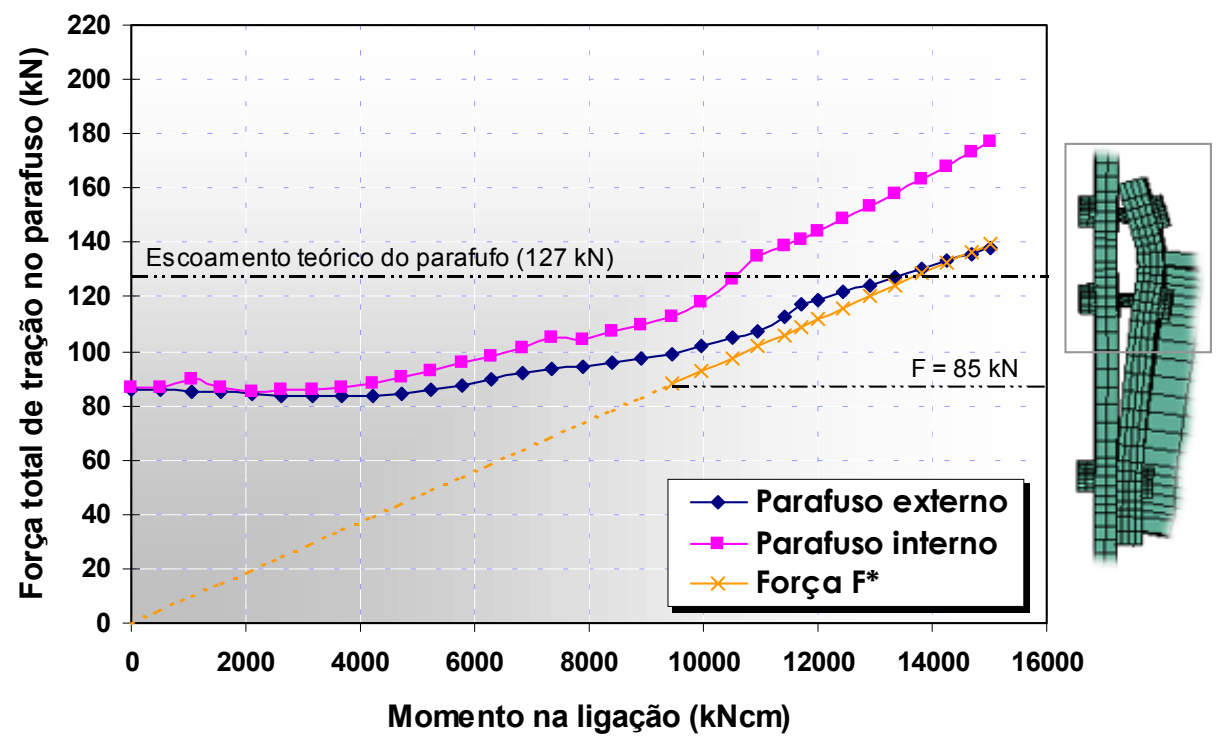

Figura 5.33 - Forças de tração nos parafusos - modelo CT1A-4

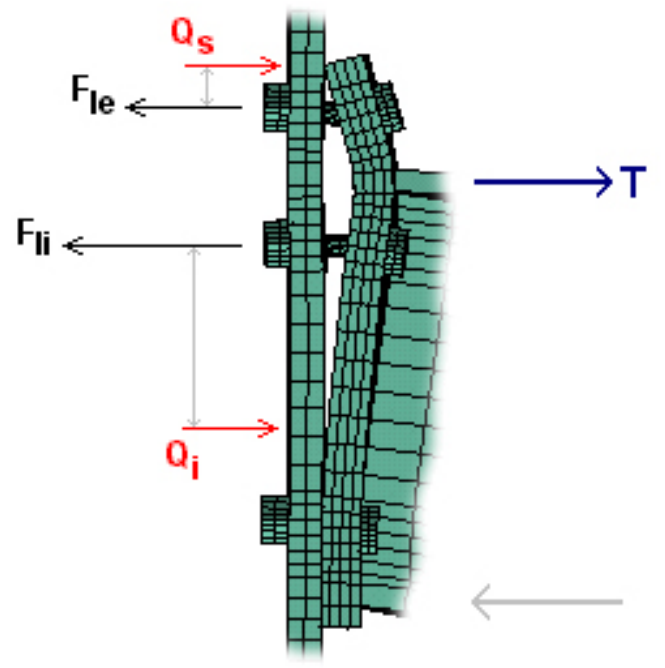

Figura 5.34 - Configuração das forças no modelo CT1A-4 
O contato entre a chapa de topo e a mesa do pilar ocasiona, com o aumentou da solicitação, uma força de reação da mesa na chapa. Esse fenômeno, conhecido como "efeito alavanca", provoca um aumento nas forças de tração dos parafusos, o que pode ser observado, qualitativamente, na figura 5.34 .

Para a configuração do modelo CT1A-4, considerando-se o equilíbrio de forças, verifica-se um aumento na solicitação dos parafusos na linha interna às mesas da viga, uma vez que o braço de alavanca entre a linha interna e o apoio inferior, na altura da força $\mathbf{Q}_{\mathbf{i}}$, é significativamente maior que a distância entre a linha externa e a extremidade superior da chapa, na altura da força $\mathbf{Q}_{\mathbf{s}}$.

Assim, pode-se observar que a força atuante no parafuso da linha interna, na figura 5.33 , é quase $\mathbf{3 0} \%$ superior a força no parafuso da linha externa, para o momento total de $15000 \mathrm{kNcm}$.

Com relação aos dois modelos, CT1A-1 e CT1A-4, ainda é possível verificar que a variação da força de tração nos parafusos atinge um crescimento significativo apenas a partir do momento em que a força de tração atuante se iguala a força aplicada na fase de protensão - $85 \mathbf{~ k N}$ para $d_{p}=16,0 \mathrm{~mm}$ e $125 \mathrm{kN}$ para $d_{p}=19,0 \mathrm{~mm}$.

$\mathrm{Na}$ tabela $\mathrm{V} . \mathrm{V}$, verifica-se que os parafusos do modelo CT1A-1 possuem distribuições de tensão muito semelhantes para todos os níveis de solicitação, ao contrário dos parafusos do modelo CT1A-4, que para a solicitação máxima apresenta tensões praticamente uniformes em todo o fuste do parafuso interno.

Quanto aos valores das tensões, considerando-se o momento fletor igual a $11700 \mathbf{k N c m}\left(\approx \mathbf{M}_{\mathbf{p}}\right)$, nota-se que existem regiões nos parafusos com

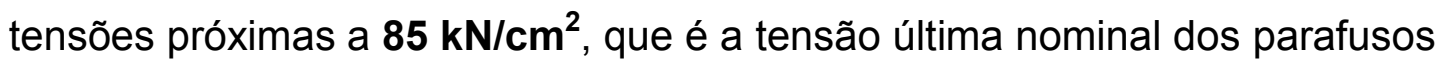
ASTM-A325. Para o momento total de $15000 \mathbf{~ k N c m}$, as tensões superam o valor da tensão última, na região da extremidade do fuste.

A ocorrência de tensões superiores à tensão de ruptura é possível uma vez que os materiais foram representados, nos modelos, por meio de diagramas bilineares, não se utilizando critérios de ruptura. 
Entre os modelos CT1B-4 $\left(t_{c h}=22,4 \mathrm{~mm} ; d_{p}=19,0 \mathrm{~mm}\right)$ e CT1B$6\left(t_{c h}=19,0 \mathrm{~mm} ; d_{p}=19,0 \mathrm{~mm}\right)$, as forças atuantes nos parafusos têm comportamento semelhante. As figuras 5.35 e 5.36, respectivas aos modelos citados, apresentam as forças atuantes para as duas linhas de parafusos.

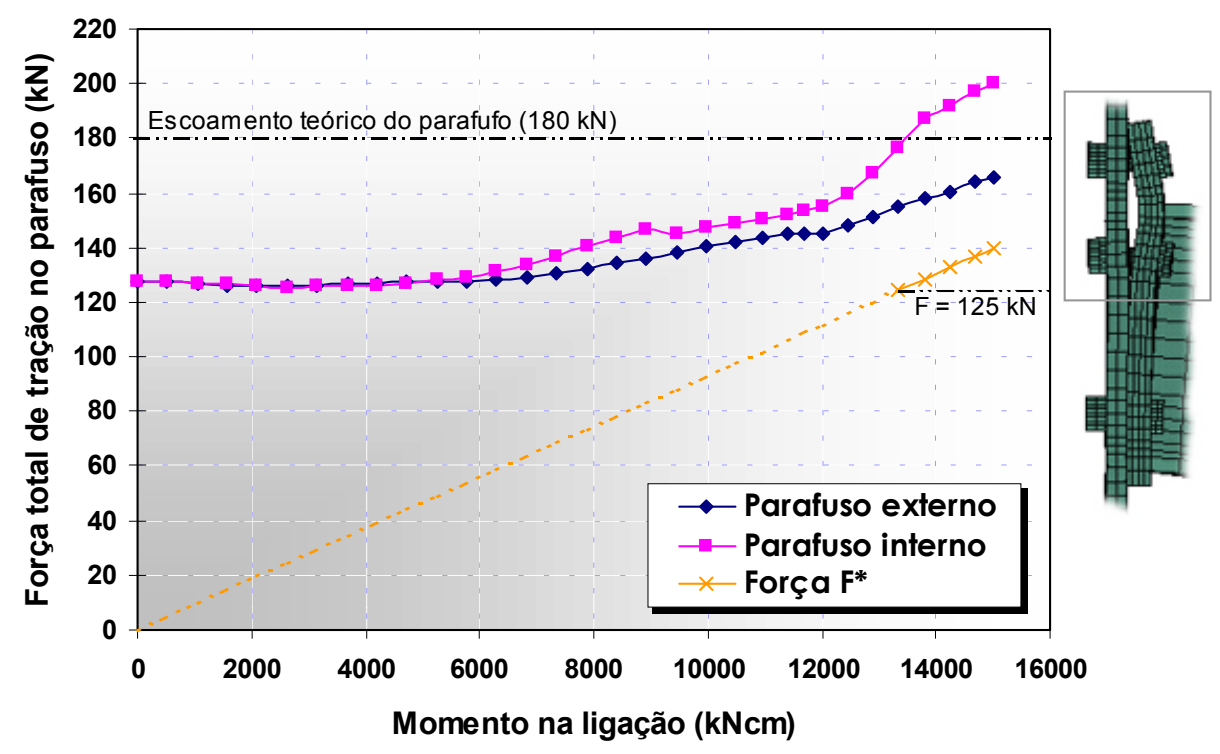

Figura 5.35 - Forças de tração nos parafusos - modelo CT1B-4 $\mathrm{F}=125 \mathrm{kN} \rightarrow$ Força de protensão

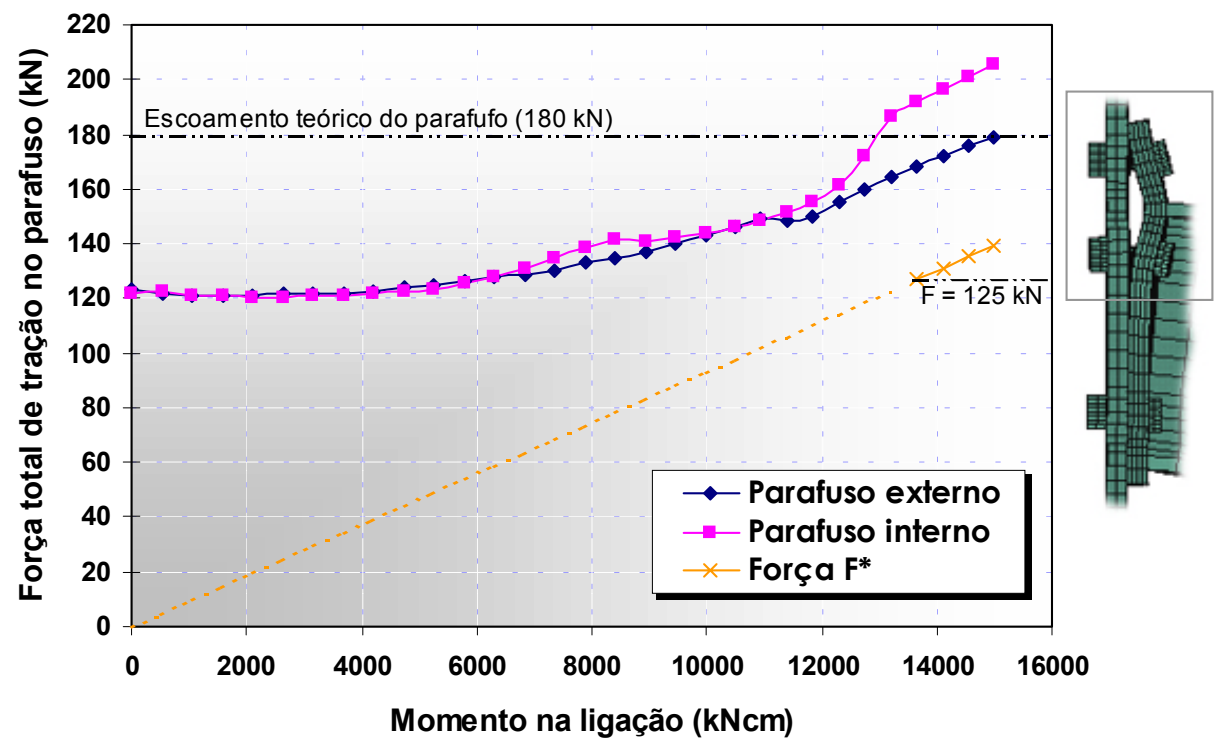

Figura 5.36 - Forças de tração nos parafusos - modelo CT1B-6 
Pode-se observar que a deformação da chapa de topo é a responsável pela rotação e deslocamento. O acréscimo de forças no parafuso, devido ao efeito alavanca, é de pequena magnitude

Dessa forma, as forças distribuem-se de forma semelhante para as linhas interna e externa, havendo diferenças significativas somente após o momento de plastificação da seção transversal da viga $\left(\mathbf{M}_{\mathrm{p}}=11700 \mathrm{kNcm}\right)$.

Tal simetria é bem notada na tabela $V . V$ para os modelos CT1B-4 e CT1B-6, na distribuição de tensões longitudinais nos parafusos.

Uma comparação adicional refere-se à variação das forças de tração nos parafusos com a variação do seu diâmetro, o que pode ser visualizado na figura 5.37, que apresenta a forças de tração nos parafusos para os modelos CT1A-4 $\left(d_{p}=16,0 \mathrm{~mm}\right)$ e CT1B-4 $\left(d_{p}=19,0 \mathrm{~mm}\right)$, ambos com chapa de $\mathbf{2 2 , 4} \mathbf{m m}$ de espessura.

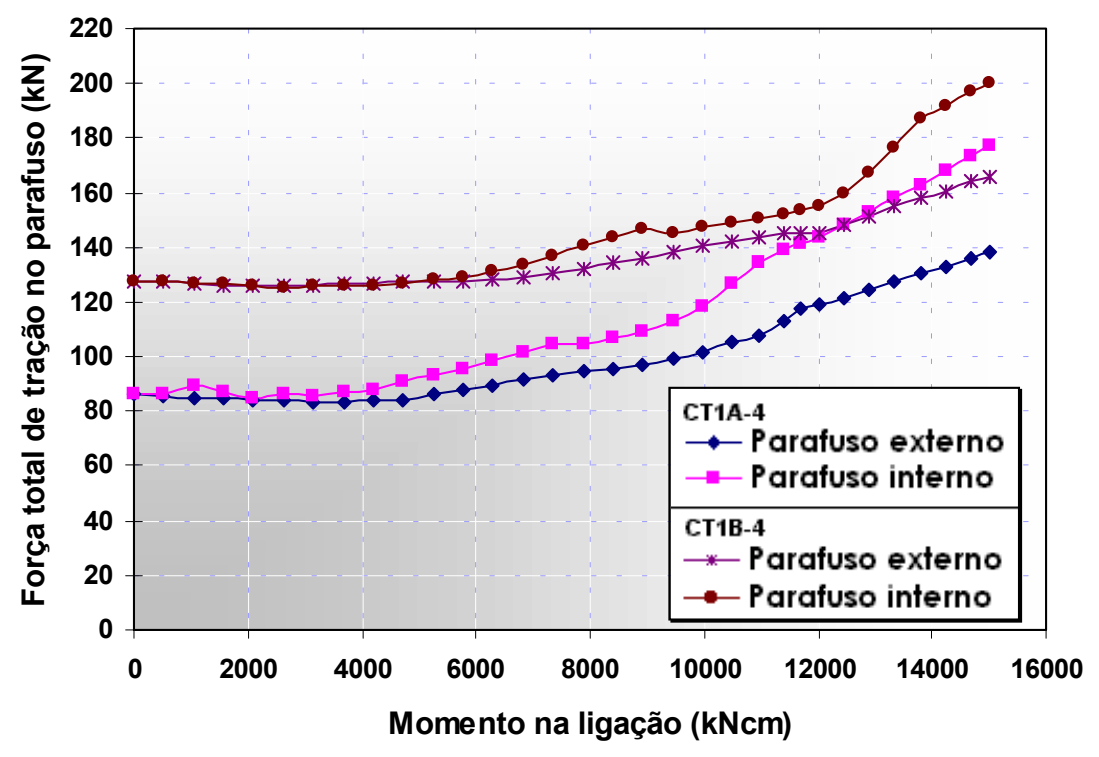

Figura 5.37 - Forças de tração nos parafusos Variação do diâmetro dos parafusos

A variação da força de tração é relativamente menor para os parafusos com maior diâmetro, ressaltando-se a força inicial para ambos os modelos, igual ao valor da força de protensão aplicada aos parafusos. 
Apresentada a distribuição das forças de tração, ainda é importante observar as deformações específicas dos parafusos para a verificação da metodologia empregada na aplicação das forças de protensão.

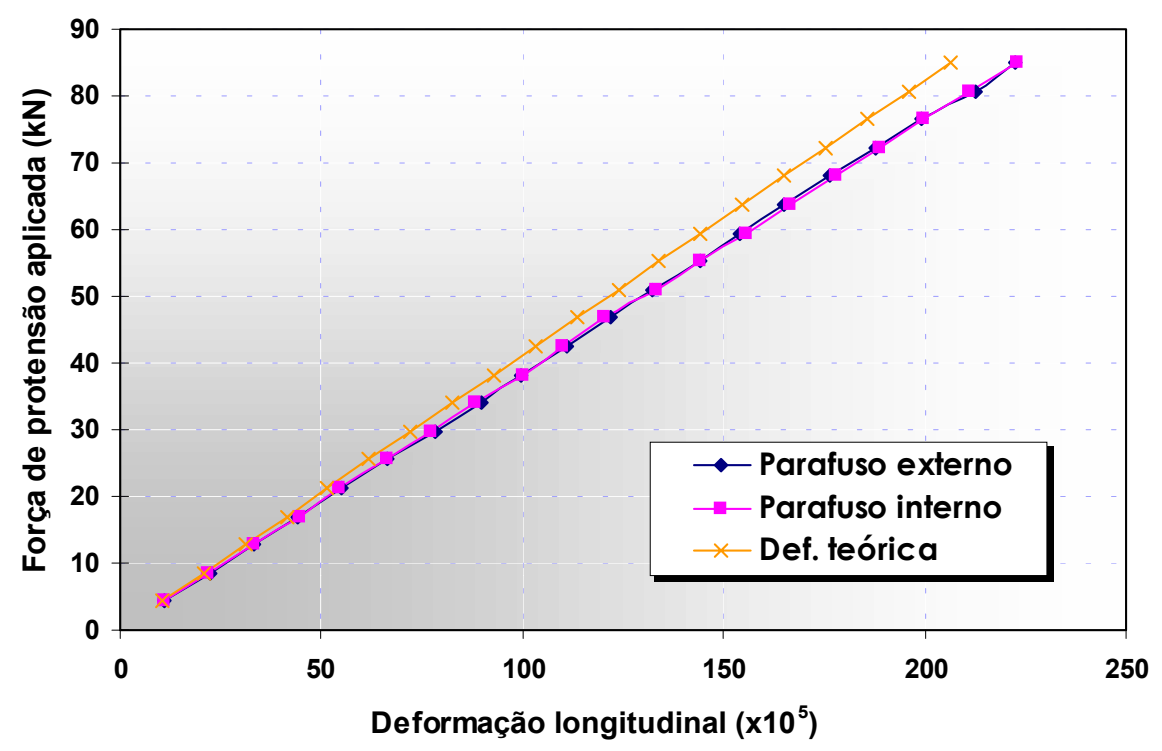

Figura 5.38 - Deformações devido à protensão $-d_{p}=16,0 \mathrm{~mm}$

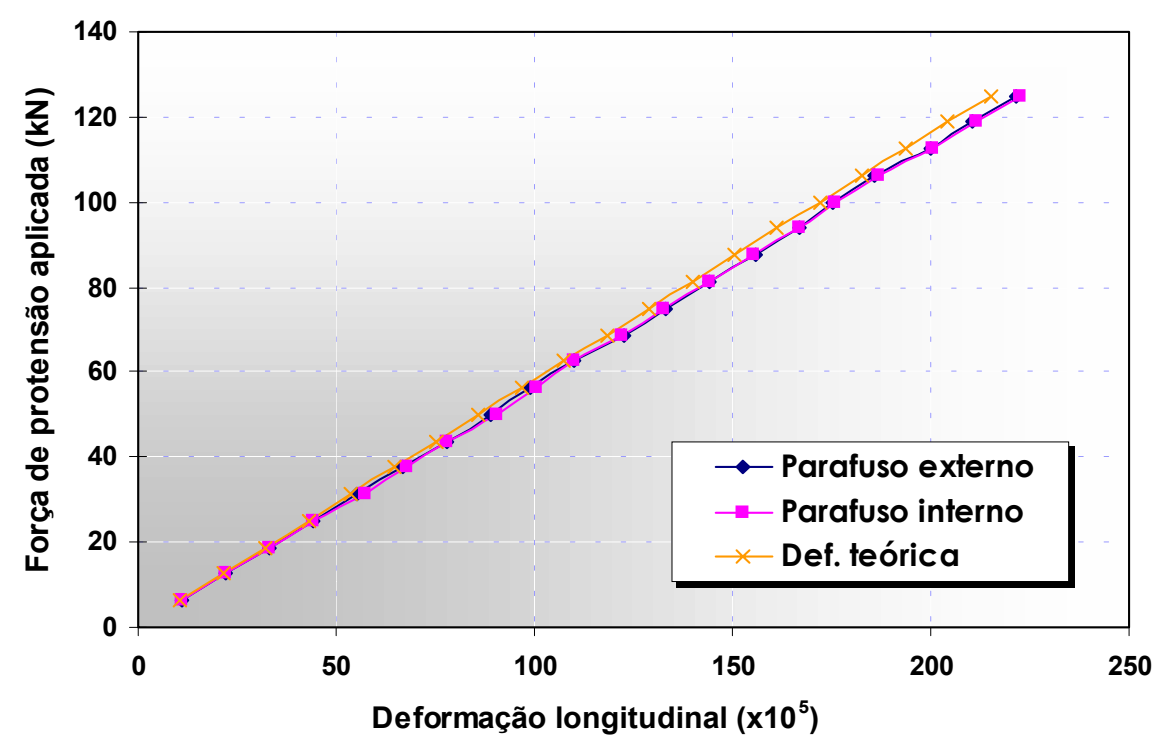

Figura 5.39 - Deformações devido à protensão $-d_{p}=19,0 \mathrm{~mm}$

Assim, as figuras 5.38 e 5.39 apresentam as deformações para os parafusos de $16,0 \mathrm{~mm}$ e $19,0 \mathrm{~mm}$, respectivamente, relativas à fase de protensão, apresentando também a deformação teórica, calculada em 
função da força de protensão aplicada e da área do parafusos, considerando

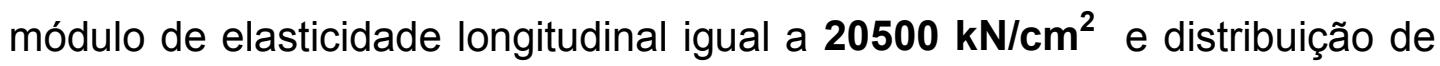
tensões constante ao longo do fuste.

Para os parafusos de $16,0 \mathrm{~mm}$, a deformação teórica prevista para o carregamento máximo de $85 \mathbf{~ k N}$ (força de protensão total aplicada) é de $206 \times 10^{-5}$. Nos modelos numéricos, a deformação específica para o carregamento máximo é de $223 \times 10^{-5}$.

Para os parafusos de $19,0 \mathrm{~mm}$, cuja força total de protensão recomendada é de 125 kN, a deformação obtida nos modelos é de 222 x $10^{-5}$ contra uma deformação teórica prevista de $215 \times 10^{-5}$.

Quanto à força de protensão, a aplicação de diferenciais de temperatura negativos no fuste dos parafusos apresenta-se como uma metodologia coerente, visto às pequenas diferenças encontradas nos valores obtidos entre as deformações previstas teoricamente e as obtidas nos modelos numéricos.

\subsection{COMENTÁRIOS GERAIS}

A apresentação dos resultados obtidos pela análise numérica, neste capítulo, teve como principal objetivo a verificação dos resultados obtidos com os modelos numéricos, ressaltando-se certos aspectos do comportamento das ligações com chapa de topo.

Assim, os resultados abordados neste capítulo permitiram verificar a variação no comportamentos das ligações e a influência da variação da espessura da chapa e do diâmetro dos parafusos.

Alguns resultados complementares, referentes aos modelos finais e aos modelos preliminares - considerando apoio rígido - são apresentados no Anexo II.

Finalmente, com relação à proposta inicial deste trabalho, é importante a confirmação da representatividade dos modelos numéricos quando comparados aos resultados experimentais existentes para os 
protótipos a que fazem referência. Essa abordagem será realizada no próximo capítulo.

Comentários específicos sobre os resultados apresentados nos capítulos 5 e 6 serão realizados no capítulo 7, dedicado à discussão e apresentação das conclusões deste trabalho. 


\section{Capítulo}

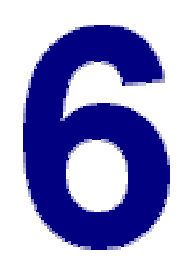

\section{COMPARAÇÃO DOS RESULTADOS NUMÉRICOS E EXPERIMENTAIS}

A partir da década de 70, a utilização de modelos numéricos para a análise do comportamento das ligações tornou-se uma alternativa viável à análise experimental, tendo em vista, principalmente, aspectos econômicos.

Tal fato torna-se mais plausível à medida em que se percebe, também, as dificuldades inerentes à metodologia empregada em uma análise experimental, citando-se, neste caso, a montagem dos protótipos, a complexidade da instrumentação e as imperfeições que podem existir nas peças a serem ensaiadas.

No entanto, tais modelos numéricos devem produzir resultados que, dentro das hipóteses e simplificações adotadas, sejam representativos do comportamento das ligações estudadas.

Dessa maneira, este capítulo tem como objetivo avaliar o grau de representatividade dos modelos numéricos tratados neste trabalho, comparando-os com os resultados da análise experimental realizada por RIBEIRO (1998).

Além disso, inicialmente, adiciona-se uma discussão sobre a metodologia empregada no Anexo J do EUROCODE-3 (1993) para a verificação da capacidade resistente das ligações, utilizando os modelos numéricos.

Com relação à natureza de tais resultados, serão apresentados dados relativos ao comportamento global da ligação, representado pelos afastamentos da chapa de topo com relação à mesa do pilar e curvas 
momento-rotação, salientando a importância desses parâmetros no enfoque adotado para este trabalho.

Especificamente para as curvas momento-rotação, serão acrescentados, quando disponíveis, os resultados obtidos numericamente por RIBEIRO(1998) para os mesmos modelos.

Enfatiza-se, novamente, que os modelos numéricos acima citados tiveram como base para suas características os protótipos ensaiados por RIBEIRO (1998), o que torna possível tais comparações.

As denominações dadas aos protótipos e aos modelos numéricos, seguem os apresentados no capítulo 4 , na tabela IV.I.

\subsection{EUROCODE-3 (1993)}

A metodologia empregada no Anexo J do EUROCODE-3 (1993) para a verificação da capacidade resistente das ligações com chapa de topo, foi apresentada no item 2.3 do capítulo 2.

O EUROCODE-3 (1993) prevê diversas verificações nos elementos básicos que compõem as ligações, incluindo considerações da maneira como esses elementos interagem na determinação dos possíveis modos de colapso, ou seja, na identificação dos estados últimos aplicáveis à ligação.

Assim, é possível analisar o comportamento dos parafusos, da chapa de topo e do apoio - neste caso, a mesa do pilar - isoladamente ou em conjunto. Recordando o item 2.3, os modos de falha que devem ser considerados estão esquematizados na figura 6.1, e são:

i. Modo $1 \rightarrow$ escoamento da mesa do pilar ou da chapa de topo;

ii. Modo $2 \rightarrow$ escoamento da mesa do pilar ou da chapa de topo e ruptura do parafuso;

iii. Modo $3 \rightarrow$ ruptura do parafuso. 


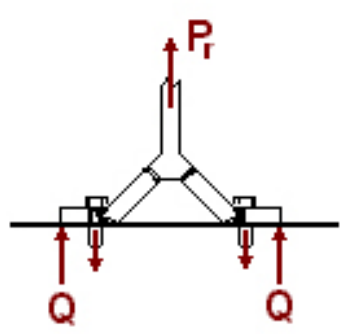

Modo 1

Escoamento total do flange do pilar ou da chapa de topo

Chapa fina,

Parafuso com grande diâmetro

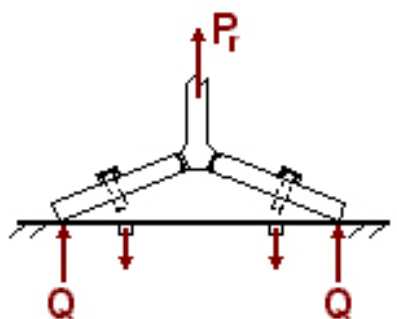

Modo 2

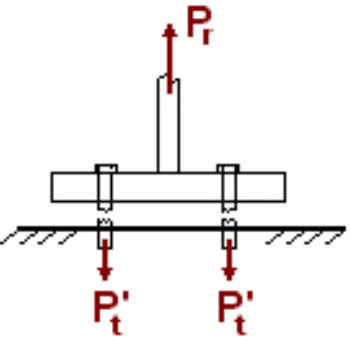

Modo 3
Ruptura do parafuso com escoamento do flange do pilar ou da chapa de topo
Ruptura dos parafusos

Chapa espessa,

Parafuso com pequeno diâmetro

Figura 6.1 - Modos de falha para a flexão da mesa do pilar ou da chapa de topo - Anexo J do EUROCODE-3 (1993)

Como prescreve o EUROCODE-3 (1993), os modos de falha apresentados na figura 6.1 devem ser verificados, determinando-se a capacidade resistente de cada linha de parafusos da região tracionada.

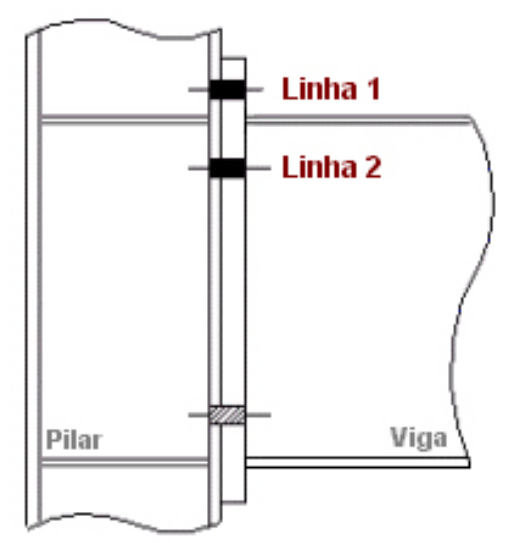

Figura 6.2 - Linhas de parafusos na região tracionada das ligações

A fim de simplificar a apresentação dos resultados obtidos para a capacidade resistente, com a utilização do EUROCODE-3 (1993), para os modelos CT1A-1, CT1A-4, CT1B-4 e CT1B-6, e considerando a forma geral das ligações estudadas neste trabalho, ilustrada na figura 6.2, a linha de parafusos externa, situada na extensão da chapa de topo, receberá a 
denominação de "linha 1". A linha compreendida entre as mesas da viga receberá a denominação de "linha 2".

Para efeito de comparação entre o EUROCODE-3 (1993) e os resultados numéricos, só há sentido em se utilizar os valores de capacidade resistente referentes à flexão da chapa de topo, uma vez que o pilar pode ser considerado rígido o suficiente para não apresentar variações no seu comportamento.

Fazendo-se um paralelo aos modelos numéricos, serão apresentados os deslocamentos da chapa de topo com relação à mesa do pilar, comparando-se, qualitativamente, os resultados dos modelos aos modos de falha citados acima. Assim, utiliza-se a seção transversal BB', na altura da viga, e as seções transversais EE' e GG', horizontais. As seções e a forma de apresentação das curvas estão ilustradas na figura 6.3.

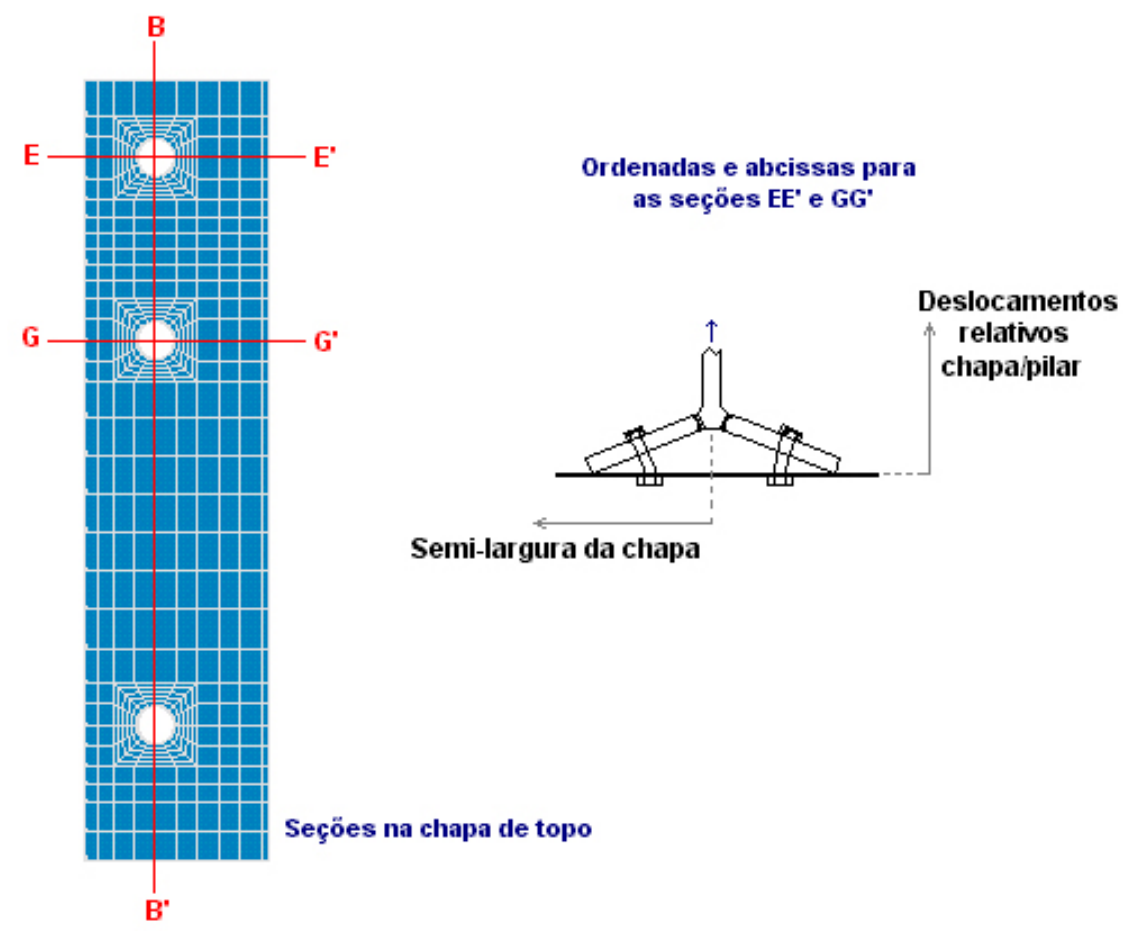

Figura 6.3 - Seções na chapa de topo 
Analisando-se, inicialmente, a variação da espessura da chapa de topo, apresenta-se na tabela VI.I os valores da capacidade resistente $\left(\mathbf{P}_{\mathbf{r}}\right)$ de cada linha de parafusos, calculados para os três modos de falha apresentados na figura 6.1 , para os modelos CT1A-1 $\left(\mathbf{t}_{\mathrm{ch}}=\mathbf{3 1 , 5} \mathrm{mm}\right) \mathrm{e}$ CT1A-4 $\left(t_{c h}=22,4 \mathrm{~mm}\right)$, ambos com parafusos de $16,0 \mathrm{~mm}$ de diâmetro.

Tabela VI.I - Capacidade resistente para a flexão da chapa de topo segundo o EUROCODE-3 (1993) - Modelos CT1A-1 e CT1A-4

\begin{tabular}{|c|c|c|c|c|c|c|}
\hline \multirow{2}{*}{ Modelo } & \multirow{2}{*}{$\begin{array}{c}\text { Espessura } \\
\text { chapa } \\
(\mathrm{mm})\end{array}$} & \multirow{2}{*}{$\begin{array}{l}\text { Diâmetro } \\
\text { parafuso } \\
(\mathrm{mm})\end{array}$} & \multirow{2}{*}{ Linha } & \multicolumn{3}{|c|}{ Modos de Falha $-\mathrm{P}_{\mathrm{r}}(\mathrm{kN})$} \\
\hline & & & & 1 & 2 & 3 \\
\hline \multirow{2}{*}{ CT1A-1 } & \multirow{2}{*}{31,5} & \multirow{2}{*}{16,0} & 1 & 476,5 & 213,4 & 180,0 \\
\hline & & & 2 & 1414,0 & 482,3 & 180,0 \\
\hline \multirow{2}{*}{ CT1A-4 } & \multirow{2}{*}{22,4} & \multirow{2}{*}{16,0} & 1 & 240,9 & 145,8 & 180,0 \\
\hline & & & 2 & 715,0 & 281,8 & 180,0 \\
\hline
\end{tabular}

Verificando-se os valores apresentados na tabela VI.I, observa-se que a capacidade resistente da ligação no modelo CT1A-1 $\left(\mathbf{t}_{\mathrm{ch}}=\mathbf{3 1 , 5} \mathrm{mm}\right.$; $d_{p}=16,0 \mathrm{~mm}$ ) é limitada pelo colapso do parafuso em ambas as linhas, representando o modo de falha $3^{\mathrm{H}}$.

Para o modelo CT1A-4 $\left(t_{c h}=22,4 \mathrm{~mm} ; d_{p}=16,0 \mathrm{~mm}\right)$, os parafusos na linha 1 (externa) tem a capacidade resistente limitada pela interação do escoamento da chapa e da ruptura dos parafuso, ou seja, pelo modo de falha 2.

Já a linha interna, continua sendo limitada pela ruptura dos parafusos (modo 3). No entanto, é interessante notar que a diminuição na espessura da chapa provoca, para a linha 2 (interna) uma redução significativa da capacidade resistente para os modos de falha $\mathbf{1}$ e $\mathbf{2}$, representando um aumento da flexão na chapa de topo.

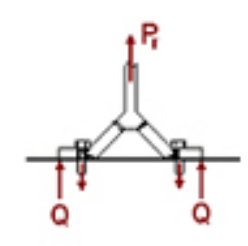

Modo 1

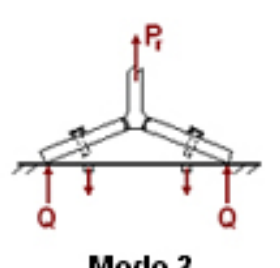

Modo 2

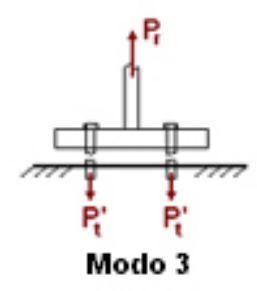


Com relação aos modelos numéricos, a figura 6.4 apresenta os deslocamentos relativos da chapa de topo para os modelos CT1A-1 e CT1A4, na seção BB', tomando-se como referência um momento fletor, na ligação, igual à 11700 kN.cm. Para todos os modelos numéricos, o valor de referência de $11700 \mathbf{~ k N . c m}$ foi escolhido por representar o Estado Limite Último de dimensionamento para a viga, ou seja, é um valor equivalente ao momento teórica de plastificação da seção transversal da viga.

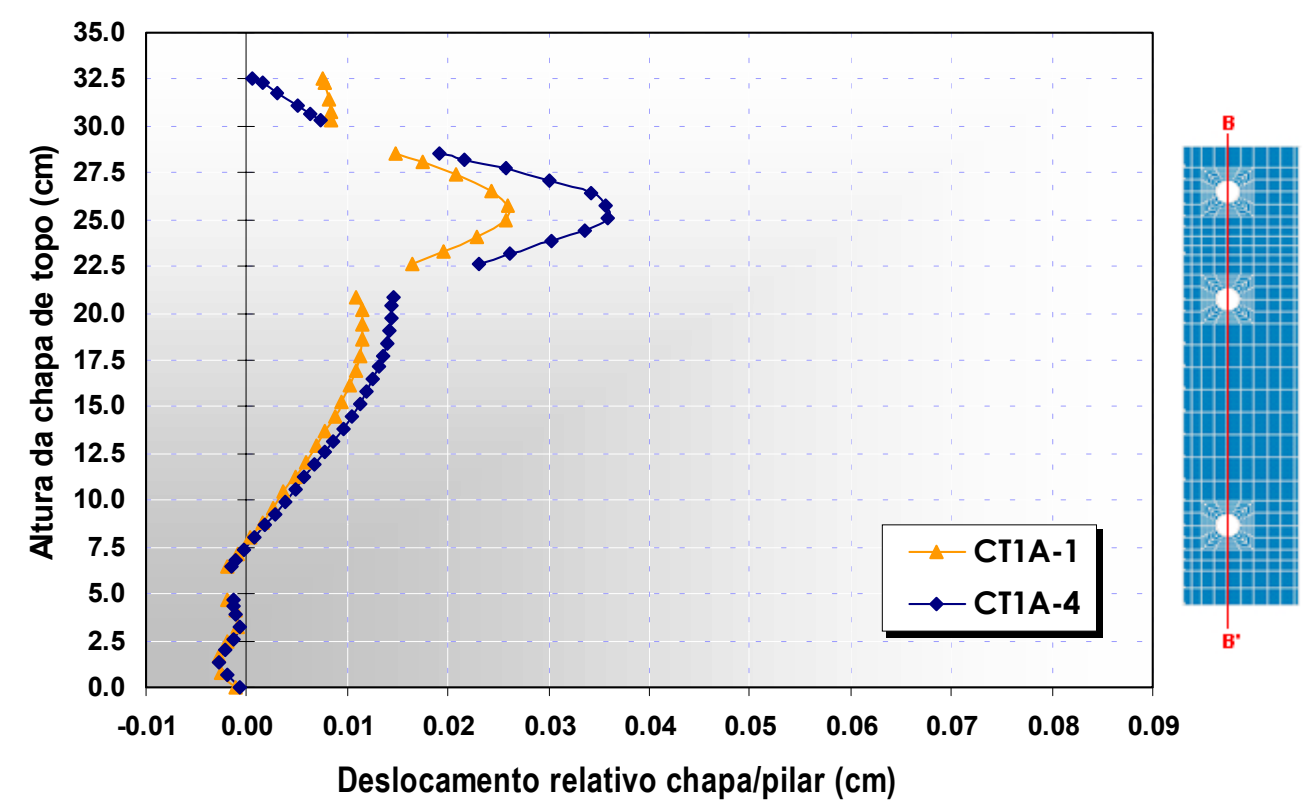

Figura 6.4 - Deslocamento relativo chapa/pilar - seção BB' CT1A-1 $\left(t_{c h}=31,5 \mathrm{~mm}\right)$ e CT1A-4 $\left(t_{c h}=22,4 \mathrm{~mm}\right)$

A chapa de topo do modelo CT1A-1, como já comentado no capítulo 5, apresenta pequenas deformações devido à flexão, descolando completamente da mesa do pilar na região tracionada. Com esse comportamento, é intuitivo observar que a deformação dos parafusos seja a maior responsável pelo deslocamento da chapa. Neste caso, a ruptura dos parafusos seria um fator limitante para a determinação da capacidade resistente, o que é indicado pelos valores obtidos com o EUROCODE-3 (1993). A figura 6.4 indica, para o modelo CT1A-1, o deslocamento da extremidade superior da chapa, o que reafirma as pequenas deformações da chapa de topo. 
Já para o modelo CT1A-4, há uma modificação do comportamento da chapa de topo, com conseqüente aparecimento do efeito alavanca e modificação dos esforços nos parafusos.

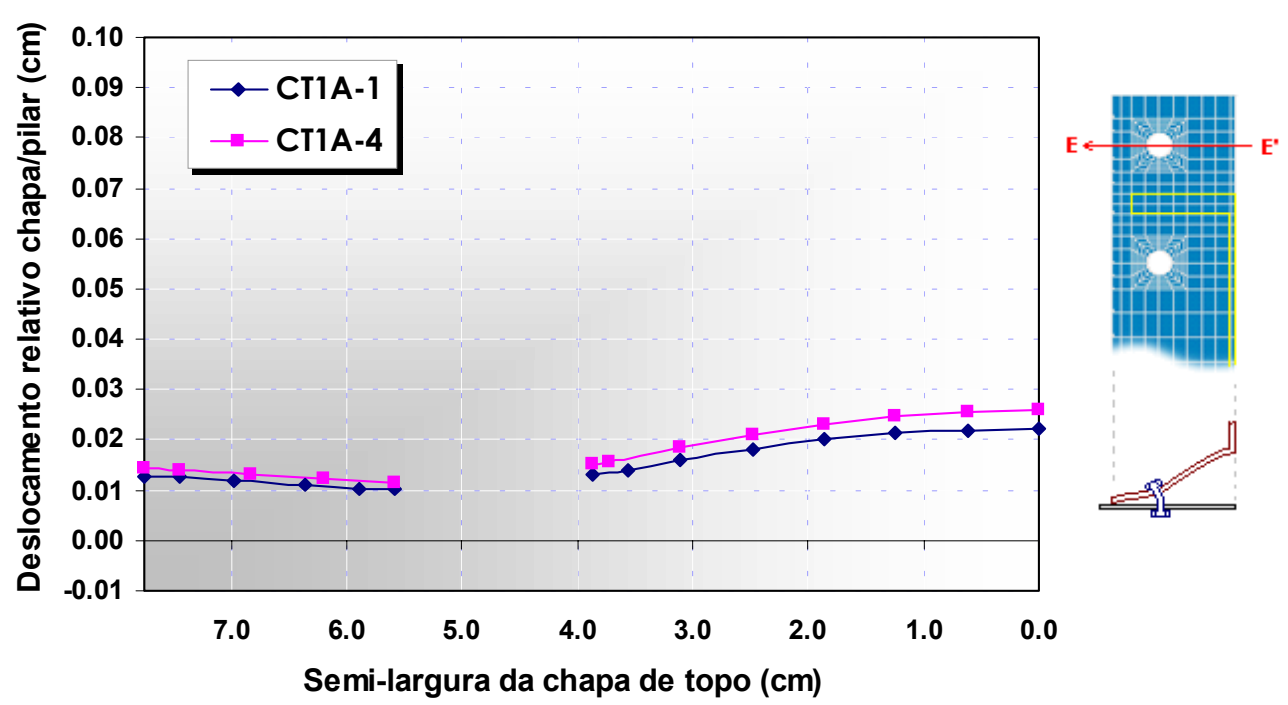

Figura 6.5 - Deslocamento relativo chapa/pilar - seção EE' CT1A-1 $\left(t_{c h}=31,5 \mathrm{~mm}\right)$ e CT1A-4 $\left(t_{c h}=22,4 \mathrm{~mm}\right)$

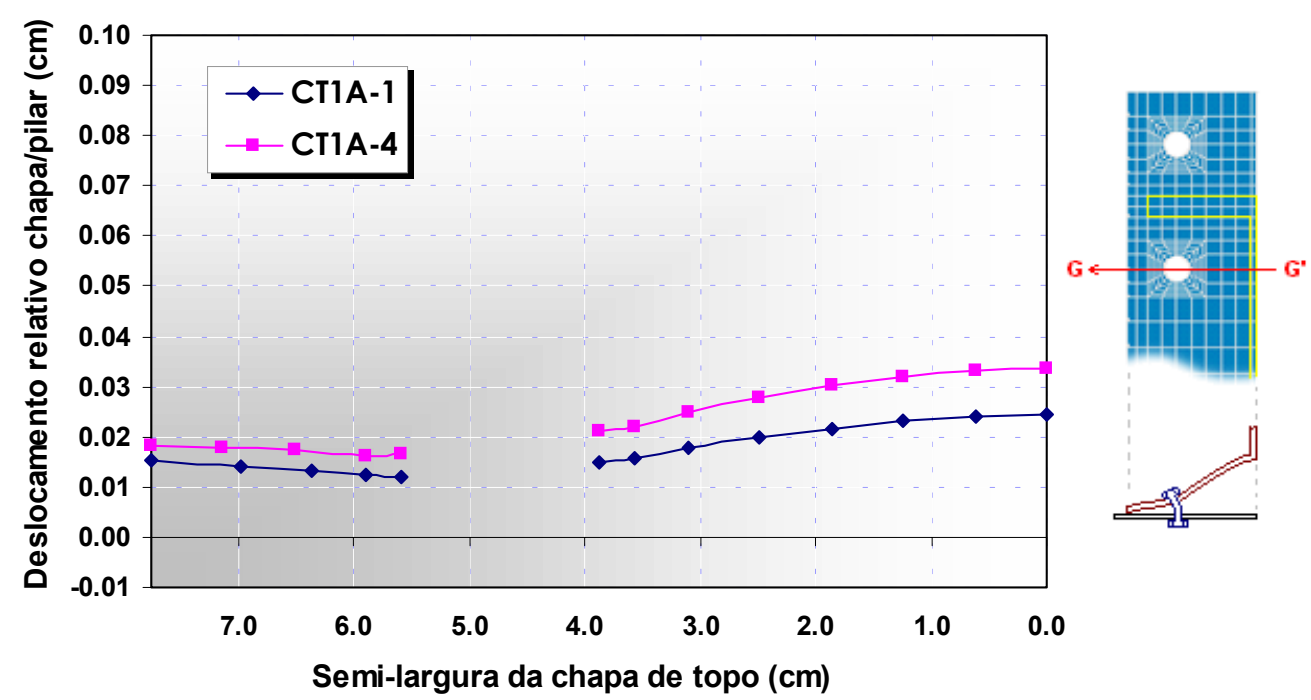

Figura 6.6 - Deslocamento relativo chapa/pilar - seção GG' CT1A-1 $\left(\mathrm{t}_{\mathrm{ch}}=31,5 \mathrm{~mm}\right)$ e CT1A-4 $\left(\mathrm{t}_{\mathrm{ch}}=22,4 \mathrm{~mm}\right)$

As diferenças entre o comportamento da chapa de topo nos modelos CT1A-1 e CT1A-4, além da figura 6.4, podem ser visualizadas nas 
figuras 6.5 e 6.6, as quais apresentam, respectivamente, as seções EE' e GG', comparando os modelos para a solicitação de $11700 \mathrm{kNcm}$.

Para o modelo CT1A-4, os deslocamentos para as linhas 1 e 2 de parafusos são maiores, percebendo-se que há um acréscimo maior do afastamento chapa/pilar para o plano médio da alma com relação à região próxima ao parafuso. Sob outro ponto de vista, há um aumento da flexão da chapa de topo.

As observações de RIBEIRO (1998), em sua análise experimental, indicam que para ambos os modelos CT1A-1 $\left(t_{c h}=31,5 \mathrm{~mm} ; d_{p}=16,0 \mathrm{~mm}\right)$ e CT1A-4 $\left(t_{c h}=22,4 \mathrm{~mm} ; d_{p}=16,0 \mathrm{~mm}\right)$ o colapso na ligação ocorreu pela ruptura de todos os parafusos da região tracionada.

A ruptura para os parafusos do modelo CT1A-1 já era prevista pelo EUROCODE-3 (1993), visto as capacidades resistentes calculadas para ambas as linhas externa e interna.

No entanto, para o modelo CT1A-4, a capacidade resistente da linha externa não é limitada somente pela ruptura dos parafusos, mas considera também a flexão da chapa. Considerando os valores calculados segundo o EUROCODE-3 (1993) e o comportamento observado no protótipo, a ruptura dos parafusos da linha externa do protótipo CT1A-4, na análise experimental de RIBEIRO (1998), chama a atenção para o caso em que há interação entre escoamento da chapa de topo e ruptura dos parafusos, devido à impossibilidade de definir, realmente, a contribuição de cada um desses elementos para o colapso da ligação.

Fazendo-se a mesma análise para a variação da espessura da chapa nos modelos com parafusos de $19,0 \mathrm{~mm}$, apresenta-se, na tabela VI.II, as capacidades resistentes para os modelos CT1B-4 $\left(\mathbf{t}_{\mathrm{ch}}=\mathbf{2 2 , 4} \mathbf{m m}\right) \mathrm{e}$ CT1B-6 $\left(\mathrm{t}_{\mathrm{ch}}=19,0 \mathrm{~mm}\right)$.

Os modelos com parafusos de $19,0 \mathrm{~mm}$ apresentam o mesmo comportamento dos modelos com parafusos de $16,0 \mathrm{~mm}$, ou seja, a diminuição da espessura da chapa de topo diminui a capacidade resistente da ligação. 
Tabela VI.II - Capacidade resistente para a flexão da chapa de topo Modelos CT1B-4 e CT1B-6

\begin{tabular}{|c|c|c|c|c|c|c|}
\hline \multirow{2}{*}{ Modelo } & \multirow{2}{*}{$\begin{array}{c}\text { Espessura } \\
\text { chapa } \\
(\mathrm{mm})\end{array}$} & \multirow{2}{*}{$\begin{array}{c}\text { Diâmetro } \\
\text { parafuso } \\
\text { (mm) }\end{array}$} & \multirow{2}{*}{ Linha } & \multicolumn{3}{|c|}{ Modos de Falha $-P_{r}(k N)$} \\
\hline & & & & 1 & 2 & 3 \\
\hline \multirow{2}{*}{ CT1B-4 } & \multirow{2}{*}{22,4} & \multirow{2}{*}{19,0} & 1 & 275,0 & 195,5 & 254,0 \\
\hline & & & 2 & 727,4 & 309,1 & 254,0 \\
\hline \multirow{2}{*}{ CT1B-6 } & \multirow{2}{*}{19,0} & \multirow{2}{*}{19,0} & 1 & 197,86 & 176,1 & 254,0 \\
\hline & & & 2 & 523,37 & 257,9 & 254,0 \\
\hline
\end{tabular}

No entanto, nota-se que os valores calculados para o modo de falha que leva em consideração somente o escoamento da chapa de topo (modo $1^{4}$ ), se aproximam dos valores calculados para o modo 2 à medida em que decresce a espessura da chapa.

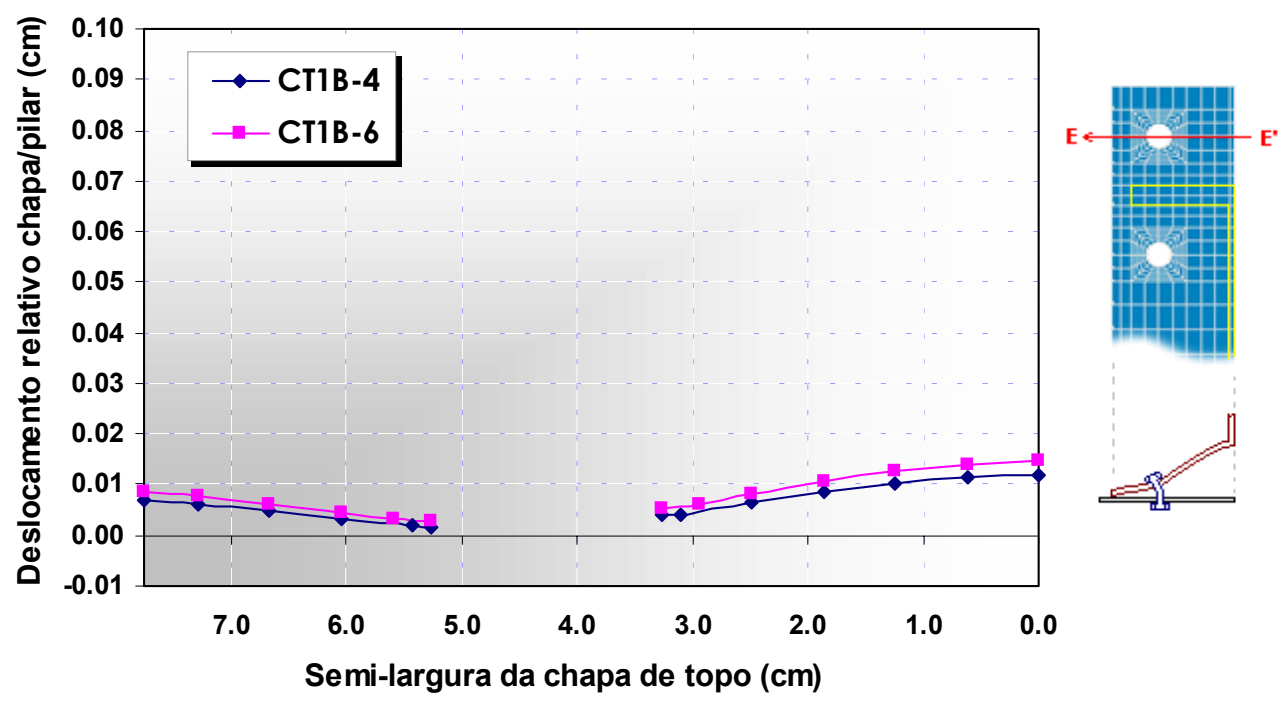

Figura 6.7 - Deslocamento relativo chapa/pilar - seção EE' CT1B-4 $\left(t_{c h}=22,4 \mathrm{~mm}\right)$ e CT1B-6 $\left(t_{c h}=19,0 \mathrm{~mm}\right)$

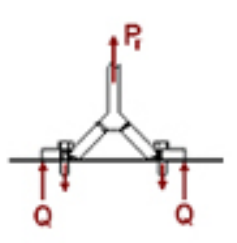

Modo 1

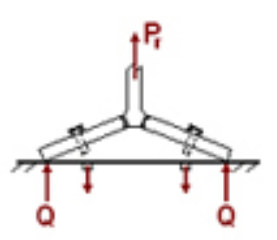

Modo 2

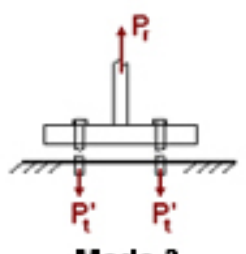

Modo 3 


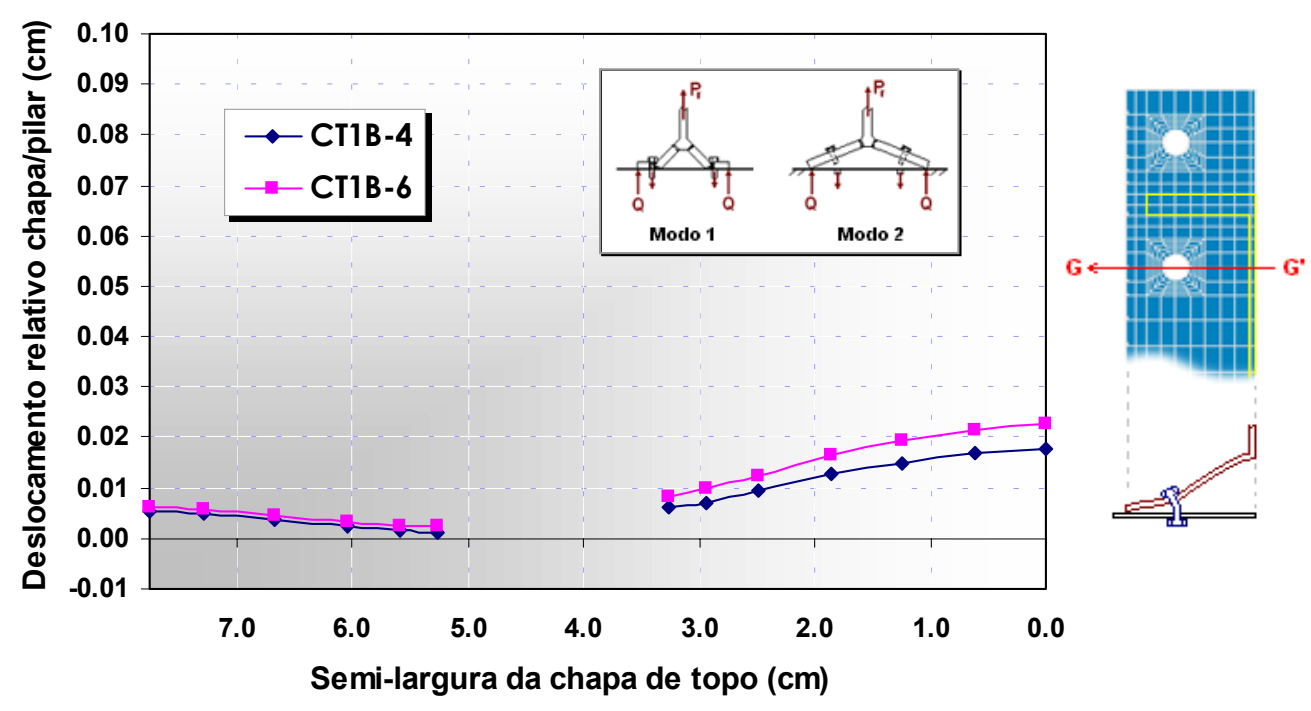

Figura 6.8 - Deslocamento relativo chapa/pilar - seção EE' CT1B-4 $\left(t_{c h}=22,4 \mathrm{~mm}\right)$ e CT1B-6 $\left(t_{c h}=19,0 \mathrm{~mm}\right)$

Para os modelos CT1B-4 e CT1B-6, os afastamentos chapa/pilar das seções EE' e GG' estão ilustrados, respectivamente, nas figuras 6.7 e 6.8.

Com relação à linha 1, para o modelo CT1B-6, observa-se um comportamento no qual há pouca deformação do parafuso, o qual impõem uma predominância da flexão da chapa de topo na determinação da capacidade resistente para a linha externa de parafusos.

Para esse modelo numérico, o EUROCODE-3 (1993) prevê, segundo a tabela VI.II, menor valor da capacidade resistente para a linha 1 considerando a ação conjunta da flexão da chapa com o colapso do parafuso (modo 2), mas o valor de $P_{r, 2}=176,1 \mathrm{kN}$ é bem próximo do valor obtido considerando-se apenas a flexão da chapa de topo (modo 1), igual à $P_{r, 1}=197,86$.

Isso quer dizer que, à medida em que se diminui a espessura da chapa de topo ao mesmo tempo em que se aumenta o diâmetro dos parafusos, o modo de falha para a região dos parafusos é, como prescreve o 
EUROCODE-3 (1993), regido pela flexão da chapa, aproximando-se do modo $1^{\mathbb{E}}$.

Com relação aos resultados experimentais, o mesmo comentário realizado para os modelos CT1A-1 e CT1A-4 é válido para o protótipo CT1B-4 $\left(t_{c h}=22,4 \mathrm{~mm} ; d_{p}=19,0 \mathrm{~mm}\right)$, no qual houve a ruptura de ambas as linhas de parafusos, sendo que a capacidade resistente da linha $\mathbf{1}$, segundo os cálculos pelo EUROCODE-3 (1993), é limitada pelo modo de falha 2.

Para o protótipo CT1B-6 $\left(t_{c h}=19,0 \mathrm{~mm} ; d_{p}=19,0 \mathrm{~mm}\right)$, há somente a ruptura dos parafusos da linha interna, o que pode ser observado na figura 6.9 onde está ilustrada a deformada final da chapa com destaque para os parafusos que entraram em colapso.

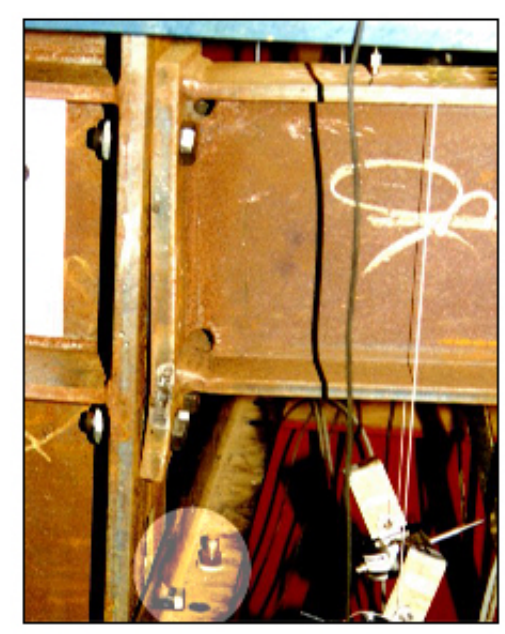

Figura 6.9 - Deformada final do protótipo CT1B-6 No detalhe, parafusos da linha interna após a ruptura

Segundo o EUROCODE-3 (1993), a capacidade resistente para a linha interna é, de acordo com o observado na figura 6.9, a ruptura dos parafusos (modo 3). No entanto, é interessante observar os valores da

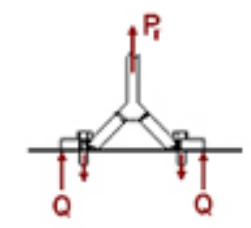

Modo 1

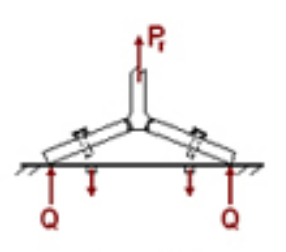

Modo 2

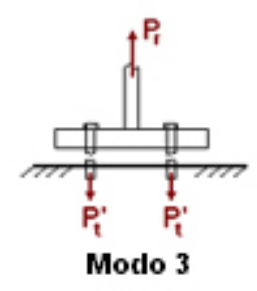


capacidade resistente para a linha externa, que apresenta valores muito próximos para os modos de falha 1 e $2^{ \pm}$.

A observação dos resultados apresentados acima permite avaliar que as previsões do EUROCODE-3 (1993) para os modos de colapso das ligações são bem determinados para as falhas devido, isoladamente, à ruptura dos parafusos (modo 3 ) ou à flexão da chapa de topo (modo 1 ). Todavia, a determinação do modo de falha 2, decorrente da interação entre a flexão da chapa e a ruptura dos parafusos, não permite identificar a contribuição da chapa ou do parafuso no colapso da ligação.

Quanto à variação do diâmetro dos parafusos, a tabela VI.III apresenta, os valores da capacidade resistente $\left(\mathbf{P}_{\mathbf{r}}\right)$ calculados para os três modos de falha apresentados na figura 6.1, para os modelos CT1A-4 $\left(\mathbf{d}_{p}=\right.$ $16,0 \mathrm{~mm})$ e CT1B-4 $\left(d_{p}=19,0 \mathrm{~mm}\right)$, ambos com chapa de $22,4 \mathrm{~mm}$ de espessura.

Tabela VI.III - Capacidade resistente para a flexão da chapa de topo Modelos CT1A-4 e CT1B-4

\begin{tabular}{|c|c|c|c|c|c|c|}
\hline \multirow{2}{*}{ Modelo } & \multirow{2}{*}{$\begin{array}{c}\text { Espessura } \\
\text { chapa } \\
(\mathrm{mm})\end{array}$} & \multirow{2}{*}{$\begin{array}{l}\text { Diâmetro } \\
\text { parafuso } \\
\text { (mm) }\end{array}$} & \multirow{2}{*}{ Linha } & \multicolumn{3}{|c|}{ Modos de Falha $-P_{r}(k N)$} \\
\hline & & & & 1 & 2 & 3 \\
\hline \multirow{2}{*}{ CT1A-4 } & \multirow{2}{*}{22,4} & \multirow{2}{*}{16,0} & 1 & 240,9 & 145,8 & 180,0 \\
\hline & & & 2 & 715,0 & 281,8 & 180,0 \\
\hline \multirow{2}{*}{ CT1B-4 } & \multirow{2}{*}{22,4} & \multirow{2}{*}{19,0} & 1 & 275,0 & 195,5 & 254,0 \\
\hline & & & 2 & 727,4 & 309,1 & 254,0 \\
\hline
\end{tabular}

O comentário aos valores apresentados na tabela VI.III refere-se, de maneira geral, ao acréscimo da capacidade resistente em cada linha de parafusos devido ao aumento do diâmetro dos parafusos.

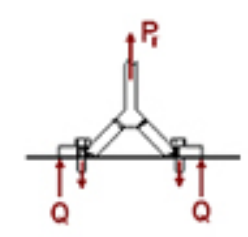

Modo 1

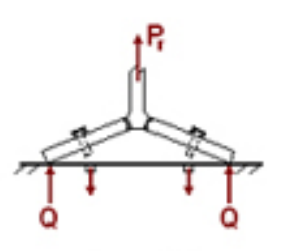

Modo 2

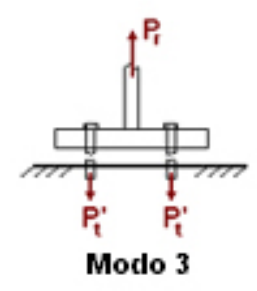


Assim é possível afirmar que as indicações do EUROCODE-3 (1993) quanto aos modos possíveis de colapso têm relação muito estreita com a variação do comportamento da ligação, devido às variações nas características geométricas da chapa de topo e dos parafusos.

\subsection{AFASTAMENTO CHAPA DE TOPO/MESA DO PILAR}

Os resultados obtidos a partir da análise numérica para os deslocamentos da chapa de topo com relação à mesa do pilar, foram analisados, no capítulo 5 , para diversas seções.

No entanto, a comparação destes resultados com os obtidos experimentalmente por RIBEIRO (1998) pode ser realizada apenas para o ponto $\mathbf{P}$, uma vez que este é o resultado disponível da instrumentação realizada na análise experimental. $\mathbf{O}$ ponto $\mathbf{P}$, cuja posição está ilustrada na figura 6.10, representa a intersecção entre o plano médio da mesa tracionada e a média espessura da chapa de topo, na borda da mesma.

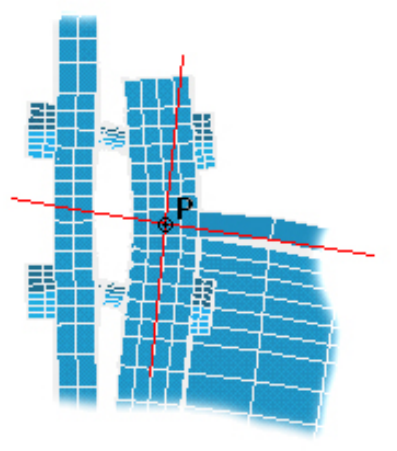

Vista lateral

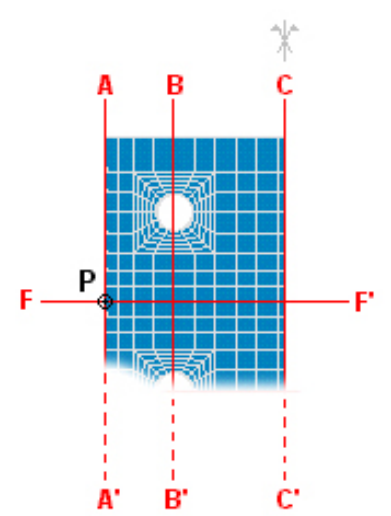

Seção na espessura média

Figura 6.10 - Ponto de medição dos afastamentos chapa/pilar

As figuras 6.11 e 6.12 apresentam os gráficos de afastamento chapa/pilar em função do momento fletor na ligação, medido no ponto $\mathbf{P}$, para os modelos numéricos CT1A-1 e CT1A-4, respectivamente, juntamente com os resultados dos protótipos experimentais que foram representados pelos modelos. 


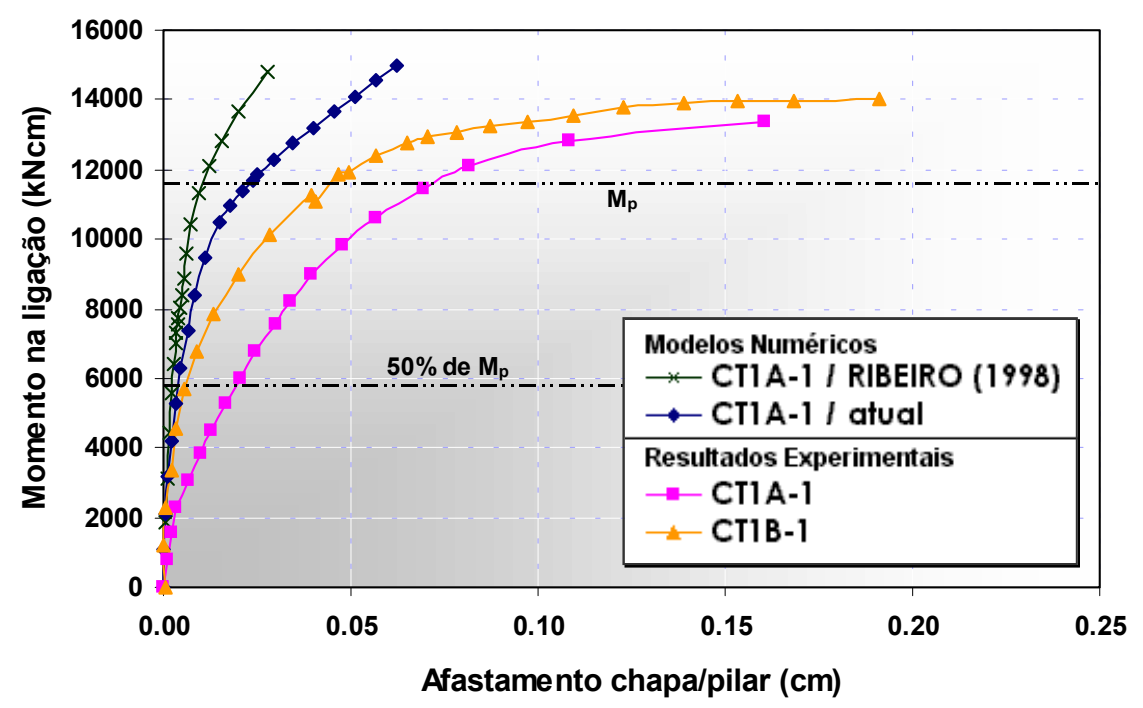

Figura 6.11 - Afastamento chapa/pilar CT1A-1 $\left(t_{c h}=31,5 \mathrm{~mm} ; d_{p}=16,0 \mathrm{~mm}\right)$

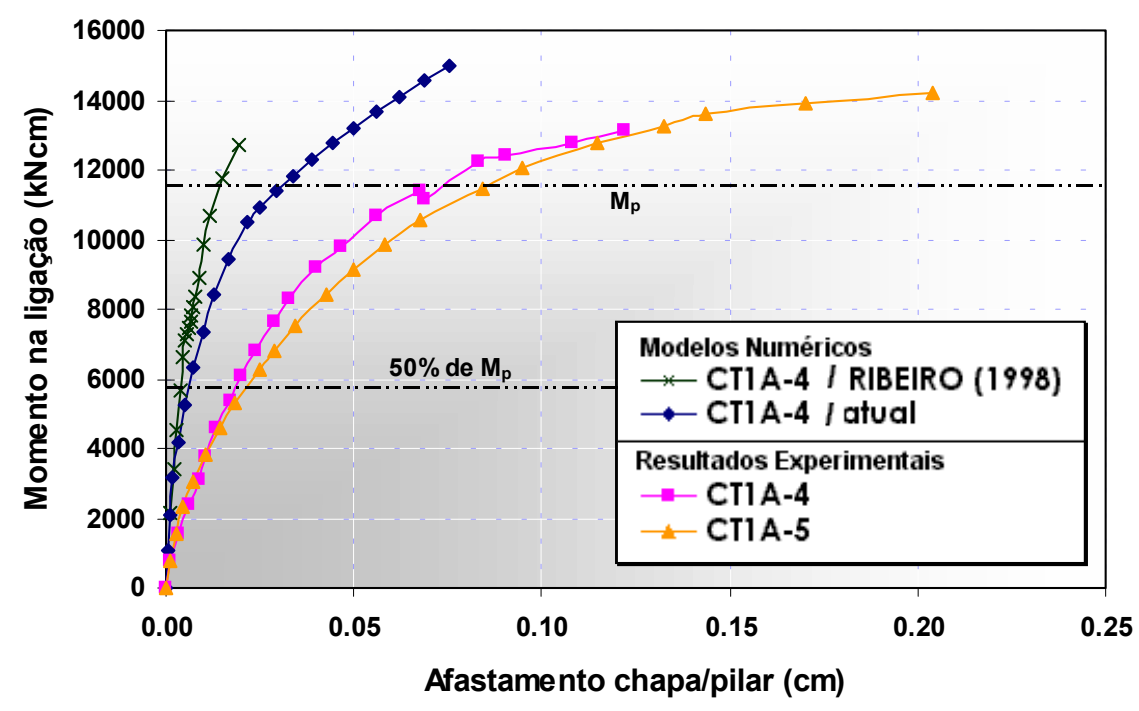

Figura 6.12 - Afastamento chapa/pilar CT1A-4 $\left(t_{c h}=22,4 \mathrm{~mm} ; d_{p}=16,0 \mathrm{~mm}\right)$

Também são apresentados os resultados obtidos por RIBEIRO (1998), na sua análise numérica, para os modelos correspondentes.

Comparando-se as curvas numéricas e experimentais, nota-se que os modelos numéricos apresentam deslocamentos menores para a chapa de topo. No entanto, a primeira observação a ser feita refere-se à diminuição 
dessas diferenças para os modelos estudados neste trabalho, quando comparados aos modelos numéricos analisados por RIBEIRO (1998).

Pode-se dizer que, para os modelos numéricos, a consideração da flexibilidade do pilar e a metodologia utilizada na modelagem dos parafusos e aplicação das forças de protensão neste trabalho, apresentadas no capítulo 4, refletem um aumento da representatividade dos modelos numéricos com relação aos resultados experimentais.

Convém salientar que o protótipo experimental CT1A-1, incluído na figura 6.11, apresentou deslocamentos iniciais elevados devido à ausência do controle de torque no aperto dos parafusos.

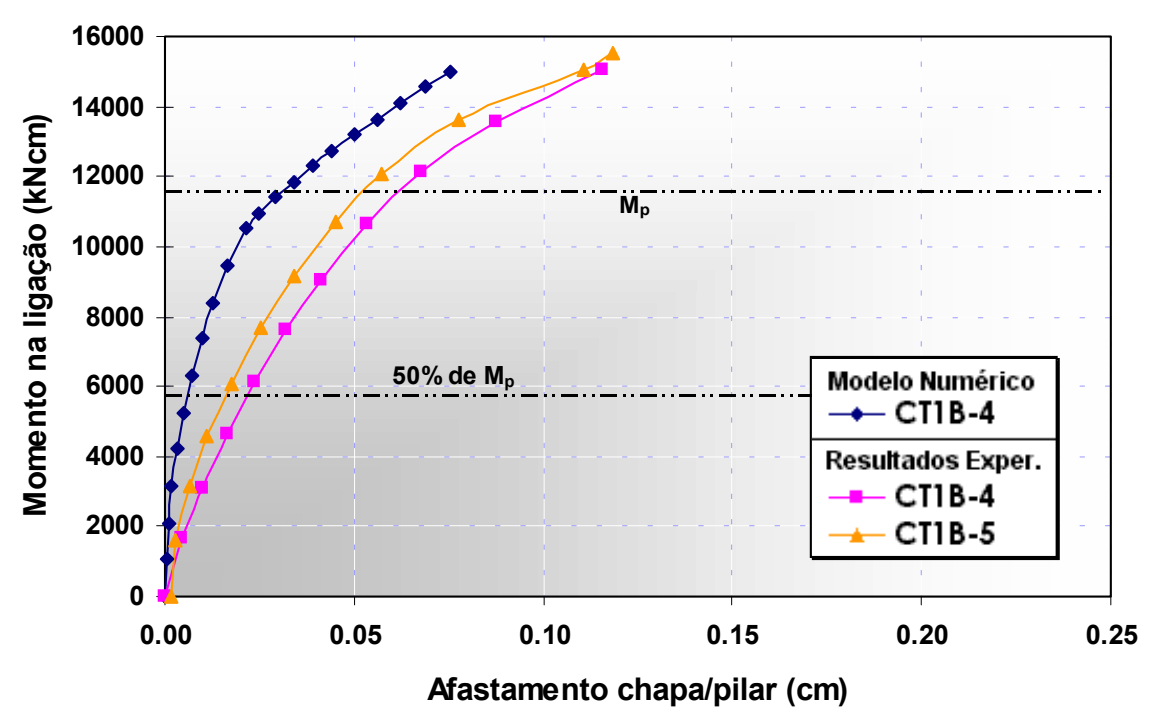

Figura 6.13 - Afastamento chapa/pilar CT1B-4 $\left(t_{c h}=22,4 \mathrm{~mm} ; d_{p}=19,0 \mathrm{~mm}\right)$

Os afastamentos chapa/pilar também podem ser observados para o modelo CT1B-4, na figura 6.13. Os dados referentes à análise numérica de RIBEIRO (1998) não estão disponíveis para estes modelos, razão pela qual não são apresentados.

Observando-se os gráficos apresentados para os modelos CT1A-1, CT1A-4 e CT1B-4, salienta-se novamente que os afastamentos chapa/pilar são menores que os obtidos com a análise experimental. 
Essas diferenças, que podem ser observadas para todos os modelos, de maneira geral são conseqüência das simplificações utilizadas na modelagem numérica.

Dentre estes fatores pode-se citar, primeiramente, as imperfeições dos materiais utilizados na análise experimental, a existência de tensões residuais, e outras imperfeições decorrentes da montagem dos protótipos e da metodologia da realização dos ensaios, características que, a menos das tensões residuais, não são possíveis de se representar nos modelos numéricos.

Outro aspecto refere-se à caracterização do comportamento tensão $\mathbf{x}$ deformação dos materiais na análise numérica realizada que, como descrito no capítulo 4, utiliza um diagrama bi-linear. Essa representação é interessante para caracterizar a diminuição de rigidez dos materiais em determinados níveis de tensão, mas não caracteriza a sua ruptura.

Esses fatores influenciam diretamente os resultados da análise numérica, fazendo com que, sistematicamente, as ligações dos modelos numéricos tenham um comportamento mais "rígido" com relação aos protótipos experimentais.

No entanto, é possível afirmar que o comportamento dos modelos numéricos é satisfatório em termos da análise da variação da rigidez da ligação.

Considerando um momento fletor igual à $11700 \mathrm{kNcm}\left(\approx \mathbf{M}_{\mathbf{p}}\right), 0$ modelo CT1A-1 apresentou afastamento chapa/pilar $\mathbf{5 0 \%}$ inferior ao protótipo CT1B-1 (figura 6.11). Para os modelos CT1A-4 e CT1B-4, tal redução é de $\mathbf{5 5 \%}$ em relação aos resultados dos protótipos.

Dessa maneira, observa-se que a redução dos afastamentos chapa/pilar nos modelos numéricos é conseqüência dos fatores já citados, independentemente da variação da espessura da chapa ou do diâmetro dos parafusos, o que valida o comportamento do modelo, de maneira geral. 


\subsection{ROTAÇÃO DAS LIGAÇÕES}

Utilizando os resultados apresentados no item 6.2, e também para os modelos CT1A-2, CT1B-2 e CT1B-6, referentes ao afastamento chapa/pilar, é possível representar o comportamento momento-rotação da ligação.

Com o objetivo de comparar, novamente, resultados numéricos e resultados experimentais, utilizar-se-á a rotação convencionalmente adotada, representada pela divisão entre o afastamento chapa/pilar no ponto $\mathbf{P}$ - cuja localização já foi apresentada - e a distância entre os planos médios das mesas da viga $\left(\mathbf{H}-\mathbf{t}_{\mathbf{f}}\right)$.

Sendo função direta do afastamento chapa/pilar, a análise com relação à representatividade do modelo, comentada no item 6.2, também se aplica às curvas momento-rotação.

No entanto, tornam-se interessantes algumas observações adicionais quanto ao comportamento dos resultados para valores menores de solicitação que representem a ligação em regime de serviço. Neste caso, adota-se um valor de $\mathbf{5 0 \%}$ de $\mathbf{M}_{\mathbf{p}}$.

Dessa forma, as figuras 6.14 e 6.15 apresentam as curvas momento-rotação para os modelos CT1A-1 e CT1A-4, respectivamente.

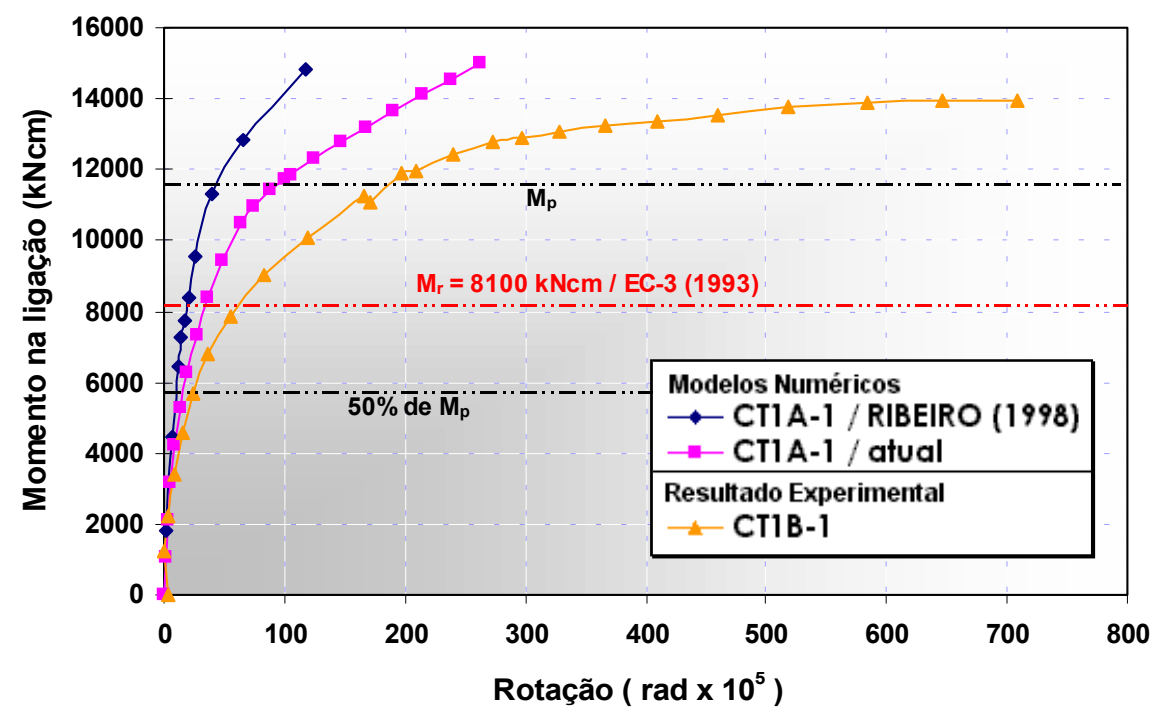

Figura 6.14 - Curvas momento-rotação da ligação Modelo CT1A-1 $\left(t_{c h}=31,5 \mathrm{~mm} ; d_{p}=16,0 \mathrm{~mm}\right)$ 


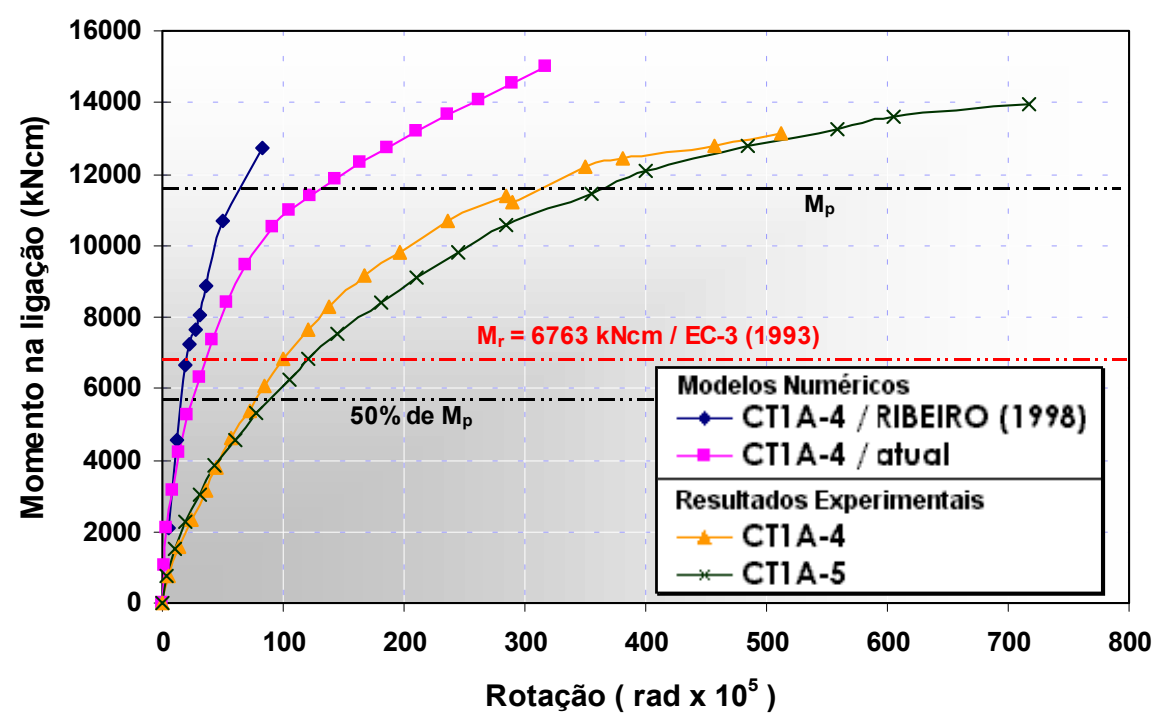

Figura 6.15 - Curvas momento-rotação da ligação Modelo CT1A-4 $\left(t_{c h}=22,4 \mathrm{~mm} ; d_{p}=16,0 \mathrm{~mm}\right)$

Também são apresentadas referências ao momento total resistente da ligação de cada modelo, calculado para a verificação da ligação segundo o EUROCODE-3 (1993), que considera a capacidade resistente de cada linha de parafusos, apresentadas no item 6.1.

O cálculo da rotação, como descrito acima, considera o plano médio da mesa comprimida como centro de rotação da chapa de topo. Neste caso, pode-se considerar que o deslocamento vertical da viga é função da rotação apresentada nas figuras 6.14 e 6.15, como esquematiza a figura 6.16.

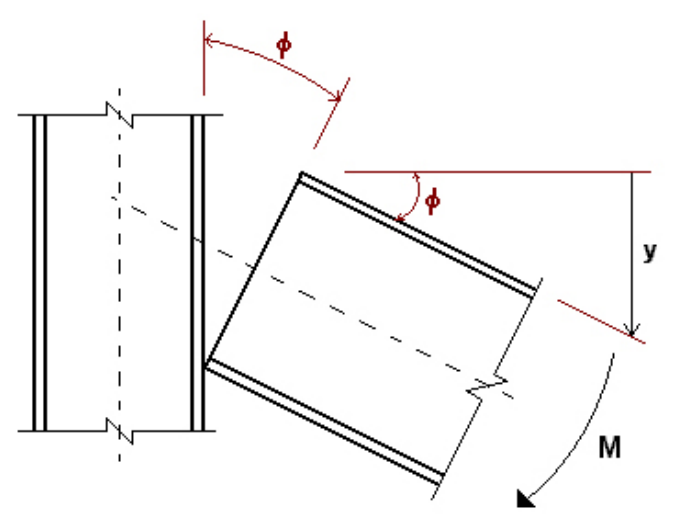

Figura 6.16 - Centro do rotação da chapa de topo 
O comportamento da chapa de topo representado na figura 6.16, obviamente, trata-se de uma simplificação, utilizado para parametrizar a rotação das ligações.

Considerando, por exemplo, um valor de referência de $\mathbf{4 , 0} \mathrm{m}$ para metade do vão de uma viga comumente utilizada em edifícios metálicos, de 8,0 $\mathrm{m}$, para o modelo CT1A-1 $\left(t_{\mathrm{ch}}=31,5 \mathrm{~mm} ; \mathrm{d}_{\mathrm{p}}=16,0 \mathrm{~mm}\right)$, 0 deslocamento vertical calculado em função da rotação para uma solicitação de $\mathbf{0 , 5} \mathbf{M}_{\mathrm{p}}$ é de $\mathbf{0 , 0 7} \mathrm{cm}$. Para a mesma solicitação, no protótipo experimental CT1B-1 obtém-se um valor de deslocamento igual a $0,01 \mathrm{~cm}$.

Para a solicitação equivalente ao momento resistente da ligação, calculada segundo o EUROCODE-3 (1993), igual à $8100 \mathbf{k N c m}$, tem-se os valores $0,133 \mathrm{~cm}$ e $\mathbf{0 , 2 4 3} \mathrm{cm}$ para os deslocamentos verticais da viga, respectivamente para o modelo numérico e para o protótipo experimental.

Apesar da diferença entre os valores numéricos e experimentais, a magnitude dos deslocamentos verticais, em ambos os casos, é desprezível, mesmo considerando o momento resistente máximo calculado pelo EUROCODE-3 (1993).

Para o modelo CT1A-4 $\left(t_{c h}=22,4 \mathrm{~mm} ; d_{p}=16,0 \mathrm{~mm}\right)$ pode-se fazer a mesma afirmação acima, indicando-se porém que o momento resistente para a ligação, segundo o EUROCODE-3 (1993), é reduzido para $6763 \mathrm{kNcm}$, devido à diminuição da espessura da chapa.

Para os modelos CT1B-4 e CT1B-6, as curvas momento-rotação estão ilustrados nas figuras 6.17 e 6.18 , respectivamente.

Com relação aos valores calculados pelo EUROCODE-3 (1993), observa-se que a máxima capacidade resistente ao momento fletor para os modelos CT1A-1 e CT1A-4, encontra-se em regiões com rotações muito baixas, apresentando folgas consideráveis com relação ao valor de $\mathbf{M}_{\mathbf{p}}$. Para os modelos CT1B-4 e CT1B-6, devido ao aumento do diâmetro dos parafusos, tal consideração não é verdadeira, uma vez que há um aumento significativo da capacidade resistente da ligação. 


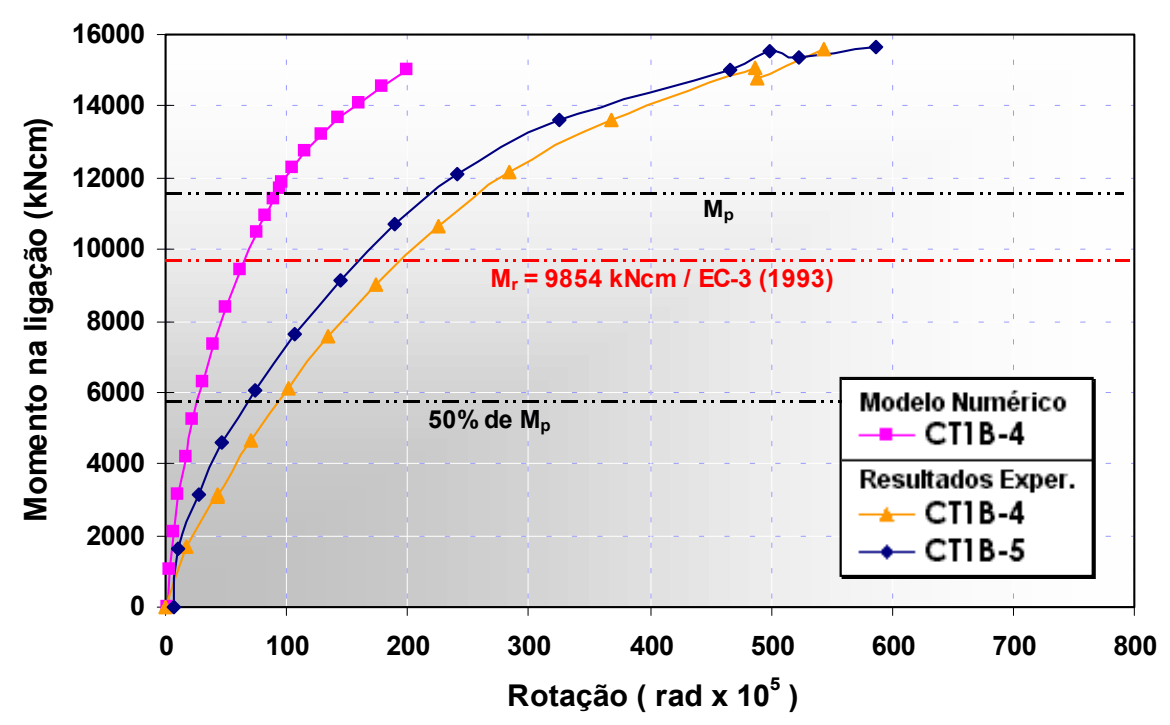

Figura 6.17 - Curvas momento-rotação da ligação Modelo CT1B-4 $\left(t_{c h}=22,4 \mathrm{~mm} ; d_{p}=19,0 \mathrm{~mm}\right)$

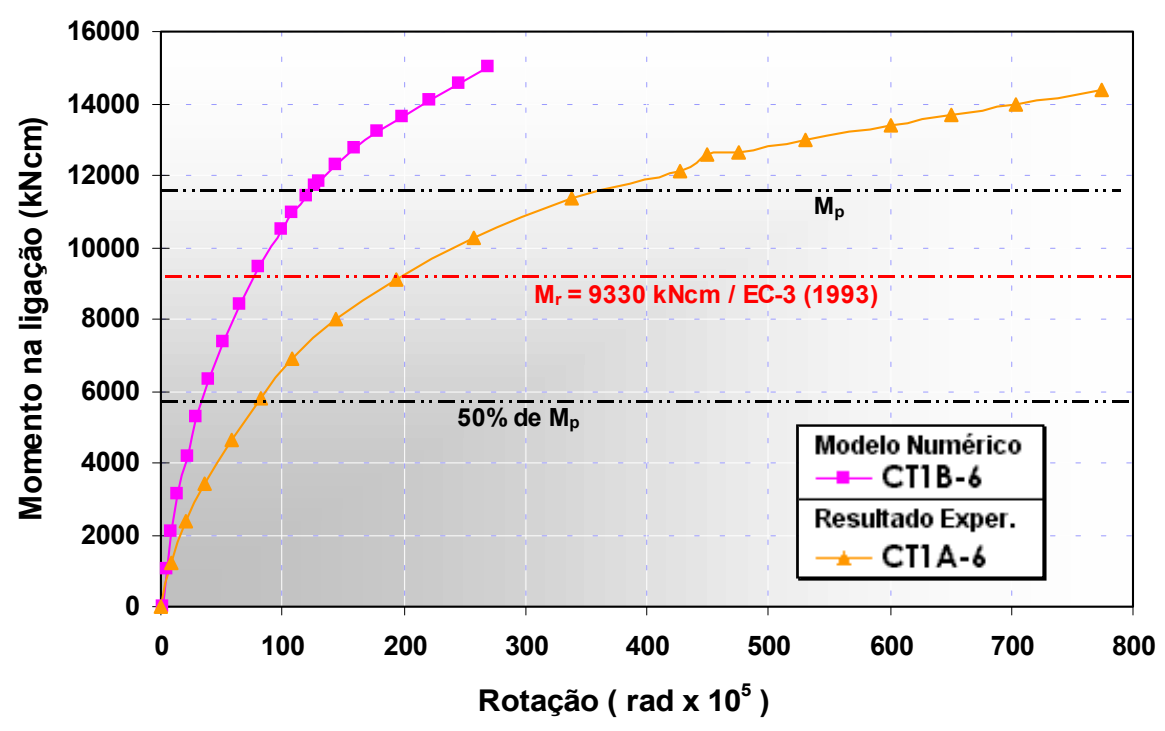

Figura 6.18 - Curvas momento-rotação da ligação Modelo CT1B-6 $\left(t_{c h}=19,0 \mathrm{~mm} ; d_{p}=19,0 \mathrm{~mm}\right)$

Assim, pode-se afirmar que os modelos numéricos estudados neste trabalho, em termos de dimensionamento, podem ser utilizados com certo grau de aproximação para avaliar as ligações em regime de serviço.

Observando-se os valores calculados segundo o EUROCODE-3 (1993), é possível verificar que a diminuição da espessura da chapa de topo provoca um decréscimo no momento resistente da ligação, devido à 
consideração da flexão da chapa, que passa a ser mais acentuada. $O$ aumento do diâmetro dos parafusos, por sua vez, ocasiona um aumento do momento resistente. Tais observações refletem a mudança de comportamento da ligação, já comentada no item 6.1 para o cálculo da capacidade resistente dos parafusos. Outro aspecto refere-se à relação entre os momentos máximos atingidos pelos protótipos e os momentos resistentes calculados pelo EUROCODE-3 (1993), que variaram entre 1,80 e 1,90 .

Com relação à rigidez das ligações, representadas pelas curvas momento-rotação, observa-se que os modelos numéricos apresentam um comportamento mais "rígido" que os protótipos experimentais, ou seja, apresentam rotações menores, para o mesmo nível de solicitação.

De maneira geral, as diferenças entre os resultados numéricos e experimentais são provenientes, como já comentado no item 6.2 , de fatores relativos ao processo de fabricação e ensaio dos protótipos, de eventuais imperfeições nos materiais e do tipo de comportamento tensão $\mathbf{x}$ deformação adotado, na análise numérica.

Aumentando-se, intencionalmente, em 2 vezes as rotações para os modelos numéricos, obtêm-se os gráficos das figuras 6.19 a 6.21 , que ilustram as curvas momento-rotação "original" e "modificada" dos modelos CT1A-1, CT1A-4 e CT1B-4, respectivamente.

As curvas assim modificadas, para os modelos citados, apresentam valores de rotação muito próximos aos resultados experimentais, salientando-se que essa proximidade pode ser observada em quase todos os níveis de solicitação, inclusive para valores superiores à $\mathrm{M}_{\mathrm{p}}$.

É possível, então, comprovar que o comportamento da ligação nos modelos numéricos, apesar das diferenças de valores observadas, é válida para representar os protótipos de ensaio, não só em regime de serviço, mas na determinação dos seus estados limites últimos. 


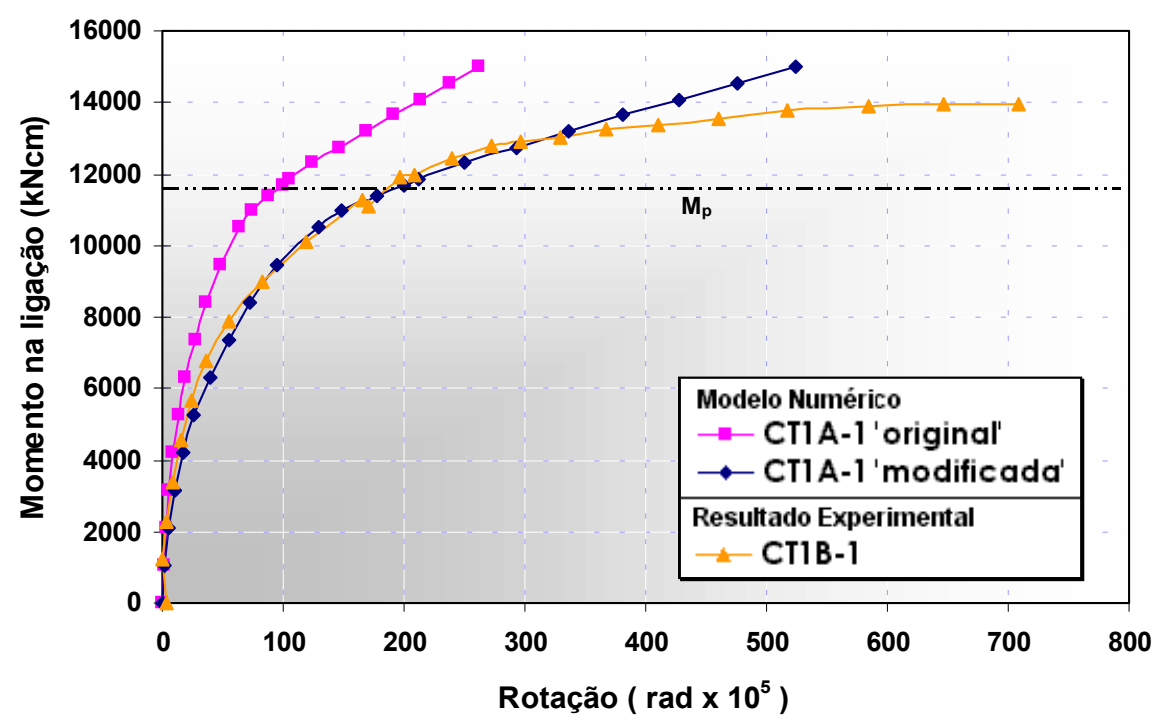

Figura 6.19 - Curva momento-rotação modificada Modelo CT1A-1 $\left(t_{c h}=31,5 \mathrm{~mm} ; d_{p}=16,0 \mathrm{~mm}\right)$

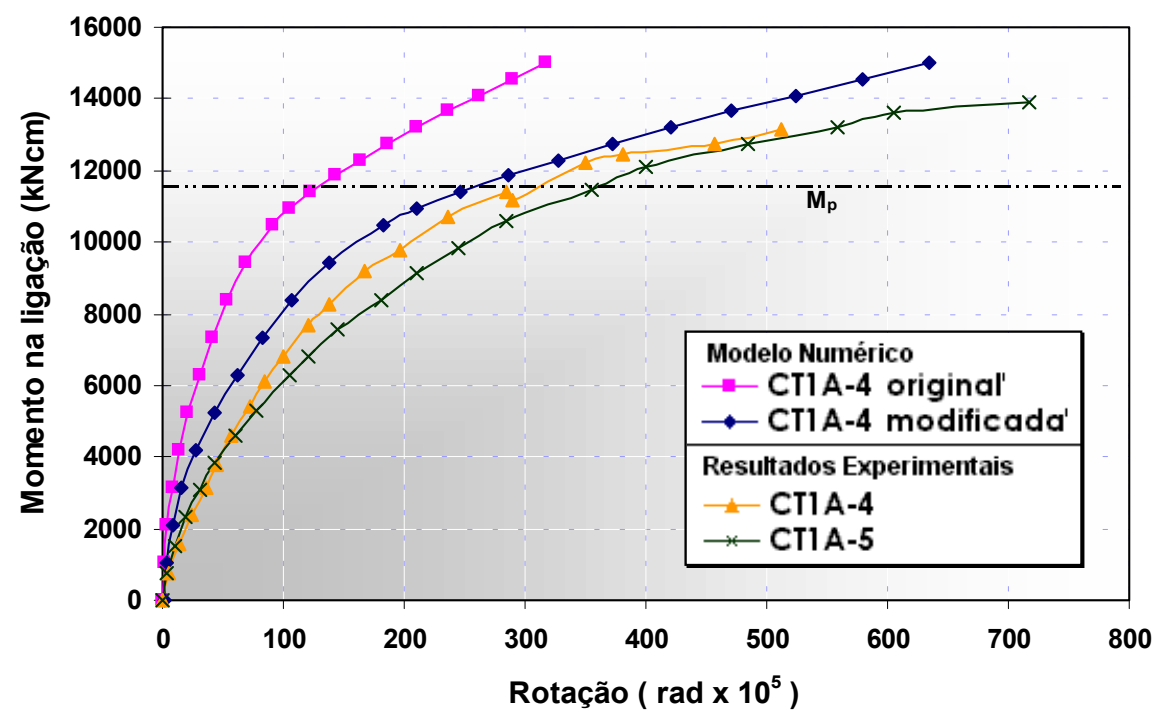

Figura 6.20 - Curva momento-rotação modificada Modelo CT1A-4 $\left(t_{c h}=22,4 \mathrm{~mm} ; d_{p}=16,0 \mathrm{~mm}\right)$ 


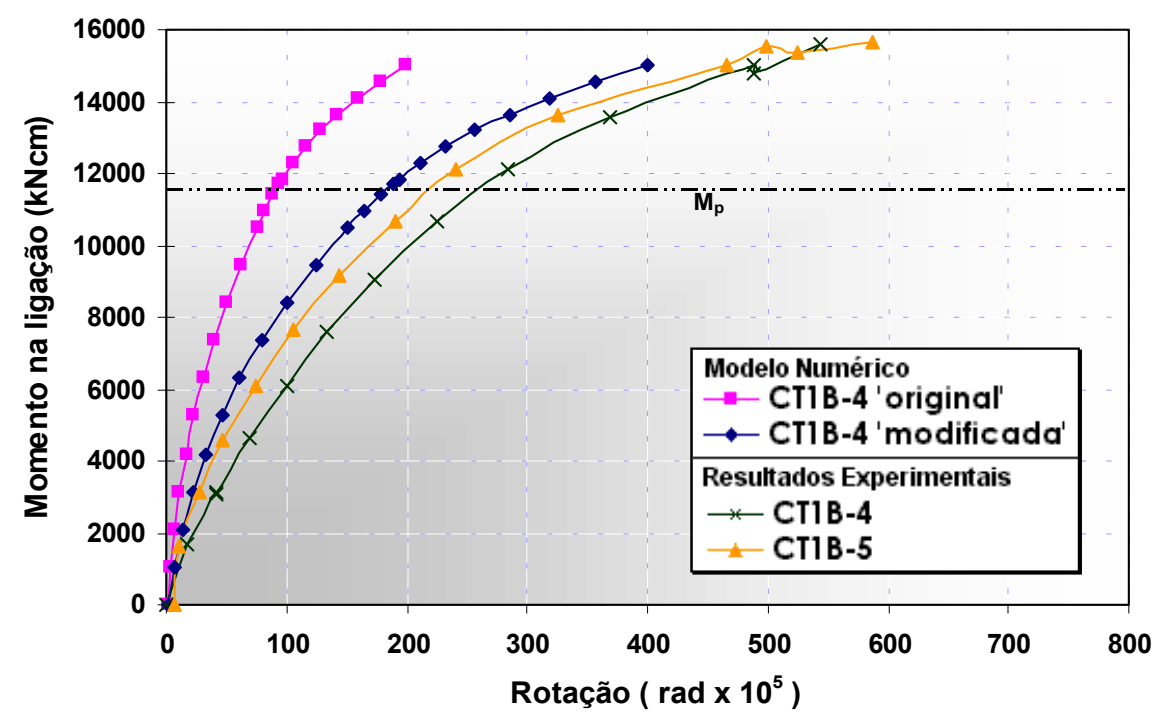

Figura 6.21 - Curva momento-rotação modificada Modelo CT1B-4 $\left(t_{c h}=22,4 \mathrm{~mm} ; d_{p}=19,0 \mathrm{~mm}\right)$

Dessa forma, é importante ressaltar que uma "melhoria" contínua nos modelos numéricos é necessária, de modo a eliminar as simplificações adotadas, principalmente com relação às folgas nos furos dos parafusos e a escolha de modelos adequados para a representação dos materiais. 


\section{Capítulo}

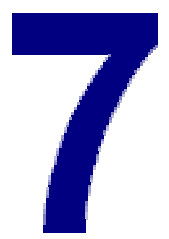

\section{CONSIDERAÇÕES FINAIS}

A proposta inicial deste trabalho teve como principal objetivo a análise de modelos numéricos, via elementos finitos, que pudessem representar, satisfatoriamente, o comportamento das ligações parafusadas viga-coluna com chapa de topo.

Realizando-se, inicialmente, uma avaliação dos resultados numéricos obtidos, constata-se que os modelos numéricos apresentaram um comportamento que, em termos qualitativos, pode ser considerado próximo ao comportamento esperado das ligações estudadas, tendo em vista as comparações com os resultados experimentais.

A observação dos afastamentos da chapa de topo com relação à mesa do pilar, das curvas momento-rotação e dos esforços nos parafusos revelaram que a metodologia adotada na modelagem numérica é consistente, evidenciando a sofisticação atribuída aos modelos pela inclusão da flexibilidade da mesa do pilar e das porcas dos parafusos.

Além disso, o método utilizado na aplicação das forças de protensão - adicionando-se diferenciais de temperatura - mostrou-se coerente, aproximando o comportamento dos parafusos nos modelos ao comportamento dos parafusos dos protótipos.

De maneira geral, a inclusão das características comentadas acima tem como conseqüência um aumento da representatividade dos resultados numéricos, o que pode ser visualizado nas comparações entre os modelos analisados por RIBEIRO (1998) e os deste trabalho. 
Todavia, se por um lado foi possível comprovar a qualidade dos modelos, algumas observações são necessárias quanto às simplificações adotadas na análise numérica que impuseram uma diferença sistemática entre os resultados numéricos e experimentais, o que pode ser observado nas curvas momento-rotação, principalmente, cujos valores para os modelos são sempre menores que os valores obtidos para os protótipos.

Pode-se atribuir a essas diferenças o fato de que os modelos numéricos são uma forma idealizada de representar as ligações, eliminando nos modelos certas características intrínsecas aos protótipos. Neste caso, pode-se citar as imperfeições dos perfis e chapas e a existência de tensões residuais decorrentes do processo de fabricação e montagem (soldagem).

Outras simplificações, talvez ainda mais significativas, sejam a desconsideração das folgas nos furos da chapa de topo e a adoção de diagramas bilineares para a caracterização do comportamento tensão $x$ deformação dos materiais na análise numérica.

Com os diagramas bilineares é possível representar a diminuição da rigidez dos elementos - redução do módulo de elasticidade - após certos níveis de tensão (escoamento do material), mas não há nenhum critério de ruptura, o que obviamente prejudica a redistribuição de tensões entre os elementos do modelo numérico. Não havendo a possibilidade de caracterizar o colapso, consequentemente inviabiliza-se a análise dos Estados Limites Últimos aplicáveis aos modelos numéricos, ou seja, às ligações.

Um comentário adicional, porém, é pertinente com relação às simplificações apontadas anteriormente. Relembrado as curvas momentorotação numérica e experimental do modelo $\mathbf{C T 1 A - 1}$, na figura 7.1 , é possível visualizar as diferenças comentadas, mas atenção especial é dada à "curva modificada" pelo aumento das rotações do modelo numérico em 2 vezes.

A coincidência entre os valores da "curva modificada" e da curva obtida para o protótipo CT1B-1 (de mesmas características do modelo CT1A-1) indica que, apesar das simplificações impostas ao modelo numérico, o seu comportamento momento-rotação é consistente, e tal 
conclusão pode ser estendida para todos os modelos analisados neste trabalho.

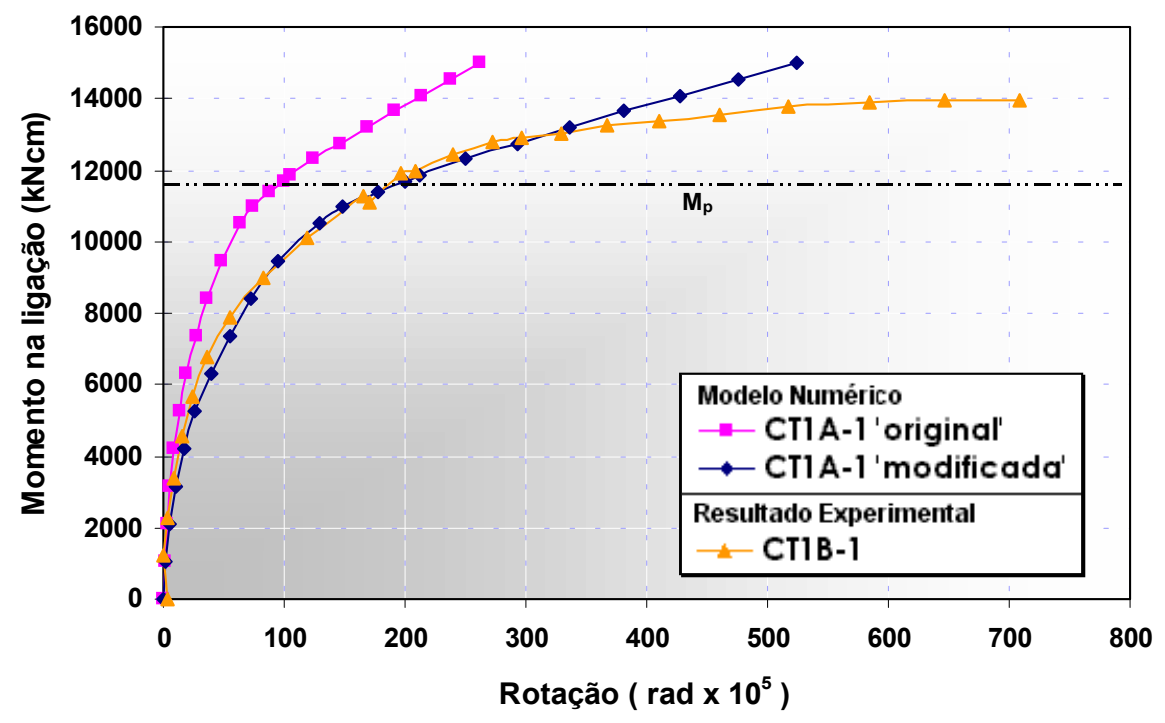

Figura 7.1 - Curvas momento-rotação - modelo CT1A-1

Neste caso, a análise da variação da espessura da chapa de topo e do diâmetro dos parafusos, realizada neste trabalho, torna-se válida e viabiliza também a utilização dos modelos numéricos, aqui estudados, na verificação da influência de outros fatores, podendo-se citar a geometria das ligações, posicionamento dos parafusos, influência nas características globais da estrutura, entre outros.

No desenvolvimento das comparações realizadas neste trabalho, foi possível também uma análise da metodologia de dimensionamento proposta pelo EUROCODE-3 (1993), considerando as verificações da capacidade resistente dos parafusos e da capacidade resistente da ligação.

Fazendo-se, inicialmente, uma comparação entre as prescrições do EUROCODE-3 (1993) e resultados experimentais, algumas observações quanto aos modos de falha da ligação, apresentados na tabela VII.I, são pertinentes. 
Tabela VII.I - Modos de falha - EUROCODE-3 (1993) vs Protótipos

\begin{tabular}{|c|c|c|c|}
\hline \multirow[b]{2}{*}{ Modelo } & \multicolumn{2}{|c|}{ EUROCODE-3 (1993) } & \multirow{2}{*}{$\begin{array}{c}\text { Protótipos experimentais } \\
\text { Modo de falha }\end{array}$} \\
\hline & $\begin{array}{l}\text { Linha de } \\
\text { parafusos }\end{array}$ & Modo de falha & \\
\hline \multirow{2}{*}{ CT1A-1 } & 1 & Parafuso & \multirow{2}{*}{$\begin{array}{c}\text { Ruptura dos parafusos em } \\
\text { ambas as linhas }\end{array}$} \\
\hline & 2 & Parafuso & \\
\hline \multirow{2}{*}{ CT1A-4 } & 1 & Chapa + parafuso & \multirow{2}{*}{$\begin{array}{c}\text { Ruptura dos parafusos em } \\
\text { ambas as linhas }\end{array}$} \\
\hline & 2 & Parafuso & \\
\hline \multirow{2}{*}{ CT1B-4 } & 1 & Chapa + parafuso & \multirow{2}{*}{$\begin{array}{c}\text { Ruptura dos parafusos em } \\
\text { ambas as linhas }\end{array}$} \\
\hline & 2 & Parafuso & \\
\hline \multirow{2}{*}{ CT1B-6 } & 1 & Chapa + parafuso & \multirow{2}{*}{$\begin{array}{l}\text { Ruptura dos parafusos } \\
\text { somente na linha } 2\end{array}$} \\
\hline & 2 & Parafuso & \\
\hline
\end{tabular}

Observando-se a tabela VII.I, é possível verificar que os protótipos CT1A-4 e CT1B-4 apresentam ruptura em ambas as linhas de parafusos, o que não é previsto pelo EUROCODE-3 (1993), visto os valores da capacidade resistente apresentados no capítulo 6.

Contudo, também é possível verificar que há uma coerência entre o colapso previsto e o observado nos protótipos CT1A-1 e CT1B-6.

Investigando-se o comportamento dos modelos numéricos e os modos de falha preconizados pelo EUROCODE-3 (1993), verifica-se que o modelo CT1A-1 apresenta um colapso no modo $3^{\mathbb{t}}$, ou seja, limitado pela capacidade resistente dos parafusos. Para o modelo CT1B-6, apesar de se prever o modo de falha 2 para a linha 1 (externa), verifica-se uma grande proximidade dessa linha para o modo de falha 1 , caracterizado somente pelo escoamento da chapa de topo.

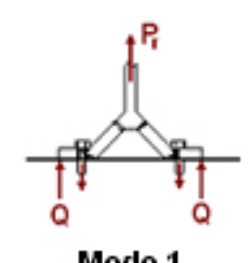

Modo 1

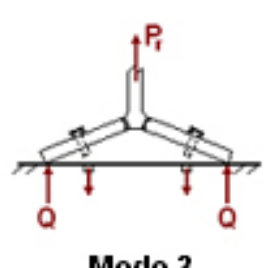

Modo 2

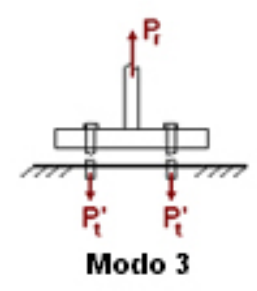

Modo 3 
Uma conclusão imediata das observações realizadas acima é que a capacidade resistente dos parafusos segundo EUROCODE-3 (1993) é bem determinada para os casos extremos, ou seja, ou para a ruptura dos parafusos ou para o escoamento da chapa de topo.

Para a interação entre chapa e parafusos (modo 2) não há como identificar a contribuição de cada um desses elementos para o colapso da ligação. Observando-se os protótipos CT1A-4 e CT1B-4, há uma indicação de que a limitação de resistência seja atribuída aos parafusos, o que não foi verificado pelo EUROCODE-3 (1993) para a linha 1 (externa).

Neste caso, ressalta-se a importância de se analisar o processo de cálculo proveniente da consideração das linhas de escoamento de tensão em torno dos parafusos.

As características apresentadas acima foram observadas e analisadas visando avaliar, como já dito, a representatividade dos modelos numéricos e dos modelos de dimensionamento adotados.

Convém ainda observar que a sofisticação dos modelos numéricos, indicada anteriormente, ocorreu durante o desenvolvimento deste trabalho, que partiu de modelos mais simples, com base na análise numérica de RIBEIRO (1998).

Uma vez que se escolheu representar os modelos com o vão total da viga utilizada nos protótipos - o que aumenta significativamente o número de elementos finitos - e pela consideração de não linearidades físicas e geométricas, o tempo de processamento de cada modelo final variou entre $\mathbf{5}$ a 6 dias, o que inviabilizou o estudo de outros parâmetros (além da espessura da chapa e do diâmetro dos parafusos), bem como a análise de outros modelos reológicos para os materiais.

Assim, visando a continuidade dos estudos referentes ao comportamento das ligações e a utilização dos modelos numéricos para esse propósito, sugere-se algumas modificações e considerações adicionais para modelagem numérica, que são: 
i. a inclusão de modelos reológicos que possam representar a ruptura do material;

ii. a consideração das folgas nos furos da chapa de topo;

iii. a redução do número de elementos finitos, considerando-se o acoplamento entre os elementos sólidos e elementos de barra, após verificada a influência desta simplificação nos resultados da ligação; e

iv. considerar a possibilidade de avaliar a influência da rigidez da ligação no comportamento global da estrutura, ou seja, simular com elementos volumétricos a região nodal acoplado a elementos de barra representando os demais elementos da estrutura.

Além disso, verifica-se a necessidade da realização de novos estudos experimentais, possibilitando assim um melhor confronto com os resultados numéricos.

Visto isso, foi possível comprovar, de maneira geral, a potencialidade da análise numérica e dos modelos como uma ferramenta eficaz, que possibilite a edição de códigos de dimensionamento mais próximos do efetivo comportamento das ligações, vislumbrando sempre a viabilização de métodos que, além de práticos, possam tornar as estruturas mais seguras e econômicas. 


\section{REFERÊNCIAS BIBLIOGRÁFICAS}

AGERSKOV, H. (1976). High-strength bolted connections subject to prying. Journal of Structural Division, v.102, n.ST1, p.161-175, January.

AGERSKOV, H. (1979). Discussion of "A fresh look at bolted end-plate behavior and design". AISC Engineering Journal, v.16, 2nd Quarter, p.54-55 / paper by KRISHNAMURTHY, N. (1978b). AISC Engineering Journal, v.15, n.2, 2nd Quarter.

AMERICAN INSTITUTE OF STEEL CONSTRUCTION (1980). Manual of steel construction. 8.ed. Chicago.

AMERICAN INSTITUTE OF STEEL CONSTRUCTION (1986). Manual of steel construction: load and resistance factor design. Chicago.

AMERICAN INSTITUTE OF STEEL CONSTRUCTION (1989). Manual of steel construction: allowable stress design. 9.ed. Chicago.

BAHAARI, M.R.; SHERBOURNE, A.N. (1994). Computer modeling of an extended end-plate bolted connection. Computers \& Structures, v.52, n.5, p.879-893.

BAHAARI, M.R.; SHERBOURNE, A.N. (1996a). Structural behavior of endplate connections to stiffened columns. Journal of Structural Division, v.122, n.8, p.926-935, August.

BAHAARI, M.R.; SHERBOURNE, A.N. (1996b). 3D simulation of bolted connections to unstiffened columns - II. Extended endplate connections. Journal of Constructional Steel Research, v.40, n.3, p.189-223, October.

BATHO, C.; BATHEMAN, E.H. (1934). Investigations on bolts and bolted joints. London, Steel Structures Research Committee, 2nd Report. 
BEEDLE, L.S.;CHRISTOPHER, R. (1964). Tests of steel moment connections. AISC Engineering Journal, v.1, n.4, p.116-125, October.

BJORHOVDE, R.; COLSON, A.; BROZZETTI, J. (1990). Classification system for beam-to-column connections. Journal of Structural Engineering, v.116, n.11, p.3059-3076.

BRITISH STANDARDS INSTITUTION (1990). BS-5950 - Structural use of steelwork in building. Part 1 - Code of practice for design in simple and continuous construction: hot rolled sections. London, BSI.

BROWN, D.G. et al. (1996). A new industry standard for moment connections in steelwork. The Structural Engineer, v.74, n.20, p.335342, October.

CHEN, W.F.; PATEL, K. V. (1981). Static behavior of beam-to-column moment connections. Journal of Structural Division, v.107, n.ST9, p.1815-1838, September.

CHEN, W.F.; LUI, E.M. (1988a). Static flange moment connections. Journal of Constructional Steel Research, v.10, p.39-88.

CHEN, W.F.; LUI, E.M. (1988b). Static web moment connections. Journal of Constructional Steel Research, v.10, p.89-131.

DAVISON, J. B.; KIRBY, P. A.; NETHERCOT, D. A. (1987a). Rotational stiffness characteristics of steel beam-to-column connections. Journal of Constructional Steel Research, v.8, n.1, p.15-54.

DAVISON, J. B.; KIRBY, P. A.; NETHERCOT, D. A. (1987b). Effect of lack of fit on connection restraint. Journal of Constructional Steel Research, v.8, n.1, p.55-69.

DOUTY, R.T.; McGUIRE, W. (1965). High-strength bolted moment connections. Journal of Structural Division, v.91, n.ST2, p.101-128, April.

EUROCODE 3 (1992). Design of steel structures: Part 1.1 - General rules and rules for buildings.

EUROCODE 3 (1993). Design of steel structures: Part 1.1 - General rules and rules for buildings - Revised Annex J: Joints in building frames. 
EUROPEAN COMMUNITY OF STEEL CONSTRUCTION (1997). Frame design including joint behaviour. Liège, ECSC. 2v.

GOVERDHAM, A. V. (1984). A collection of experimental moment rotation curves and evaluation of predict equations for semi-rigid connections. Nashville. Master's Thesis - Vanderbilt University.

HUANG, J.S.; CHEN, W.F.; BEEDLE, L.S. (1973). Behavior and design of steel beam-to-column moment connections. Welding Research Council Bulletin, n.188, p.1-23, October.

HUMER, C.; TSCHEMMERNEGG, F.A (1988). A nonlinear joint model for the design of structural steel frames. Costruzioni Metalliche, v.40, n.1, p.31-41, gen./feb.

JONES, S. W.; KIRBY, P. A.; NETHERCOT, D. A. (1980). Effect of semirigid connections on steel column strength. Journal of Constructional Steel Research, v.1, n.1, p.38-46.

JONES, S. W.; KIRBY, P. A.; NETHERCOT, D. A. (1983). The analysis of frames with semi-rigid connections: a state of the art report. Journal of Constructional Steel Research, v.3, n.2, p.2-13.

JOHNSON, L.G. (1959). Tests on welded connections between I-section beams and stanchions. British Welding Journal, p.38-46, January.

KISHI, N.; CHEN, W. F. (1986). Data base of steel beam-to-column connections. West Lafayette, School of Civil Engineering, Purdue University. 2v. (Structural Engineering Report n. CE-STR-86-26).

KISHI, N. (1994). Semi-rigid connections. In: CHEN, W. F.; TOMA, S., eds. Advanced analysis of steel frames. Boca Raton, CRC Press. Cap.3, p.91-137.

KISHI, N.; HASAN, R.; CHEN, W. F.; GOTO, Y (1997). Study of Eurocode 3 steel connection classification. Engineering Structures, v. 19, n. 9, p.772-779.

KRISHNAMURTHY, N. (1973a). Finite element analysis of splice-plate connections: a feasible study. Auburn, Alabama, Auburn University. (Report n. CE-AISC-MBMA-1). 
KRISHNAMURTHY, N. (1973b). Effects of plate thickness and pretensioning in typical bolted end-plate connections. Auburn, Alabama, Auburn University. (Report n. CE-AISC-MBMA-2).

KRISHNAMURTHY, N. (1974a). Two-dimensional finite element analysis of steel end-plate connections: parametric considerations. Auburn, Alabama, Auburn University. (Report n. CE-AISC-MBMA-3).

KRISHNAMURTHY, N. (1974b). Correlation between three-dimensional and two-dimensional finite element analysis of end-plate connections. Auburn, Alabama, Auburn University. (Report n. CE-AISC-MBMA-4).

KRISHNAMURTHY, N. (1974c). Parameter study of steel end-plate connections by two-dimensional finite element analysis. Auburn, Alabama, Auburn University. (Report n. CE-AISC-MBMA-5).

KRISHNAMURTHY, N. (1975a). Discussion of "High strength bolts subject to tension and prying". Journal of the Structural Division, v.101, n.ST1, p.335-337, January / paper by NAIR, R.S.; BIRKEMOE, P.C.; MUNSE, W.H. (1974). Journal of Structural Division, v.100, n.ST2, p.351-372, February.

KRISHNAMURTHY, N. (1975b). Two-dimensional finite element analysis of extended and flush connections with multiple rows of bolts. Auburn, Alabama, Auburn University. (Report n. CE-AISC-MBMA-6).

KRISHNAMURTHY, N. (1975c). Tests on bolted end-plate connections and comparisons with finite element analysis. Auburn, Alabama, Auburn University. (Report n. CE-AISC-MBMA-7).

KRISHNAMURTHY, N. (1975d). Effects of reduction in boltt size and pretension on end-plate connection behavior. Auburn, Alabama, Auburn University. (Report n. CE-AISC-MBMA-8).

KRISHNAMURTHY, N. (1975e). Auburn University research on end-plate connections: a summary. Auburn, Alabama, Auburn University. (Report n. CE-AISC-MBMA-9).

KRISHNAMURTHY, N. (1976). Design of end-plate connections. Vanderbilt, Tennessee, Vanderbilt University. (Report n. CE-AISC-MBMA-10). 
KRISHNAMURTHY, N.; GRADDY, D. (1976). Correlation between 2- and 3dimensional finite element analysis of steel bolted end-plate connections. Computers \& Structures, v.6, p.381-389.

KRISHNAMURTHY, N. (1977). Discussion of "High-strength bolted connections subject to prying". Journal of Structural Division, v.103, n.ST1, p.299-300, January / paper by NAIR, R.S.; BIRKEMOE, P.C.; MUNSE, W.H. (1974). Journal of Structural Division, v.100, n.ST2, p.351372, February.

KRISHNAMURTHY, N. (1978a). Discussion of "Analysis of bolted connections subject to prying". Journal of the Structural Division, v.104, n.ST12, p.1928-1930, December / paper by AGERSKOV, H. (1977b). Journal of Structural Division, v.103, n.ST11, p.2145-2163, November.

KRISHNAMURTHY, N. (1978b). A fresh look at bolted end-plate behavior and design. AISC Engineering Journal, v.15, 2nd Quarter, p.39-49, April.

KRISHNAMURTHY, N. (1978c). Photoelastic and finite element investigation of steel bolted tee hangers. Vanderbilt, Tennessee, Vanderbilt University. (Report n. CE-MBMA-1903-1).

KRISHNAMURTHY, N. (1978d). Effects of bolt heads and welds in steel bolted tee-type connections. Vanderbilt, Tennessee, Vanderbilt University. (Report n. CE-MBMA-1903-11).

KRISHNAMURTHY, N. (1978e). Analytical investigation of end-plate connection design. Vanderbilt, Tennessee, Vanderbilt University. (Report n. CE-MBMA-1902-1).

KRISHNAMURTHY, N. (1979a). Experimental validation of end-plate connection design. Vanderbilt, Tennessee, Vanderbilt University. (Report n. CE-AISC-37025-1).

KRISHNAMURTHY, N. (1979b). Experimental investigation of bolted stiffened tee-stubs. Vanderbilt, Tennessee, Vanderbilt University. (Report n. CE-MBMA-1902-2). 
KRISHNAMURTHY, N. (1979c). Closure of "A fresh look at bolted end-plate behavior and design". AISC Engineering Journal, v.16, 2nd Quarter, p.60-64 / paper by KRISHNAMURTHY, N. (1978b). AISC Engineering Journal, v.15, 2nd Quarter, p.39-49, April.

LIGHTFOOT, E.; LeMESSURIER, A.P. (1974). Elastic analysis of frameworks with elastic connections. Journal of the Structural Division, v.100, n.ST6, p.1297-1309, June.

LIONBERGER, S.R.; WEAVER, W. (1969). Dynamic response of frames with non-rigid connections. Journal of Engineering Mechanical Division, v.95, n.1, p.95-114.

LUI, E.M.; CHEN, W.F. (1986). Analysis and behavior of flexibly jointed frames. Engineering Structures, v.8, n.2, p.107-118.

MANUAL brasileiro para cálculo de estruturas metálicas (1988). Brasília-DF, $\mathrm{MCl} / \mathrm{STI}$. v.3, tomo 2.

McGUIRE, W. (1979). Discussion of "A fresh look at bolted end-plate behavior and design". AISC Engineering Journal, v.16, 2nd Quarter, p.55-56 / paper by KRISHNAMURTHY, N. (1978b). AISC Engineering Journal, v.15, 2nd Quarter, p.39-49, April.

McGUIRE, W. (1988). Introduction. In: CHEN, W. F., ed. Steel beam-tocolumn building connections. London, Elsevier. p. 1-35.

MONFORTON, A.R.; WU, T.S. (1963). Matrix analysis of semi-rigidly connected frames. Journal of the Structural Division, v.87, n.ST6, p.1342, December.

MUNSE, W.H.; PETERSEN, K.S.; CHESSON JR., E. (1959a). Strength of rivets and bolts in tension. Journal of Structural Division, v.85, n.ST3, p.7-28, March.

MUNSE, W.H.; PETERSEN, K.S.; CHESSON JR., E. (1959b). Behavior of riveted and bolted beam-to-column connections. Journal of Structural Division, v.85, n.ST3, p.29-50, March.

NAIR, R.S.; BIRKEMOE, P.C.; MUNSE, W.H. (1974). High-strength bolts subject to tension and prying. Journal of Structural Division, v.100, n.ST2, p.351-372, February. 
NETHERCOT, D. A. (1985). Utilization of experimentally obtained connection data in assessing the performance of steel frames. In: CHEN, W. F., ed. Connection flexibility and steel frames (Proceedings of session sponsored by Structural Division, Detroit, October). New York, ASCE. p.13-37.

NETHERCOT, D. A.; LI, T. Q.; CHOO, B. S (1995). Required rotations and moment redistribution for composite and continuous beams. Journal of Constructional Steel Research, v.35, n.2, p.121-163.

NETHERCOT, D. A.; LI, T. Q.; AHMED, B (1998). Unified classification system for beam-to-column connections. Journal of Constructional Steel Research, v.45, n.1, p.39-65.

PARFITT JR, J.; CHEN, W.F. (1976). Tests of welded steel beam-to-column moment connections. Journal of Structural Division, v.102, n.ST1, p.189-202, January.

PRELORENTZOU, P. A. (1991). Um estudo sobre ligações viga-coluna em estruturas de aço. São Carlos. 221p. Dissertação (Mestrado) - Escola de Engenharia de São Carlos, Universidade de São Paulo.

QUEIRÓZ, G. (1992). Estudo do comportamento e sistematização do projeto de ligações rígidas entre perfis I com almas coplanares. Belo Horizonte. 159p. Dissertação (Mestrado) - Escola de Engenharia, Universidade Federal de Minas Gerais.

QUEIRÓZ, G. (1995). Análise experimental de ligações soldadas. Belo Horizonte. 285p. Tese (Doutorado) - Escola de Engenharia, Universidade Federal de Minas Gerais.

RATHBUN, J.C. (1936). Elastic properties of riveted connections. Transactions of ASCE, v.101, p.524-563.

REGEC, J.E.; HUANG, J.S.; CHEN, W.F. (1973). Test of a fully-welded beam-to-column connection. Welding Research Council Bulletin, n.188, p.24-35, October.

RESEARCH COUNCIL ON RIVETED AND BOLTED STRUCTURAL JOINTS (1949). Specification for assembly of structural joints using highstrength bolts. Philadelphia. 
RESEARCH COUNCIL ON RIVETED AND BOLTED STRUCTURAL JOINTS (1962). Specification for structural joints using ASTM A325 bolts. Journal of the Structural Division, v.88, n.ST5, p.11-24, October.

RIBEIRO, L. F. L. (1998). Estudo do comportamento estrutural de ligações parafusadas viga-coluna com chapa de topo: análise teóricoexperimental. São Carlos. 524p. Tese (Doutorado) - Escola de Engenharia de São Carlos, Universidade de São Paulo.

RODRIGUES, F. C. (1991). Previsão do comportamento de pórticos planos metálicos com ligações semi-rígidas. Rio de Janeiro, COPPE/UFRJ. ( $3^{\circ}$. Seminário de Doutoramento).

ROMSTAD, K.M.; SUBRAMANIAN, C.V. (1970). Analysis of frames with partial connection rigidity. Journal of Structural Division, v.96, n.ST11, p.2283-2300, November.

RUBLE, E.J. (1959). Riveted and bolt council research. Journal of Structural Division, v.85, n.ST3, p.1-6, March.

STEEL CONSTRUCTION INSTITUTE / BRITISH CONSTRUCTIONAL STEELWORK ASSOCIATION (1996). Joints in steel construction: moment connections. London, SCI/BCSA.

TARPY, T.S.; CARDINAL, J.W. (1981). Behavior of semi-rigid beam-tocolumn end plate connections. In: HOWLETT, J.H.; JENKINS, W.M.; STAINSBY, R., eds. Joints in structural steelwork. London, Pentech Press. p.2.3-2.25.

VASARHELY, D.D. (1959). Effects of fabrication techniques on bolted joints. Journal of the Structural Division, v.85, n.ST3, p.71-116, March.

WILSON, W. M.; MOORE, H. F. (1917). Tests to determine the rigidity of riveted joints of steel structures. Urbana, IL, University of Illinois, Engineering Experiment Station. (Bulletin n. 104).

WILSON, W.M.; THOMAS, F.P. (1938). Fatigue tests on riveted joints.

Urbana, IL, University of Illinois, Engineering Experiment Station. (Bulletin n.302). 
WITTEVEEN, J. et al. (1982). Welded and bolted beam-to-column connections. Journal of Structural Division, v.108, n.ST2, p.433-455, February. 
Anexo

I

CÁLCULO DA CAPACIDADE RESISTENTE SEGUNDO O EUROCODE-3 (1993) 


\section{A1.1 Resumo da formulação utilizada}

- Modos de Falha:

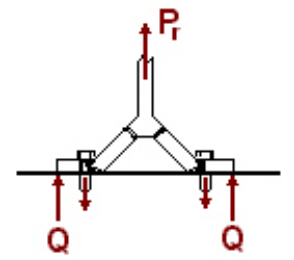

Modo 1

Escoamento total do flange do pilar ou da chapa de topo

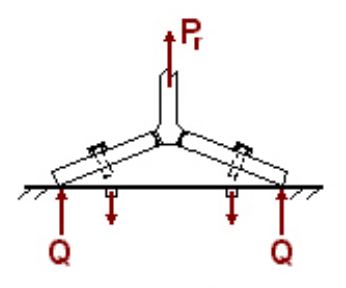

Modo 2

Ruptura do parafuso com escoamento do flange do pilar ou da chapa de topo

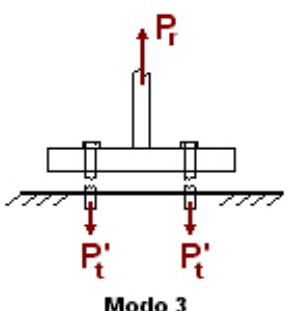

Ruptura dos parafusos

- Características geométricas gerais
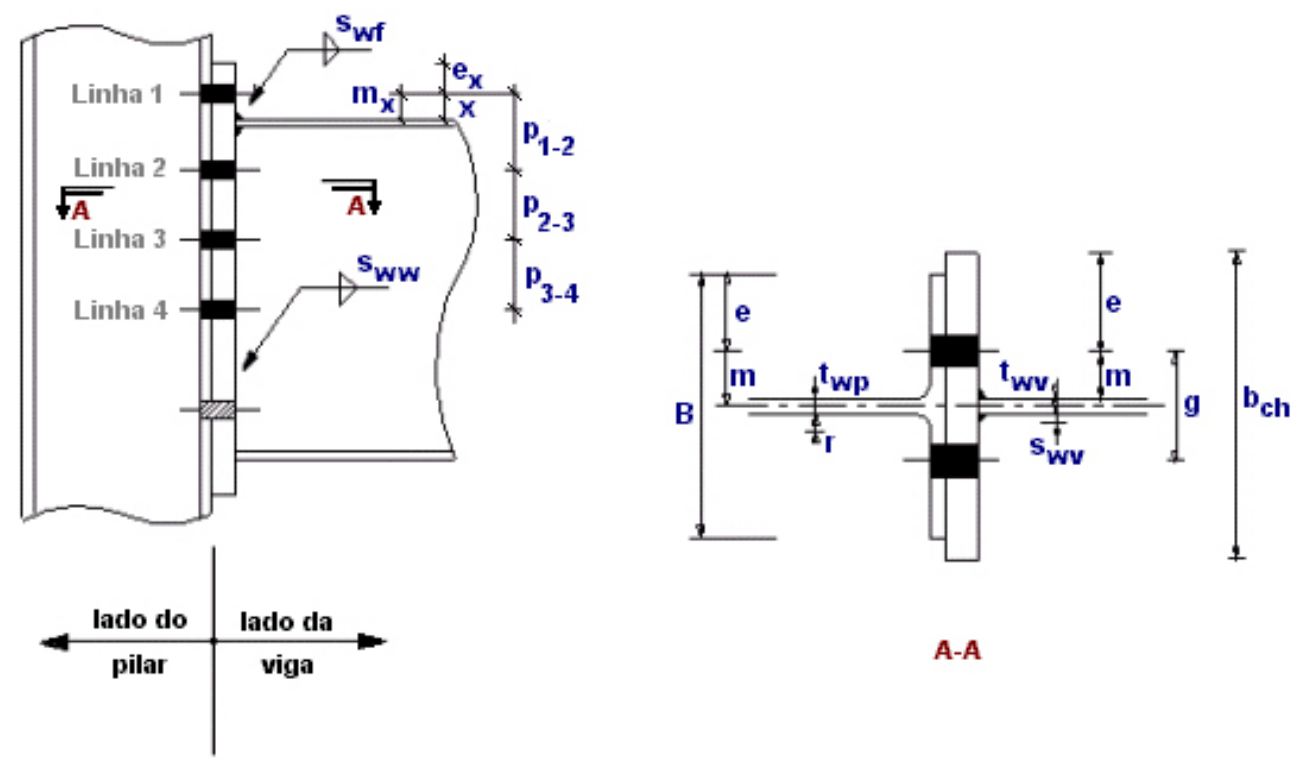

A-A 
- Expressões para cálculo da capacidade resistente $\left(\mathbf{P}_{\mathbf{r}}\right)$ :

i. Modo 1

$P_{r}=\frac{4 M_{p}}{m}$

$\operatorname{com} M_{p}=\frac{L_{e f} t^{2} f_{y}}{4}$

ii. Modo 2

$\mathrm{P}_{\mathrm{r}}=\frac{2 \mathrm{M}_{\mathrm{p}}+\mathrm{n} \sum \mathrm{P}_{\mathrm{t}}^{\prime}}{\mathrm{m}+\mathrm{n}}$

iii. Modo 3

$\mathrm{P}_{\mathrm{r}}=\sum \mathrm{P}_{\mathrm{t}}^{\prime}$

onde: $\quad \mathbf{M}_{\mathbf{p}}=$ momento de plastificação total do perfil "T" equivalente, representando o flange do pilar ou a chapa de topo;

$\mathbf{L}_{\text {ef }} \quad=$ comprimento efetivo da linha de escoamento no perfil "T" equivalente, apresentado em forma de tabelas, de acordo com a posição das linhas ou grupos de linhas de parafusos e da presença ou não de enrijecedores ou da mesa da viga;

$\mathbf{t}=$ espessura do flange do pilar ou da chapa de topo;

$\mathbf{f}_{\mathbf{y}} \quad=$ limite de escoamento do material do flange do pilar ou da chapa de topo;

$\mathbf{P}_{\mathbf{r}} \quad=$ capacidade resistente da linha ou grupo de linhas de parafusos;

$\mathbf{P}_{\mathbf{t}}{ }^{\prime} \quad=$ limite superior de resistência do parafuso quando o efeito de alavanca é considerado; 


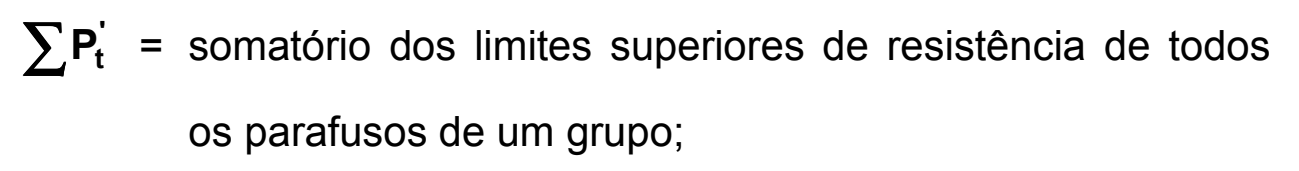

m = distância do centro do parafuso à face da alma do pilar ou da viga, menos $80 \%$ do raio flange/alma (pilar) ou da dimensão da solda alma/chapa de topo (viga);

n = distância efetiva do centro do parafuso à borda do flange do pilar ou da chapa de topo, tomada como o valor

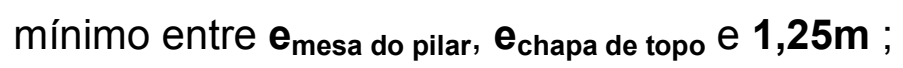

$\mathbf{m}_{\mathbf{x}}$ = distância do centro do parafuso à face da mesa da viga, menos $80 \%$ da dimensão da solda chapa de topo/mesa da viga;

$\mathbf{e}_{\mathbf{x}}=$ distância do centro do parafuso à extremidade da chapa de topo;

$\mathbf{n}_{\mathbf{x}}=$ menor valor entre $\mathbf{e}_{\mathbf{x}}$ e $\mathbf{1 , 2 5 m _ { \mathbf { x } }}$;

g = distância horizontal entre o centro dos parafusos;

$\mathbf{b}_{\text {ch }}=$ largura da chapa de topo;

B = largura da mesa do pilar;

$\mathbf{t}_{\mathrm{wv}}=$ espessura da alma da viga;

$\mathbf{t}_{\mathrm{wp}}=$ espessura da alma do pilar;

$\mathbf{s}_{\mathbf{w w}}=$ altura da solda de filete entre chapa e alma da viga;

$\mathbf{s}_{\mathrm{wf}}=$ altura da solda de filete entre chapa e mesa da viga.

- Cálculo do comprimento $L_{\text {ef }}$ do perfil "T" equivalente e do parâmetro $\alpha$ :

\section{Vide tabelas A1.I , A1.II e A1.III}

- Características adicionais dos cálculos:

i. pela presença dos enrijecedores e da mesa da viga, as linhas de parafusos serão consideradas com atuando isoladamente; 
ii. a linha 1 refere-se aos parafusos externos e a linha 2 refere-se aos parafusos internos às mesas da viga;

iii. a verificação à tração para as almas da viga e do pilar não será efetuada, devido à presença dos enrijecedores dentro dos comprimentos efetivos, como prescreve o método;

iv. a tensão de escoamento considerada têm o valor de $25 \mathrm{kN} / \mathrm{cm}^{2}$.

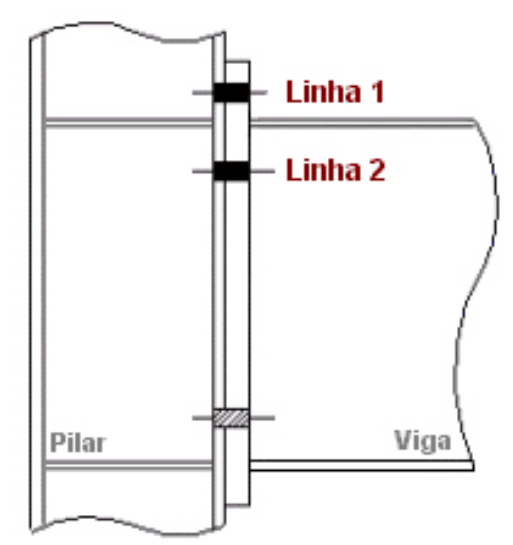

A1.2 Cálculo da capacidade resistente das linhas de parafuso

\section{A1.2a Modelo CT1A-1}

- Características geométricas

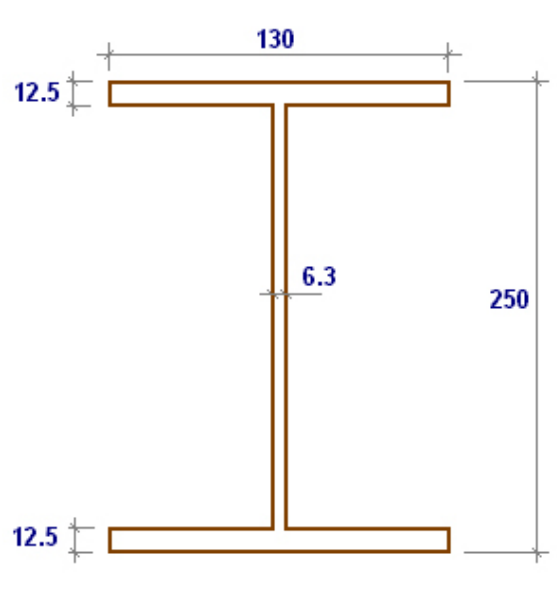

Viga VS $250 \times 37$

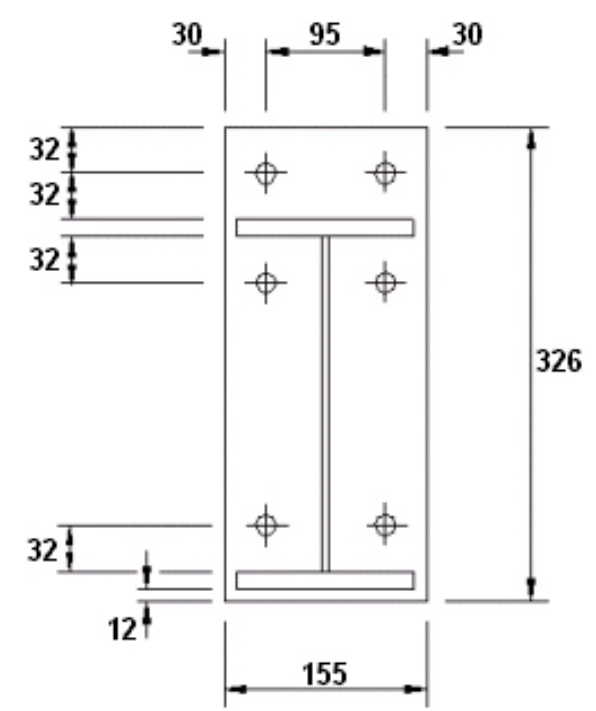

Chapa de topo

$t_{\mathrm{ch}}=\mathbf{3 1 , 5} \mathrm{mm}$ 
$\rightarrow$ Verificação à flexão na chapa de topo

$$
\begin{aligned}
& \mathrm{m}=\frac{9,5}{2}-\frac{0,63}{2}-0,8 \times 0,5=4,035 \mathrm{~cm} \\
& e=\frac{15,5}{2}-\frac{9,5}{2}=3 \mathrm{~cm}
\end{aligned}
$$

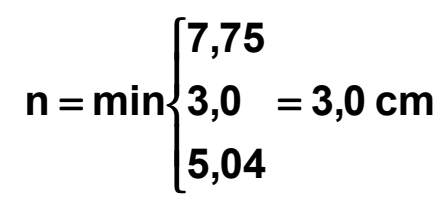

$$
\begin{aligned}
& \mathrm{m}_{\mathrm{x}}=2,8 \mathrm{~cm} \\
& e_{x}=3,2 \mathrm{~cm} \\
& n_{x}=\min \left\{\begin{array}{l}
3,2 \\
3,5
\end{array}=3,2 \mathrm{~cm}\right. \\
& \rightarrow \text { Linha } 1 \\
& L_{\text {ef }}=\min \{v i i, v i i i, i x, x, x i\} \\
& \text { vii) } L_{\text {ef }}=\frac{b_{p}}{2}=\frac{15,5}{2}=7,75 \mathrm{~cm} \\
& \text { viii) } L_{e f}=2 m_{x}+0,625 e_{x}+g / 2=12,35 c m \\
& \text { ix) } L_{e f}=2 m_{x}+0,625 e_{x}+e=10,6 \mathrm{~cm} \\
& \text { x) } L_{e f}=4 m_{x}+1,25 e_{x}=15,2 \mathrm{~cm}
\end{aligned}
$$

\footnotetext{
${ }^{1}$ Vide tabelas A1.I e A1.II
} 


$$
\mathrm{L}_{\mathrm{ef}}=7,75 \mathrm{~cm}
$$

- Determinação de $\mathrm{M}_{\mathrm{p}}$ :

$$
\begin{aligned}
& M_{p}=\frac{L_{e f} t^{2} f_{y}}{4} \\
& t=3,15 \mathrm{~cm} \\
& M_{p}=480,62 \mathrm{kNcm}
\end{aligned}
$$

- Modo 1:

$$
P_{r, 1}=\frac{4 M_{p}}{m}=476,45 \mathrm{kN}
$$

- Modo 2:

$$
\begin{aligned}
& P_{r, 2}=\frac{2 M_{p}+n\left(\sum P_{t}{ }^{\prime}\right)}{m+n} \quad \sum P_{t}{ }^{\prime}=2 \times 90=180 k N \\
& P_{r, 2}=213,4 k N \\
& \text { - Modo 3: } \\
& P_{r, 3}=\sum P_{t}{ }^{\prime}=180 k N \\
& \rightarrow \text { Linha 2 } \\
& \text { - Determinação de } L_{e f:} \\
& \text { (Linha abaixo da mesa da viga) } \\
& \text { Lef }=\text { min }\{\text { max }\{\text { ii, iii }\}, i \text { }
\end{aligned}
$$




$$
\begin{aligned}
& \text { i) } \mathrm{L}_{\text {ef }}=2 \pi \mathrm{m}=25,35 \mathrm{~cm} \\
& \text { ii) } L_{\text {ef }}=4 \mathrm{~m}+1,25 \mathrm{e}=19,89 \mathrm{~cm} \\
& \text { iii) } L_{\text {ef }}=\alpha m_{1} \text {, } \\
& \left.\begin{array}{ll}
\mathrm{m}_{1}=4,035 & \lambda_{1}=0,57 \\
\mathrm{~m}_{2}=2,8 & \lambda_{2}=0,40
\end{array}\right\} \quad \alpha=5,7 \\
& \mathrm{~L}_{\mathrm{ef}}=23,0 \mathrm{~cm}
\end{aligned}
$$

- Determinação de $\mathrm{M}_{\mathrm{p}}$ :

$$
\begin{aligned}
& M_{p}=\frac{L_{e f} t^{2} f_{y}}{4} \\
& t=3,15 \mathrm{~cm} \\
& M_{p}=1426,4 \mathrm{kNcm}
\end{aligned}
$$

- Modo 1:

$$
P_{r, 1}=\frac{4 M_{p}}{m}=1414,0 k N
$$

- Modo 2:

$$
\begin{aligned}
& P_{r, 2}=\frac{2 M_{p}+n\left(\sum P_{t}{ }^{\prime}\right)}{m+n} \quad \sum P_{t}{ }^{\prime}=2 \times 90=180 k N \\
& P_{r, 2}=482,3 k N
\end{aligned}
$$


- Modo 3:

$$
P_{r, 3}=\sum P_{t}^{\prime}=180 k N
$$

$\rightarrow$ Verificação à flexão na mesa do pilar

$$
\begin{aligned}
& m=\frac{9,5}{2}-\frac{1,25}{2}-0,8 \times 0,6=3,645 \mathrm{~cm} \\
& e=\frac{25}{2}-\frac{9,5}{2}=7,75 \mathrm{~cm} \\
& n=\min \left\{\begin{array}{l}
7,75 \\
3,0 \\
4,56
\end{array}=3,0 \mathrm{~cm}\right. \\
& m_{x}=2,8 \mathrm{~cm} \\
& e_{x}=3,2 \mathrm{~cm} \\
& n_{x}=\min \left\{\begin{array}{l}
3,2 \\
3,5
\end{array}=3,2 \mathrm{~cm}\right.
\end{aligned}
$$

$\rightarrow$ Linha 1

- Determinação de $L_{e f}$ :

$$
\begin{aligned}
& \text { (Linha próxima ao enrijecedor) } \\
& L_{\text {ef }}=\min \{\max \{\mathrm{ii}, \mathrm{iii}\}, \mathrm{i}\} \\
& \text { i) } \mathrm{L}_{\text {ef }}=2 \pi \mathrm{m}=22,9 \mathrm{~cm} \\
& \text { ii) } \mathrm{L}_{\text {ef }}=4 \mathrm{~m}+1,25 \mathrm{e}=24,27 \mathrm{~cm} \\
& \text { iii) } \mathrm{L}_{\text {ef }}=\alpha \mathrm{m}_{1}
\end{aligned}
$$




$$
\left.\begin{array}{ll}
\mathrm{m}_{1}=3,645 & \lambda_{1}=0,32 \\
\mathrm{~m}_{2}=2,72 & \lambda_{2}=0,24
\end{array}\right\} \quad \alpha=2 \pi
$$

$$
L_{\text {ef }}=22,9 \mathrm{~cm}
$$

- Determinação de $M_{p}$ :

$$
\begin{aligned}
& M_{p}=\frac{L_{e f} t^{2} f_{y}}{4} \\
& t=1,9 \mathrm{~cm} \\
& M_{p}=516,7 \mathrm{kNcm}
\end{aligned}
$$

- Modo 1:

$$
P_{r, 1}=\frac{4 M_{p}}{m}=567,0 \mathrm{kN}
$$

- Modo 2:

$$
\begin{aligned}
& P_{r, 2}=\frac{2 M_{p}+n\left(\sum P_{t}{ }^{\prime}\right)}{m+n} \quad \sum P_{t}^{\prime}=2 \times 90=180 k N \\
& P_{r, 2}=236,8 k N
\end{aligned}
$$

- Modo 3:

$$
P_{r, 3}=\sum P_{t}^{\prime}=180 k N
$$

$\rightarrow$ Linha 2

Mesmos valores da linha 1 
$\rightarrow$ Resumo das capacidades (em kN)

\begin{tabular}{|c|c|c|c|c|c|c|c|}
\hline \multirow{4}{*}{$\frac{\bar{s}}{\sigma}$} & & \multicolumn{3}{|c|}{ Flexão na chapa de topo } & \multicolumn{3}{|c|}{ Flexão na mesa do pilar } \\
\hline & Linha & Modo 1 & Modo 2 & Modo 3 & Modo 1 & Modo 2 & Modo 3 \\
\hline & 1 & 476,45 & 213,4 & 180,0 & 567,0 & 236,8 & 180,0 \\
\hline & 2 & 1414,0 & 482,3 & 180,0 & 567,0 & 236,8 & 180,0 \\
\hline
\end{tabular}

\section{A1.2b Modelo CT1A-4}

Segue o modelo CT1A-1, a menos da determinação de $M_{p}$, para o qual deve ser utilizado $t=2,24 \mathrm{~cm}$ (espessura da chapa de topo) para a verificação da flexão na chapa de topo.

$\rightarrow$ Verificação à flexão na chapa de topo

$\rightarrow$ Linha 1

- Determinação de $\mathrm{M}_{\mathrm{p}}$ :

$$
\begin{aligned}
& M_{p}=\frac{L_{e f} t^{2} f_{y}}{4} \\
& t=2,24 \mathrm{~cm} \\
& M_{p}=243,04 \mathrm{kNcm}
\end{aligned}
$$

- Modo 1:

$$
P_{r, 1}=\frac{4 M_{p}}{m}=240,9 k N
$$


- Modo 2:

$$
\begin{aligned}
& P_{r, 2}=\frac{2 M_{p}+n\left(\sum P_{t}{ }^{\prime}\right)}{m+n} \quad \sum P_{t}^{\prime}=2 \times 90=180 k N \\
& P_{r, 2}=145,85 k N
\end{aligned}
$$

- Modo 3:

$$
P_{r, 3}=\sum P_{t}^{\prime}=180 k N
$$

$\rightarrow$ Linha 2

- Determinação de $M_{p}$ :

$$
\begin{aligned}
& M_{p}=\frac{L_{e f} t^{2} f_{y}}{4} \\
& t=2,24 \mathrm{~cm} \\
& M_{p}=721,3 \mathrm{kNcm}
\end{aligned}
$$

- Modo 1:

$$
P_{r, 1}=\frac{4 M_{p}}{m}=715,0 \mathrm{kN}
$$

- Modo 2:

$$
\begin{aligned}
& P_{r, 2}=\frac{2 M_{p}+n\left(\sum P_{t}^{\prime}\right)}{m+n} \quad \sum P_{t}^{\prime}=2 \times 90=180 k N \\
& P_{r, 2}=281,8 k N
\end{aligned}
$$


- Modo 3:

$$
P_{r, 3}=\sum P_{t}^{\prime}=180 k N
$$

$\rightarrow$ Verificação à flexão na mesa do pilar

Mesmos valores do modelo CT1A-1

$\rightarrow$ Resumo das capacidades (em kN)

\begin{tabular}{|c|c|c|c|c|c|c|c|}
\hline & & \multicolumn{3}{|c|}{ Flexão na chapa de topo } & \multicolumn{3}{|c|}{ Flexão na mesa do pilar } \\
\hline \multirow{3}{*}{$\frac{⿱ 亠 䒑}{\frac{1}{5}}$} & Linha & Modo 1 & Modo 2 & Modo 3 & Modo 1 & Modo 2 & Modo 3 \\
\hline & 1 & 240,9 & 145,85 & 180,0 & 567,0 & 236,8 & 180,0 \\
\hline & 2 & 715,0 & 281,8 & 180,0 & 567,0 & 236,8 & 180,0 \\
\hline
\end{tabular}




\section{A1.2c Modelo CT1B-4}

- Características geométricas

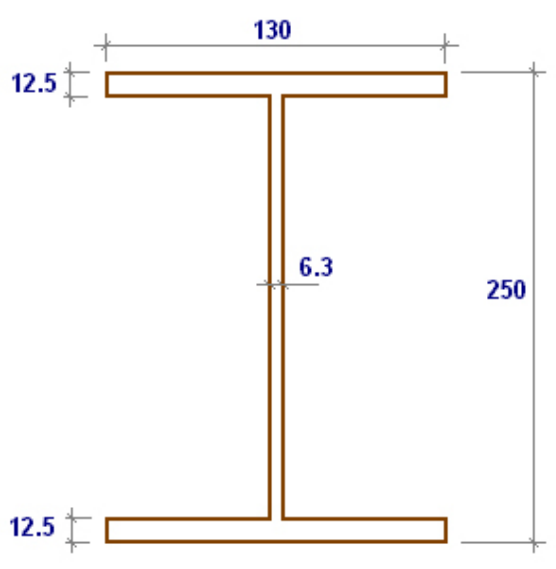

Viga VS $250 \times 37$

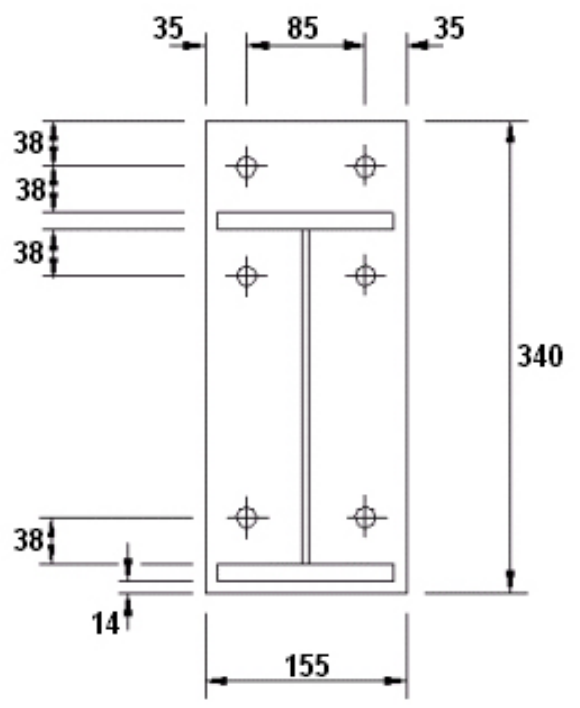

Chapa de topo $t_{c h}=22,4 \mathrm{~mm}$

$\rightarrow$ Verificação à flexão na chapa de topo

$$
\begin{aligned}
& m=\frac{8,5}{2}-\frac{0,63}{2}-0,8 \times 0,5=3,535 \mathrm{~cm} \\
& e=\frac{15,5}{2}-\frac{8,5}{2}=3,5 \mathrm{~cm} \\
& n=\min \left\{\begin{array}{l}
8,25 \\
3,5=3,5 \mathrm{~cm} \\
4,42
\end{array}\right. \\
& m_{x}=3,4 \mathrm{~cm} \\
& e_{x}=3,8 \mathrm{~cm} \\
& n_{x}=\min \left\{\begin{array}{l}
3,8 \\
4,25
\end{array}=3,8 \mathrm{~cm}\right.
\end{aligned}
$$


$\rightarrow$ Linha 1

- Determinação de $L_{e f}$ :

(Linha na extensão da chapa de topo)

$L_{\text {ef }}=\min \{v i i, v i i i, i x, x, x i\}$

vii) $L_{\text {ef }}=\frac{b_{p}}{2}=\frac{15,5}{2}=7,75 \mathrm{~cm}$

viii) $L_{e f}=2 m_{x}+0,625 e_{x}+g / 2=13,42 c m$

ix) $L_{e f}=2 m_{x}+0,625 e_{x}+e=12,67 \mathrm{~cm}$

x) $L_{e f}=4 m_{x}+1,25 e_{x}=18,35 \mathrm{~cm}$

xi) $L_{e f}=2 \pi m_{x}=21,36 \mathrm{~cm}$

$\mathrm{L}_{\mathrm{ef}}=7,75 \mathrm{~cm}$

- Determinação de $M_{p}$ :

$$
\begin{aligned}
& M_{p}=\frac{L_{e f} t^{2} f_{y}}{4} \\
& t=2,24 \mathrm{~cm} \\
& M_{p}=243,04 \mathrm{kNcm}
\end{aligned}
$$

- Modo 1:

$$
P_{r, 1}=\frac{4 M_{p}}{m}=275,0 \mathrm{kN}
$$


- Modo 2:

$$
\begin{aligned}
& P_{r, 2}=\frac{2 M_{p}+n\left(\sum P_{t}{ }^{\prime}\right)}{m+n} \quad \sum P_{t}{ }^{\prime}=2 \times 127=254 k N \\
& P_{r, 2}=195,46 k N
\end{aligned}
$$

- Modo 3:

$$
P_{r, 3}=\sum P_{t}^{\prime}=254 k N
$$

$\rightarrow$ Linha 2

- Determinação de $L_{e f}$ :

(Linha abaixo da mesa da viga)

$$
L_{\text {ef }}=\min \{\max \{i i, i i i\}, i\}
$$

$$
\begin{aligned}
& \text { i) } \mathrm{L}_{\text {ef }}=2 \pi \mathrm{m}=22,21 \mathrm{~cm} \\
& \text { ii) } \mathrm{L}_{\text {ef }}=4 \mathrm{~m}+1,25 \mathrm{e}=18,51 \mathrm{~cm} \\
& \text { iii) } L_{\text {ef }}=\alpha m_{1} \\
& \left.\begin{array}{ll}
\mathrm{m}_{1}=3,535 & \lambda_{1}=0,50 \\
\mathrm{~m}_{2}=3,4 & \lambda_{2}=0,48
\end{array}\right\} \quad \alpha=5,8 \\
& L_{e f}=20,5 \mathrm{~cm}
\end{aligned}
$$

- Determinação de $\mathrm{M}_{\mathrm{p}}$ :

$$
\begin{aligned}
& M_{p}=\frac{L_{e f} t^{2} f_{y}}{4} \\
& t=2,24 \mathrm{~cm}
\end{aligned}
$$




$$
M_{p}=642,88 \mathrm{kNcm}
$$

- Modo 1:

$$
P_{r, 1}=\frac{4 M_{p}}{m}=727,44 k N
$$

- Modo 2:

$$
\begin{aligned}
& P_{r, 2}=\frac{2 M_{p}+n\left(\sum P_{t}{ }^{\prime}\right)}{m+n} \quad \sum P_{t}^{\prime}=2 \times 127=254 k N \\
& P_{r, 2}=309,13 k N
\end{aligned}
$$

- Modo 3:

$$
P_{r, 3}=\sum P_{t}^{\prime}=254 k N
$$

$\rightarrow$ Verificação à flexão na mesa do pilar

$$
\begin{aligned}
& m=\frac{8,5}{2}-\frac{1,25}{2}-0,8 \times 0,6=3,145 \mathrm{~cm} \\
& e=\frac{25}{2}-\frac{8,5}{2}=8,25 \mathrm{~cm} \\
& n=\min \left\{\begin{array}{l}
8,25 \\
3,5=3,5 \mathrm{~cm} \\
4,42
\end{array}\right. \\
& m_{x}=3,4 \mathrm{~cm} \\
& e_{x}=3,8 \mathrm{~cm} \\
& n_{x}=\min \left\{\begin{array}{l}
3,8 \\
4,25
\end{array}=3,8 \mathrm{~cm}\right.
\end{aligned}
$$


$\rightarrow$ Linha 1

- Determinação de $L_{e f}$ :

$$
\begin{aligned}
& \text { (Linha próxima ao enrijecedor) } \\
& L_{e f}=\min \{\max \{i i, i i i\}, i\} \\
& \text { i) } L_{\text {ef }}=2 \pi \mathrm{m}=19,76 \mathrm{~cm} \\
& \text { ii) } \mathrm{L}_{\text {ef }}=4 \mathrm{~m}+1,25 \mathrm{e}=22,89 \mathrm{~cm} \\
& \text { iii) } L_{\text {ef }}=\alpha m_{1} \\
& \left.\begin{array}{ll}
\mathrm{m}_{1}=3,145 & \lambda_{1}=0,28 \\
\mathrm{~m}_{2}=3,32 & \lambda_{2}=0,29
\end{array}\right\} \quad \alpha=2 \pi \\
& L_{\text {ef }}=19,76 \mathrm{~cm} \\
& L_{e f}=19,76 \mathrm{~cm}
\end{aligned}
$$

- Determinação de $M_{p}$ :

$$
\begin{aligned}
& M_{p}=\frac{L_{e f} t^{2} f_{y}}{4} \\
& t=1,9 \mathrm{~cm} \\
& M_{p}=445,83 \mathrm{kNcm}
\end{aligned}
$$

- Modo 1:

$$
P_{r, 1}=\frac{4 M_{p}}{m}=567,0 k N
$$


- Modo 2:

$$
\begin{aligned}
& P_{r, 2}=\frac{2 M_{p}+n\left(\sum P_{t}{ }^{\prime}\right)}{m+n} \quad \sum P_{t}{ }^{\prime}=2 \times 127=254 k N \\
& P_{r, 2}=267,96 k N
\end{aligned}
$$

- Modo 3:

$$
P_{r, 3}=\sum P_{t}^{\prime}=254 k N
$$

$\rightarrow$ Linha 2

\begin{tabular}{|c|c|c|c|c|c|c|c|}
\hline & & Flexãc & la chapa & e topo & Flexã & la mesa & pilar \\
\hline \multirow{3}{*}{$\begin{array}{l}\dot{y} \\
\dot{m} \\
\end{array}$} & Linha & Modo 1 & Modo 2 & Modo 3 & Modo 1 & Modo 2 & Modo 3 \\
\hline & 1 & 275,0 & 195,46 & 254,0 & 567,03 & 267,96 & 254 \\
\hline & 2 & 727,44 & 309,13 & 254,0 & 567,03 & 267,96 & 254 \\
\hline
\end{tabular}

Mesmos valores da linha 1

$\rightarrow$ Resumo das capacidades (em kN) 


\section{A1.2d Modelo CT1B-6}

Segue o modelo CT1B-4, a menos da determinação de $M_{p}$, para o qual deve ser utilizado $t=1,9 \mathrm{~cm}$ (espessura da chapa de topo) para a verificação da flexão na chapa de topo.

$\rightarrow$ Verificação à flexão na chapa de topo

$\rightarrow$ Linha 1

- Determinação de $M_{p}$ :

$$
\begin{aligned}
& M_{p}=\frac{L_{\text {ef }} t^{2} f_{y}}{4} \\
& t=1,9 \mathrm{~cm} \\
& M_{p}=174,86 \mathrm{kNcm}
\end{aligned}
$$

- Modo 1:

$$
\mathbf{P}_{r, 1}=\frac{\mathbf{4} \mathbf{M}_{p}}{\mathbf{m}}=197,86 \mathbf{k N}
$$

- Modo 2:

$$
\begin{aligned}
& P_{r, 2}=\frac{2 M_{p}+n\left(\sum P_{t}^{\prime}\right)}{m+n} \quad \sum P_{t}^{\prime}=2 \times 127=254 k N \\
& P_{r, 2}=176,08 k N
\end{aligned}
$$


- Modo 3:

$$
P_{r, 3}=\sum P_{t}^{\prime}=254 k N
$$

$\rightarrow$ Linha 2

- Determinação de $M_{p}$ :

$$
\begin{aligned}
& M_{p}=\frac{L_{\text {ef }} t^{2} f_{y}}{4} \\
& t=1,9 \mathrm{~cm} \\
& M_{p}=462,53 \mathrm{kNcm}
\end{aligned}
$$

- Modo 1:

$$
P_{r, 1}=\frac{4 M_{p}}{m}=523,37 k N
$$

- Modo 2:

$$
\begin{aligned}
& P_{r, 2}=\frac{2 M_{p}+n\left(\sum P_{t}{ }^{\prime}\right)}{m+n} \quad \sum P_{t}{ }^{\prime}=2 \times 127=254 k N \\
& P_{r, 2}=257,86 k N
\end{aligned}
$$

- Modo 3:

$$
P_{r, 3}=\sum P_{t}^{\prime}=254 k N
$$

$\rightarrow$ Verificação à flexão na mesa do pilar

$$
\text { Mesmos valores do modelo CT1B-4 }
$$


$\rightarrow$ Resumo das capacidades (em kN)

\begin{tabular}{|c|c|c|c|c|c|c|c|}
\cline { 2 - 8 } \multicolumn{4}{c|}{} & \multicolumn{3}{c|}{ Flexão na chapa de topo } & \multicolumn{3}{c|}{ Flexão na mesa do pilar } \\
\hline \multirow{2}{*}{$\underset{\mathfrak{m}}{\mathbf{L}}$} & Linha & Modo 1 & Modo 2 & Modo 3 & Modo 1 & Modo 2 & Modo 3 \\
\cline { 2 - 8 } & $\mathbf{1}$ & 197,86 & 176,08 & 254,0 & 567,03 & 267,96 & 254 \\
\cline { 2 - 8 } & $\mathbf{2}$ & 523,37 & 257,86 & 254,0 & 567,03 & 267,96 & 254 \\
\hline
\end{tabular}

\section{A1.3 Momentos resistentes}

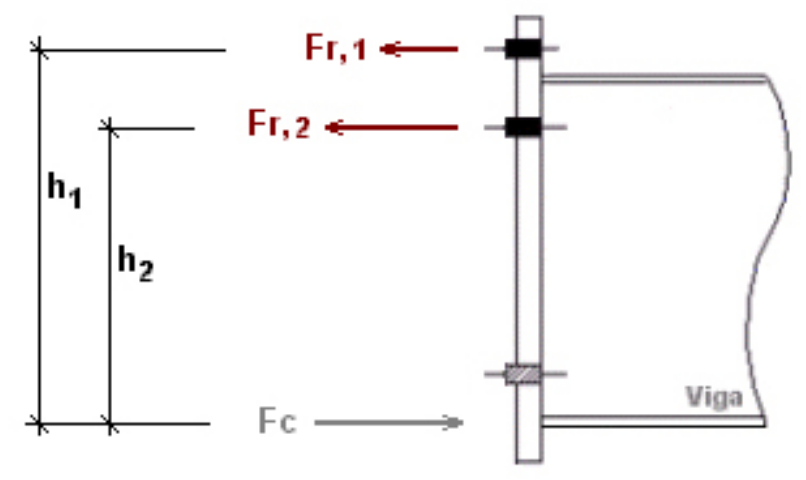

- Equação geral:

$$
M_{r}=F_{r, 1} \times h_{1}+F_{r, 2} \times h_{2}
$$

- Resumo dos momentos resistentes

\begin{tabular}{|c|c|c|c|c|}
\hline Modelos & CT1A-1 & CT1A-4 & CT1B-4 & CT1B-6 \\
\hline $\mathbf{M}_{\mathbf{r}} \mathbf{( k N c m )}$ & 8100,0 & 6763,0 & 9853,8 & 9332,0 \\
\hline
\end{tabular}


Tabela A1.I - Comprimento equivalente $L_{\text {ef }}$ para linhas de parafusos atuando isoladamente - Fonte: SCI/BCSA(1996)

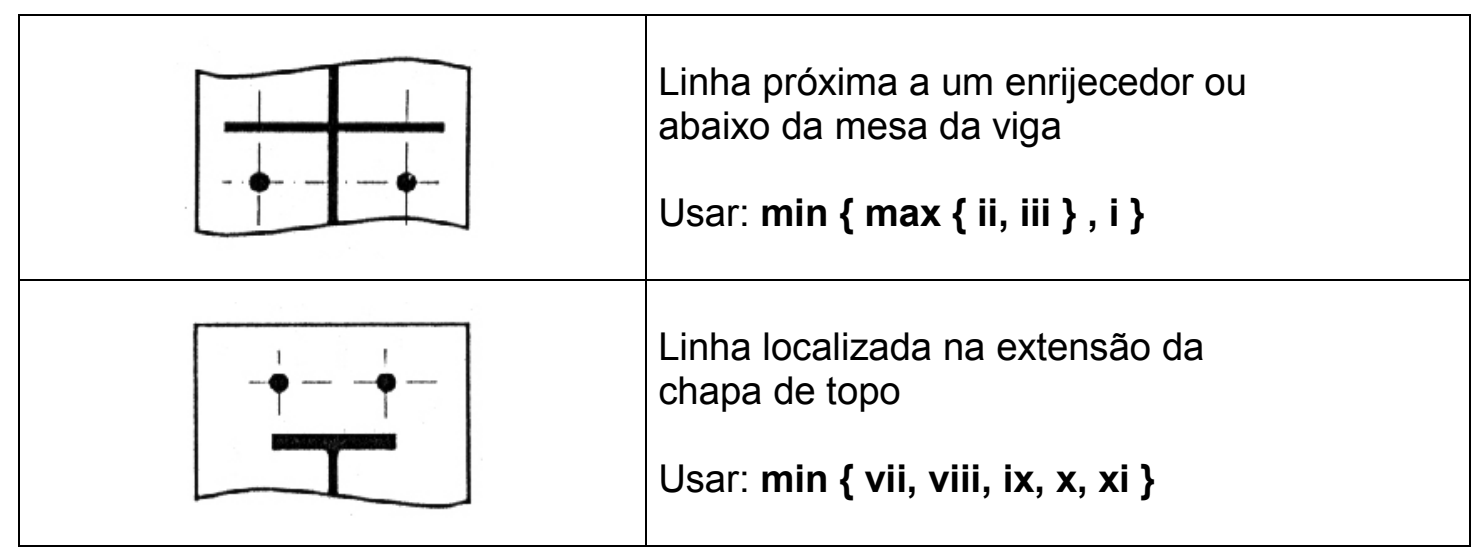

Tabela A1.II - Configurações para determinação do comprimento equivalente $L_{e f}$ - Fonte: SCI/BCSA (1996)

\begin{tabular}{|l|l|}
\hline & $\begin{array}{l}\text { Configuração (i) } \\
\text { Plastificação circular } \\
\mathrm{L}_{\text {ef }}=2 \pi \mathrm{m}\end{array}$ \\
\hline $\begin{array}{l}\text { Configuração (ii) } \\
\text { Plastificação lateral }\end{array}$ & \begin{tabular}{l}
$\mathrm{L}_{\text {ef }}=4 \mathrm{~m}+1,25 \mathrm{e}$ \\
\hline
\end{tabular} \\
\hline
\end{tabular}


Tabela A1.II - Continuação

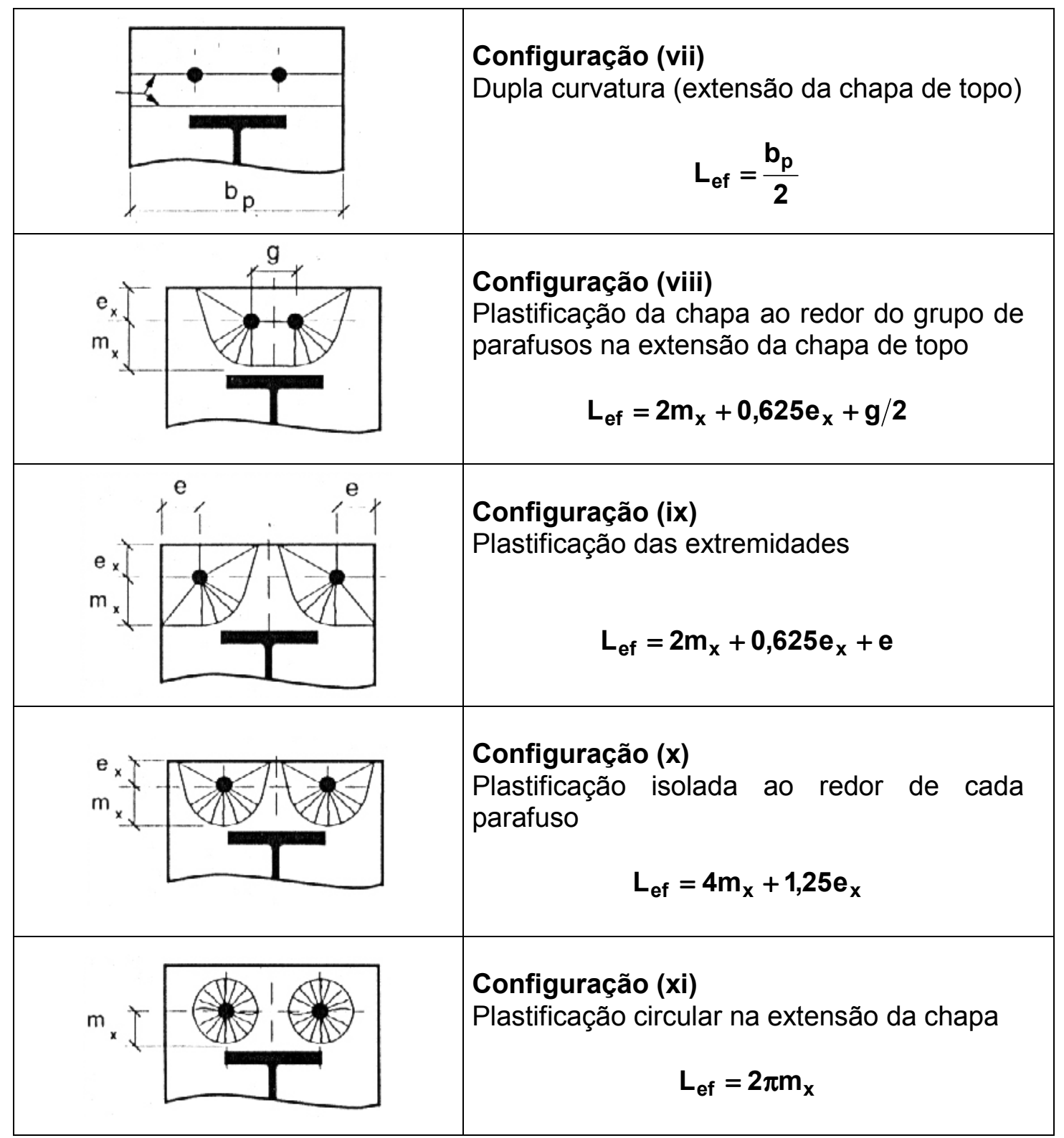


Tabela A1.III - Gráfico para determinação do parâmetro $\alpha$ Fonte: SCI/BCSA (1996)
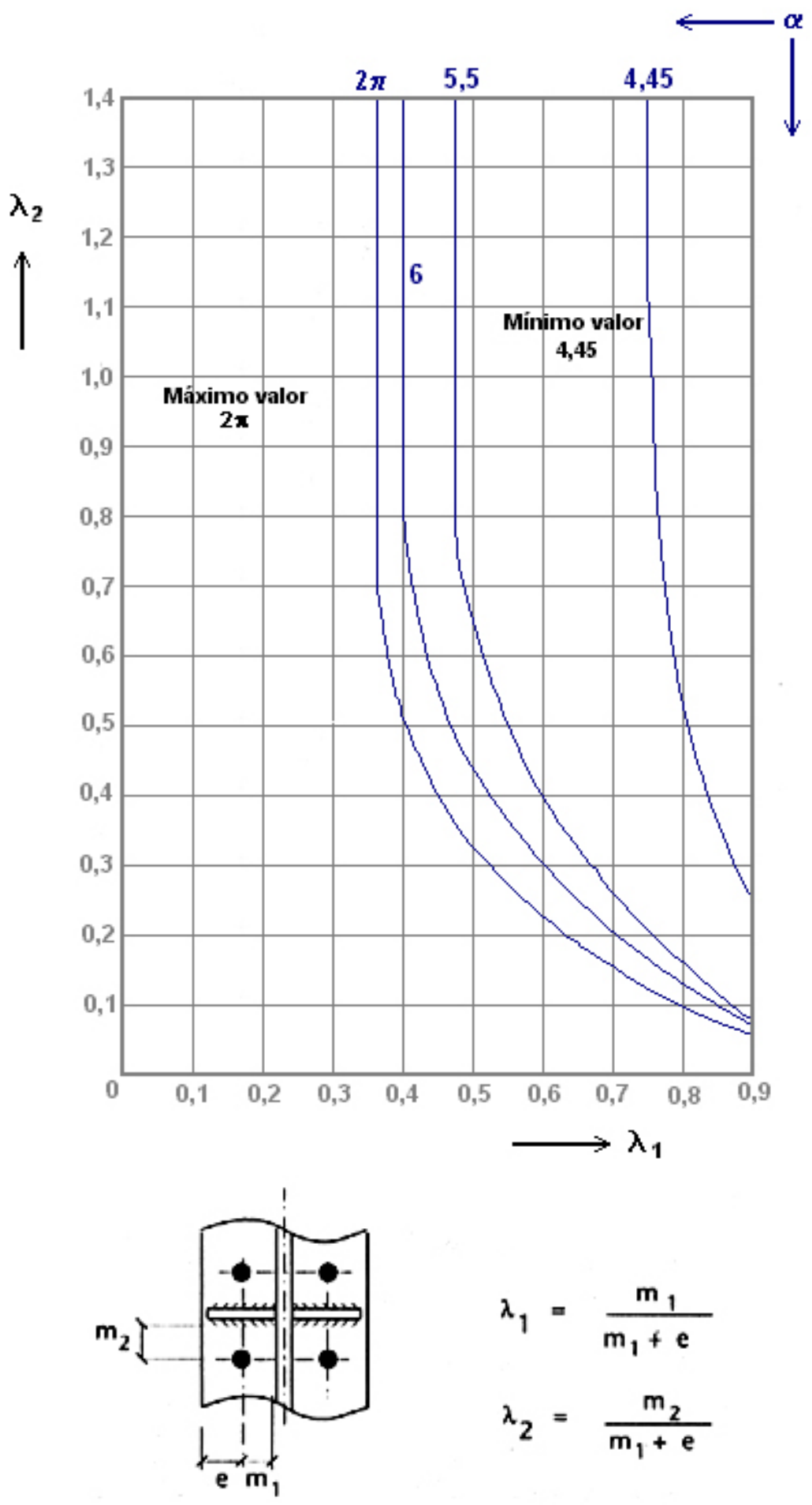

$$
\begin{aligned}
& \lambda_{1}=\frac{m_{1}}{m_{1}+e} \\
& \lambda_{2}=\frac{m_{2}}{m_{1}+e}
\end{aligned}
$$




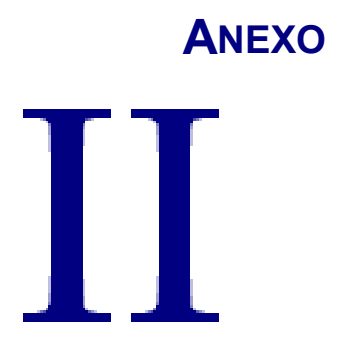

RESULTADOS COMPLEMENTARES 
Apresenta-se, neste Anexo, um complemento aos resultados obtidos com os modelos numéricos, incluindo-se alguns resultados obtidos com o modelo preliminar CT1A-1R, que considerou a mesa do pilar como um apoio totalmente rígido.

Com relação ao modelo CT1A-1R deve-se observar que foram realizadas 3 tipos de análises: a primeira considerando o material linear, a segunda considerando um diagrama bilinear para representar o material e a terceira considerando material não linear e grandes deslocamentos. O tipo de análise e o modelo estão indicados em cada gráfico.

O objetivo deste Anexo é ressaltar alguns aspectos verificados e que não foram comentados nos capítulos deste trabalho. Tais aspectos estão indicados e os gráficos correspondentes são apresentados na seqüência.

\section{A2.1 Tensões longitudinais}

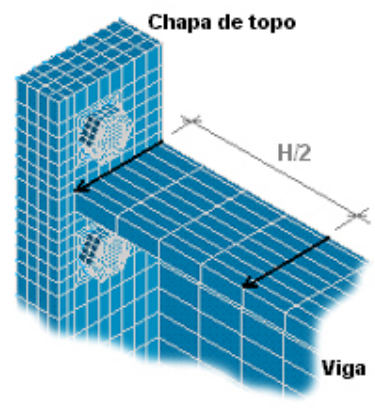

Sentido da distribuição de tensões Plano médio da alma $\rightarrow$ borda da mesa 
- Distorções verificadas na seção de intersecção viga/chapa devido à variação da espessura da chapa e do diâmetro dos parafusos.

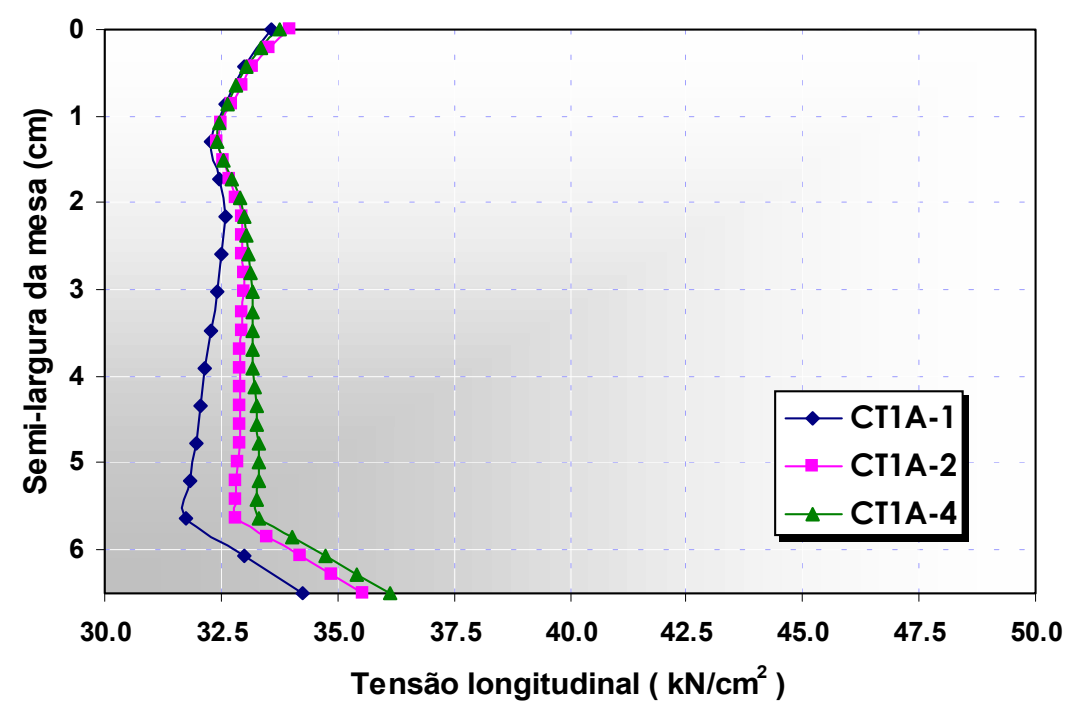

Fig. A2.1

Distribuição de tensões longitudinais - Intersecção viga/chapa Variação da espessura da chapa de topo

Momento na seção $=11700 \mathrm{kNcm}$

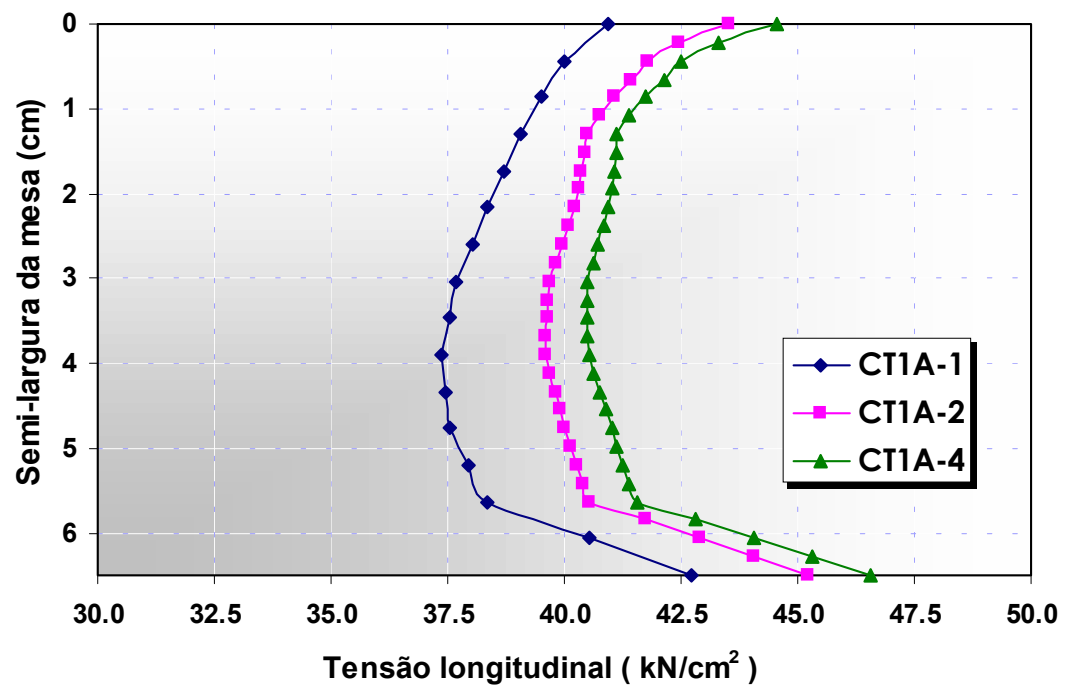

Fig. A2.2

Distribuição de tensões longitudinais - Intersecção viga/chapa Variação da espessura da chapa de topo Momento na seção $=15000 \mathrm{kNcm}$ 


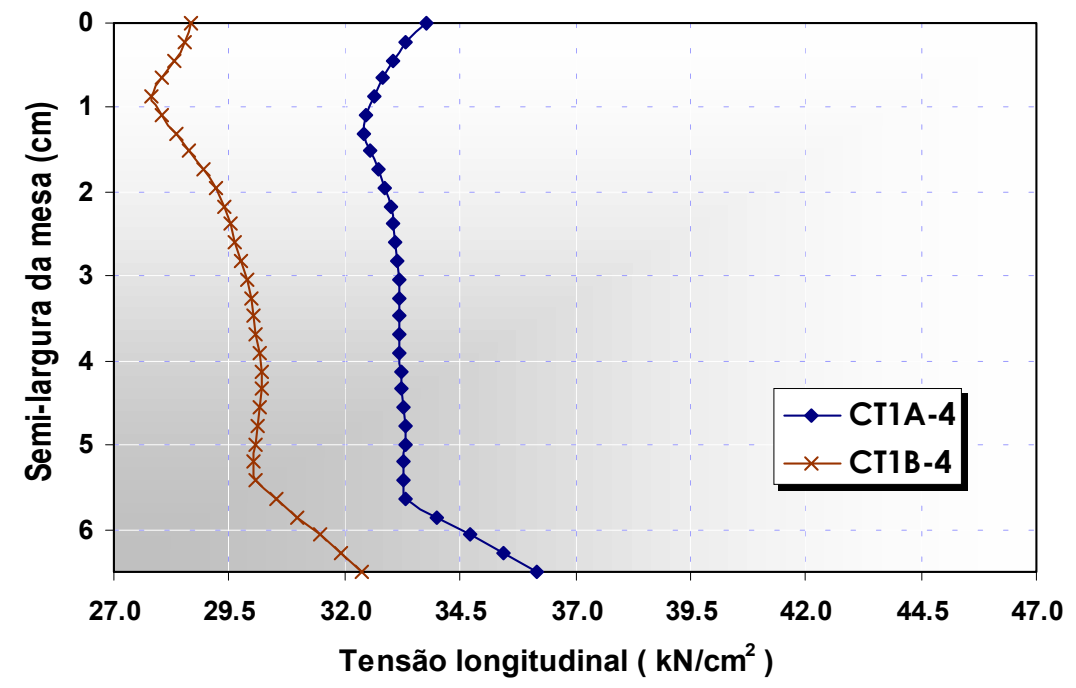

Fig. A2.3

Distribuição de tensões longitudinais - Intersecção viga/chapa Variação do diâmetro do parafuso

Momento na seção $=11700 \mathrm{kNcm}$

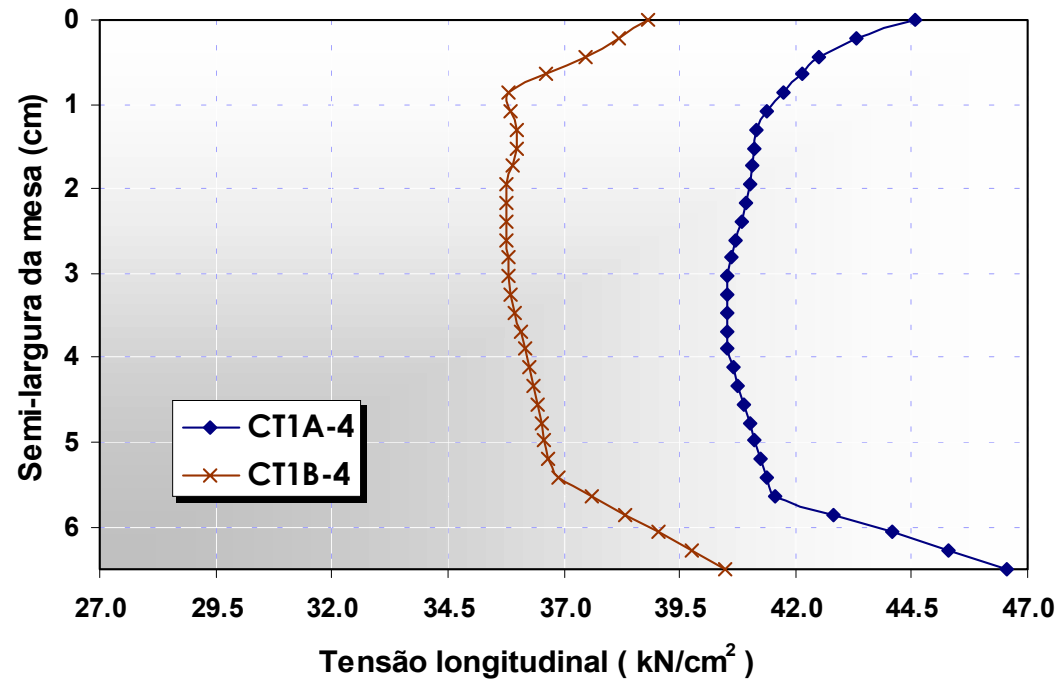

Fig. A2.4

Distribuição de tensões longitudinais - Intersecção viga/chapa Variação do diâmetro do parafuso Momento na seção $=15000 \mathrm{kNcm}$ 
- Efeito "shear-lag" $\rightarrow$ enrijecimento causado pela alma verificado na seção H/2 para baixos níveis de carregamento;

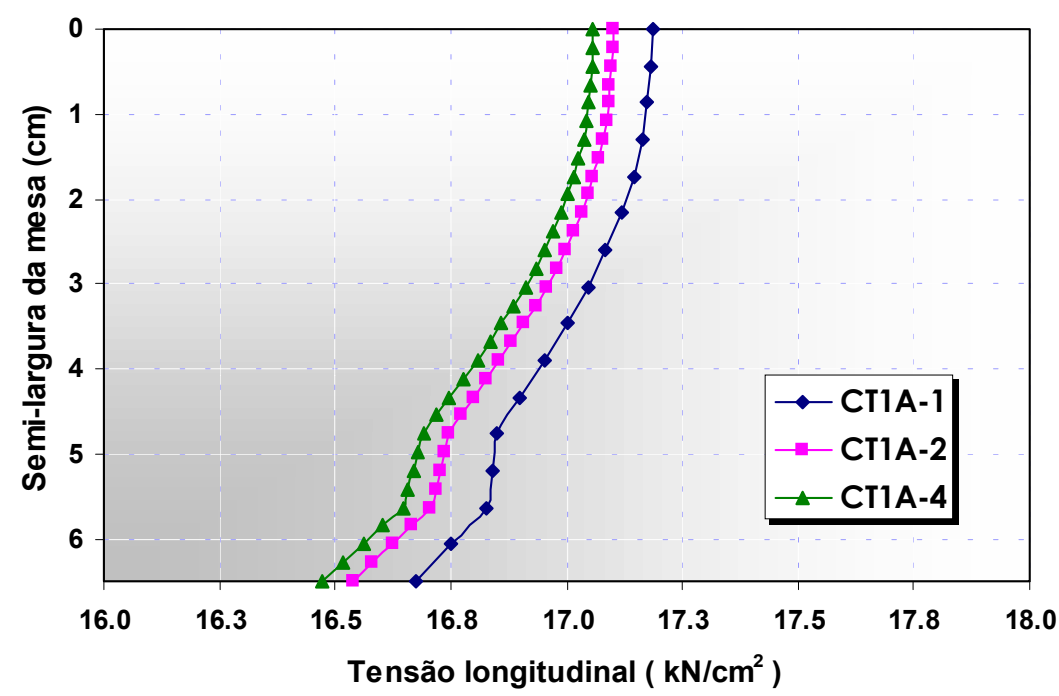

Fig. A2.5

Distribuição de tensões longitudinais - Seção H/2

Variação da espessura da chapa de topo

Momento na seção $=7220 \mathrm{kNcm}$

- Plastificação da seção transversal H/2 para $\mathrm{M}=13750 \mathrm{kNcm}$

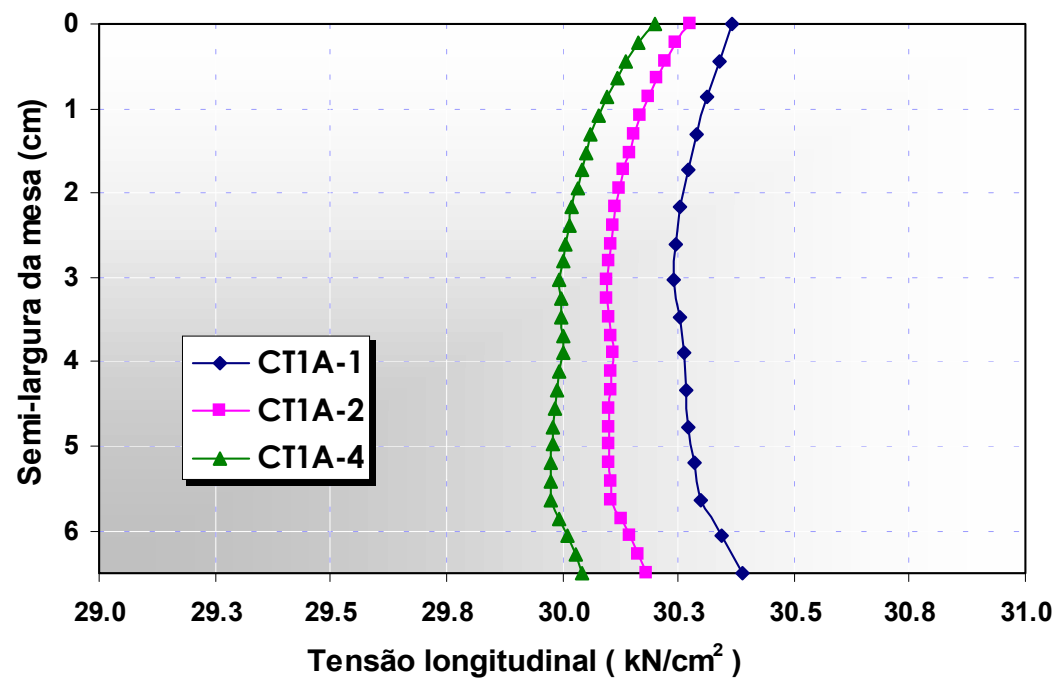

Fig. A2.6

Distribuição de tensões longitudinais - Seção H/2

Variação da espessura da chapa de topo

Momento na seção $=13750 \mathrm{kNcm}$ 
- Distorções na seção de intersecção chapa/viga das tensões longitudinais na alma da viga.

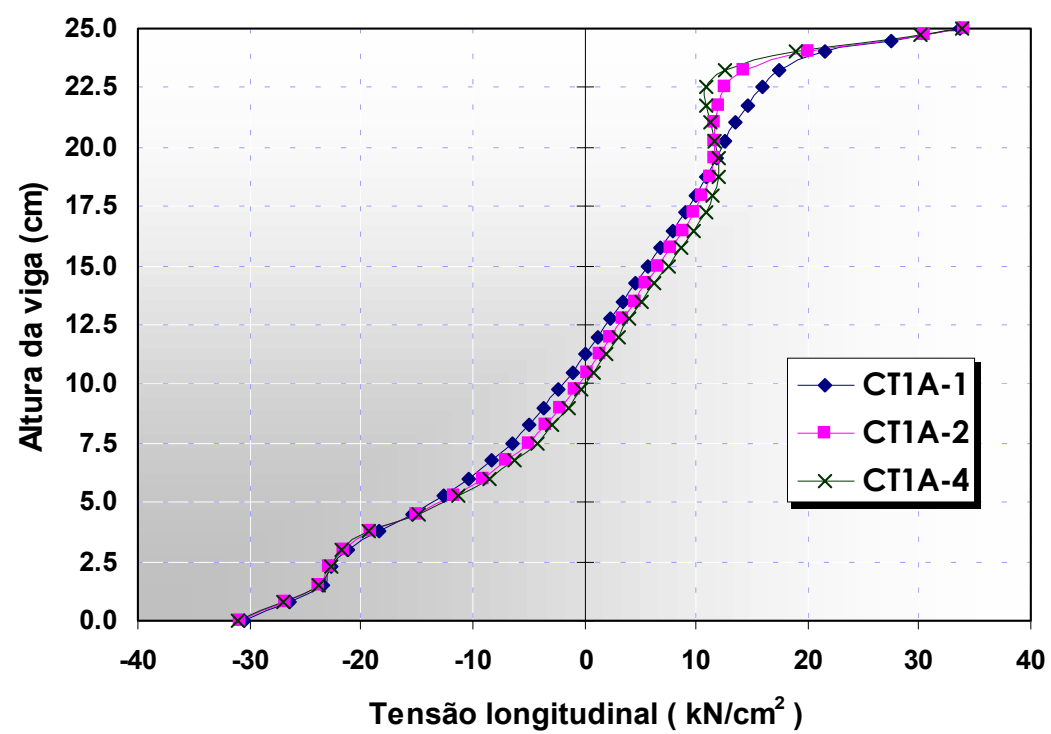

Fig. A2.7

Distribuição de tensões longitudinais na alma - Seção $H / 2$ Variação da espessura da chapa de topo

Momento na seção $=11700 \mathrm{kNcm}$

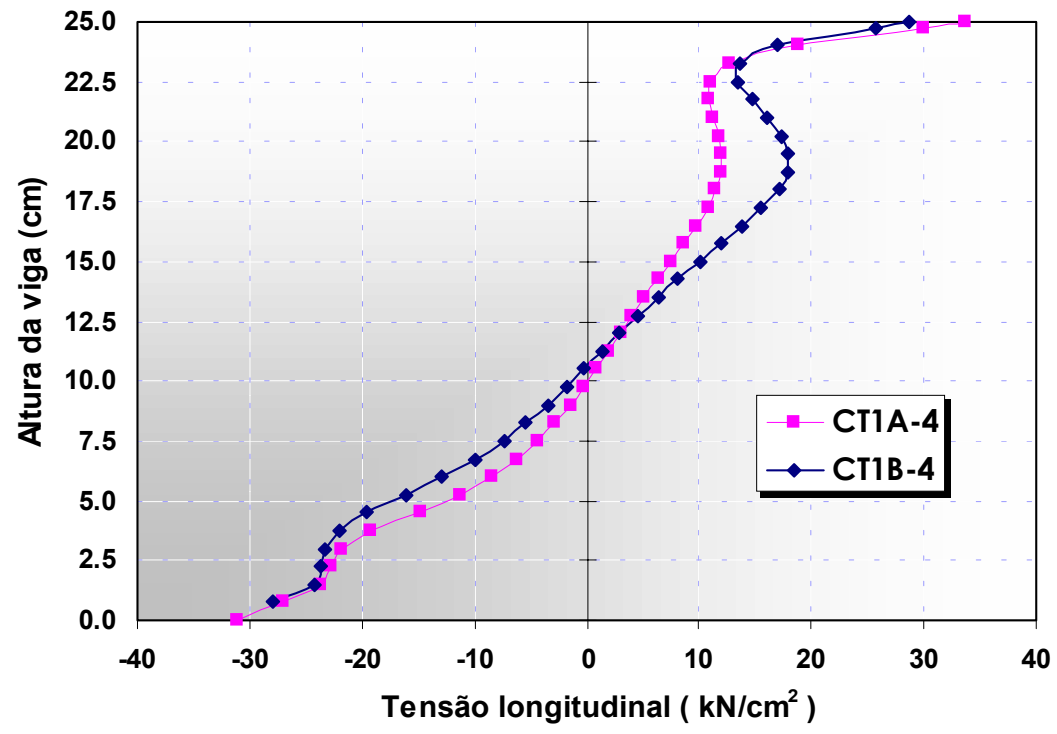

Fig. A2.8

Distribuição de tensões longitudinais na alma - Seção H/2 Variação do diâmetro dos parafusos

Momento na seção $=11700 \mathrm{kNcm}$ 


\section{A2.2 Deslocamento vertical da extremidade livre da viga}

- Comparação entre resultados numéricos e experimentais

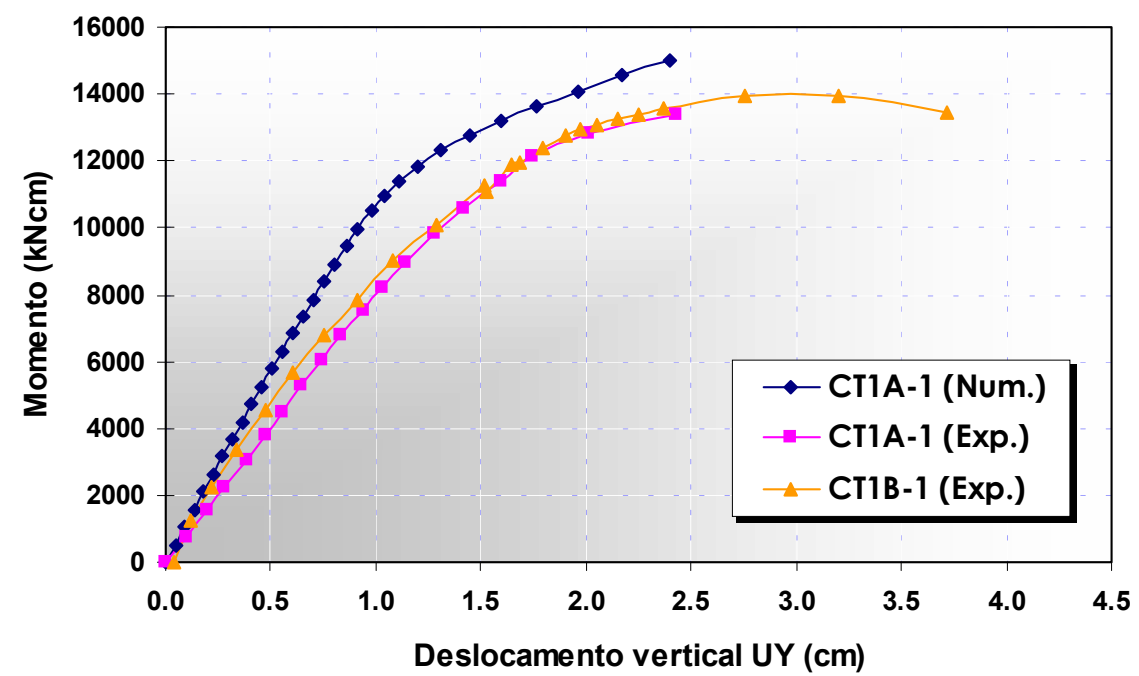

Fig. A2.9

Deslocamentos da extremidade livre da viga Modelo CT1A-1 $\left(t_{c h}=31,5 \mathrm{~mm} ; d_{p}=16,0 \mathrm{~mm}\right)$

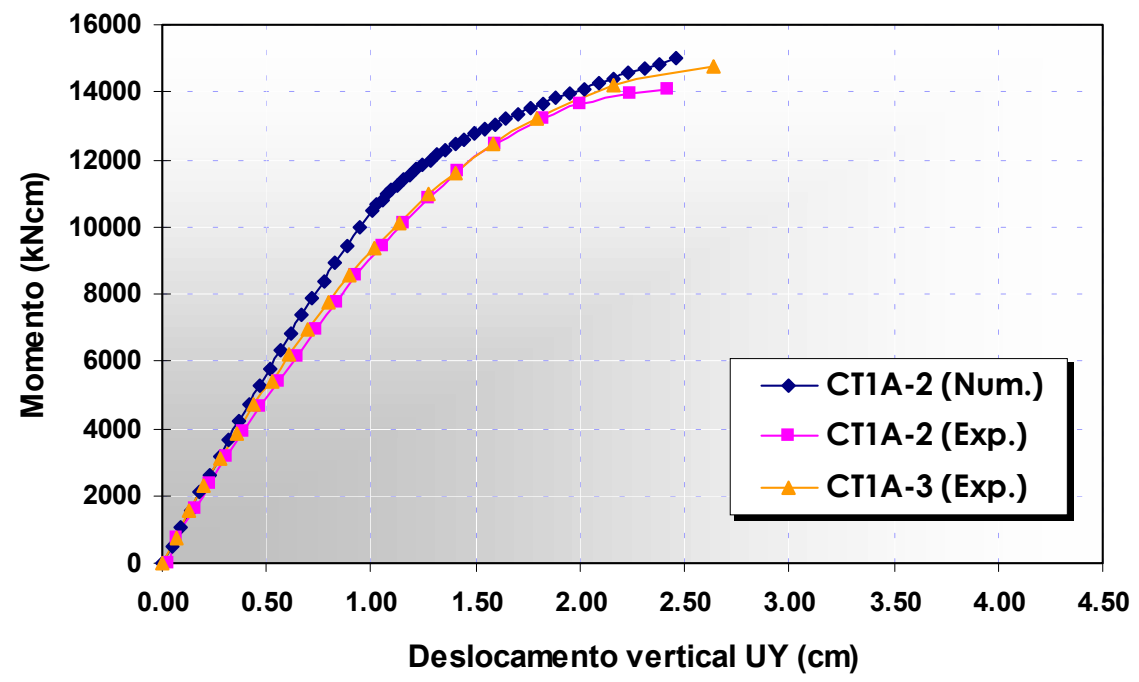

Fig. A2.10

Deslocamentos da extremidade livre da viga Modelo CT1A-2 $\left(t_{c h}=25,0 \mathrm{~mm} ; d_{p}=16,0 \mathrm{~mm}\right)$ 


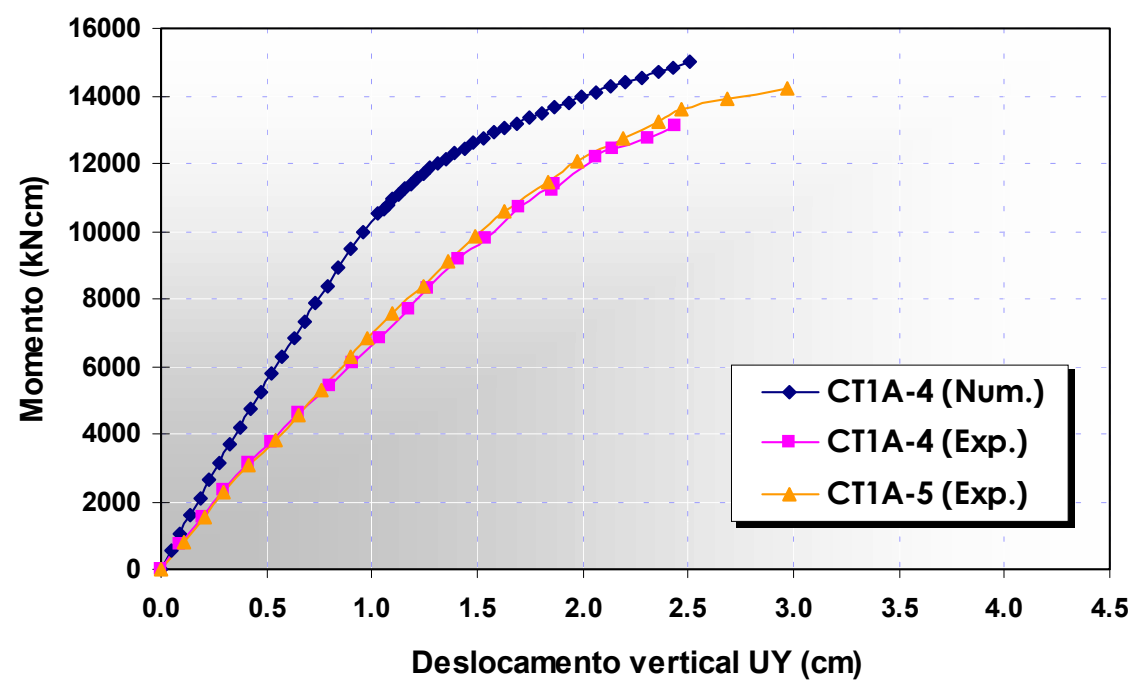

Fig. A2.11

Deslocamentos da extremidade livre da viga Modelo CT1A-4 $\left(t_{c h}=22,4 \mathrm{~mm} ; d_{p}=16,0 \mathrm{~mm}\right)$

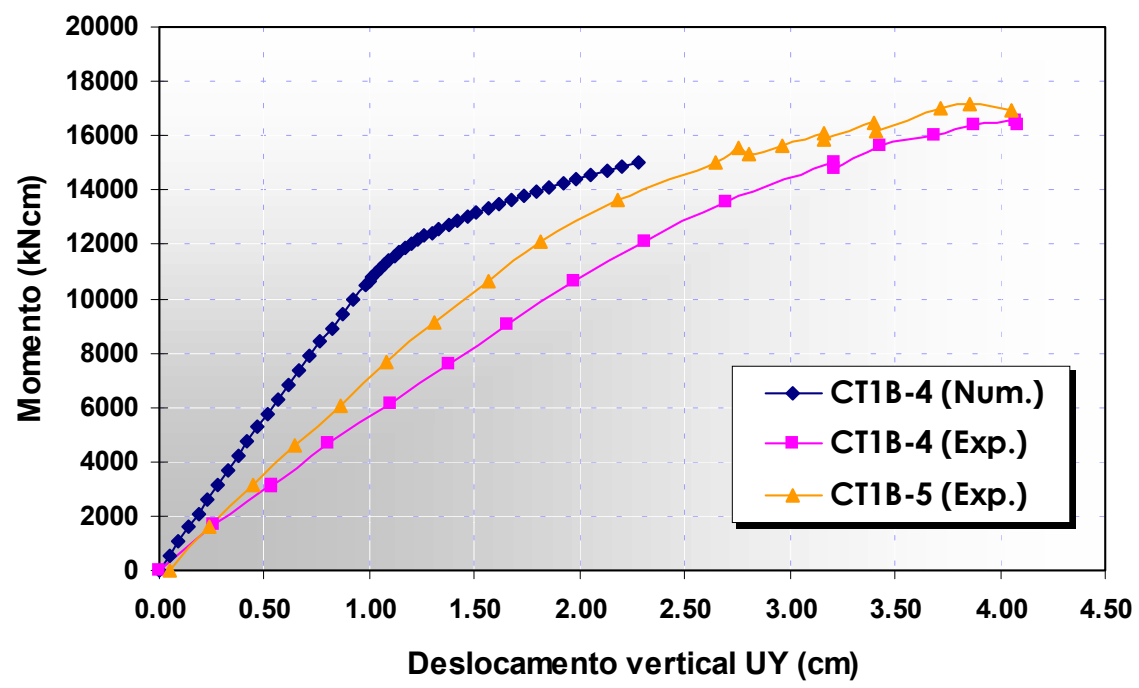

Fig. A2.12

Deslocamentos da extremidade livre da viga Modelo CT1B-4 $\left(t_{c h}=22,4 \mathrm{~mm} ; d_{p}=16,0 \mathrm{~mm}\right)$ 
- Modelo CT1A-1R, comparando-se os três tipos de análise: material linear, material não-linear e consideração de grandes deslocamentos com material não linear (grandes deslocamentos).

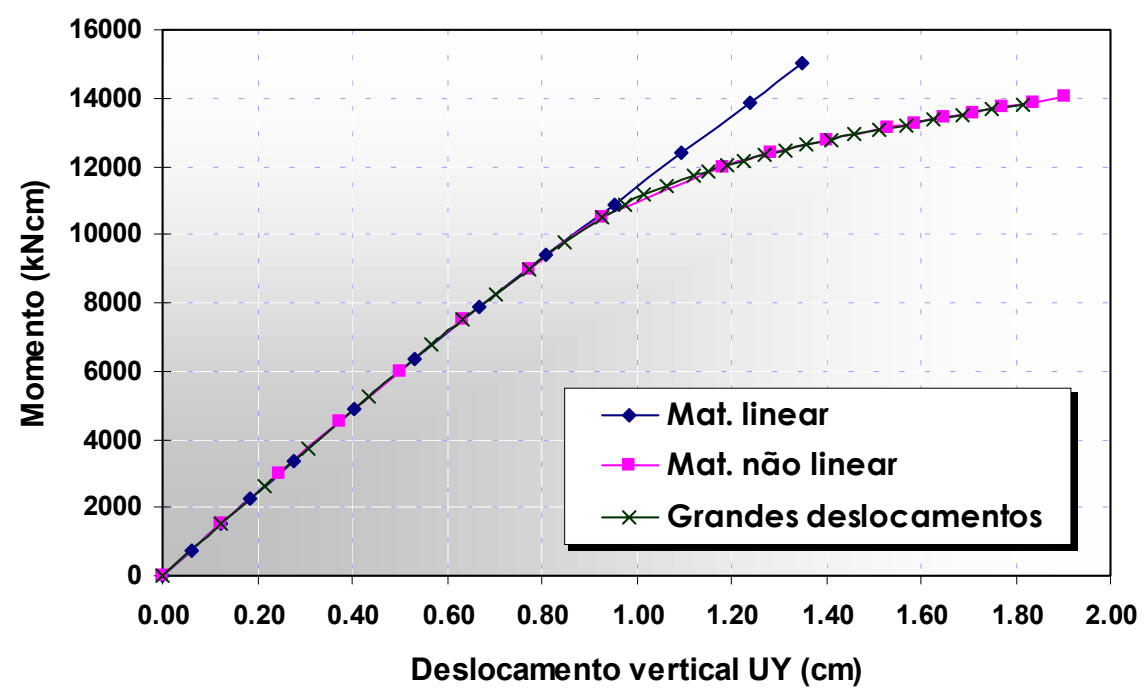

Fig. A2.13

Deslocamentos da extremidade da viga para o modelo CT1A-1R

- Comparação entre modelos CT1A-1 e CT1A-R

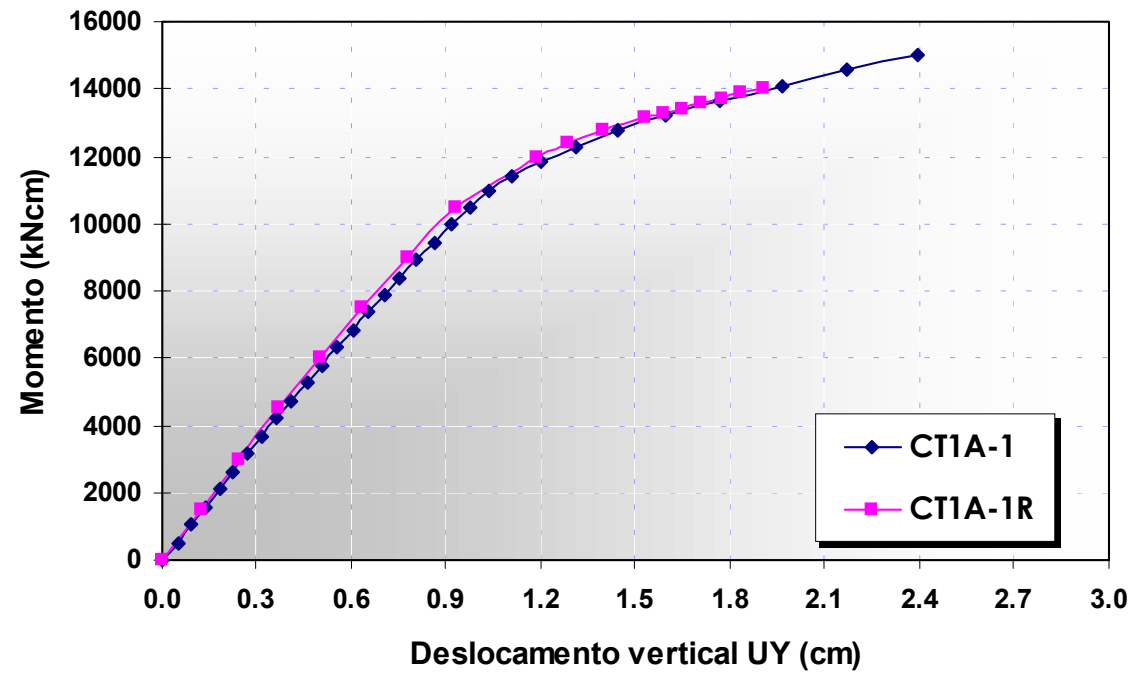

Fig. A2.14

Deslocamentos da extremidade da viga Comparação entre CT1A-1 e CT1A-1R 


\section{A2.3 Curvas momento-rotação}

- Comparação entre os modelos CT1A-1 e CT1A-1R

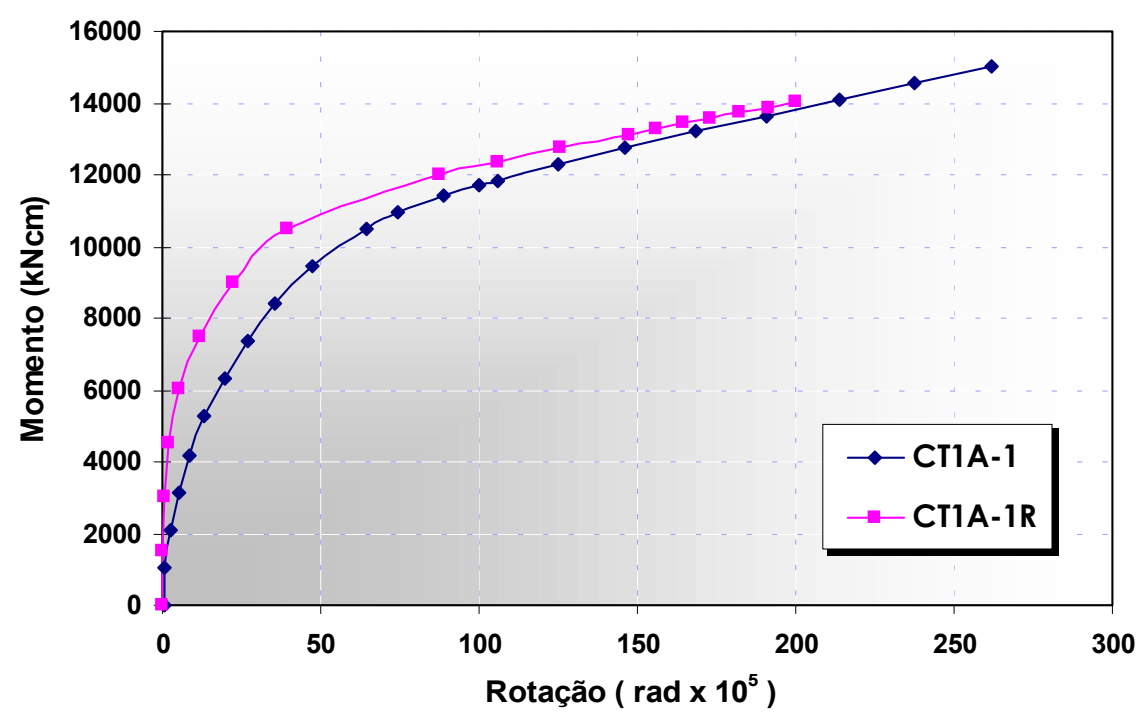

Fig. A2.15

Curvas momento-rotação

Comparação entre CT1A-1 e CT1A-1R

\section{A2.4 Deformações na chapa de topo}

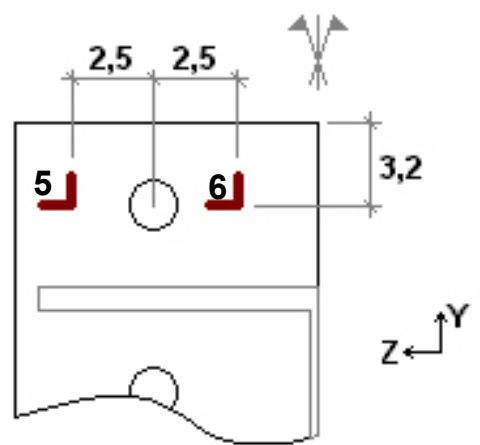

Posição das rosetas na chapa de topo Modelo CT1A-1 
- Comparação entre numérico e experimental para o modelo CT1A-1

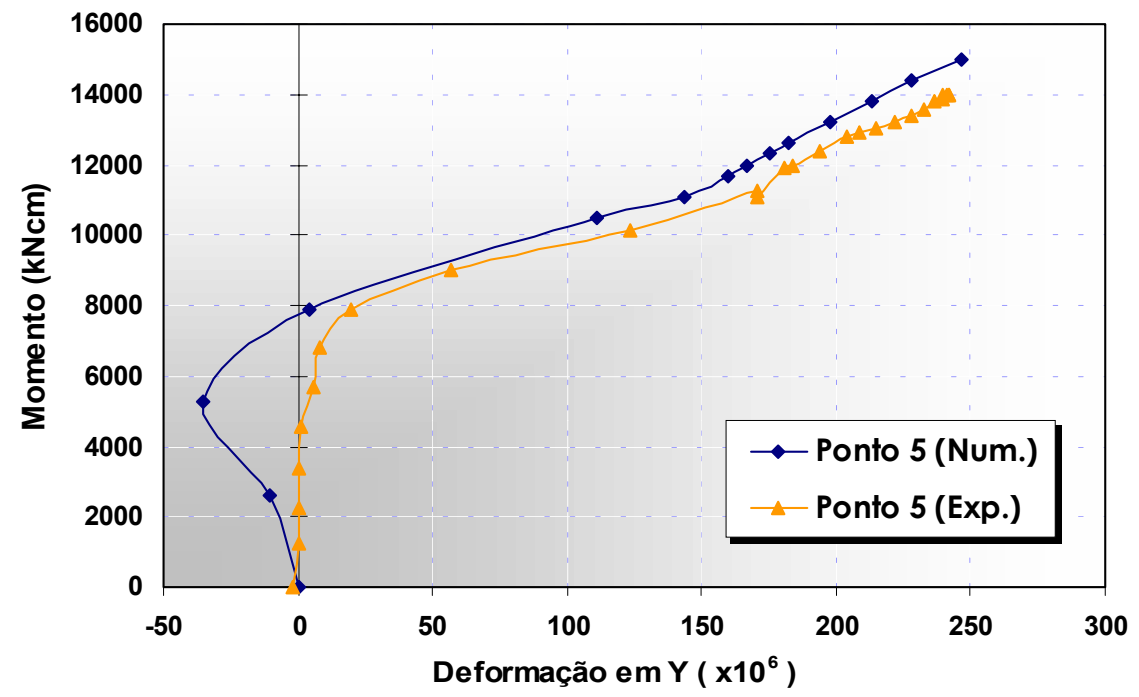

Fig. A2.16

Deformações na direção Y - Roseta 5 - Modelo CT1A-1

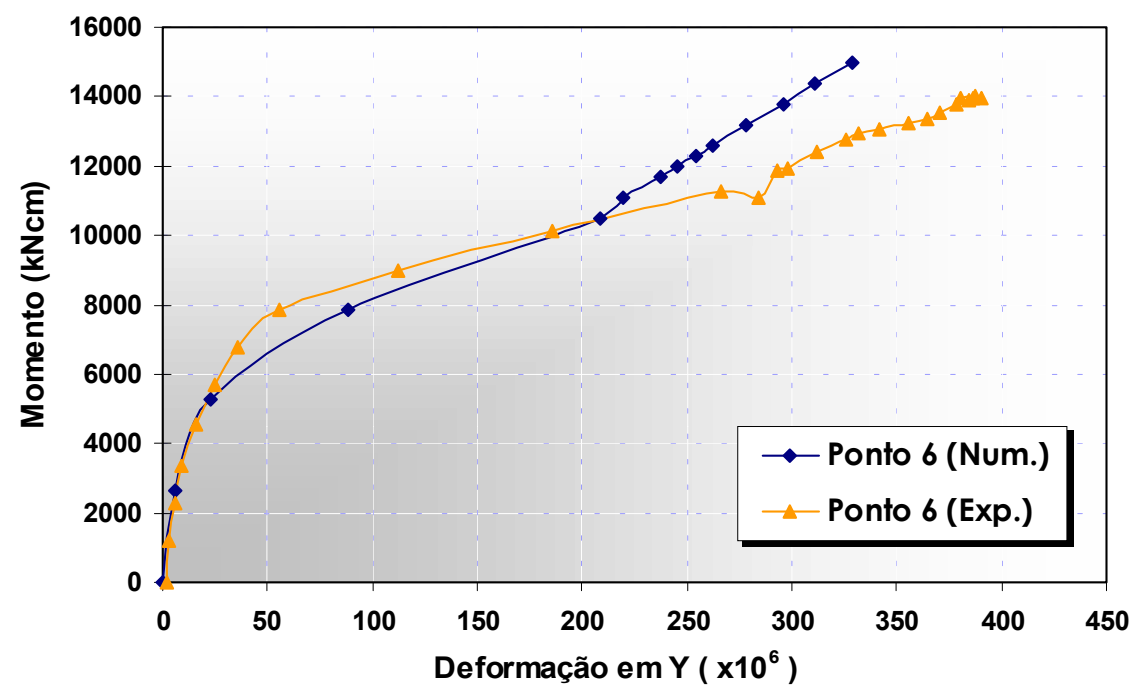

Fig. A2.17

Deformações na direção Y - Roseta 6 - Modelo CT1A-1 


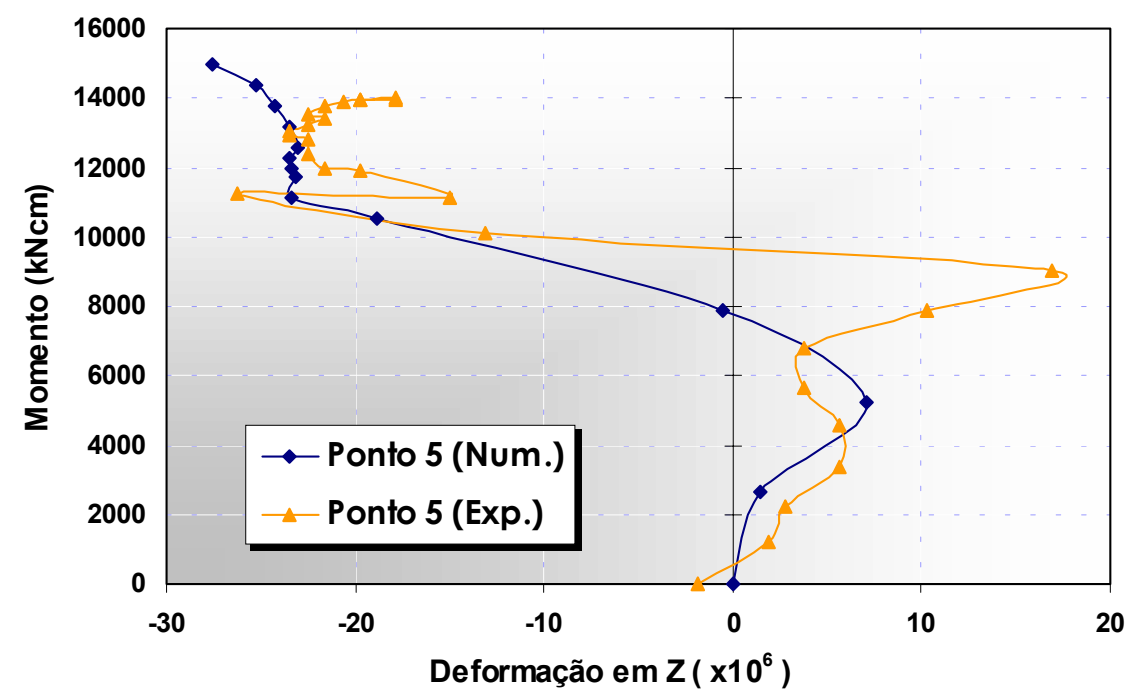

Fig. A2.18

Deformações na direção Z - Roseta 5 - Modelo CT1A-1

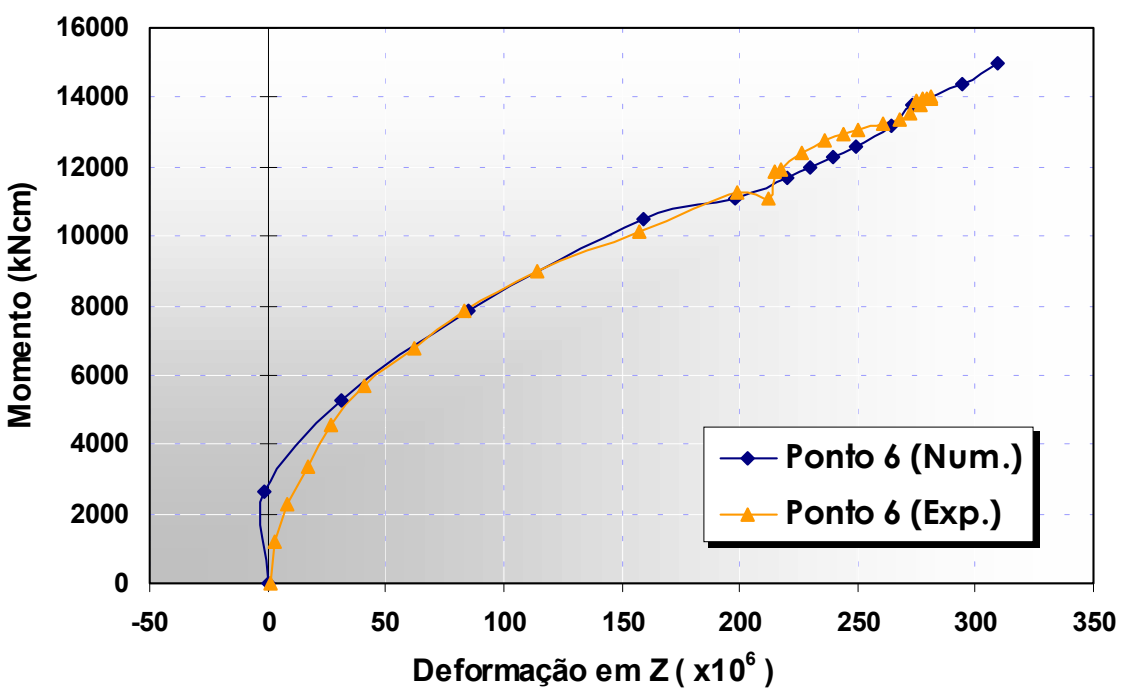

Fig. A2.19

Deformações na direção Z - Roseta 6 - Modelo CT1A-1 


\section{A2.5 Deformações na mesa e alma da viga}

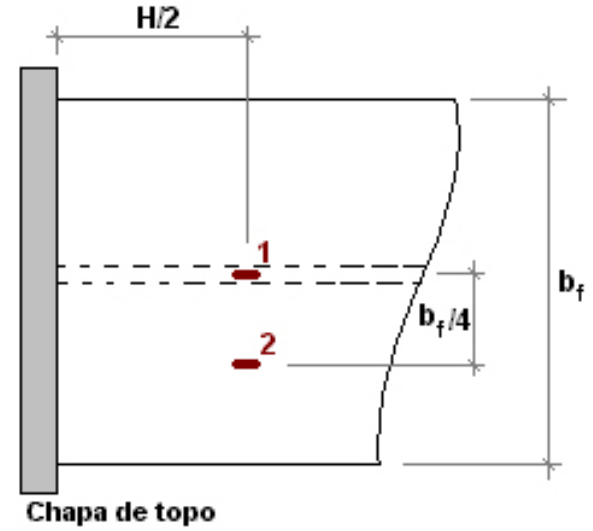

Posição dos extensômetros nas mesas da viga

- Comparação entre resultados numéricos e experimentais para o modelo CT1A-1.

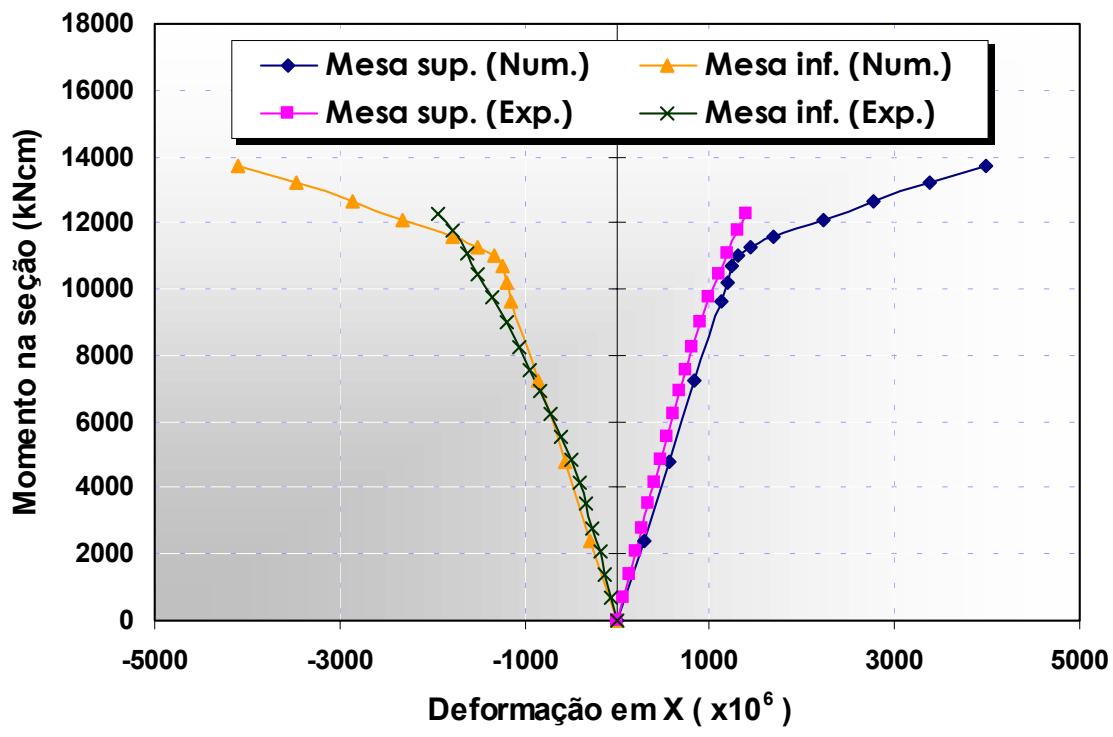

Fig. A2.20

Deformações longitudinais nas mesas da viga

Seção H/2 - Extensômetro 1

Modelo CT1A-1 


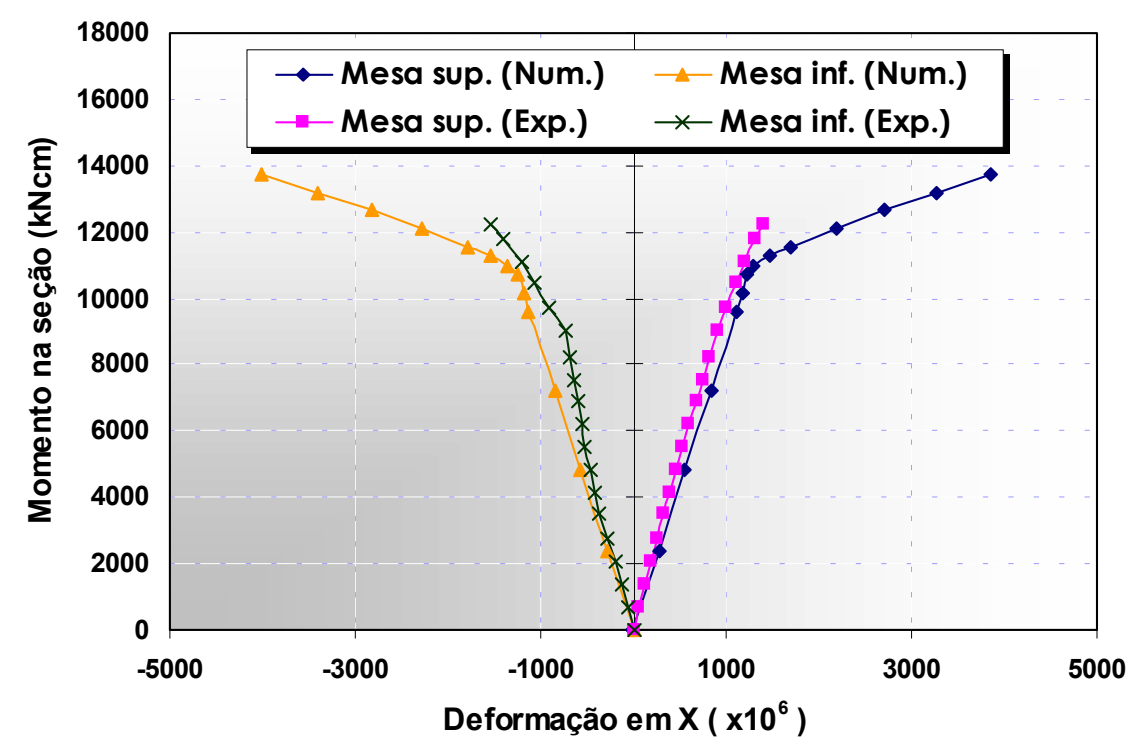

Fig. A2.21

Deformações longitudinais nas mesas da viga

Seção H/2 - Extensômetro 2

Modelo CT1A-1

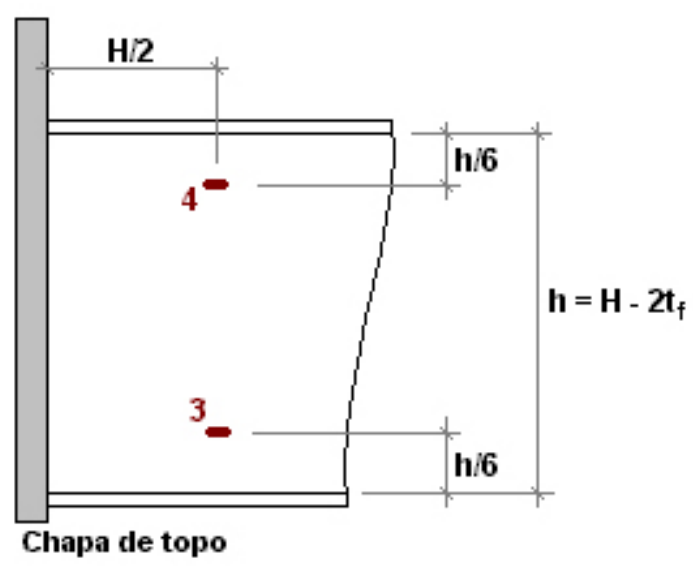

Posição dos extensômetros na alma da viga 


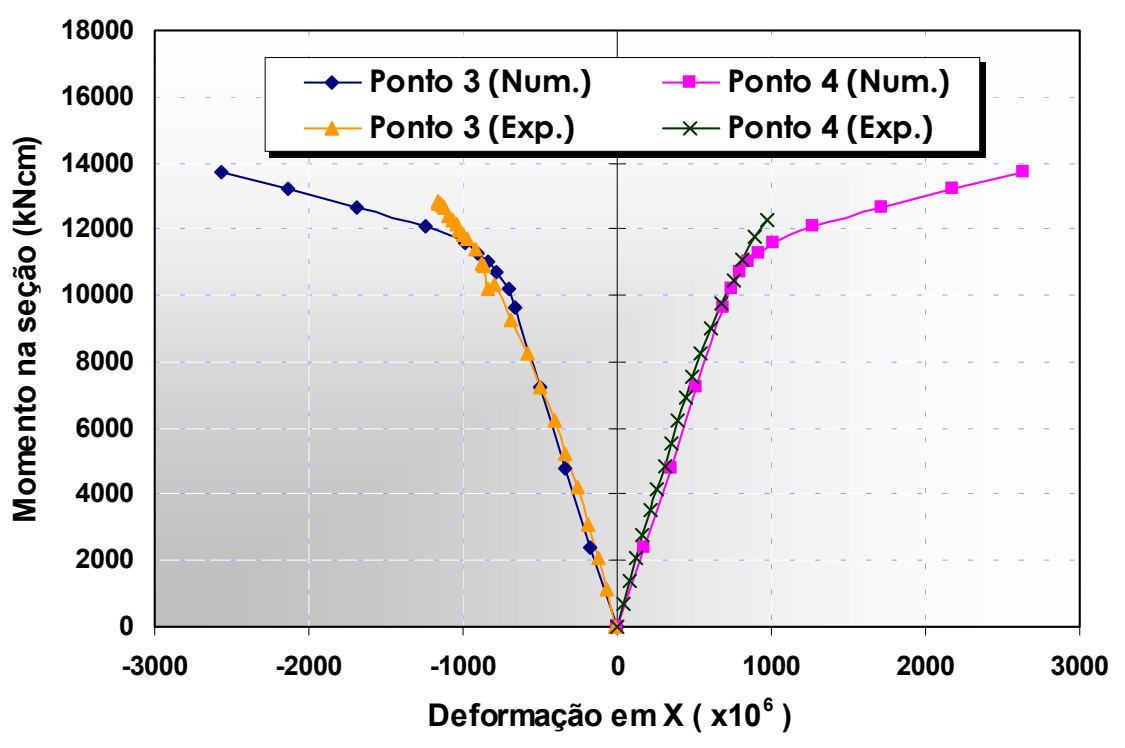

Fig. A2.22

Deformações longitudinais na alma da viga

Seção H/2 - Extensômetros 3 e 4

Modelo CT1A-1 